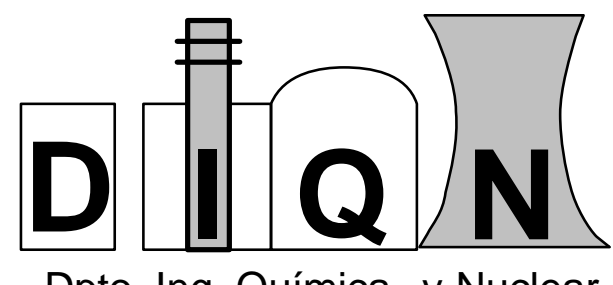

Dpto. Ing. Química y Nuclear

Universidad Politécnica de Valencia

Departamento de Ingeniería Química y Nuclear

Tesis Doctoral:

\title{
Modelado dinámico de procesos de ultrafiltración tangencial aplicados a la separación de macromoléculas
}

Autora:

María Cinta Vincent Vela

Directores de la Tesis:

Dr. Jaime Lora García

Dra. Silvia Álvarez Blanco

Valencia, 2006 



\section{Agradecimientos:}

En el momento de finalizar el programa de doctorado me gustaría dedicar unas palabras a aquellas personas que de un modo $u$ otro me han ayudado a recorrer este camino.

En primer lugar debo hacer referencia a mis directores, Jaime Lora García y Silvia Álvarez Blanco, por su constante apoyo, por enseñarme cómo afrontar un trabajo de investigación, cómo desarrollarlo y llevarlo a buen puerto, y por haberme mantenido siempre en el camino correcto en el largo proceso de elaboración de la Tesis Doctoral. Gracias por sus ideas, sugerencias, recomendaciones...

También debo agradecer a José Marcial Gozálvez Zafrilla sus muchas sugerencias y aportaciones, así como que me animase a entrar en el mundo académico tras acabar la Ingeniería.

Asimismo debo agradecer a Enrique Bergantiños Rodríguez y a Luis Crespo Cambil tanto por el apoyo recibido como por su ayuda en la realización de los experimentos en el laboratorio.

Tampoco debo olvidar las muchas contribuciones recibidas en los distintos foros donde hemos presentado comunicaciones relacionadas con el contenido de la Tesis Doctoral. Así me gustaría agradecer las sugerencias recibidas en los congresos: en el Network Young Membrains 6 (Hamburgo, 2004), en el Euromembrane (Hamburgo, 2004), en el Desalination and the Environment (Santa Margherita Ligure, 2005), en el International Congress on Membranes and Membrane Processes (Seoul, 2005), en el Membrane Science and Technology Conference of the Visegrad Countries (Polanica Zrój, 2005) y en el $5^{\circ}$ Congreso Iberoamericano de Ciencia y Tecnología de Membranas (Valencia, 2005).

Finalmente me gustaría agradecer el apoyo e interés mostrado por los miembros del grupo de investigación en membranas, Grupo de Procesos de Membrana y Tratamiento Medioambiental de Efluentes (PROMETEO), del Departamento de Ingeniería Química y Nuclear de la Universidad Politécnica de Valencia; sin h ayuda de los cuales no hubiese sido posible la realización de este trabajo de investigación. 



\section{Índice:}

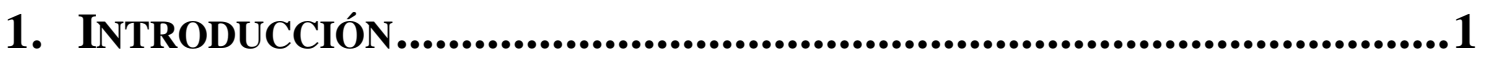

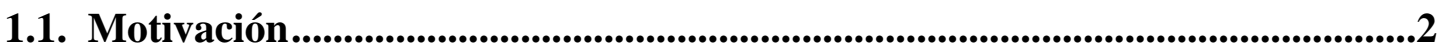

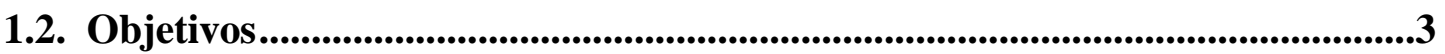

1.3. Contribución de la Tesis Doctoral..............................................................................4

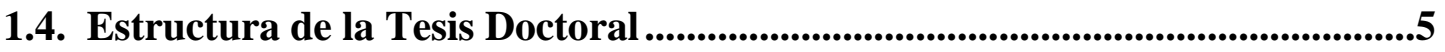

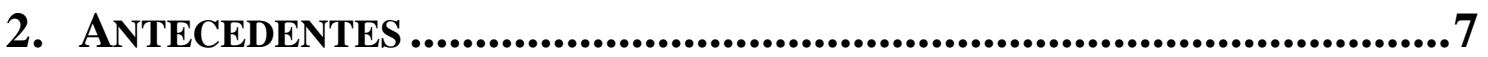

2.1. Tecnología de membranas ......................................................................................7

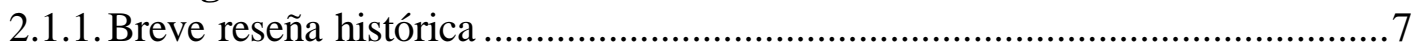

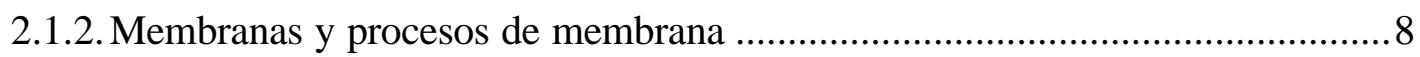

2.1.3. Ventajas e inconvenientes de los procesos de membrana.............................. 10

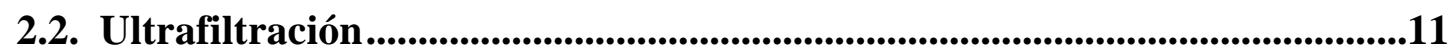

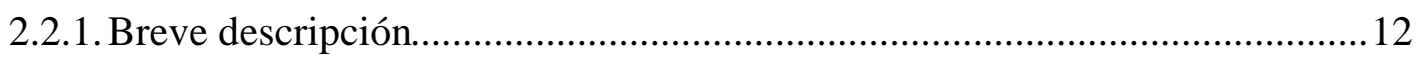

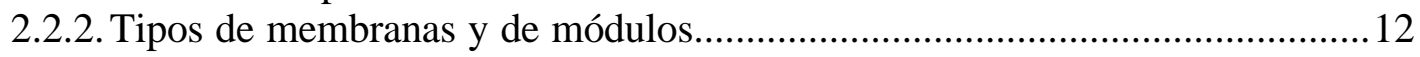

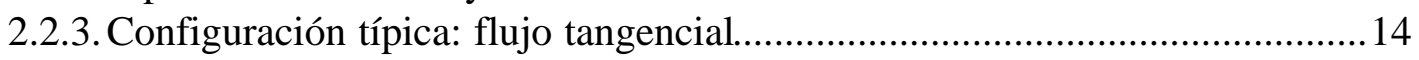

2.2.4. Ensuciamiento de membranas de ultrafiltración........................................... 14

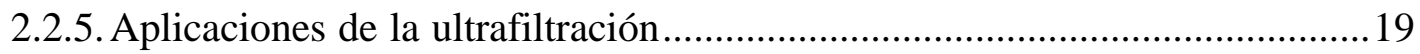

3. MODELOS DE ULTRAFILTRACIÓN DINÁMICOS .................................23

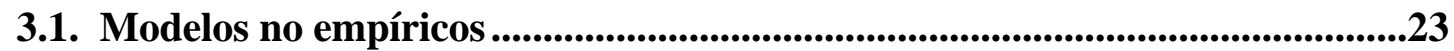

3.1.1. Modelo de aplicación de la teoría de la ultrafiltración transversal en el

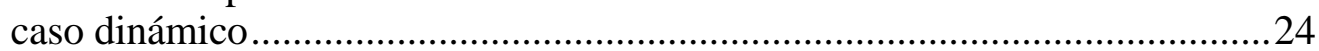

3.1.2. Modelo de difusión inducido por cizalla aplicado en el caso de la

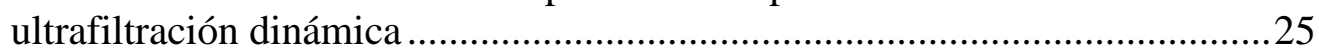

3.1.3. Modelo dinámico de Song para la ultrafiltración tangencial.........................27

3.1.4. Modelo dinámico de Bhattacharjee y Bhattacharya para la ultrafiltración controlada por la presión osmótica o por la capa gel

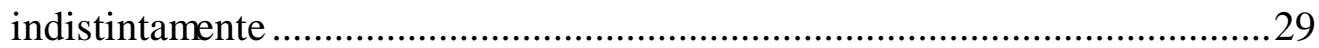

3.1.5. Modelo dinámico que combina el bloqueo de poros y la formación de

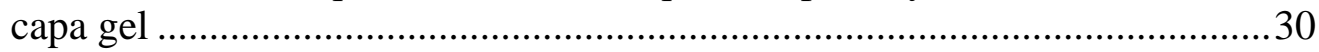

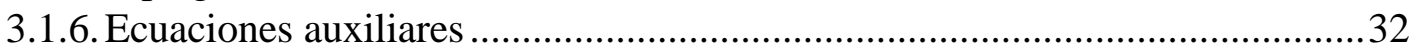

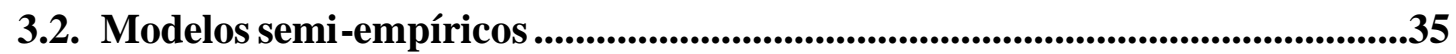

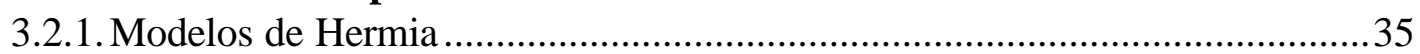

3.2.2. Adaptación de los Modelos de Hermia para flujo tangencial...........................40

3.2.3. Cálculo teórico de los parámetros de los modelos de Hermia adaptados

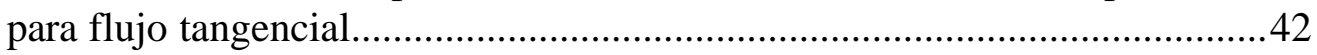

4. MAterialeS y MÉTODOS..............................................................45

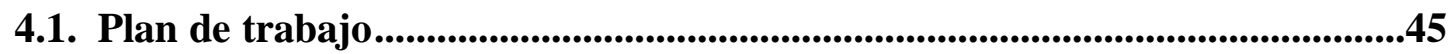

4.2. Revisión bibliográfica.................................................................................46

4.3. Planta piloto de ultrafiltración................................................................47 
4.6. Métodos de análisis y medida ........................................................................55

4.6.1. Método para la determinación de la curva de evolución de la densidad de flujo de permeado con el tiempo. .55

4.6.2. Determinación de la concentración de polietilenglicol (PEG) ........................56

4.6.3. Determinación de la Demanda Química de Oxígeno (DQO) ..........................56

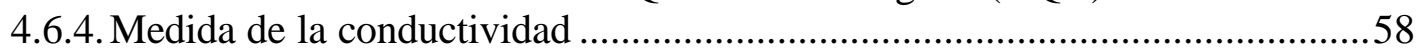

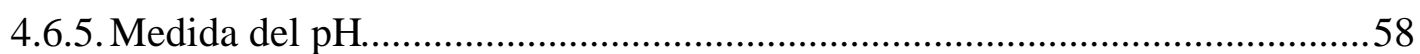

4.6.6. Determinación de la densidad y viscosidad de las disoluciones de

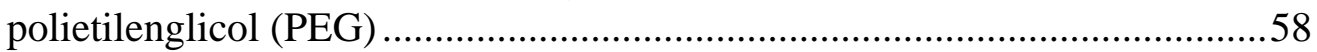

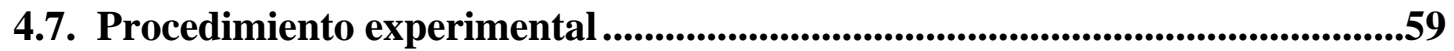

4.7.1.Ensayos de caracterización de las membranas de ultrafiltración....................59

4.7.2. Ensayos de ensuciamiento de las membranas de ultrafiltración......................60

4.7.3. Protocolo de limpieza de las membranas de ultrafiltración............................63

5. ANÁLISIS DE LOS RESULTADOS Y DISCUSIÓN..................................65

5.1. Caracterización de las membranas de ultrafiltración......................................65

5.1.1. Determinación de la resistencia intrínseca de la membrana $\left(\mathrm{R}_{\mathrm{m}}\right)$.................68

5.1.2. Determinación de la concentración de PEG en el alimento y en el

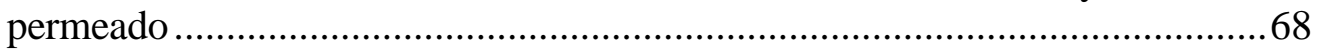

5.2. Datos de partida y cálculos previos................................................................70

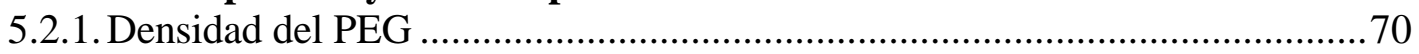

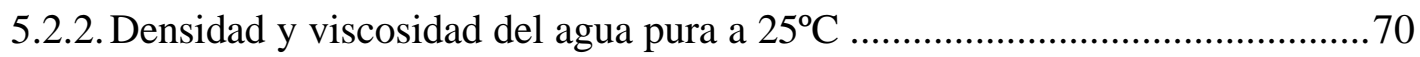

5.2.3. Radio equivalente del PEG en función de su peso molecular .......................71

5.2.4. Coeficiente de difusión del PEG en función de su peso molecular ................. 71

5.2.5. Presión osmótica de una disolución de PEG en agua ......................................71

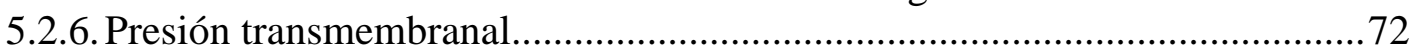

5.2.7. Equivalencia entre el caudal de alimentación y la velocidad tangencial dentro del módulo de membrana .............................................................73

5.3. Análisis del comportamiento de las membranas en la ultrafiltración de macromoléculas .........................................................................................................74

5.3.1. Influencia de la velocidad tangencial en la variación de la densidad de flujo de permeado con el tiempo para la me mbrana Carbosep M2 ............... 74

5.3.2. Influencia de la velocidad tangencial en la variación de la densidad de flujo de permeado con el tiempo para la membrana Tami MSKT .................80

5.3.3. Influencia de la PTM en la variación de la densidad de flujo de permeado con el tiempo para la membrana Carbosep M2 ...........................86

5.3.4. Influencia de la PTM en la variación de la densidad de flujo de permeado con el tiempo para la membrana Tami MSKT.

5.3.5. Influencia de la concentración de soluto en la variación de la densidad de flujo de permeado con el tiempo para la membrana Tami MSKT.............95

5.3.6. Influencia de la temperatura en la variación de la densidad de flujo de permeado con el tiempo para la membrana Tami MSKT ............................ 100

5.3.7. Índice de rechazo de la membrana al PEG 101 
5.4. Aplicación de modelos dinámicos de ultrafiltración no empíricos

5.4.1. Modelo de aplicación de la teoría de la ultrafiltración transversal en el caso dinámico.

5.4.2. Modelo de difusión inducido por cizalla aplicado en el caso de la ultrafiltración dinámica

5.4.3. Modelo dinámico de Song para la ultrafiltración tangencial

5.4.4. Modelo dinámico de Bhattacharjee y Bhattacharya para la ultrafiltración controlada por la presión osmótica o por la capa gel indistintamente

5.4.5. Modelo dinámico que combina el bloqueo de poros y la formación de capa gel

5.4.6. Conclusiones de la aplicación teórica de los modelos dinámicos de ultrafiltración no empíricos ....

5.4.7. Modelo de difusión inducido por cizalla aplicado en el caso de la ultrafiltración dinámica con estimación empírica de la concentración en la capa gel...

5.4.8. Modelo dinámico de Song para la ultrafiltración tangencial con estimación empírica de la concentración en la capa gel....

5.4.9. Conclusiones de la aplicación de los modelos dinámicos de ultrafiltración no empíricos cuando h concentración en la capa gel se estima de forma empírica

5.5. Aplicación de modelos dinámicos de ultrafiltración semi-empíricos

5.5.1. Resultados de la aplicación de los Modelos de Hermia

5.5.2. Resultados de la aplicación de los Modelos de Hermia adaptados para flujo tangencial.

5.5.3. Resultados de la aplicación de los Modelos de Hermia adaptados para flujo tangencial calculando teóricamente sus parámetros............................ 166

5.5.4. Análisis de los parámetros de los modelos .................................................. 174

6. CONClUSIONES.......................................................................... 181

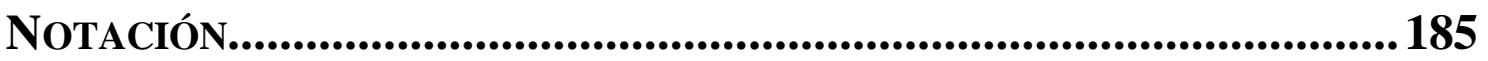

REFERENCIAS................................................................................. 191

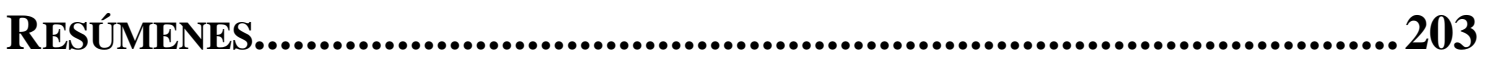





\section{Índice de figuras:}

Figura 1. Esquema básico de un proceso de separación con membranas..... 9

Figura 2. Niveles de separación en los procesos de membrana gobernados por la presión 10

Figura 3. Representación esquemática de los procesos de polarización por concentración y formación de capa gel.

Figura 4. Representación esquemática de las tres etapas de descenso de la densidad de flujo de permeado con el tiempo

Figura 5. Aplicación de la tecnología de membranas en la industria láctea

Figura 6. Procesado del suero lácteo.

Figura 7. Mecanismos de ensuciamiento considerados por los modelos: a) modelo de bloqueo completo de poros; b) modelo de bloqueo intermedio de poros; c) modelo de bloqueo estándar de poros y d) modelo de formación de torta

Figura 8. Fotografía de la planta piloto de ultrafiltración utilizada en los ensayos.....47

Figura 9. Esquema de la planta piloto de ultrafiltración utilizada en los ensayos.......48

Figura 10. Fotografía de las membranas de ultrafiltración utilizadas en los ensayos

Figura 11. Densidad de flujo de permeado al agua desionizada en función de la presión transmembranal para la membrana Carbosep M2

Figura 12. Densidad de flujo de permeado al agua desionizada en función de la presión transmebranal para la membrana Tami MSKT ....

Figura 13. Curva de calibrado de índice de refracción frente a concentración de polietilenglicol

Figura 14. Curva de calibrado de la DQO frente a la concentración de polietilenglicol

Figura 15. Relación entre el caudal de alimentación y la velocidad tangencial

Figura 16. Influencia de la velocidad tangencial en la variación de la densidad de flujo de permeado con el tiempo para una presión transmembranal de 0.1 MPa para la membrana Carbosep M2. 
Figura 17. Influencia de la velocidad tangencial en la variación de la densidad de flujo de permeado con el tiempo para una presión transmembranal de $0.2 \mathrm{MPa}$ para la membrana Carbosep M2

Figura 18. Influencia de la velocidad tangencial en la variación de la densidad de flujo de permeado con el tiempo para una presión transmembranal de $0.3 \mathrm{MPa}$ para la membrana Carbosep M2

Figura 19. Influencia de la velocidad tangencial en la variación de la densidad de flujo de permeado con el tiempo para una presión transmembranal de 0.4 MPa para la membrana Carbosep M2

Figura 20. Influencia de la velocidad tangencial en la densidad de flujo de permeado estacionaria para la membrana Carbosep M2.

Figura 21. Influencia de la velocidad tangencial en la variación de la densidad de flujo de permeado con el tiempo para una presión transmembranal de $0.2 \mathrm{MPa}$ y una concentración de $5 \mathrm{~g} / \mathrm{L}$ para la membrana Tami MSTK

Figura 22. Influencia de la velocidad tangencial en la variación de la densidad de flujo de permeado con el tiempo para una presión transmembranal de $0.5 \mathrm{MPa}$ y una concentración de $5 \mathrm{~g} / \mathrm{L}$ para la membrana Tami MSTK

Figura 23. Influencia de la velocidad tangencial en la densidad de flujo de permeado estacionaria para una concentración de $5 \mathrm{~g} / \mathrm{L}$ para la membrana Tami MSTK

Figura 24. Influencia de la velocidad tangencial en la variación de la densidad de flujo de permeado con el tiempo para una presión transmembranal de $0.2 \mathrm{MPa}$ y una concentración de $15 \mathrm{~g} / \mathrm{L}$ para la membrana Tami MSTK

Figura 25. Influencia de la velocidad tangencial en la variación de la densidad de flujo de permeado con el tiempo para una presión transmembranal de $0.5 \mathrm{MPa}$ y una concentración de $15 \mathrm{~g} / \mathrm{L}$ para la membrana Tami MSTK

Figura 26. Influencia de la velocidad tangencial en la densidad de flujo de permeado estacionaria para una concentración de $15 \mathrm{~g} / \mathrm{L}$ para la membrana Tami MSTK

Figura 27. Influencia de la presión transmembranal en la variación de la densidad de flujo de permeado con el tiempo para una velocidad tangencial de 1 m/s para la membrana Carbosep M2 
Figura 28. Influencia de la presión transmembranal en la variación de la densidad de flujo de permeado con el tiempo para una velocidad tangencial de 2 m/s para la membrana Carbosep M2

Figura 29. Influencia de la presión transmembranal en la variación de la densidad de flujo de permeado con el tiempo para una velocidad tangencial de 3 $\mathrm{m} / \mathrm{s}$ para la membrana Carbosep M2

Figura 30. Influencia de la presión transmembranal en la variación de la densidad de flujo de permeado con el tiempo para una velocidad tangencial de 1 $\mathrm{m} / \mathrm{s}$ y una concentración de $5 \mathrm{~g} / \mathrm{L}$ para la membrana Tami MSTK

Figura 31. Influencia de la presión transmembranal en la variación de la densidad de flujo de permeado con el tiempo para una velocidad tangencial de 3 $\mathrm{m} / \mathrm{s}$ y una concentración de $5 \mathrm{~g} / \mathrm{L}$ para la membrana Tami MSTK

Figura 32. Influencia de la presión transmembranal en la variación de la densidad de flujo de permeado con el tiempo para una velocidad tangencial de 1 $\mathrm{m} / \mathrm{s}$ y una concentración de $15 \mathrm{~g} / \mathrm{L}$ para la membrana Tami MSTK

Figura 33. Influencia de la presión transmembranal en la variación de la densidad de flujo de permeado con el tiempo para una velocidad tangencial de 3 $\mathrm{m} / \mathrm{s}$ y una concentración de $15 \mathrm{~g} / \mathrm{L}$ para la membrana Tami MSTK

Figura 34. Influencia de la concentración de soluto en la variación de la densidad de flujo de permeado con el tiempo para una velocidad tangencial de 1 $\mathrm{m} / \mathrm{s}$ y una presión transmembranal de $0.2 \mathrm{MPa}$ para la membrana Tami MSTK

Figura 35. Influencia de la concentración de soluto en la variación de la densidad de flujo de permeado con el tiempo para una velocidad tangencial de 1 $\mathrm{m} / \mathrm{s}$ y una presión transmembranal de $0.5 \mathrm{MPa}$ para la membrana Tami MSTK

Figura 36. Influencia de la concentración de soluto en la densidad de flujo de permeado estacionaria para una velocidad tangencial de $1 \mathrm{~m} / \mathrm{s}$ para la membrana Tami MSTK

Figura 37. Influencia de la concentración de soluto en la variación de la densidad de flujo de permeado con el tiempo para una velocidad tangencial de 3 $\mathrm{m} / \mathrm{s}$ y una presión transmembranal de $0.2 \mathrm{MPa}$ para la membrana Tami MSTK 
Figura 38. Influencia de la concentración de soluto en la variación de la densidad de flujo de permeado con el tiempo para una velocidad tangencial de 3 $\mathrm{m} / \mathrm{s}$ y una presión transmembranal de $0.5 \mathrm{MPa}$ para la membrana Tami MSTK.....

Figura 39. Influencia de la concentración de soluto en la densidad de flujo de permeado estacionaria para una velocidad tangencial de $3 \mathrm{~m} / \mathrm{s}$ para la membrana Tami MSTK

Figura 40. Influencia de la temperatura en la variación de la densidad de flujo de permeado con el tiempo para una concentración de soluto de $5 \mathrm{~g} / \mathrm{L}$, una velocidad tangencial de $1 \mathrm{~m} / \mathrm{s}$ y una presión transmembranal de 0.5 MPa para la membrana Tami MSTK

Figura 41. Influencia de la presión transmembranal en la variación del rechazo con el tiempo para una velocidad tangencial de $1 \mathrm{~m} / \mathrm{s}$ y una concentración de $5 \mathrm{~g} / \mathrm{L}$ para la membrana Tami MSTK

Figura 42. Influencia de la presión transmembranal en la variación del rechazo con el tiempo para una velocidad tangencial de $3 \mathrm{~m} / \mathrm{s}$ y una concentración de $5 \mathrm{~g} / \mathrm{L}$ para la membrana Tami MSTK

Figura 43. Influencia de la velocidad tangencial y de la presión transmembranal en el rechazo en estado estacionario para una concentración de 5 g/L para la membrana Tami MSTK.

Figura 44. Influencia de la velocidad tangencial en la variación del rechazo con el tiempo para una presión transmembranal de $0.3 \mathrm{MPa}$ y una concentración de $15 \mathrm{~g} / \mathrm{L}$ para la membrana Tami MSTK

Figura 45. Influencia de la concentración de soluto en la variación del rechazo con el tiempo para una velocidad tangencial de $1 \mathrm{~m} / \mathrm{s}$ y una presión transmembranal de $0.5 \mathrm{MPa}$ para la membrana Tami MSTK

Figura 46. Comparación entre los datos experimentales y las predicciones del modelo que se describe en el apartado 3.1.1 para una velocidad tangencial de $1 \mathrm{~m} / \mathrm{s}$ y una concentración de $5 \mathrm{~g} / \mathrm{L}$ para la membrana Carbosep M2

Figura 47. Comparación entre los datos experimentales y las predicciones del modelo que se describe en el apartado 3.1.1 para una velocidad tangencial de $2 \mathrm{~m} / \mathrm{s}$ y una concentración de $5 \mathrm{~g} / \mathrm{L}$ para la membrana Carbosep M2 
Figura 48. Comparación entre los datos experimentales y las predicciones del modelo que se describe en el apartado 3.1.1 para una velocidad tangencial de $3 \mathrm{~m} / \mathrm{s}$ y una concentración de $5 \mathrm{~g} / \mathrm{L}$ para la membrana Carbosep M2

Figura 49. Comparación entre los datos experimentales y las predicciones del modelo que se describe en el apartado 3.1.2 para una velocidad tangencial de $1 \mathrm{~m} / \mathrm{s}$ y una concentración de $5 \mathrm{~g} / \mathrm{L}$ para la membrana Carbosep M2

Figura 50. Comparación entre los datos experimentales y las predicciones del modelo que se describe en el apartado 3.1.2 para una velocidad tangencial de $2 \mathrm{~m} / \mathrm{s}$ y una concentración de $5 \mathrm{~g} / \mathrm{L}$ para la membrana Carbosep M2

Figura 51. Comparación entre los datos experimentales y las predicciones del modelo que se describe en el apartado 3.1.2 para una velocidad tangencial de $3 \mathrm{~m} / \mathrm{s}$ y una concentración de $5 \mathrm{~g} / \mathrm{L}$ para la membrana Carbosep M2

Figura 52. Comparación entre los datos experimentales y las predicciones del modelo que se describe en el apartado 3.1.3 para una velocidad tangencial de $1 \mathrm{~m} / \mathrm{s}$ y una concentración de $5 \mathrm{~g} / \mathrm{L}$ para la membrana Carbosep M2

Figura 53. Comparación entre los datos experimentales y las predicciones del modelo que se describe en el apartado 3.1.3 para una velocidad tangencial de $2 \mathrm{~m} / \mathrm{s}$ y una concentración de $5 \mathrm{~g} / \mathrm{L}$ para la membrana Carbosep M2

Figura 54. Comparación entre los datos experimentales y las predicciones del modelo que se describe en el apartado 3.1.3 para una velocidad tangencial de $3 \mathrm{~m} / \mathrm{s}$ y una concentración de $5 \mathrm{~g} / \mathrm{L}$ para la membrana Carbosep M2

Figura 55. Comparación entre los datos experimentales y las predicciones del modelo que se describe en el apartado 3.1.4 para una velocidad tangencial de $1 \mathrm{~m} / \mathrm{s}$ y una concentración de $5 \mathrm{~g} / \mathrm{L}$ para la membrana Carbosep M2

Figura 56. Comparación entre los datos experimentales y las predicciones del modelo que se describe en el apartado 3.1.4 para una velocidad tangencial de $2 \mathrm{~m} / \mathrm{s}$ y una concentración de $5 \mathrm{~g} / \mathrm{L}$ para la membrana Carbosep M2 
Figura 57. Comparación entre los datos experimentales y las predicciones del modelo que se describe en el apartado 3.1.4 para una velocidad tangencial de $3 \mathrm{~m} / \mathrm{s}$ y una concentración de $5 \mathrm{~g} / \mathrm{L}$ para la membrana Carbosep M2

Figura 58. Comparación entre los datos experimentales y las predicciones del modelo que se describe en el apartado 3.1.5 para una velocidad tangencial de $1 \mathrm{~m} / \mathrm{s}$ y una concentración de $5 \mathrm{~g} / \mathrm{L}$ para la membrana Carbosep M2

Figura 59. Comparación entre los datos experimentales y las predicciones del modelo que se describe en el apartado 3.1.5 para una velocidad tangencial de $2 \mathrm{~m} / \mathrm{s}$ y una concentración de $5 \mathrm{~g} / \mathrm{L}$ para la membrana Carbosep M2

Figura 60. Comparación entre los datos experimentales y las predicciones del modelo que se describe en el apartado 3.1.5 para una velocidad tangencial de $3 \mathrm{~m} / \mathrm{s}$ y una concentración de $5 \mathrm{~g} / \mathrm{L}$ para la membrana Carbosep M2

Figura 61. Comparación entre los datos experimentales y las predicciones del modelo que se describe en el apartado 3.1.2 cuando la concentración de la capa gel se estima de forma empírica para una velocidad tangencial de $1 \mathrm{~m} / \mathrm{s}$ y una concentración de $5 \mathrm{~g} / \mathrm{L}$ para la membrana Carbosep M2

Figura 62. Comparación entre los datos experimentales y las predicciones del modelo que se describe en el apartado 3.1.2 cuando la concentración de la capa gel se estima de forma empírica para una velocidad tangencial de $3 \mathrm{~m} / \mathrm{s}$ y una concentración de $5 \mathrm{~g} / \mathrm{L}$ para la membrana Carbosep M2

Figura 63. Comparación entre los datos experimentales y las predicciones del modelo que se describe en el apartado 3.1.2 cuando la concentración de la capa gel se estima de forma empírica para una velocidad tangencial de $1 \mathrm{~m} / \mathrm{s}$ y una concentración de $5 \mathrm{~g} / \mathrm{L}$ para la membrana Tami MSKT.

Figura 64. Comparación entre los datos experimentales y las predicciones del modelo que se describe en el apartado 3.1.2 cuando la concentración de la capa gel se estima de forma empírica para una velocidad tangencial de $3 \mathrm{~m} / \mathrm{s}$ y una concentración de $5 \mathrm{~g} / \mathrm{L}$ para la membrana Tami MSKT. 
Figura 65. Comparación entre los datos experimentales y las predicciones del modelo que se describe en el apartado 3.1.2 cuando la concentración de la capa gel se estima de forma empírica para una velocidad tangencial de $1 \mathrm{~m} / \mathrm{s}$ y una concentración de $15 \mathrm{~g} / \mathrm{L}$ para la membrana Tami MSKT.

Figura 66. Comparación entre los datos experimentales y las predicciones del modelo que se describe en el apartado 3.1.2 cuando la concentración de la capa gel se estima de forma empírica para una velocidad tangencial de $3 \mathrm{~m} / \mathrm{s}$ y una concentración de $15 \mathrm{~g} / \mathrm{L}$ para la membrana Tami MSKT.

Figura 67. Comparación entre los datos experimentales y las predicciones del modelo que se describe en el apartado 3.1.3 cuando la concentración de la capa gel se estima de forma empírica para una velocidad tangencial de $1 \mathrm{~m} / \mathrm{s}$ y una concentración de $5 \mathrm{~g} / \mathrm{L}$ para la membrana Carbosep M2

Figura 68. Comparación entre los datos experimentales y las predicciones del modelo que se describe en el apartado 3.1.3 cuando la concentración de la capa gel se estima de forma empírica para una velocidad tangencial de $1 \mathrm{~m} / \mathrm{s}$ y una concentración de $5 \mathrm{~g} / \mathrm{L}$ para la membrana Tami MSKT.

Figura 69. Comparación entre los datos experimentales y las predicciones del modelo que se describe en el apartado 3.1.3 cuando la concentración de la capa gel se estima de forma empírica para una velocidad tangencial de $1 \mathrm{~m} / \mathrm{s}$ y una concentración de $15 \mathrm{~g} / \mathrm{L}$ para la membrana Tami MSKT.

Figura 70. Ajuste empírico del Modelo de bloqueo completo de poros para una velocidad tangencial de $1 \mathrm{~m} / \mathrm{s}$ y una concentración de $5 \mathrm{~g} / \mathrm{L}$ para la membrana Carbosep M2

Figura 71. Ajuste empírico del Modelo de bloqueo completo de poros para una velocidad tangencial de $2 \mathrm{~m} / \mathrm{s}$ y una concentración de $5 \mathrm{~g} / \mathrm{L}$ para la membrana Carbosep M2 .

Figura 72. Ajuste empírico del Modelo de bloqueo completo de poros para una velocidad tangencial de $3 \mathrm{~m} / \mathrm{s}$ y una concentración de $5 \mathrm{~g} / \mathrm{L}$ para la membrana Carbosep M2 
Figura 73. Ajuste empírico del Modelo de bloqueo intermedio de poros para una velocidad tangencial de $1 \mathrm{~m} / \mathrm{s}$ y una concentración de $5 \mathrm{~g} / \mathrm{L}$ para la membrana Carbosep M2

Figura 74. Ajuste empírico del Modelo de bloqueo intermedio de poros para una velocidad tangencial de $2 \mathrm{~m} / \mathrm{s}$ y una concentración de $5 \mathrm{~g} / \mathrm{L}$ para la membrana Carbosep M2

Figura 75. Ajuste empírico del Modelo de bloqueo intermedio de poros para una velocidad tangencial de $3 \mathrm{~m} / \mathrm{s}$ y una concentración de $5 \mathrm{~g} / \mathrm{L}$ para la membrana Carbosep M2.

Figura 76. Ajuste empírico del Modelo de bloqueo estándar de poros para una velocidad tangencial de $1 \mathrm{~m} / \mathrm{s}$ y una concentración de $5 \mathrm{~g} / \mathrm{L}$ para la membrana Carbosep M2

Figura 77. Ajuste empírico del Modelo de bloqueo estándar de poros para una velocidad tangencial de $2 \mathrm{~m} / \mathrm{s}$ y una concentración de $5 \mathrm{~g} / \mathrm{L}$ para la membrana Carbosep M2

Figura 78. Ajuste empírico del Modelo de bloqueo estándar de poros para una velocidad tangencial de $3 \mathrm{~m} / \mathrm{s}$ y una concentración de $5 \mathrm{~g} / \mathrm{L}$ para la membrana Carbosep M2

Figura 79. Ajuste empírico del Modelo de formación de torta para una velocidad tangencial de $1 \mathrm{~m} / \mathrm{s}$ y una concentración de $5 \mathrm{~g} / \mathrm{L}$ para la membrana Carbosep M2

Figura 80. Ajuste empírico del Modelo de formación de torta para una velocidad tangencial de $2 \mathrm{~m} / \mathrm{s}$ y una concentración de $5 \mathrm{~g} / \mathrm{L}$ para la membrana Carbosep M2

Figura 81. Ajuste empírico del Modelo de formación de torta para una velocidad tangencial de $3 \mathrm{~m} / \mathrm{s}$ y una concentración de $5 \mathrm{~g} / \mathrm{L}$ para la membrana Carbosep M2

Figura 82. Ajuste empírico del Modelo de bloqueo completo de poros adaptado para flujo tangencial para una velocidad tangencial de $1 \mathrm{~m} / \mathrm{s}$ y una concentración de $5 \mathrm{~g} / \mathrm{L}$ para la membrana Carbosep M2

Figura 83. Ajuste empírico del Modelo de bloqueo completo de poros adaptado para flujo tangencial para una velocidad tangencial de $2 \mathrm{~m} / \mathrm{s}$ y una concentración de $5 \mathrm{~g} / \mathrm{L}$ para la membrana Carbosep M2 
Figura 84. Ajuste empírico del Modelo de bloqueo completo de poros adaptado para flujo tangencial para una velocidad tangencial de $3 \mathrm{~m} / \mathrm{s}$ y una concentración de $5 \mathrm{~g} / \mathrm{L}$ para la membrana Carbosep M2

Figura 85. Ajuste empírico del Modelo de bloqueo intermedio de poros adaptado para flujo tangencial para una velocidad tangencial de $1 \mathrm{~m} / \mathrm{s}$ y una concentración de $5 \mathrm{~g} / \mathrm{L}$ para la membrana Carbosep M2

Figura 86. Ajuste empírico del Modelo de bloqueo intermedio de poros adaptado para flujo tangencial para una velocidad tangencial de $2 \mathrm{~m} / \mathrm{s}$ y una concentración de $5 \mathrm{~g} / \mathrm{L}$ para la membrana Carbosep M2

Figura 87. Ajuste empírico del Modelo de bloqueo intermedio de poros adaptado para flujo tangencial para una velocidad tangencial de $3 \mathrm{~m} / \mathrm{s}$ y una concentración de $5 \mathrm{~g} / \mathrm{L}$ para la membrana Carbosep M2

Figura 88. Ajuste empírico del Modelo de bloqueo estándar de poros adaptado para flujo tangencial para una velocidad tangencial de $1 \mathrm{~m} / \mathrm{s}$ y una concentración de $5 \mathrm{~g} / \mathrm{L}$ para la membrana Carbosep M2

Figura 89. Ajuste empírico del Modelo de bloqueo estándar de poros adaptado para flujo tangencial para una velocidad tangencial de $2 \mathrm{~m} / \mathrm{s}$ y una concentración de $5 \mathrm{~g} / \mathrm{L}$ para la membrana Carbosep M2

Figura 90. Ajuste empírico del Modelo de bloqueo estándar de poros adaptado para flujo tangencial para una velocidad tangencial de $3 \mathrm{~m} / \mathrm{s}$ y una concentración de $5 \mathrm{~g} / \mathrm{L}$ para la membrana Carbosep M2

Figura 91. Ajuste empírico del Modelo de formación de capa gel adaptado para flujo tangencial para una velocidad tangencial de $1 \mathrm{~m} / \mathrm{s}$ y una concentración de $5 \mathrm{~g} / \mathrm{L}$ para la membrana Carbosep M2

Figura 92. Ajuste empírico del Modelo de formación de capa gel adaptado para flujo tangencial para una velocidad tangencial de $2 \mathrm{~m} / \mathrm{s}$ y una concentración de $5 \mathrm{~g} / \mathrm{L}$ para la membrana Carbosep M2

Figura 93. Ajuste empírico del Modelo de formación de capa gel adaptado para flujo tangencial para una velocidad tangencial de $3 \mathrm{~m} / \mathrm{s}$ y una concentración de $5 \mathrm{~g} / \mathrm{L}$ para la membrana Carbosep M2

Figura 94. Comparación entre los datos experimentales y las predicciones del Modelo de bloqueo completo de poros adaptado para flujo tangencial para una velocidad tangencial de $1 \mathrm{~m} / \mathrm{s}$ y una concentración de $5 \mathrm{~g} / \mathrm{L}$ para la membrana Carbosep M2 
Figura 95. Comparación entre los datos experimentales y las predicciones del Modelo de bloqueo completo de poros adaptado para flujo tangencial para una velocidad tangencial de $2 \mathrm{~m} / \mathrm{s}$ y una concentración de $5 \mathrm{~g} / \mathrm{L}$ para la membrana Carbosep M2

Figura 96. Comparación entre los datos experimentales y las predicciones del Modelo de bloqueo completo de poros adaptado para flujo tangencial para una velocidad tangencial de $3 \mathrm{~m} / \mathrm{s}$ y una concentración de $5 \mathrm{~g} / \mathrm{L}$ para la membrana Carbosep M2

Figura 97. Comparación entre los datos experimentales y las predicciones del Modelo de bloqueo intermedio de poros adaptado para flujo tangencial para una velocidad tangencial de $1 \mathrm{~m} / \mathrm{s}$ y una concentración de $5 \mathrm{~g} / \mathrm{L}$ para la membrana Carbosep M2

Figura 98. Comparación entre los datos experimentales y las predicciones del Modelo de bloqueo intermedio de poros adaptado para flujo tangencial para una velocidad tangencial de $2 \mathrm{~m} / \mathrm{s}$ y una concentración de $5 \mathrm{~g} / \mathrm{L}$ para la membrana Carbosep M2

Figura 99. Comparación entre los datos experimentales y las predicciones del Modelo de bloqueo intermedio de poros adaptado para flujo tangencial para una velocidad tangencial de $3 \mathrm{~m} / \mathrm{s}$ y una concentración de $5 \mathrm{~g} / \mathrm{L}$ para la membrana Carbosep M2 


\section{Índice de tablas:}

Tabla 1. Clasificación de los procesos de membrana 8

Tabla 2. Especificaciones técnicas de las membranas.

Tabla 3. Características del PEG utilizado en los ensayos

Tabla 4. Características del $\mathrm{NaOH}$ utilizado en la preparación de las disoluciones de limpieza.

Tabla 5. Características del $\mathrm{NaClO}$ utilizado en la preparación de las disoluciones de limpieza

Tabla 6. Condiciones experimentales utilizadas en los ensayos de ultrafiltración con las membranas Carbosep M2 .

Tabla 7. Condiciones experimentales utilizadas en los ensayos de ultrafiltración a temperatura constante con las membranas Tami MSKT

Tabla 8. Error cuadrático medio de los ajustes de los Modelos de Hermia a los datos experimentales obtenidos con la membrana Carbosep M2

Tabla 9. Parámetros resultantes de la aplicación de los Modelos de Hermia en el caso de la membrana Carbosep M2.

Tabla 10. Parámetros resultantes de la aplicación de los Modelos de Hermia adaptados para flujo tangencial en el caso de la membrana Carbosep M2.

Tabla 11. Comparación entre las densidades de flujo de permeado iniciales obtenidas experimentalmente con la membrana Carbosep M2 y las resultantes de la aplicación de los Modelos de Hermia.

Tabla 12. Comparación entre las densidades de flujo de permeado iniciales obtenidas experimentalemente con la membrana Carbosep M2 y las resultantes de la aplicación de los Modelos de Hermia adaptados para flujo tangencial.

Tabla 13. Comparación entre las densidades de flujo de permeado estacionarias obtenidas experimentalmente con la membrana Carbosep M2 y las resultantes de la aplicación de los Modelos de Hermia adaptados para flujo tangencial. 



\section{Capítulo}

\section{1}

\section{INTRODUCCIÓN}

La presente Tesis Doctoral ha sido desarrollada en el Departamento de Ingeniería Química y Nuclear de la Universidad Politécnica de Valencia (UPV), dentro del grupo de investigación "Procesos de Membrana y Tratamiento Medioambiental de Efluentes" (PROMETEO).

Esta Tesis analiza la aplicación de modelos dinámicos para predecir el descenso de la densidad de flujo de permeado con el tiempo debido al ensuciamiento en procesos de membrana de ultrafiltración tangencial. Se ha estudiado la adecuación de modelos de ultrafiltración tanto empíricos como no empíricos para describir los procesos de ensuciamiento que tienen lugar en la ultrafiltración de macromoléculas.

Asimismo, se proponen, analizan y comparan entre sí varios modelos. Se comparan también los resultados predichos por los modelos con los resultados experimentales obtenidos bajo las diferentes condiciones de operación y utilizando varios tipos de membrana. Se han estudiado diferentes variables que pueden afectar al ensuciamiento de las membranas de ultrafiltración: temperatura, concentración de la alimentación, velocidad tangencial, presión transmembranal (PTM) y naturaleza de las membranas. 
El principal objetivo del presente trabajo ha sido contribuir al entendimiento de los fenómenos de ensuciamiento en los procesos de ultrafiltración y avanzar en su modelización.

Para este propósito, se realizaron varios experimentos en planta piloto con una disolución acuosa de polietilenglicol (PEG), bajo diferentes condiciones de operación y con diferentes tipos de membranas cerámicas. Se sel eccionó el PEG para los ensayos debido a que éste ha sido utilizado frecuentemente (Ganguly y Bhattacharya, 1994; Ghose et al., 2000) como molécula estándar en ensayos de ultrafiltración, para comparar los modelos que predicen la variación de la densidad de flujo de permeado con el tiempo con los resultados experimentales. Además, por este motivo se encuentran en la bibliografía numerosos datos y correlaciones para estimar las propiedades físicas de dicho compuesto en función de su peso molecular.

\subsection{Motivación}

Los fenómenos de ensuciamiento están presentes en todas las aplicaciones de los procesos de ultrafiltración. El ensuciamiento de las membranas es el responsable de la naturaleza no estacionaria de los procesos de ultrafiltración, causando un descenso de la densidad de flujo de permeado con el tiempo; y es el principal factor limitante en la aplicación de la tecnología de membranas. Por esta razón, los modelos de estado estacionario no son capaces de describir adecuadamente el comportamiento de las membranas en los procesos de ultrafiltración y es necesario hacer uso de modelos no estacionarios para lograr una mejor compresión de dichos procesos.

En la bibliografía existen muchos modelos no estacionarios que describen procesos de ultrafiltración; pero la mayoría de ellos son empíricos. Aunque los modelos empíricos son muy precisos, su aplicabilidad está restringida por ser incapaces de hacer predicciones y por requerir siempre una fase experimental previa. 
El desarrollo de modelos dinámicos no empíricos o semi-empíricos para describir los procesos de ultrafiltración es interesante no sólo por contribuir a un mejor entendimiento de los mecanismos implicados en la ultrafiltración, sino también por ser capaces de predecir el comportamiento de sistemas de ultrafiltración bajo diferentes condiciones experimentales (características del alimento, presión transmembranal (PTM), velocidad tangencial, temperatura, etc.), evitando tener que recurrir a largos y costosos ensayos en planta piloto.

Estos modelos son muy útiles, por ejemplo, cuando es necesario realizar un cambio en las variables de operación en una planta de ultrafiltración. Además pueden ayudar en la selección de las variables de proceso óptimas para una determinada aplicación.

\subsection{OBJETIVOS}

El objetivo principal de esta Tesis Doctoral es estudiar la adecuación de modelos dinámicos de ultrafiltración no empíricos y semiempíricos en la descripción de los procesos de ultrafiltración tangencial de macromoléculas.

Para la consecución de este objetivo se han considerado los siguientes objetivos específicos:

- A nálisis de modelos dinámicos de ultrafiltración tangencial que permitan describir la variación de la densidad de flujo de permeado con el tiempo. Se prestará especial atención a aquellos modelos que no sean empíricos, es decir, en los que no sea necesario calcular los parámetros a partir de los resultados obtenidos en los ensayos de ultrafiltración.

- Comparación de los modelos con los resultados experimentales bajo diferentes condiciones de operación.

- Identificación de las limitaciones de los modelos y de las causas de las mismas, así como de las posibles discrepancias 
entre los resultados experimentales y los predichos por el modelo.

- Selección del modelo o modelos más apropiados para describir los fenómenos de ensuciamiento en los procesos de ultrafiltración.

\subsection{Contribución dela Tesis Doctoral}

Además de realizar una extensa revisión bibliográfica sobre el modelado dinámico de los procesos de ultrafiltración, tanto desde una vertiente teórica como empírica, las principales contribuciones de esta Tesis Doctoral podrían resumirse en los siguientes puntos:

- Permite comprobar la validez delos modelos de ultrafiltración bajo diferentes condiciones experimentales.

- Compara los distintos modelos, mostrando las diferencias y semejanzas existentes entre ellos en función de la precisión en las predicciones y de las hipótesis de partida de cada uno de ellos.

- Analiza la relación entre las hipótesis de partida y la concordancia de los resultados predichos por los model os con los resultados experimentales.

- Propone un modelo semi-empírico como el más idóneo para describir y predecir los fenómenos de ensuciamiento en la ultrafiltración de macromoléculas.

- Determina teóricamente los parámetros del modelo semiempírico escogido, de forma que, utilizando como únicos datos empíricos la densidad de flujo de permeado estacionaria alcanzada y el flujo inicial, el modelo es capaz de predecir la variación de la densidad de flujo de permeado con el tiempo.

Parte del trabajo real izado en esta Tesis ha sido expuesto en la sexta edición de Network Young Membrains (Vincent, 2004), en la séptima y octava edición del congreso Euromembrane Nincent et al., 2004; Vincent et al., 2006a), en la quinta edición del congreso 
Desalination and the Environment (Vincent et al., 2005a), en la séptima edición del congreso International Congress on Membranes and Membrane Processes (Vincent et al., 2005b), en la segunda edición del congreso Membrane Science and Technology Conference of Visegrad Countries (Vincent et al., 2005c), en el quinto Congreso Iberoamericano de Ciencia y Tecnología de Membranas (Vincent et al. , 2005d) y en la cuarta edición del congreso Desalination Strategies in the South Mediterranean Countries (Vincent et al. , 2006b; Vincent et al. , 2006c; Vincent et al. , 2006d).

A simismo, la presente Tesis a dado lugar a ocho publicaciones: una en la revista Ingeniería Química (Vincent et al., 2005e) y siete en la revista Desalination (Vincent et al., 2005f; Vincent et al., 2006e; Vincent et al., 2006f; Vincent et al., 2006g; Vincent et al., 2006h; Vincent et al., 2006i; Vincent et al., 2006j).

\subsection{Estructura de LA TESIS D OCTORAL}

La estructura de la presente Tesis Doctoral es la siguiente: Una vez expuestos la motivación, los objetivos y la contribución de la Tesis Doctoral en el capítulo primero, en el capítulo segundo se exponen brevemente los fundamentos de la tecnología de membranas, centrándose en particular en la ultrafiltración y el ensuciamiento de membranas de ultrafiltración. A su vez se hace referencia a la evolución de la investigación en dichas áreas.

En el capítulo tercero se comentan los principales modelos que describen el ensuciamiento de las membranas de ultrafiltración. Se han seleccionado modelos dinámicos no empíricos o semi-empíricos aplicables en la ultrafiltración de macromoléculas, realizando una amplia revisión de los trabajos que se han efectuado hasta el momento.

El capítulo cuarto está dedicado a la descripción de la metodología empleada en esta Tesis Doctoral, incluyendo los materiales e 
infraestructuras utilizadas; así como el procedimiento seguido en la realización de los experimentos.

En el capítulo quinto se comentan los resultados experimentales y se comparan con los resultados predichos por los modelos. Además se analizan cuáles son las limitaciones de los modelos que pueden afectar a la predicción de la densidad de flujo de permeado y se estudia su posible efecto sobre los resultados. En el capítulo sexto se exponen las conclusiones de la Tesis.

Finalmente, se incluyen tres anexos: uno con los símbolos y abreviaturas utilizados en la memoria de la Tesis, otro con las referencias bibliográficas citadas en la misma y el tercero con los resúmenes de la presente Tesis Doctoral en castellano, valenciano e inglés. 


\section{Capítulo}

\section{ANTECEDENTES}

\subsection{TECNOLOGÍA DE MEMBRANAS}

\subsubsection{B reve reseña histórica}

Tal y como señala Mulder (2000), las primeras referencias sobre la investigación en el campo de las membranas datan de mediados del siglo XVIII. En dichos trabajos se observaron y estudiaron fenómenos osmóticos. Sin embargo, hubo que esperar hasta el siglo $X X$ para que se comercializasen las primeras membranas. Pero sin duda, el hito más importante en tecnología de membranas se produjo hace tan sólo tres décadas con el desarrollo de las membranas asimétricas, consistentes en una fina capa selectiva depositada sobre un soporte poroso. Estas membranas permitían obtener mayores densidades de flujo de permeado con el mismo espesor que una membrana simétrica.

Durante estos últimos treinta años la tecnología de membranas ha atraído numerosos esfuerzos de investigación. Los trabajos más recientes se han centrado en el desarrollo de nuevos materiales para la fabricación de membranas, en la modelización de los diversos procesos de separación por membranas y en la determinación de la influencia de numerosas variables en dichos procesos. 


\subsubsection{Membranas y procesos de membrana}

Una membrana semipermeable es una barrera selectiva que permite el paso de ciertas sustancias a su través en mayor proporción, mientras que impide o restringe el paso de otras sustancias. De este modo es posible enriquecer o empobrecer una corriente en uno o varios compuestos. La densidad de flujo de estas sustancias a través de la membrana se debe a la acción de diferentes fuerzas impulsoras, siendo las más importantes los gradientes de presión, concentración o potencial eléctrico a ambos lados de la membrana.

La American Water Works Association (AWWA) Research Foundation (1998) define un proceso de membrana como una operación unitaria de separación donde el elemento separador es una membrana semipermeable, y donde el proceso de separación tiene lugar debido a la existencia de una fuerza impulsora.

Los procesos de membrana se pueden clasificar, atendiendo a la fuerza impulsora, tal y como se muestra en la Tabla 1.

Tabla 1. Clasificación de los procesos de membrana

\begin{tabular}{ll}
\hline \multicolumn{1}{c}{ Proceso } & \multicolumn{1}{c}{ Fuerza impulsora } \\
\hline $\begin{array}{l}\text { Ósmosis inversa (OI) } \\
\text { Nanofiltración (NF) } \\
\text { Ultrafiltración (UF) }\end{array}$ & Diferencia de presión \\
Microfiltración (MF) & \\
\hline Diálisis(D) & Diferencia de concentración \\
\hline Electrodiálisis (ED) & $\begin{array}{l}\text { Diferencia de potencial } \\
\text { eléctrico }\end{array}$ \\
\hline Permeación de gases (PG) & Diferencia de presión \\
\hline Pervaporación (PV) & Diferencia de presión parcial \\
\hline
\end{tabular}

En todo proceso de membrana una corriente alimento se pone en contacto con la membrana, de forma que, debido a la fuerza 
impulsora aplicada, la corriente se separa en otras dos: el permeado o corriente formada por los componentes que han atravesado la membrana y el rechazo o corriente que no ha atravesado la membrana. En la Figura 1 se muestra el esquema básico un proceso de membrana.

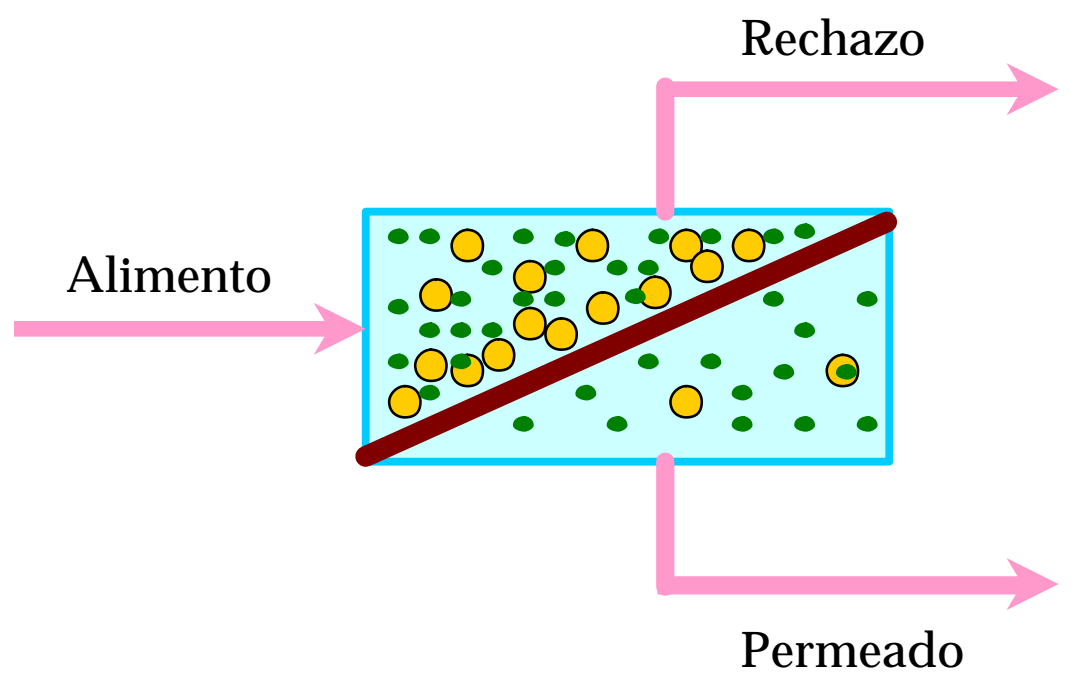

Figura 1. Esquema básico de un proceso de separación con membranas

Hasta la fecha, el grupo de procesos de membrana más estudiados son aquellos en los que la fuerza impulsora es el gradiente de presión, y en el se incluyen la microfiltración (MF), la ultrafiltración (UF), la nanofiltración (NF) y la ósmosis inversa (OI). La descripción de los fundamentos de cada una de estas técnicas y de sus distintas aplicaciones industriales se encuentran ampliamente detalladas en libros temáticos (Cheryan, 1998; Mulder, 2000) y en trabajos anteriores realizados en el Departamento de Ingeniería Química y Nuclear de la Universidad Politécnica de Valencia (Mendoza, 2000; Bes, 2003; Gozálvez, 1998).

Los procesos de membrana cuya fuerza impulsora es el gradiente de presión se pueden clasificar atendiendo al tipo de sustancias que son rechazadas por la membrana. Esta clasificación se puede observar en la Figura 2 (Cheryan, 1998). 
Las diferentes geometrías de las membranas (planas, tubulares, de arrollamiento en espiral, de fibras huecas, etc.) así como la naturaleza de las mismas (orgánica e inorgánica) y sus principales aplicaciones se encuentran detalladas en libros especializados (Cheryan, 1998; Mulder, 2000).

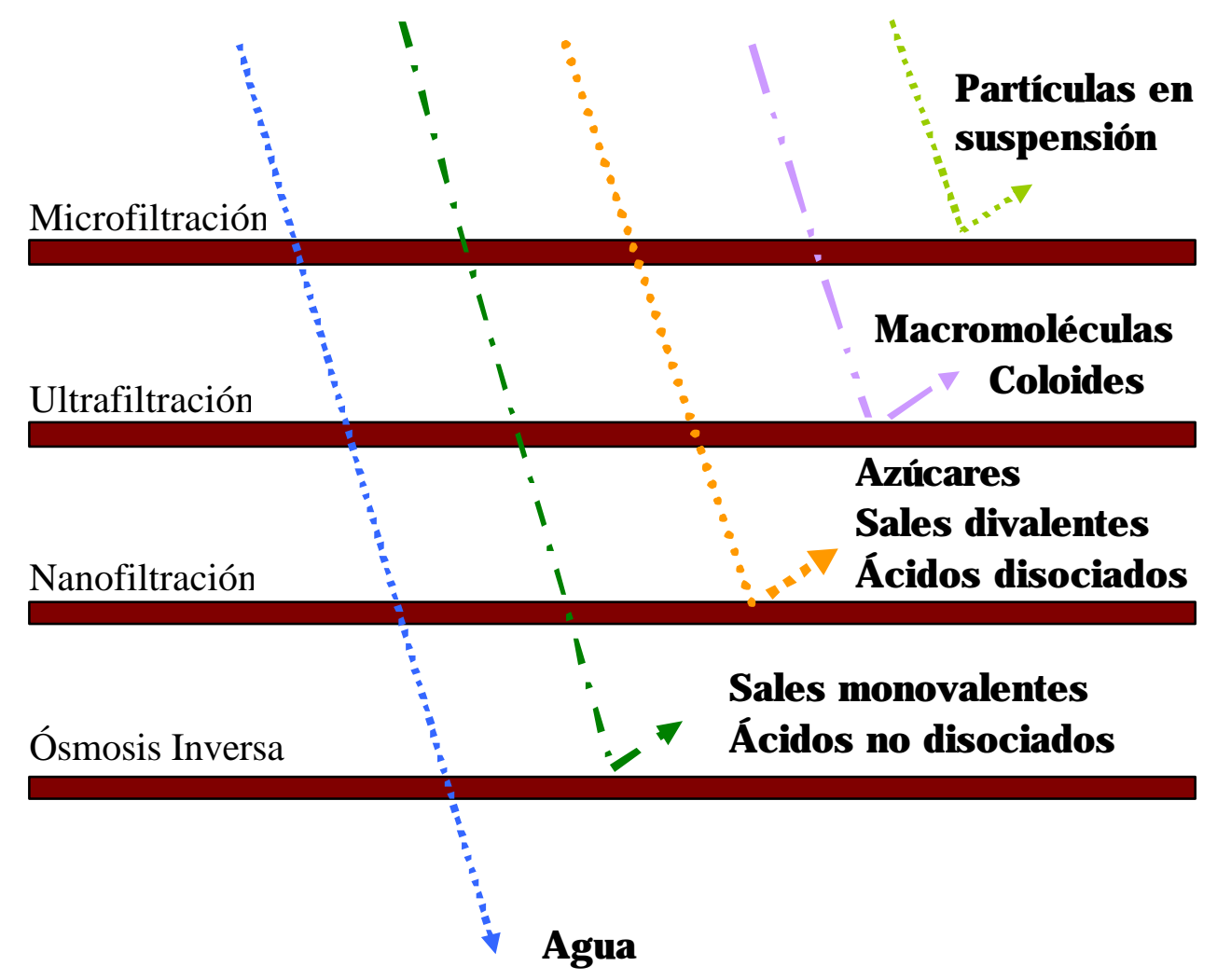

Figura 2. Niveles de separación en los procesos de membrana gobernados por la presión

\subsubsection{Ventajas e inconvenientes de los procesos de membrana}

Las ventajas de los procesos de separación por membrana frente a otros procesos de separación son las siguientes (Mulder, 2000):

- Posibilidad de operar bajo condiciones suaves. Por ejemplo, mediante los procesos de membrana es posible separar compuestos sin necesidad de trabajar a altas temperaturas. 
- Posibilidad de llevar a cabo el proceso de separación en continuo.

- Adaptabilidad a la capacidad de producción, pues se trata de equipos modulares.

- Se pueden utilizar en aplicaciones muy diversas, gracias a que las propiedades de las membranas son variables.

- No se necesita incorporar ningún producto químico ajeno a la disolución o suspensión a tratar.

- Los equipos suelen ser relativamente pequeños.

- Bajo consumo energético. Normalmente el gasto energético principal es el bombeo de sustancias (M olinari et al., 1995).

- Facilidad de instalación, desinstalación y operación.

- Cambio de escala sencillo debido a la utilización de configuraciones modulares.

- Posibilidad de ser combinados con otros procesos de tratamiento.

Pese a las numerosas ventajas de los procesos de membrana, también podemos encontrar inconvenientes como los siguientes:

- Problemas de ensuciamiento y degradación de las membranas, lo que afecta a sus propiedades físicas, químicas y mecánicas, haciendo que la membrana pierda eficacia a lo largo de la operación y reduciendo considerablemente su vida útil.

- Gestión de las corrientes concentradas, cuando no son el objeto de la separación, así como las de limpieza en determinadas situaciones.

- Elevado coste de las membranasinorgánicas.

\subsection{ULTRAFILTRACIÓN}

A continuación, se presentan algunos detalles del proceso que va a ser objeto de estudio en la presente Tesis Doctoral. 


\subsubsection{B reve descripción}

La ultrafiltración se define, según Krishnan et al. (1994), como un método para separar macromoléculas y sustancias coloidales, donde una membrana actúa como barrera selectiva. Las membranas de ultrafiltración pueden retener moléculas de un peso molecular superior a 1000 Da y el tamaño de poro abarca desde los 5 a los $100 \mathrm{~nm}$.

En el proceso de ultrafiltración, la diferencia de presión a través de la membrana, o presión transmembranal, es la responsable de que el disolvente y los solutos de reducido tamaño de la alimentación pasen a través de la membrana y formen parte de la corriente de permeado.

Los solutos de mayor tamaño, macromoléculas y agregados coloidales, son retenidos por la membrana pasando a formar parte de la corriente de rechazo. El mecanismo predominante por el cual las sustancias son retenidas por la membrana es la diferencia de tamaño entre los poros de la membrana y la geometría molecular de las sustancias a retener; aunque también influyen otros factores como la naturaleza de la membrana y las interacciones entre la membrana y las moléculas de soluto.

\subsubsection{Tipos demembranas y de módulos}

Las membranas utilizadas en ultrafiltración son de tipo asimétrico. Están formadas por una capa superior muy delgada $(0.1-1 \mu \mathrm{m})$ constituida por poros pequeños que es la que se pone en contacto con el alimento y participa activamente en el proceso de separación. Esta capa está apoyada sobre un soporte poroso de mayor espesor que es el que proporciona la resistencia mecánica a la membrana y cuyos poros son de un tamaño muy superior a los de la capa activa. Gracias a la estructura asimétrica, la membrana presenta elevada permeabilidad. 
A tendiendo a su natural eza, las membranas se dividen en orgánicas e inorgánicas. En general, las membranas orgánicas son más fáciles de fabricar y por lo tanto más baratas; mientras que las inorgánicas suelen ser más caras, pero presentan ventajas tales como la resistencia a altas temperaturas y a agentes químicos agresivos.

Los polímeros más utilizados en la fabricación de membranas orgánicas de ultrafiltración son las poliamidas, el poliacrilonitrilo, el fluoruro de polivinilideno, las polisulfonasy las poli imidas.

En cuanto a las membranas inorgánicas, la capa selectiva suele ser de $\mathrm{ZrO}_{2}, \mathrm{TiO}_{2}$ ó $\mathrm{Al}_{2} \mathrm{O}_{3}$ y el soporte poroso generalmente es de carbono o de $\mathrm{Al}_{2} \mathrm{O}_{3}$.

El módulo de membranas sirve para alojar a las mismas facilitando la forma de establecer una determinada presión transmembranal. Los módulos pueden ser planos, tubulares, de arrollamiento en espiral o capilares.

Los módulos planos se utilizan poco debido a que tienen una relación superficie de membrana - volumen de módulo muy baja. Los tubulares son ampliamente utilizados por presentar ventajas desde el punto de vista del ensuciamiento. Los de arrollamiento en espiral se ensucian con más facilidad que los tubulares y son más difíciles de limpiar, pero tienen una relación superficie de membrana - volumen de módulo muy elevada, con lo cual también se utilizan frecuentemente en ultrafiltración. Finalmente, los capilares se utilizan en ultrafiltración cuando no existen serios problemas de ensuciamiento y delimpieza.

Una descripción más detallada de los tipos de membranas y módulos de ultrafiltración puede hallarse en los trabajos de Mendoza (2000) y de Cheryan (1998). 


\subsubsection{Configuración típica: flujo tangencial}

Los procesos de ultrafiltración sellevan a cabo con flujo tangencial a la superficie de la membrana (Davis, 1992). La corriente de alimento fluye en paralelo a la superficie de la membrana. La presión transmembranal provoca a su vez un flujo de permeado a través de la misma. Además se forma una capa de ensuciamiento sobre la membrana. Esta capa no crece constantemente con el tiempo sino que alcanza un valor máximo. Esto es debido a que el flujo tangencial hace que se desprendan algunas moléculas formadoras de la capa de ensuciamiento y se dirijan hacia la salida de la corriente de rechazo, con lo cual la capa de ensuciamiento siempre mantiene un espesor limitado. Esto permite mantener densidades de flujo de permeado relativamente elevadas durante largos periodos de tiempo.

Durante las dos últimas décadas se ha investigado sobre los mecanismos mediante los cuales el flujo tangencial afecta a la formación de la capa de ensuciamiento sobre la membrana. Como resultado de estas investigaciones se han desarrollado modelos para predecir la evolución de la densidad de flujo de permeado con el tiempo.

\subsubsection{Ensuciamiento de membranas de ultrafiltración}

Uno de los mayores obstáculos que dificulta la aplicación de los procesos de ultrafiltración es el fenómeno de descenso de la densidad de flujo de permeado con el tiempo. Este fenómeno se denomina comúnmente ensuciamiento, como traducción directa del término "fouling", haciendo referencia a una serie de mecanismos que representan una resi stencia adicional al paso de líquido a través dela membrana.

El ensuciamiento, al disminuir la velocidad de producción de permeado, incrementa la complejidad de las operaciones con 
membranas, dado que el sistema ha de ser detenido frecuentemente para someterlo a operaciones de limpieza que reestablezcan la densidad de flujo de permeado. El elevado coste de estas operaciones hace que la ultrafiltración sea menos viable económicamente para muchos de los problemas de separación (Song, 1998a).

El ensuciamiento de las membranas de ultrafiltración se debe a varios mecanismos que pueden actuar juntos o por separado en las distintas etapas del proceso de ultrafiltración. Estos mecanismos son:

- Taponamiento de los poros de la membrana, tanto a nivel superficial como en el interior de los mismos, debido a que el tamaño de las moléculas de soluto es similar al de los poros de la membrana.

- Formación de capa gel, debida al establecimiento de una red tridimensional entre las macromoléculas de soluto y el disolvente La concentración en la capa gel es constante para unas determinadas condiciones experimentales (ver la Figura 3); pero varía con la velocidad tangencial y la concentración de la alimentación para un mismo soluto (Mulder, 2000).

- Adsorción de moléculas sobre la superficie de membrana, debido a afinidades químicas entre la membrana y el soluto. La adsorción puede producirse también en el interior de los poros, reduciendo así el diámetro efectivo de los mismos.

- Formación de depósitos sobrela superficie de la membrana o en el interior de la misma por precipitación de las moléculas de soluto o sedimentación de materia en suspensión.

De todos estos mecanismos, los dos primeros, taponamiento de los poros de la membrana y formación de capa gel, son los mecanismos esenciales que explican el ensuciamiento de las membranas de ultrafiltración. Los dos restantes pueden afectar a uno o ambos de los mecanismos esenciales (Song, 1998a). 
Otro fenómeno que también contribuye al descenso de la densidad de flujo de permeado con el tiempo es la polarización por concentración (ver representación esquemática en la Figura 3). Dicho fenómeno consiste en el incremento de la concentración del soluto que no es capaz de atravesar la membrana en las cercanías de la superficie de la misma. Este incremento de la concentración de soluto se debe al transporte convectivo del mismo causado por la presión transmembranal.

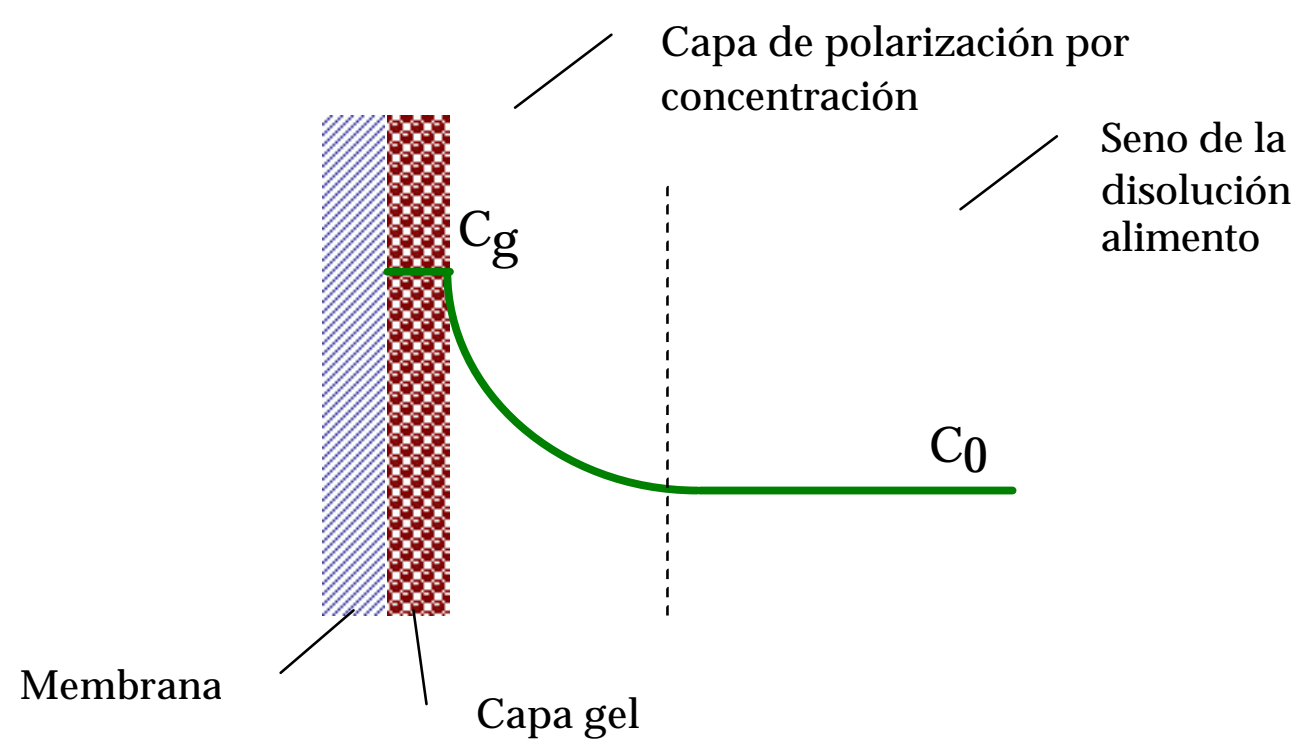

Figura 3. Representación esquemática de los procesos de polarización por concentración y formación de capa gel

La polarización por concentración no se considera como un mecanismo de ensuciamiento, ya que es un fenómeno intrínseco al proceso de concentración y no afecta a las propiedades de la membrana. El ensuciamiento requiere limpieza para su eliminación, mientras que la polarización por concentración desaparece al parar el proceso.

Una representación esquemática de los procesos de polarización por concentración y formación de capa gel se muestra en la Figura 3. 
En la Figura 4 se muestra una curva típica de la evolución de la densidad de flujo de permeado con el tiempo para un proceso de ultrafiltración.

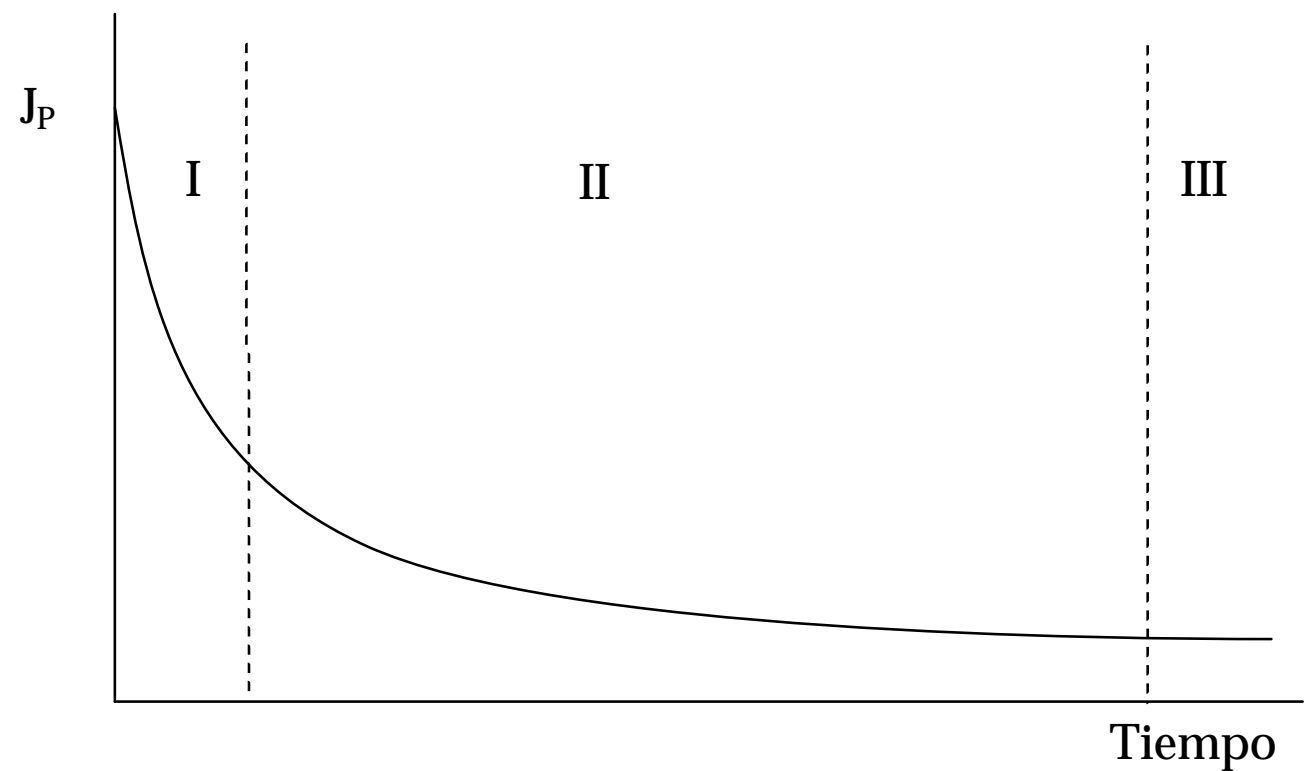

Figura 4. Representación esquemática de las tres etapas de descenso de la densidad de flujo de permeado con el tiempo

La zona I se corresponde con un rápido descenso inicial de la densidad de flujo de permeado. La zona II representa un descenso gradual que se prolonga durante un tiempo significativamente más largo que la zona I. Finalmente, la zona III corresponde a la densidad de flujo de permeado estacionaria.

La zona II existe en todos los procesos de ensuciamiento de membranas de ultrafiltración; mientras que las zonas I y III puede que en ocasiones no se observen debido a varias razones. Por ejemplo, si la PTM es lo suficientemente elevada y la concentración del alimento es lo suficientemente baja, la densidad de flujo de permeado estacionaria sólo puede alcanzarse después de un largo periodo de operación (Song, 1998a). 
El rápido descenso inicial de la densidad de flujo de permeado se debe al taponamiento repentino de los poros de la membrana. Al principio de la ultrafiltración la densidad de flujo de permeado es máxima porque ningún poro de la membrana está obstruido. La densidad de flujo de permeado comienza a descender cuando los poros de la membrana empiezan a ser taponados por las moléculas de soluto de la alimentación. Los poros pueden obstruirse parcial o totalmente en función del tamaño de los mismos y del tamaño delas moléculas de soluto. La obstrucción será tanto más completa cuanto más similar sea el tamaño de las moléculas de soluto y el de los poros (Belfort et al., 1994; Hlavacek y Bouchet, 1993).

El taponamiento de los poros es un proceso mucho más rápido que la formación de capa gel debido a que para lograr el taponamiento máximo alcanzable basta con tener menos de una capa de moléculas de soluto depositada sobre la superficie de la membrana (Hlavacek y Bouchet, 1993).

La formación de la capa gel en la superficie de la membrana sucede con posterioridad a la obstrucción de los poros. Esta capa se va formando conforme aumenta la cantidad de moléculas de soluto de la alimentación que son retenidas. La resistencia que dicha capa ofrece al paso del permeado aumenta al aumentar su espesor.

La densidad de flujo de permeado estacionaria se al canza cuando el espesor de la capa gel ha alcanzado su espesor máximo. Este espesor máximo viene determinado por los parámetros de operación y aumenta con la PTM aplicada al haber un mayor aporte de moléculas de soluto hacia la superficie de la membrana en este caso (Song, 1998b). En la ultrafiltración de disoluciones muy diluidas a altas PTMs, la densidad de flujo de permeado estacionaria tarda mucho en alcanzarse, ya que el espesor máximo de la capa gel es elevadoy el crecimiento de la misma es lento (Song, 1998a). 


\subsubsection{A plicaciones de la ultrafiltración}

La ultrafiltración es un proceso que puede utilizarse con eficacia en diversos modos de operación, tales como:

- Concentración de macromoléculas. En este caso el rechazo se va concentrando en las sustancias retenidas por la membrana.

- Fraccionamiento. Mediante la ultrafiltración es posible separar moléculas de distintos tamaños, que presentan distintos grados de rechazo por parte de la membrana.

- Purificación. Es posible purificar una disolución de macromoléculas mediante la eliminación de los solutos contaminantes de reducido peso molecular. Estos microsolutos se eliminan mejor si se añade disolvente a la alimentación a la misma velocidad que se elimina el disolvente en el permeado. Este tipo de operación recibe el nombre de diafiltración.

Son muchas las aplicaciones concretas de la UF: concentración y recuperación pinturas electroforéticas del agua de lavado en la industria del automóvil (Costa, 1985), fraccionamiento de proteínas de lactosuero en la industria láctea (Cheryan, 1998), aislamiento, concentración y purificación de sustancias biológicamente activas, tales como enzimas, virus, proteínas específicas y ácidos nucleicos en la industria farmacéutica (Madaeni et al., 1995). Estas y otras aplicaciones han sido ampliamente descritas en la bibliografía (Cheryan, 1998; Mendoza, 2000).

A modo de ejemplo, en la Figura 5 se incluye un esquema que muestra las diferentes posibilidades de aplicación de la tecnología de membranas en la industria láctea. En la Figura 6 se muestra con más detalle un resumen de los diversos procesos utilizados en el tratamiento del lactosuero. La ultrafiltración permite en este caso separar las proteínas presentes en el mismo de la lactosa y las sales minerales por diafiltración y concentrarlas para su uso en 
alimentación animal y humana. Utilizando diferentes membranas de ultrafiltración también es posible fraccionar estas proteínas para la industria farmacéutica y cosmética.

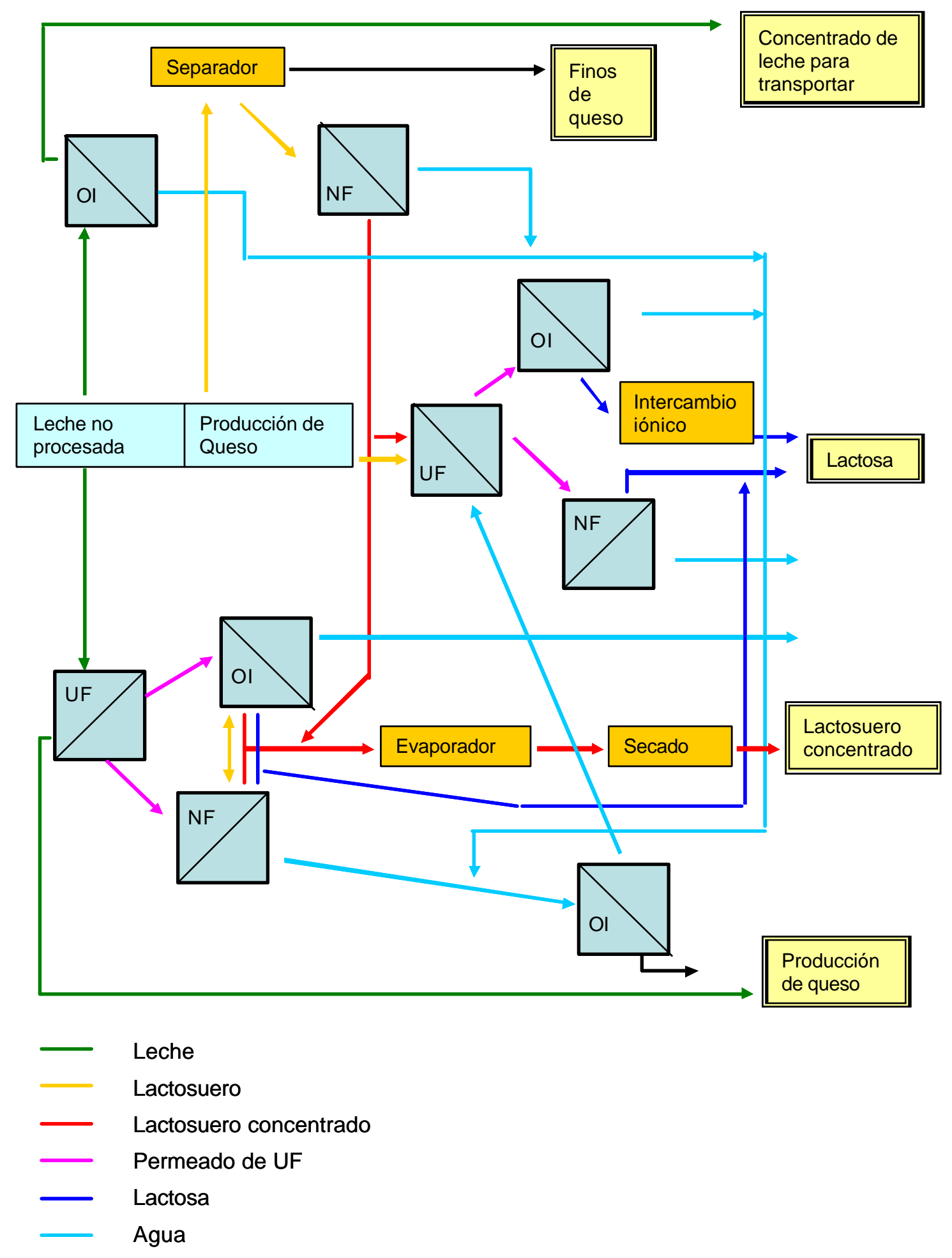

Figura 5. A plicación de la tecnología de membranas en la industria láctea 


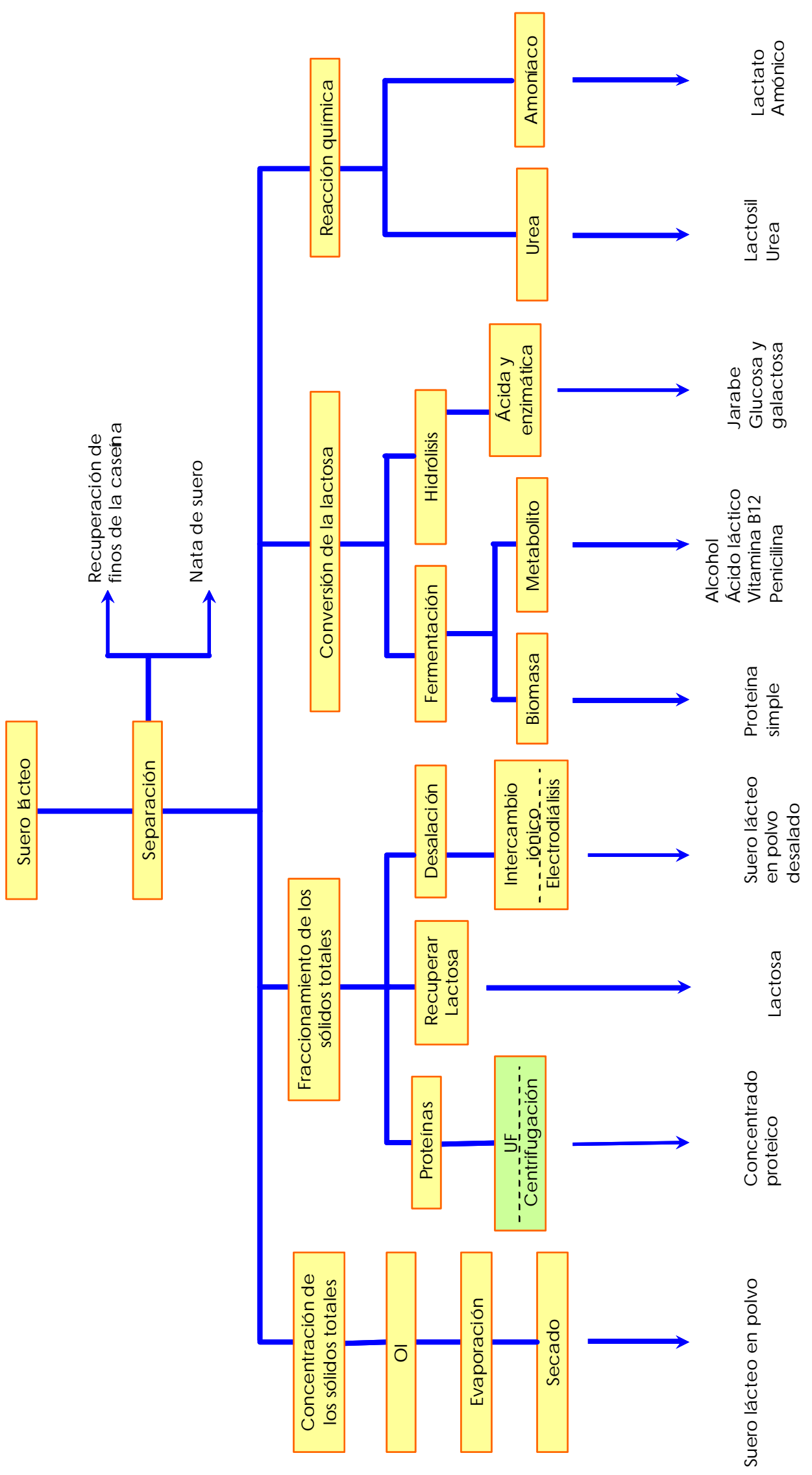

Figura 6. Procesado del suero lácteo 



\section{Capítulo}

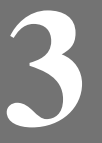

\section{MODELOS DE ULTRAFILTRACIÓN DINÁMICOS}

En las dos últimas décadas se han realizado numerosos trabajos con el objeto de investigar el efecto de varios parámetros en el descenso de la densidad de flujo de permeado y en los mecanismos de ensuciamiento de las membranas de ultrafiltración. Pese a que, en numerosos experimentos de ultrafiltración realizados bajo diferentes condiciones de operación, se han obtenido muchos datos de la variación de la densidad de flujo de permeado con el tiempo; no se han realizado grandes progresos en el conocimiento de los mecanismos fundamentales del ensuciamiento de membranas de ultrafiltración.

Actualmente se desconoce de forma cuantitativa cómo afectan al ensuciamiento de las membranas de ultrafiltración los parámetros básicos del proceso tales como la velocidad tangencial, la PTM aplicada, el tamaño de las moléculas de soluto de la alimentación, etc. Es decir, no existe un modelo que describa cuantitativamente la dinámica de los procesos de ultrafiltración; y que pueda ser utilizado por los ingenieros en el diseño, simulación y operación de dichos procesos.

\subsection{MODELOS NO EM PÍRICOS}

La gran mayoría de modelos dinámicos no empíricos que describen los procesos de ultrafiltración han sido desarrollados únicamente 
para el caso en el que la formación de capa gel es el mecanismo dominante en el proceso de ensuciamiento de las membranas.

Cuando el mecanismo dominante que contribuyeal descenso de la densidad de flujo de permeado es la formación de capa gel, se pueden distinguir dos etapas en el proceso de ensuciamiento de la membrana (Davis, 1992). La primera etapa corresponde al descenso inicial de la densidad de flujo de permeado que se produce en los primeros minutos o incluso horas de la ultrafiltración y es debida al crecimiento de la capa gel. Durante la segunda etapa, que tiene lugar a continuación, se produce la compactación de la capa gel. Dicha etapa puede durar horas o incluso días.

Todos los modelos que se describen en este apartado dependen, al menos, de la PTM, de la velocidad tangencial, de la temperatura, de la concentración de la disolución alimento y del tamaño de las moléculas de soluto.

\subsubsection{Modelo de aplicación de la teoría de la ultrafiltración transversal en el caso dinámico}

El siguiente modelo (Davis, 1992) ha sido desarrollado para el caso de la ultrafiltración con flujo transversal a la superficie de la membrana. Este modelo ha sido objeto de investigación para su aplicación en la ultrafiltración tangencial en muchas ocasiones. Así se ha utilizado en la purificación de disoluciones en la industria azucarera (Jacob y Jaffrin, 2000), en la recuperación de proteínas (Parnham y Davis, 1996), en la separación de un biocatalizador (Meindersma et al., 1997), etc. Pero mayoritariamente se ha aplicado de manera empírica, obteniendo los parámetros del modelo mediante ajuste de datos experimentales.

Según este modelo, el descenso de la densidad de flujo de permeado con el tiempo viene descrito por la Ec. 1. 


$$
J_{P}=\frac{\Delta P}{\mu \cdot R_{m}} \cdot\left(1+2 \cdot R_{c}^{\prime} \cdot \frac{\Delta P}{\left(\mu \cdot R_{m}\right)^{2}} \frac{C_{0}}{C_{g}-C_{0}} \cdot t\right)^{-\frac{1}{2}}
$$

Según el modelo, la densidad de flujo de permeado inicial corresponde al valor para la membrana limpia. A continuación desciende linealmente con el tiempo para periodos cortos de operación, debido al crecimiento de la capa gel. A la vez que la densidad de flujo de permeado disminuye, la velocidad de formación de la capa gel también lo hace. Para periodos largos de operación, la densidad de flujo de permeado es inversamente proporcional a la raíz cuadrada del tiempo.

En la elaboración del modelo se han considerado las siguientes hipótesis:

- Rechazo completo al paso de moléculas de soluto.

- Presión transmembranal siempre constante.

- Flujo transversal a la membrana.

- $R_{m}$ constante, por lo tanto no se produce la compactación de la membrana con el tiempo.

- El único mecanismo de ensuciamiento de la membrana es la formación de capa gel.

\subsubsection{Modelo de difusión inducido por cizalla aplicado en el caso de la ultrafiltración dinámica}

Este modelo (Davis, 1992) describe la evolución descendente de la densidad de flujo de permeado con el tiempo en el caso de la ultrafiltración tangencial, debida a la formación de capa gel por parte de las moléculas rechazadas por la membrana. El modelo predice la evolución de la densidad de flujo de permeado con el tiempo hasta el momento en que el flujo tangencial compensa el 
aporte de solutos hacia la membrana debido al flujo de permeado, evitando que la capa gel continúe incrementando su grosor y alcanzándose un estado cuasi-estacionario.

Las ecuaciones de este modelo son las siguientes:

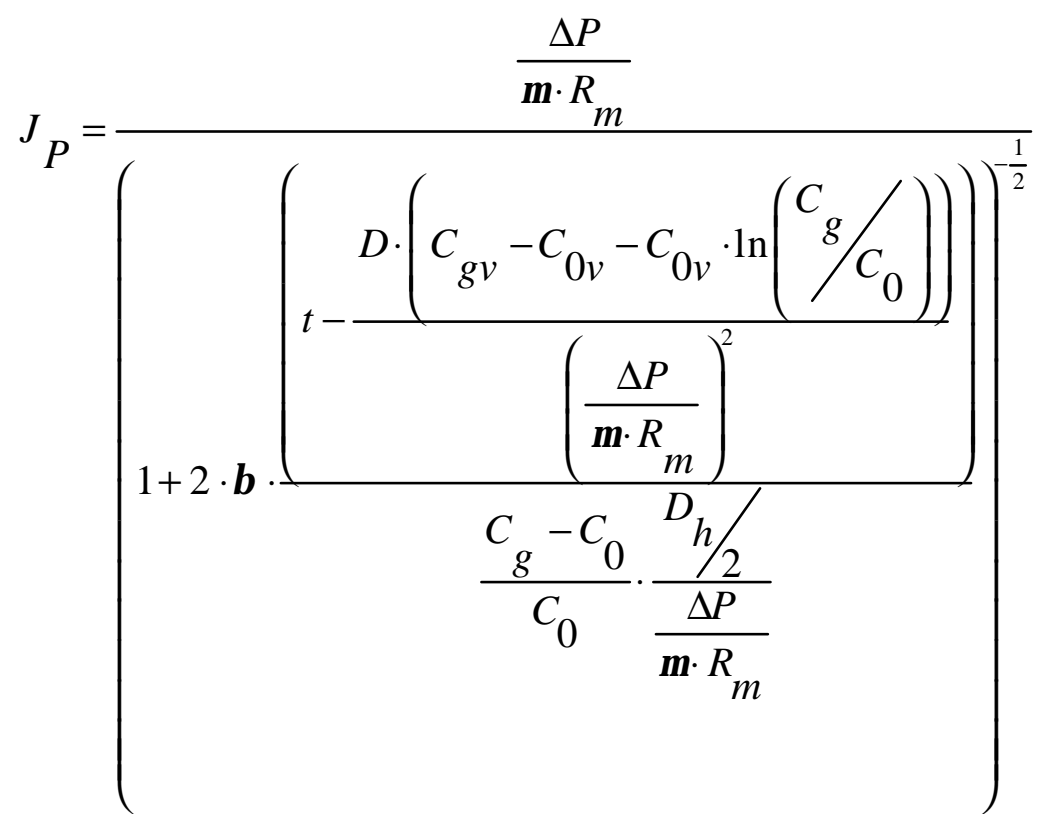

Ec. 2

donde la resistencia de la capa gel adimensional viene dada por la Ec. 3.

$$
\beta=\frac{D_{h}}{2} \cdot \frac{R_{C}}{R_{m}}
$$

Las hipótesis consideradas en el desarrollo de este model o son:

- Coeficiente de difusión y viscosidad constantes durante todo el proceso de ultrafiltración.

- El tiempo requerido para el inicio de la formación de una capa gel adherida a la membrana es despreciable.

- La acumulación de moléculas en la capa de polarización es pequeña en comparación a la acumulación de las mismas en la capagel. 
- $R_{m}$ es constante, por lo tanto no se produce la compactación de la membrana con el tiempo.

- El único mecanismo de ensuciamiento de la membrana es la formación de capa gel.

En algunas ocasiones, el ensuciamiento de las membranas no sólo se debe a la formación de la capa gel, sino que además se produce el ensuciamiento interno de los poros de la membrana. En este caso, la segunda etapa de descenso de la densidad de flujo de permeado con el tiempo se caracteriza por un descenso gradual debido al ensuciamiento interno de los poros además de a la compactación de la capa gel. Esta segunda etapa no es capaz de predecirla bien el modelo.

\subsubsection{M odelo dinámico de Song para la ultrafiltración tangencial}

Este modelo ha sido desarrollado por Song (1998a) para la ultrafiltración tangencial, teniendo en cuenta que es un proceso dinámico que evoluciona de una condición de no-equilibrio hacia una de equilibrio, en la cual el espesor de la capa gel se mantiene constante.

El modelo viene descrito por la Ec. 4:

$$
J_{P}=\frac{\Delta P-\Delta P_{c}}{\mu \cdot R_{b m}} \cdot\left(1+2 \cdot r_{c} \cdot \frac{\Delta P-\Delta P_{c}}{\left(\mu \cdot R_{b m}\right)^{2}} \cdot \frac{C_{0}}{C_{g}} \cdot t\right)^{-\frac{1}{2}}
$$

Este modelo considera una presión transmembranal crítica mínima necesaria para la aparición de fenómenos de ensuciamiento, la cual viene dada por la Ec. 5:

$$
\Delta P_{c}=\frac{3 \cdot k \cdot T}{4 \cdot \pi \cdot a_{p}{ }^{3}} \cdot N_{F c}
$$


Uno de los parámetros del modelo es el número crítico de filtración. Dicho número representa el cociente entre la energía que se necesita para transportar una molécula desde la superficie de la membrana al seno de la disolución alimento y la energía térmica (disipativa) de la molécula. Para el cál culo del mismo se ha utilizado la Ec. 6 (Song, 1998b; Song y Elimelech, 1995).

$$
N_{F c}=\int_{0}^{\theta_{g v}} \frac{1+\frac{2}{3} \cdot \theta^{5}}{1-\frac{3}{2} \cdot \theta+\frac{3}{2} \cdot \theta^{5}-\theta^{6}} d \theta
$$

donde:

$$
\theta=C_{v}^{1 / 3} \quad \theta_{g v}=C_{g v}^{1 / 3}
$$

El modelo es únicamente válido cuando se cumplen las siguientes hipótesis:

- La ultrafiltración es de tipo tangencial.

- La PTM aplicada es mucho mayor que la presión transmembranal crítica por debajo de la cual no se produce ensuciamiento $\left(\Delta \mathrm{P}_{c}\right)$.

- Las moléculas de soluto no se agregan ni se disgregan.

- Las moléculas de soluto que son impulsadas por el flujo de permeado hacia la capa de polarización por concentración se depositan inmediatamente en la superficie de la membrana o sobre la capa gel. Esto implica que las moléculas depositadas no pueden ser nuevamente impulsadas hacia la capa de polarización por concentración y la velocidad de formación del depósito es independiente de la velocidad de cizalla.

- La capa de polarización por concentración está totalmente desarrollada cuando se empieza a formar la capa gel. Su desarrollo es tan rápido en comparación con la formación de la capa gel que no se considera en el modelo. De hecho, la capa 
de polarización se desarrolla a la vez que el fenómeno de taponamiento deporos.

Diversos autores (Zhang y Song, 2000a; Wang y Song, 1999) realizaron simulaciones con disoluciones modelo que consistían en suspensiones coloidales de sílice. Con ello comprobaron que los resultados experimentales obtenidos y las predicciones del modelo eran similares.

\subsubsection{Modelo dinámico de Bhattacharjee y Bhattacharya para la ultrafiltración controlada por la presión osmótica o por la capa gel indistintamente}

Generalmente, la ultrafiltración de solutos de bajo peso molecular está controlada por la presión osmótica al menos durante los primeros minutos de la ultrafiltración, mientras que la ultrafiltración de solutos de elevado peso molecular está controlada por la formación de capa gel desdeel inicio de la ultrafiltración.

Bhattacharjee y Bhattacharya (1992a) desarrollaron un modelo teórico basado en el modelo de resistencias en seriecon el objetivo de integrar en un mismo modelo tanto los procesos de ultrafiltración controlados por la presión osmótica como los controlados por la formación de capa gel.

El primer término de la ecuación del modelo (Ec. 8) incluye la influencia de la presión osmótica, mientras que el segundo término considera el fenómeno de formación de capa gel.

$$
J_{P}=\left(\frac{\left[\mu \cdot\left(R_{m}+R_{a}+R_{o s m}\right)\right]^{2}}{\Delta P^{2}}+\frac{2 \cdot a \cdot C_{0} \cdot \mu}{\Delta P} \cdot t\right)^{-\frac{1}{2}} \quad \text { EC. } 8
$$


El modelo considera las siguientes hipótesis:

- La concentración en la capa gel es independiente de la PTM aplicada.

- Una vez se ha alcanzado el equilibrio en la adsorción de soluto, la resistencia debida a este fenómeno se mantiene constante. El modelo la considera constante en todo momento.

- Según la ecuación del modelo (Ec. 8), para tiempo cero la densidad de flujo de permeado estacionaria no coincide con la densidad de flujo de permeado para el agua pura bajo las mismas condiciones. Sólo coincidiría si se despreciasen las resistencias debidas a la adsorción y a fenómenos osmóticos.

\subsubsection{Modelo dinámico que combina el bloqueo de poros y la formación de capa gel}

Este modelo, desarrollado por Ho y Zydney (2000), contempla simultáneamente dos mecanismos de ensuciamiento: $\mathrm{d}$ taponamiento de los poros y la formación de capa gel. El modelo elimina la necesidad de usar formulaciones matemáticas diferentes para describir estos dos fenómenos.

La predicción de la densidad de flujo de permeado con el tiempo, según estemodelo, viene dada por la Ec. 9:

$$
J_{P}=\frac{\Delta P}{\mu \cdot R_{m}}\left\{\exp \left(-\frac{\alpha \cdot \Delta P \cdot C_{0}}{\mu \cdot R_{m}} \cdot t\right)+\frac{R_{m}}{R_{m}+R_{g}} \cdot\left[1-\exp \left(-\frac{\alpha \cdot \Delta P \cdot C_{0}}{\mu \cdot R_{m}} \cdot t\right)\right]\right\} \quad \text { EC. } 9
$$

Para periodos de tiempo cortos, la evolución de la densidad de flujo de permeado con el tiempo está controlada por el primer término. Este primer término corresponde al flujo a través de los poros abiertos y considera el fenómeno de bloqueo de poros. Además, predice un descenso exponencial simple de la densidad de flujo de permeado con el tiempo. 
Para periodos de tiempo largos, la evol ución de la densidad de flujo de permeado está controlada por el segundo término de la ecuación, que considera la formación de capa gel. Este segundo término incluye también el flujo a través de los poros bloqueados.

La resistencia dela capa gel aumenta con el tiempo según la Ec. 10.

$$
R_{g}=\left(R_{m}+R_{c o}\right) \cdot \sqrt{1+\frac{2 \cdot f^{\prime} \cdot a \cdot \Delta P \cdot C_{0} \cdot t}{\mu \cdot\left(R_{m}+R_{c o}\right)^{2}}}-R_{m}
$$

El parámetro de bloqueo de poros viene dado por la Ec. 11

$$
\alpha=\frac{f \cdot A_{\text {poro }}}{M_{\text {agg }}}
$$

El modelo ha sido desarrollado considerando las siguientes hipótesis:

- El taponamiento de los poros no es total, pues siempre existe un pequeño flujo finito a través de los poros bloqueados.

- La capa gel sólo se forma sobre aquellas zonas de la membrana cuyos poros han sido previamente bloqueados.

- La velocidad de taponamiento de poros y de formación de la capa gel son proporcionales al flujo convectivo de las moléculas hacia la membrana.

- El flujo a través de los poros abiertos disminuye exponencialmente con el tiempo a una vel ocidad proporcional a la concentración del alimento.

El modelo se ha aplicado con éxito en procesos de ultrafiltración de disoluciones de proteínas (Zydney y Ho, 2002; Palacio et al., 2003) y de materia orgánica natural (Yuan et al. , 2002; Taniguchi et al. , 2003). Los parámetros del modelo se calcularon empíricamente en todos los casos. 


\subsubsection{Ecuaciones auxiliares}

En este apartado se describen las ecuaciones necesarias para el cálculo de algunos de los parámetros de los modelos. El significado de los símbolos utilizados en las ecuaciones se encuentra descrito al final de esta Tesis Doctoral, en el apartado deNotación.

\section{$\underline{\text { Resistencia específica de la capa gel }}$}

Para estimar la resistencia específica de la capa gel, existen en la bibliografía diferentes expresiones. En cada una de ellas dicha resistencia viene dada en unidades diferentes. La utilización de una u otra expresión dependerá de las unidades en las que haya que introducir la resistencia específica de la capa gel en las ecuaciones del modelo para que éste sea dimensionalmente coherente. Todas las expresiones consideran que la capa gel es incompresible.

Según la ecuación de Carman-Kozeny (Ec. 12), la resistencia específica de la capa gel viene dada en kg/ m³ s (Song, 1998a; Belfort et al., 1994; Davis, 1992).

$$
r_{c}=\frac{45 \cdot \mu \cdot(1-\varepsilon)^{2}}{a_{p}^{2} \cdot \varepsilon^{3}} \quad \varepsilon=1-C_{g v}
$$

Por otra parte, en la ecuación propuesta por De y Bhattacharya (1997) (Ec. 13), la resistencia específica de la capa gel está expresada en $\mathrm{m} / \mathrm{kg}$.

$$
a=180 \cdot \frac{(1-\varepsilon)}{\varepsilon^{3} \cdot\left(2 \cdot a_{p}\right)^{2} \cdot \rho_{g}}=45 \cdot \frac{(1-\varepsilon)}{\varepsilon^{3} \cdot a_{p}{ }^{2} \cdot \rho_{g}} \quad \varepsilon=1-C_{g v}
$$


A demás, Davis (1992) propone la siguiente ecuación para estimar la resistencia específica de la capa gel, que en esta ocasión se expresa en $\mathrm{m}^{-2}$ :

$$
\begin{array}{lll}
R_{c}=5 \cdot \frac{(1-\varepsilon)^{2} \cdot S_{0}^{2}}{\varepsilon^{3}} \quad \varepsilon=1-C_{g v} \quad \text { EC. } 14
\end{array}
$$

donde $S_{0}$ representa el área superficial por unidad de volumen de soluto o de agregado de moléculas de soluto en el caso de que se forme. Esteárea corresponde a la capa gel y sedetermina por medio dela Ec. 15 (Bhattacharjee y Datta, 2003),

$$
S_{0}^{2}=\frac{\varepsilon^{3}}{\varepsilon \cdot(1-\varepsilon)^{2} \cdot P_{m}}
$$

donde $P_{m}$ es el coeficiente de permeabilidad, que se calcula mediante la Ec. 16 (Bhattacharjee y Datta, 2003).

$$
P_{m}=\frac{1}{a \cdot(1-\varepsilon) \cdot \rho_{g}}
$$

Sustituyendo la Ec. 13, la Ec. 15 y la Ec. 16 en la Ec. 14 se obtiene la siguiente expresión para la resistencia específica de la capa gel (Ec. 17).

$$
R_{c}=225 \cdot \frac{(1-\varepsilon)^{2}}{\varepsilon^{4} \cdot a_{p}{ }^{2}}
$$

Finalmente, Mikulášek et al. (2004) propusieron la utilización de la Ec. 18 para estimar la resistencia específica de la capa gel, también expresada en $\mathrm{m}^{-2}$.

$$
R_{c}^{\prime}=45 \cdot \frac{(1-\varepsilon)^{2}}{\varepsilon^{3} \cdot a_{p}^{2}}
$$


Concentración cerca de la superficie de la membrana

Para el cálculo de la concentración en las proximidades de la superficie de la membrana se hace uso de las ecuaciones del módulo de polarización por concentración $\left(\mathrm{C}_{\mathrm{g}} / \mathrm{C}_{0}\right)$ recopiladas por Lee et al. (1999). En el caso de membranas tubulares y flujo turbulento la ecuación correspondiente es la siguiente:

$$
\frac{C_{g}}{C_{0}}=\exp \left(\frac{J_{P_{S S}} \cdot D_{\text {int }}^{0.11} \cdot v^{0.56}}{0.023 \cdot v_{\text {tang }}{ }^{0.89} \cdot D^{0.67}}\right)
$$

Esta ecuación sólo es válida en el caso de estado estacionario, cuando existe formación de capa gel y cuando el soluto es total mente rechazado por la membrana.

\section{Densidad de flujo de permeado estacionaria}

Zhang y Song (2000a) propusieron una expresión para estimar la densidad de flujo de permeado estacionaria (Ec. 20). Dicha expresión es válida para disoluciones diluidas y supone que las moléculas de soluto son esferas rígidas, por lo que considera tanto la densidad de flujo estacionaria como la concentración en la superficie de la membrana independientes de la presión transmembranal aplicada.

$$
J_{P S S}=1.31 \cdot\left(\frac{C_{g v} \cdot D^{2} \cdot \gamma}{C_{0 v} \cdot L}\right)^{1 / 3}
$$

Velocidad de cizalla

La velocidad de cizalla en la superficie de una membrana tubular se ha estimado por medio de la Ec. 21 (Davis, 1992; Zhang y Song, 2000b; Castro et al., 2000). 


$$
\gamma=\frac{4 \cdot v_{\text {tang }} \cdot\left[\pi \cdot\left(\frac{D_{\text {int }}}{2}\right)^{2}\right]}{\pi \cdot D_{\text {int }}{ }^{3}}
$$

\subsection{ODELOS SEMI-EM PÍRICOS}

En la bibliografía pueden encontrarse gran número de modelos empíricos (Bhattacharya et al., 2001; Bhattacharjee y Datta, 2003). En menor medida se pueden encontrar también algunos modelos semiempíricos (Zydney y Ho, 2002). Si bien los modelos empíricos aportan gran precisión, los semi-empíricos son capaces de explicar mejor los fenómenos de ensuciamiento que tienen lugar en los procesos de membranas.

En el desarrollo de modelos empíricos cuyos parámetros tienen significado físico se pueden diferenciar cuatro tipos básicos de ensuciamiento: bloqueo completo, bloqueo intermedio, bloqueo estándar y formación de capa gel.

\subsubsection{Modelos de Hermia}

Hermia (1982) desarrolló cuatro modelos correspondientes a los cuatro tipos de ensuciamiento mencionados. Éstos fueron inicialmente desarrollados para flujo transversal. Todos ellos parten de la ecuación característica (Ec. 22) de la filtración a presión constante:

$$
\frac{d^{2} t}{d V_{P}^{2}}=K\left(\frac{d t}{d V_{P}}\right)^{n}
$$

El parámetro $n$ define el modelo de ensuciamiento. En la Figura 7 se representan los mecanismos de ensuciamiento correspondientes a cada uno de los modelos. 
a)

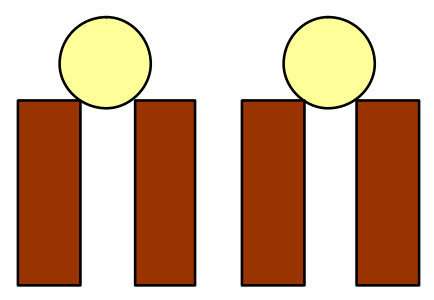

c)

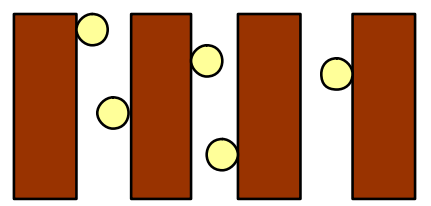

b)

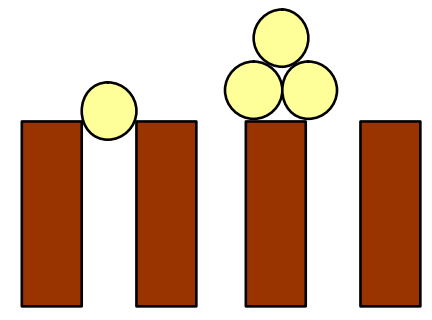

d)

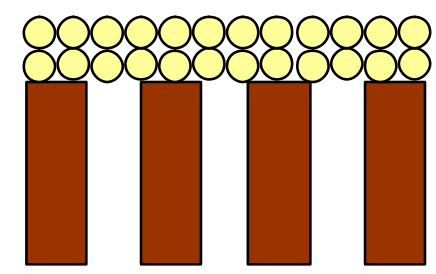

Figura 7. Mecanismos de ensuciamiento considerados por los modelos: a) modelo de bloqueo completo de poros; b) modelo de bloqueo intermedio de poros; c) modelo de bloqueo estándar de poros y d) modelo de formación detorta

Modelo de bloqueo completo de poros $(n=2)$

Según este modelo toda molécula que alcanza la superficie de la membrana bloquea un poro de la misma. Además, ninguna molécula se sitúa sobre otra que previamente se ha depositado sobre la membrana. Bajo estas suposiciones Hermia (1982) Ilega a la conclusión de que en este caso $n$ ha de ser igual a dos.

Para $n=2$, la Ec. 22, que relaciona la densidad de flujo de permeado con el tiempo, una vez linealizada y adaptada, queda dela siguiente forma (Ec. 23) (Limy Bai, 2003):

$$
\ln J_{P}=\ln J_{0}-K_{c} \cdot t
$$

El parámetro $K_{c}$ se expresa en función de la superficie de membrana bloqueada por unidad de volumen total permeado a través de la 
membrana, $K_{A}$, y de la densidad de flujo de permeado inicial según la Ec. 24 (Bowen et al., 1995):

$$
K_{c}=K_{A} \cdot J_{0}
$$

Este tipo de ensuciamiento se debe a moléculas de mayor tamaño que los poros de la membrana, produciéndose el bloqueo de los poros en la superficie de la misma y no dentro de los poros. (H wang y Lin, 2002). Los poros se bloquean completamente a la vez quese reduce la superficie de la membrana (de Barros et al. , 2003)

Modelo de bloqueo intermedio de poros $(n=1)$

Al igual que en el M odelo de bloqueo completo de poros, cuando una molécula alcanza un poro abierto de la membrana lo bloquea. Sin embargo, el M odelo de bloqueo intermedio de poros es menos restrictivo puesto que considera la posibilidad de que unas moléculas se depositen sobre otras. Dicho de otro modo, no toda molécula que alcanza la superficie de la membrana bloquea un poro de la misma. En este modelo se evalúa la probabilidad que tiene una molécula de bloquear un poro de la membrana. Bajo estas consideraciones se deduce quen ha de ser igual a uno (Hermia, 1982).

La ecuación linealizada que relaciona la variación de la densidad de flujo de permeado con el tiempo correspondiente al Modelo de bloqueo intermedio de poros es la siguiente (EC. 25) (Mohammadi et al., 2003):

$$
\frac{1}{J_{P}}=\frac{1}{J_{0}}+K_{i} \cdot t
$$

Al igual que en el M odelo de bloqueo completo de poros, parámetro $\mathrm{K}_{\mathrm{i}}$ se expresa en función de la superficie de membrana bloqueada por unidad de volumen total permeado a través de la membrana, $\mathrm{K}_{\mathrm{A}}, \mathrm{y}$ de según la Ec. 26 (Bowen et al., 1995): 


$$
K_{i}=K_{A}
$$

El mecanismo de ensuciamiento por bloqueo intermedio tiene lugar cuando el diámetro de las moléculas de soluto es similar al de los poros de la membrana. Por este motivo, en ocasiones las moléculas de soluto pueden obstruir la entrada a un poro sin bloquearlo completamente.

La probabilidad de que una molécula bloquee un poro se reduce continuamente con el tiempo debido a que la superficie de poros no bloqueados se reduce con el tiempo (Koltuniewicz y Fiel d, 1996).

\section{Modelo de bloqueo estándar de poros ( $n=3 / 2)$}

Para deducir el valor de la constante $n$ en el Modelo de bloqueo estándar de poros se considera que el volumen de poros desciende proporcionalmente al volumen de permeado filtrado como consecuencia de que las moléculas se depositan sobre las paredes del poro. De esta forma, el descenso del volumen de poros con $A$ tiempo es igual al descenso dela sección transversal de los mismos. Se asume que los poros de la membrana poseen un diámetro y una longitud constante a lo largo de toda la membrana.

La ecuación correspondiente al M odelo de bloqueo estándar de poros, expresada en forma de densidad de flujo de permeado en función del tiempo y linealizada, es la siguiente (Ec. 27):

$$
\frac{1}{J_{P}^{1 / 2}}=\frac{1}{J_{0}^{1 / 2}}+K_{e} \cdot t
$$

El parámetro K e sedefine según la Ec. 28 (Bowen et al., 1995): 


$$
K_{e}=2 \cdot \frac{K_{B}}{A_{0}} \cdot A \cdot J_{0}^{1 / 2}
$$

Las moléculas de soluto contenidas en la disolución alimento que producen este tipo de ensuciamiento son más pequeñas que el poro, de forma que originan un bloqueo interno del mismo (Mohammadi et al., 2003).

Modelo de formación de torta $(n=0)$

En este caso se considera que no se produce el bloqueo de los poros, sino únicamente la formación de una torta sobre la superficie de la membrana. Hermia (1982) dedujo mediante balances de materia que en este caso la constanten ha de ser igual a cero.

Para este modelo, la ecuación linealizada que se deduce a partir de la Ec. 22 y que describe el descenso de la densidad de flujo de permeado con el tiempo es la siguiente (Ec. 29) (Lim y Bai, 2003):

$$
\frac{1}{J_{P}^{2}}=\frac{1}{J_{0}^{2}}+K_{c g} \cdot t
$$

El parámetro $K_{c g}$ se define según la Ec. 30 (Bowen et al., 1995):

$$
K_{c g}=\frac{2 \cdot R_{g} \cdot K_{D}}{J_{0} \cdot R_{m}}
$$

Este tipo de ensuciamiento es similar al que se produce en el bloqueo completo de poros. En ambos casos, las moléculas de soluto son mucho más grandes que el poro y no penetran en él (Hwang y Lin, 2002). 


\subsubsection{Adaptación de los M odelos de Hermia para flujo tangencial}

La adaptación de los M odelos de Hermia para flujo tangencial (de Barros et al., 2003) se realiza teniendo en cuenta la influencia de la velocidad tangencial en la eliminación de los agentes de ensuciamiento de la superficie de la membrana para cada modelo de ensuciamiento (Ec. 31).

$$
-\frac{d J_{P}}{d t}=K_{C F} \cdot\left(J_{P}-J_{P S S}\right) \cdot J_{P}^{2-n_{C F}}
$$

A partir del ajuste empírico del modelo a los resultados experimentales se puede estimar el valor de $\mathrm{n}_{\mathrm{CF}}$. De este modo se puede deducir el mecanismo de ensuciamiento involucrado en un determinado proceso de ultrafiltración.

Para diferentes valores de $\mathrm{n}_{\mathrm{CF}}$, se obtienen los distintos $\mathrm{M}$ odelos de H ermia adaptados para flujo tangencial, los cuales se corresponden con los M odelos de H ermia originales para flujo transversal.

Modelo de bloqueo completo de poros para flujo tangencial $\left(\mathrm{n}_{\mathrm{CF}}=2\right)$

Para realizar la adaptación del model o al caso del flujo tangencial se considera que, dependiendo de la velocidad tangencial, la densidad de flujo de permeado se puede incrementar aumentando la presión transmembranal. Se ha de añadir a la Ec. 23 un término que represente la velocidad de desprendimiento de moléculas de las entradas a los poros (Field et al.; 1995). La ecuación resultante en este caso es la Ec. 32:

$$
J_{P}=J_{P_{S S}}+\left(J_{0}-J_{P S s}\right) \cdot e^{-K_{c C F} \cdot J_{0} \cdot t}
$$


Modelo de bloqueo intermedio de poros para flujo tangencial $\left(\mathrm{n}_{\underline{\mathrm{CF}}}=\right.$ 1)

Este modelo adaptado para flujo tangencial (Ec. 33) tiene en cuenta la situación dinámica de bloqueo-desbloqueo de poros que se produce por efecto del flujo tangencial a la superficie de la membrana.

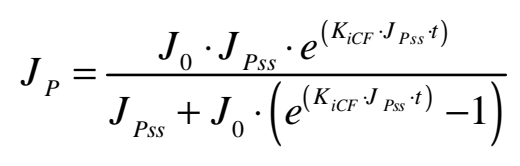

Modelo de bloqueo estándar de poros para flujo tangencial $\left(\mathrm{n}_{\underline{\mathrm{F}}}=\right.$ 3/2)

En este caso las irregularidades de los poros favorecen que las moléculas de soluto se fijen fuertemente en las paredes del interior de los poros. Esto es debido a que las moléculas de soluto se adsorben o sedepositan sobre las paredes internas de los poros.

Al ser el ensuciamiento de los poros de tipo interno, dicho ensuciamiento es independiente de la velocidad tangencial y no se alcanza un valor de densidad de flujo de permeado estacionaria, sino que ésta tiende a cero para tiempo infinito (Todisco et al., 1996).

En esta forma de ensuciamiento no interviene la difusión de las moléculas de soluto que hay sobre la superficie de la membrana hacia el seno de la disolución alimento (Field et al., 1995). Por lo tanto, la ecuación que describe este modelo coincide con su equivalente para flujo transversal (Ec. 27). 
Modelo de formación de capa gel para flujo tangencial $\left(\mathrm{n}_{\mathrm{CF}}=0\right)$

Se introduce la influencia de la velocidad tangencial incluyendo un término que considere la erosión de la capa gel, con lo que la Ec. 29 se transforma en la Ec. 34.

$$
t=\frac{1}{K_{c g C F} \cdot J_{P S S}{ }^{2}} \cdot \ln \left[\left(\frac{J_{P}}{J_{0}} \cdot \frac{J_{0}-J_{P_{S S}}}{J_{P}-J_{P S s}}\right)-J_{P S s} \cdot\left(\frac{1}{J_{P}}-\frac{1}{J_{0}}\right)\right] \quad \text { EC. } 34
$$

\subsubsection{Cálculo teórico de los parámetros de los modelos de Hermia adaptados para flujo tangencial}

Modelo de bloqueo completo de poros para flujo tangencial $\left(\mathrm{n}_{\mathrm{CF}}=2\right)$

Los parámetros empíricos del M odelo de bloqueo completo adaptado para flujo tangencial pueden estimarse teóricamente (Ec. 35) a partir de dos únicos valores experimentales: la densidad de flujo de permeado estacionario y la densidad de flujo de permeado inicial (Bowen et al., 1995; Hermia, 1982). Para ello se utiliza la siguiente ecuación:

$$
K_{c C F}=\frac{3}{4} \cdot \frac{\rho_{m} \cdot X_{m}}{\rho_{s} \cdot a_{p} \cdot \psi}
$$

Los parámetros $\rho_{\mathrm{m}}$ y $\mathrm{X}_{\mathrm{m}}$ pueden calcularsemediante la Ec. 36 y la Ec. 37 respectivamente, conociendo el valor de la concentración de soluto sobre la superficie de la membrana, $\mathrm{C}_{\mathrm{m}}$, así como la densidad del soluto, $\rho_{s}$ y la densidad del disolvente, $\rho$.

$$
\rho_{m}=C_{m}+\rho \cdot\left(1-\frac{C_{m}}{\rho_{s}}\right)
$$

Ec. 36 


$$
X_{m}=\frac{C_{m}}{\rho \cdot\left(1-\frac{C_{m}}{\rho_{s}}\right)+C_{m}}
$$

El factor de forma de la molécula de soluto, $\psi$, se calcula como el cociente entre la dimensión mayor de la moléculas y la dimensión menor. En el presente trabajo, dicha relación se ha estimado teniendo en cuenta las distancias de enlace entre los átomos de la molécula de PEG (Lide, 2003).

La concentración de soluto sobre la superficie de la membrana puede determinarse a partir de la densidad de flujo de permeado estacionaria mediante la Ec. 38 (Cheryan, 1998).

$$
J_{P s s}=k_{T M} \cdot \ln \left(\frac{C_{m}-C_{P}}{C_{0}-C_{P}}\right)
$$

donde el coeficiente de transferencia de materia para flujo turbulento viene expresado por la Ec. 39 (Cheryan, 1998).

$$
k_{T M}=0.023 \cdot R e^{0.8} \cdot S c^{0.33} \cdot \frac{D}{D_{\text {int }}}
$$

$\operatorname{con} R e=\frac{D_{\text {int }} \cdot v_{\text {tang }} \cdot \rho}{\mu}$ y $S c=\frac{\nu}{D}$.

Modelo de bloqueo inter medio de poros para flujo tangencial $\left(\mathrm{n}_{\underline{C F}}=\right.$ 1)

En el Modelo de bloqueo intermedio de poros para flujo tangencial, e parámetro $K_{\text {icF }}$ se calcula de la misma forma queK $K_{C C F}$ en el M odelo de bloqueo completo adaptado para flujo tangencial (Ec. 35) (Hermia, 1982; Koltuniewicz y Field, 1996). 
Modelo de bloqueo estándar de poros para flujo tangencial $n_{\underline{C F}}=$ 3/ 2)

No es posible calcular de forma teórica el parámetro $K_{e}$ (Ec. 28) en el modelo $M$ odelo de bloqueo estándar de poros para flujo tangencial, pues dicho parámetro es función del parámetro $K_{B}$ (Bowen et al., 1995). El parámetro $K_{B}$ representa la disminución del área transversal de los poros por unidad de volumen de permeado filtrado y sólo es posible estimarl o de manera empírica.

Modelo de formación de capa gel para flujo tangencial $\left(\mathrm{n}_{\underline{C F}}=0\right)$

En el M odel o de formación de capa gel para flujo tangencial, el parámetro $K_{\text {cgCF }}$ (Ec. 40) también es función de un parámetro que sólo es posible determinar de forma empírica, $K_{\text {cgcf }}^{\prime}$ (Field et al., 1995). Este parámetro es la llamada constante de filtración, que relaciona la masa de capa gel por unidad de área de membrana con el volumen de permeado filtrado. El parámetro $K_{\text {cgcF }}^{\prime}$ es función de ciertas propiedades físicas de las moléculas formadoras de la capa gel.

$$
K_{c g C F}=\frac{a \cdot K_{c g C F}^{\prime}}{J_{0} \cdot R_{m}}
$$




\section{Capítulo}

\section{MATERIALES Y MÉTODOS}

\subsection{Plan de trabajo}

Las fases para la elaboración de esta Tesis Doctoral se resumen en:

Fase 1. Revisión bibliográfica.

Fase 2. Diseño y construcción de la planta piloto de ultrafiltración.

Fase 3. Puesta a punto de la planta piloto.

Fase 4. Ensayos de caracterización de las membranas.

Fase 5. Realización de los ensayos de ensuciamiento.

Fase 6. Simulación de procesos de ultrafiltración utilizando modelos dinámicos no empíricos.

Fase 7. Comparación de los resultados de la simulación con modelos no empíricos con los resultados experimentales.

Fase 8. Simulación de procesos de ultrafiltración utilizando modelos dinámicos semi-empíricos y determinando los parámetros de los modelos mediante ajuste.

Fase 9. Comparación de los resultados de la simulación con modelos semi-empíricos con los resultados experimentales.

Fase 10. Selección del mejor modelo.

Fase 11. Simulación de procesos de ultrafiltración utilizando el modelo seleccionado y determinando los parámetros de dicho modelo de forma teórica, minimizando así el uso de datos experimentales en las simulaciones. 


\subsection{REVISIÓN BIBLIOGRÁFICA}

La extensa búsqueda bibliográfica realizada en esta Tesis Doctoral se ha centrado principalmente en los siguientes temas. ensuciamiento de membranas de ultrafiltración, modelos dinámicos de descenso de la densidad de flujo de permeado con el tiempo en los procesos de ultrafiltración y métodos analíticos para la determinación de la concentración de PEG en disoluciones acuosas.

Esta búsqueda bibliográfica se ha llevado a cabo utilizando la base de datos Scifinder Scholar. Las palabras claves de la búsqueda fueron: ultrafiltration, fouling, dynamic modelling, modelling, model, flux decline, macromolecules y PEG.

Los artículos consultados encontrados en dicha base de datos corresponden principalmente a las revistas: Journal of Membrane Science, Desalination, Environmental Science and Technology, Journal of Environmental Engineering, Environmental Engineering Science, Advances in Colloid and Interface Science, Journal of Colloid and Interface Science, Separation and Purification Technology, Separation and Purification Methods, Separation Science and Technology, Chemical Engineering Communications, Chemical Engineering Science y Water Supply.

La mayoría de los artículos se han obtenido a través de la hemeroteca de la UPV y del servicio de artículos en formato electrónico de Science Direct que tiene contratado la UPV. Otros proceden también del servicio de artículos en formato electrónico de Science Direct, pero en este caso perteneciente ala Universidad de Lancaster (Reino Unido). El resto se han solicitado y obtenido a través del Servicio de Adquisición de Artículos de la Hemeroteca delaUPV. 


\subsection{Planta piloto de Ultrafiltración}

Los ensayos de ultrafiltración tangencial se realizaron en la planta piloto que se muestra en la Figura 8, la cual se diseñó en el Departamento de Ingeniería Química y Nuclear de la UPV para la realización de esta Tesis Doctoral.

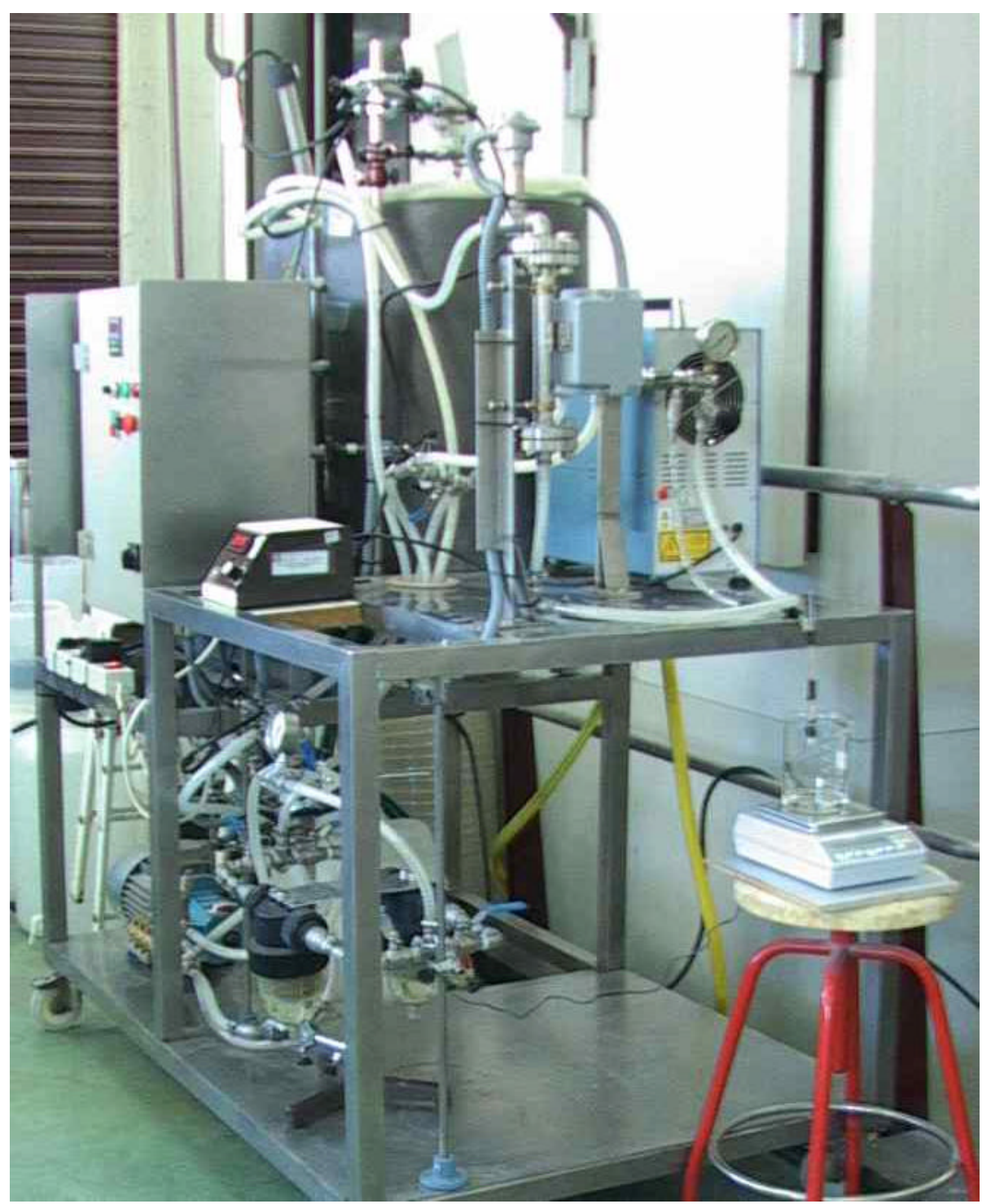

Figura 8. Fotografía de la planta piloto de ultrafiltración utilizada en los ensayos

Según se puede observar en el esquema representado en la Figura 9; la planta piloto de ultrafiltración dispone de dos tanques, un tanque 
de alimentación y otro de limpieza. El tanque de alimentación incorpora un agitador para homogeneizar la disolución alimento y un interruptor de nivel que permite trabajar de forma continua sin parar la instalación. Un filtro (F1) de 100 micras situado a la entrada de la bomba de alimentación (BA) de velocidad variable retiene cualquier partícula en suspensión que pudiera dañar la bomba.

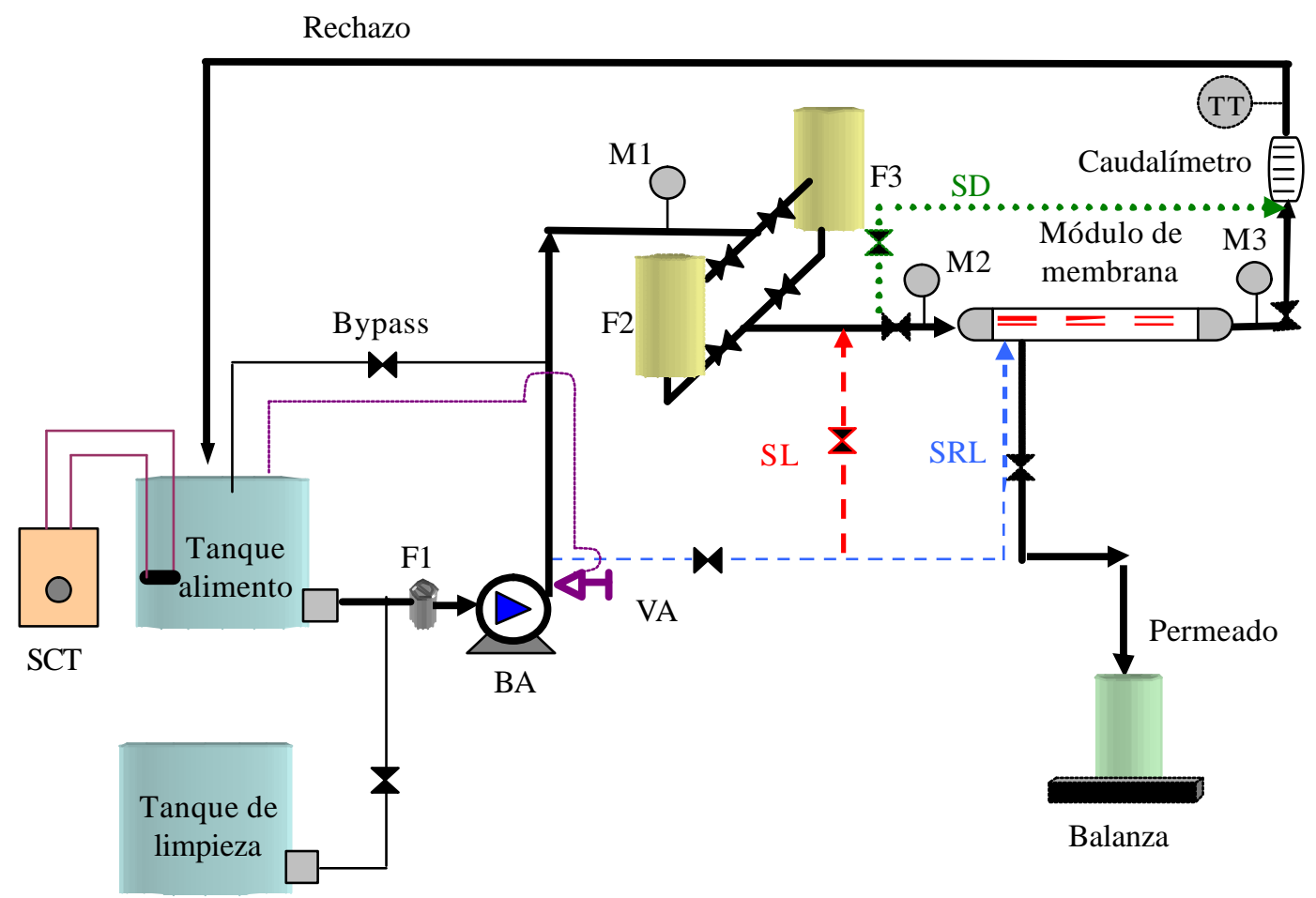

Figura 9. Esquema de la planta piloto de ultrafiltración utilizada en los ensayos

A la salida de la bomba hay una válvula de seguridad o válvula de alivio de presión (VA) que limita la presión máxima de la planta, desviando parte del caudal al tanque de alimentación si se alcanza la presión de tarado; en este caso 7 bar. Dos filtros (F2 y F3) de 25 micras situados aguas abajo de la bomba evitan el acceso a la membrana de agregados moleculares del alimento. Sólo uno de estos dos filtros está operativo durante los ensayos de ultrafiltración. En cada extremo de los filtros se sitúan sendos manómetros (M 1 y M2) para comprobar la caída de presión en los mismos. 
Tras los filtros se sitúa el módulo de membrana tubular. Otro par de manómetros (M2 y M3) en cada extremo del módulo permiten medir la caída de presión en el mismo. El caudalímetro situado en la corriente de rechazo permite medir el caudal volumétrico. La válvula de regulación situada justo antes del caudalímetro se utiliza para regular la PTM. Un sistema de recogida de permeado con una balanza permite determinar la densidad de flujo de permeado gravimétricamente.

La planta piloto también está equipada con un sistema de lavado y otro sistema para realizar retro-lavados, además de un sistema de control de la temperatura y un sistema de desvío.

El sistema de lavado (SL) consiste simplemente en un tramo de tubería con las correspondientes válvulas para evitar el paso de la disolución de limpieza por los filtros (F2 y F3) previos a la entrada del módulo de membranas, ya que podría dañarlos.

El sistema de retro-lavado (SRL) está diseñado de forma similar al de lavado, pero en esta ocasión la disolución de limpieza se introduce en el módulo de membrana por el lado del permeado.

El sistema de control de temperatura (SCT) consta principalmente de tres dispositivos: un intercambiador de calor para refrigerar, una resistencia eléctrica para calentar y un sensor de temperatura (TT) situado en la corriente de rechazo.

El sistema de desvío (SD) consiste en un by-pass que permiteel paso de la disolución contenida en el tanque por toda la planta de ultrafiltración a excepción del módulo de membrana. De este modo se consigue ajustar la temperatura de ensayo y el caudal de alimentación evitando el contacto de la disolución alimento con la membrana durante el proceso de ajuste de las condiciones de operación. 
La disolución alimento es impulsada hacia el modulo de membranas por la bomba de al imentación de velocidad variable, la cual permite operar con diferentes velocidades tangenciales. Dos manómetros situados en cada uno de los extremos del modulo de membranas miden la presión transmembranal, la cual se controla mediante la válvula situada a la salida del módulo (válvula de regulación). El caudalímetro situado en la corriente de rechazo permite controlar de modo continuo el caudal volumétrico de rechazo. La temperatura se mantiene constante gracias al sistema de control de temperatura.

Una vez que la disolución alimento se ha puesto en circulación cerrada a través del SD con el caudal volumétrico y la temperatura deseados, la válvula de acceso al modulo de membrana se abrey se cierra el SD. El caudal volumétrico de rechazo se comprueba con el caudalímetro, mientras que la válvula de regulación se cierra parcialmente hasta conseguir la presión transmembranal deseada. A partir de este momento se toman medidas continuas de la densidad de flujo de permeado hasta que se alcanza el estado quasiestacionario.

Las características de los principales elementos que integran la planta piloto de ultrafiltración se detallan a continuación:

- Tanque de alimentación cilíndrico de acero inoxidable con base cónica de $100 \mathrm{~L}$ de capacidad.

- Tanque de limpieza rectangular de acero inoxidable con base piramidal de $80 \mathrm{~L}$ de capacidad.

- Filtro de 100 micras (F1).

- Bomba de pistones de velocidad variable modelo 2SF13E de Cat Pumps (Estados Unidos), cuyas especificaciones son:

Caudal máximo: $780 \mathrm{~L} / \mathrm{h}$

Presión máxima: 90 bar

Velocidad degiro: $2800 \mathrm{rpm}$

- Manómetros de presión de 6 bares con una precisión de \pm 0.096 bar. 
- Filtros de 25 micras(F2 y F3).

- Módulo de ultrafiltración Carbosep de Orelis, S.A. (Francia) para membranas tubulares.

- Caudalímetro modelo SC-250 de Tecfluid (España), con un caudal de medida máximo de 500 L/ h y una precisión del $2.5 \%$ del valor final dela escala.

- Resistencia cal efactora hecha a medida con una potencia de 1000 w.

- Refrigerador modelo 3000778 de J.P. Selecta (España) con un intervalo de temperaturas de trabajo de entre-20 y $20 \stackrel{\circ}{\circ}$ y una potencia calorífica de $276 \mathrm{w}$ a $-20^{\circ} \mathrm{C}$.

- Agitador modelo RZR-1 de Heidolph (Alemania) con regulación mecánica y en continuo de la velocidad, con eje portavarillas y gama de velocidades desde 280 a $2200 \mathrm{rpm}$

- Balanza de precisión modelo 572 KB 600-2 de KERN (Suiza) con un campo de pesaje de $610 \mathrm{~g}$ y una precisión de $0.01 \mathrm{~g}$.

\subsection{MEMBRANAS UTILIZADAS EN LOS EXPERIMENTOS}

En los ensayos se utilizaron dos tipos de membranas cerámicas monotubulares: membranas Carbosep M2 de Orelis, S.A . (Francia) y membranas Céram Inside - MSKTT02510010 de Tami Industries (Francia)

Se trata de membranas comerciales constituidas por un tubo cilíndrico de $20 \mathrm{~cm}$ de longitud, $10 \mathrm{~mm}$ de diámetro externo y $6 \mathrm{~mm}$ de diámetro interno. El área efectiva de las membranas es de 35.5 $\mathrm{cm}^{2}$.

La capa activa de la membrana Carbosep M2 consiste en una fina capa de $\mathrm{ZrO}_{2}-\mathrm{TiO}_{2}$ depositada sobre la superficie interna del soporte tubular de carbono. El umbral de corte molecular de la misma es de $15 \mathrm{kDa}$, con un tamaño medio de poro de $4 \mathrm{~nm}$ aproximadamente. 
A diferencia de la membrana Carbosep M2 la capa activa de la membrana Tami MSKTT02510010 es de $\mathrm{Al}_{2} \mathrm{O}_{3}-\mathrm{TiO}_{2}$ y el soporte poroso es de alúmina. El umbral de corte molecular de la misma es de $5 \mathrm{kDa}$.

En la Figura 10 se muestra una foto de ambas membranas. La membrana oscura es la Carbosep M2 y la clara es la Tami MSKT.

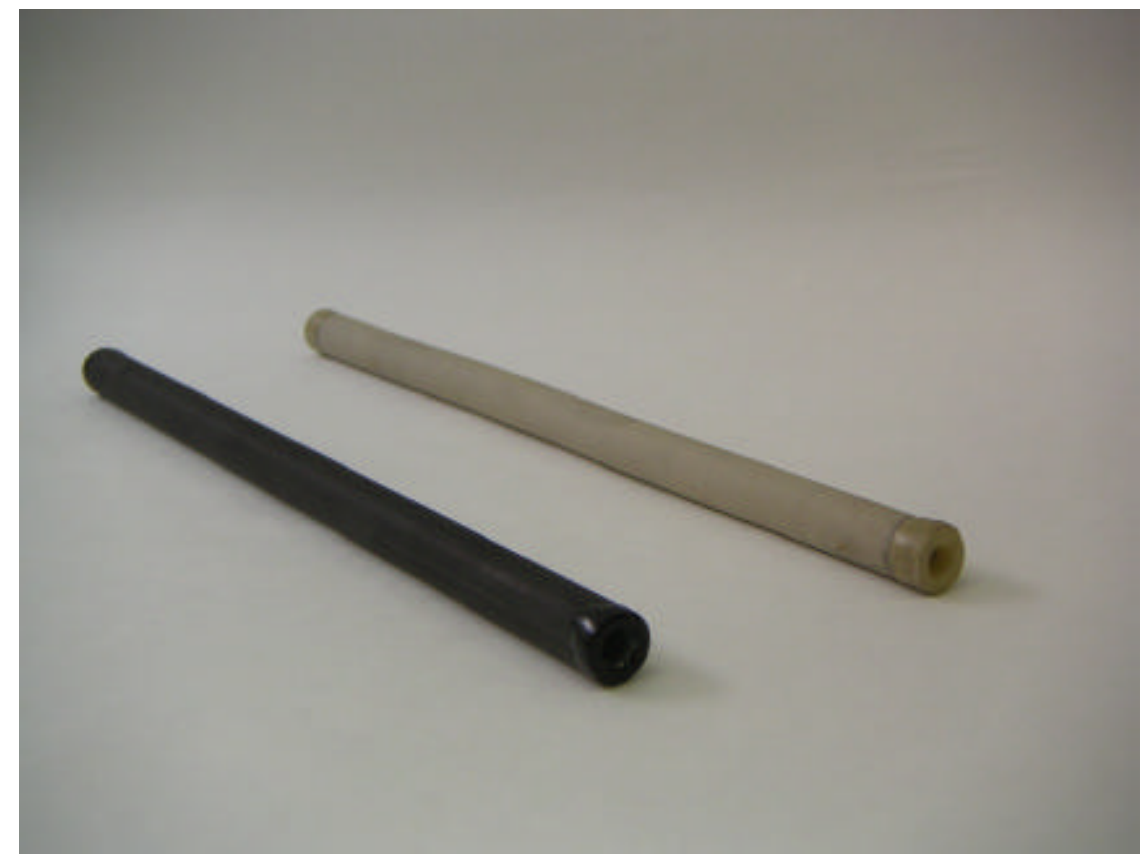

Figura 10. Fotografía de las membranas de ultrafiltración utilizadas en los ensayos

Las especificaciones técnicas de ambas membranas se recogen en la Tabla 2. 
Tabla 2. Especificaciones técnicas de las membranas

\begin{tabular}{lcc}
\hline \multicolumn{1}{c}{ Parámetro } & $\begin{array}{c}\text { Carbosep } \\
\text { M2 }\end{array}$ & $\begin{array}{c}\text { Tami } \\
\text { MSKT }\end{array}$ \\
\hline Densidad de flujo de permeado al & $150-350$ & $50-80$ \\
agua pura a 25ㄷ y 0.4 M Pa $\left(\mathrm{L} \cdot \mathrm{m}^{-2} \cdot \mathrm{h}^{-1}\right)$ & & \\
Máxima temperatura de operación $\left({ }^{\circ} \mathrm{C}\right)$ & 100 & 150 \\
Máxima presión de operación (MPa) & 1.5 & 4.5 \\
Intervalo de pH & $0-14$ & $0-14$ \\
\hline
\end{tabular}

Se han escogido membranas cerámicas en vez de membranas orgánicas, puesto que resulta más fácil limpiarlas tras los ensayos de ensuciamiento; ya que permiten utilizar temperaturas más elevadas e intervalos de pH más amplios en las operaciones de limpieza. Otra razón es el empleo futuro de la ultrafiltración en el tratamiento de aguas residuales industriales (textil, tratamiento de superficies, ...)

\subsection{Productos Químicos UTILIZAdos EN LOS EXPERIMENTOS}

En la preparación de la disolución acuosa que constituye el alimento se utilizó PEG para síntesis suministrado por Merck-Schuchardt (Alemania). El peso molecular del PEG suministrado es de 35 kDa. Las características del producto se recogen en la Tabla 3.

Tabla 3. Características del PEG utilizado en los ensayos

\begin{tabular}{lc}
\hline \multicolumn{1}{c}{ Parámetro } & Valores \\
\hline Densidad a 20C $\left(\mathrm{kg} / \mathrm{m}^{3}\right)$ & 1200 \\
$\mathrm{pH}$ de $100 \mathrm{~kg} / \mathrm{m}^{3}$ de PEG en agua a $20^{\circ} \mathrm{C}$ & $5-7$ \\
Punto de fusión $\left({ }^{\circ} \mathrm{C}\right)$ & $60-65$ \\
Presión de vapor a 20ㄷ $(\mathrm{MPa})$ & $<1 \cdot 10^{-6}$ \\
Solubilidad en agua a $20^{\circ} \mathrm{C}\left(\mathrm{kg} / \mathrm{m}^{3}\right)$ & 500 \\
Temperatura de descomposición $\left({ }^{\circ} \mathrm{C}\right)$ & 220 \\
\hline
\end{tabular}


En la preparación delas disoluciones de limpieza de las membranas Carbosep M2 se utilizó $\mathrm{NaOH}$ químicamente puro en lentejas suministrado por Panreac (España). Las características del producto se recogen en la Tabla 4.

Tabla 4. Características del $\mathrm{NaOH}$ utilizado en la preparación de las disoluciones de limpieza

\begin{tabular}{lc}
\hline \multicolumn{1}{c}{ Parámetro } & Valores \\
\hline Densidad a $20^{\circ} \mathrm{C}\left(\mathrm{kg} / \mathrm{m}^{3}\right)$ & 2130 \\
Punto de fusión $\left({ }^{\circ} \mathrm{C}\right)$ & 318 \\
Solubilidad en agua a $20^{\circ} \mathrm{C}\left(\mathrm{kg} / \mathrm{m}^{3}\right)$ & 1090 \\
\hline
\end{tabular}

En la preparación de las disoluciones de limpieza de las membranas Tami MSKT se utilizó, además de $\mathrm{NaOH}$ químicamente puro en lentejas suministrado por Panreac (España), $\mathrm{NaClO}$ también suministrado por Panreac (España) en una disolución al $10 \%$ (p/ v). Las características del producto se recogen en la Tabla 5.

Tabla 5. Características del $\mathrm{NaClO}$ utilizado en la preparación de las disoluciones de limpieza

\begin{tabular}{lc}
\hline \multicolumn{1}{c}{ Parámetro } & Valores \\
\hline Densidad a 20C $\left(\mathrm{kg} / \mathrm{m}^{3}\right)$ & 1180 \\
Solubilidad en agua a $20^{\circ} \mathrm{C}\left(\mathrm{kg} / \mathrm{m}^{3}\right)$ & Miscibilidad total \\
\hline
\end{tabular}

El agua desionizada utilizada en la preparación de las disoluciones alimento y las disoluciones de limpieza fue producida en el laboratorio del departamento de Ingeniería Química y Nuclear, mediante el equipo desmineral izador de afino Station $8000 \mathrm{E} / 35$ y la resina de intercambio iónico Station 8000 L 5.2, ambos suministrados por Veolia Water Systems (Francia). El agua desionizada obtenida es de calidad grado reactivo tipo III según la norma ASTM D 1193-91, equivalente al agua bidestilada. Este agua presenta una conductividad máxima de $0.25 \mu \mathrm{S} / \mathrm{cm}$. El pH de la 
misma es más o menos estable al carecer ésta de una cantidad suficiente de constituyentes que puedan alterar el pH.

\subsection{MÉTODOS DE ANÁLISISY MEDIDA}

\subsubsection{M étodo para la determinación de la curva de evolución de la densidad de flujo de permeado con el tiempo}

La densidad de flujo de permeado a través de la membrana se determina gravimétricamente mediante pesada de un volumen determinado de permeado equivalente a 2, 3, 4 ó $5 \mathrm{~g}$ y recogido en un tiempo determinado que semide con un cronómetro.

Las lecturas en la balanza se realizan en intervalos de tiempo de 3, 5, $10,15,20$ y 30 minutos, dependiendo del tiempo transcurrido desde el inicio del experimento. Las lecturas se espacian más al final del experimento, cuando éste se aproxima al estado quasi-estacionario.

Debido a que la concentración de las disoluciones utilizadas es reducida $(5,10$ y $15 \mathrm{~g} / \mathrm{L})$ y a que dicha concentración aún será menor en el permeado, se ha consideradola densidad de las mimas igual a la densidad del agua a $25^{\circ} \mathrm{C}\left(\rho=997.07 \mathrm{~kg} / \mathrm{m}^{3}\right)$. Prádanos et al. (1995) han demostrado la validez de esta simplificación en sus ensayos de ultrafiltración con PEG utilizando la misma concentración que en esta Tesis Doctoral .

El volumen recogido se calculó considerando su masa y una densidad de la disolución igual a la del agua a 25ㄷ․ Una vez calculado el volumen, la densidad de flujo de permeado se calcula dividiendo el volumen entre el tiempo y el área de la membrana según la Ec. 41.

$$
J_{P}=\frac{V}{t \cdot A}
$$




\subsubsection{Determinación de la concentración de polietilenglicol} (PEG)

La concentración de PEG se ha determinado a partir de la medida del índice de refracción a $25^{\circ} \mathrm{C}$. Para ello se ha utilizado el refractómetro digital Abbe modelo NAR-3T de Atago (Japón). El intervalo de medida de índice de refracción del refractómetro es de 1.30000-1.71000, con una precisión de \pm 0.0001 . Para mantener la temperatura constante durante la determinación se utilizó un baño termostatado con el termostato de inmersión Digisat DIGI-100 de Raypa (España).

Se ha seleccionado este método debido a que son numerosas las referencias bibliográficas que lo han utilizado para la determinación de la concentración de PEG (Ghose et al., 2000; Poddar et al., 1999; Prádanos et al., 1995; Ganguly y Bhattacharya, 1994; Bhattacharjee y Bhattacharya, 1992b; Das Gupta y Bhattacharya, 1990).

\subsubsection{Determinación de la Demanda $Q$ uímica de 0 xígeno (DQ 0 )}

Los resultados de las medidas de DQO realizadas en el alimento y en el permeado servirán para el cálculo del índice de rechazo, el cual se define por medio de la siguiente ecuación:

$$
R=\frac{C_{0}-C_{P}}{C_{0}}
$$

donde $C_{0}$ y $C_{p}$ representan la concentración de PEG en la alimentación y en el permeado respectivamente.

La DQO se ha determinado por medio del test en cubetas para la medida de la DQO de Merck (Alemania), siguiendo un procedimiento análogo al descrito en las normas EPA 410.4, US Standard Methods 5220 D e ISO 15705. La selección de este método 
para la determinación de la DQO se debe a que es un método rápido y eficaz.

Dicho método se basa en la oxidación mediante $\mathrm{K}_{2} \mathrm{Cr}_{2} \mathrm{O}_{7}$ de las sustancias oxidables contenidas en el agua y la posterior determinación fotométrica del $\mathrm{Cr}_{2} \mathrm{O}_{7}{ }^{2-}$ no consumido.

El equipo utilizado para la determinación de la DQO se compone de:

- Espectrofotómetro Spectroquant NOVA 60 suministrado por Merck.

- Cubetas con reactivo para la determinación de la DQO en un intervalo de 25 a 1500 ppm.

- Cubetas con reactivo para la determinación de la DQO en un intervalo de 500 a 10000 ppm.

- Termo-reactor TR 300 de Merck.

El procedimiento para la determinación de la DQO es el siguiente:

- El análisis de las muestras se realiza inmediatamente después de la toma de las mismas.

- Las muestras que lo requieran se diluyen para conseguir que el valor de la DQO entre en el intervalo de medida de las cubetas con reactivo.

- La cubeta se agita por balanceo para poner en suspensión el sedimento del fondo de la misma.

- Para los test de intervalo de medida entre 25 y 1500 ppm se toman $3 \mathrm{~mL}$ de muestra y se introducen en la cubeta de reacción.

- Para los test de intervalo de medida entre 500 y 10000 ppm se toman $1 \mathrm{~mL}$ de muestra y se introducen en la cubeta de reacción.

- Secierra la cubeta de reacción y se agita. 
- La cubeta de reacción con la muestra se introduce rápidamente en el termo-reactor previamente precalentado y se deja allí durante dos horas a $148^{\circ} \mathrm{C}$.

- Pasadas las dos horas se sacan las cubetas del termo-reactor, se dejan enfriar 10 minutos, se agitan por balanceo y se dejan enfriar nuevamente hasta temperatura ambiente.

- Para realizar la medida se introduce la cubeta de reacción en el espectrofotómetro, leyéndose directamentela DQO en ppm.

\subsubsection{Medida de la conductividad}

Los valores de conductividad se han utilizado como indicadores de la calidad del agua desionizada. La conductividad se ha medido con el conductivímetro portátil 524 de CRISON (España) de célula de referencia 52-90 con sonda de compensación de temperatura.

\subsubsection{Medida del $\mathrm{pH}$}

Los valores de $\mathrm{pH}$ también se han utilizado como indicadores de la calidad del agua desionizada. El pH se ha determinado utilizando el pH-metro GLP 22 de CRISON con electrodo de referencia 52-02.

\subsubsection{Determinación de la densidad y viscosidad de las disoluciones de polietilenglicol (PEG)}

Las densidades de las disoluciones acuosas de PEG a las concentraciones de 5,10 y $15 \mathrm{~g} / \mathrm{L}$ se midieron siguiendo el procedimiento indicado en la norma UNE-EN ISO 3675 con un aerómetro de vidrio M50 SP número 2691 suministrado por G.H. Zeal (Londres).

A simismo, las viscosidades dinámi cas de las disoluciones acuosas se determinaron siguiendo el procedimiento de las normas ASTM D445/ 65 y D-2515, utilizando un viscosímetro Cannon-Fenske de la 
serie 50 con baño termostático distribuido por vidra FOC S.A. (España).

\subsection{Procedimiento eXPerimental}

4.7.1. Ensayos de caracterización de las membranas de ultrafiltración

Para determinar la permeabilidad al agua pura y la resistencia intrínseca de las membranas se realizaron ensayos con agua desionizada a diferentes PTM $(0.1,0.2,0.3,0.4$ y $0.5 \mathrm{MPa})$. En todos ellos, la velocidad tangencial de circulación del agua desionizada fue de $3 \mathrm{~m} / \mathrm{s}$ y la temperatura de $25^{\circ} \mathrm{C}$.

Todos los ensayos se realizaron a ${ }^{25^{\circ}} \mathrm{C}$, ya que ésta es una temperatura de referencia en la bibliografía consultada. La velocidad tangencial no tiene repercusión sobre el comportamiento de la membrana con agua pura.

Durante cada ensayo se midió la densidad de flujo de permeado cada 3 minutos. La duración de cada ensayo fue de 30 minutos.

En todos los ensayos se comprobó que el agua desionizada obtenida mediante la resina de intercambio iónico fuese de calidad grado reactivo tipo III, de acuerdo con el apartado 4.5 de esta Tesis Doctoral. Para ello se midieron la conductividad y el pH, aceptando sólo valores de conductividad inferiores a $0.25 \mu \mathrm{S} / \mathrm{cm}$ y valores de $\mathrm{pH}$ entre 5 y 8. 


\subsubsection{Ensayos de ensuciamiento de las membranas de ultrafiltración}

El procedimiento experimental en los ensayos de ensuciamiento fue el siguiente:

1.- Se prepara la disolución alimento disolviendo PEG en agua desionizada hasta al canzar la concentración deseada y se introduce en el tanque de alimentación.

2.- Se pone en marcha la instalación evitando el paso de la alimentación a través de la membrana hasta que la temperatura se estabilice en $25^{\circ} \mathrm{C}$.

3.- Se pone en marcha el experimento previo desplazamiento del volumen almacenado en la instalación con un volumen superior. Como tiempo cero de inicio del experimento (puesta en marcha del cronómetro), se toma el instante en el que se abre la válvula de permeado una vez fijados la PTM y el caudal. El rechazo y el permeado se recirculan al tanque de alimentación.

4.- Se realizan mediciones de la densidad de flujo de permeado tal y como se describe en el apartado 4.6.1

5.- Finalmente, la planta se para cuando hayan transcurrido 7 horas desde su puesta en marcha, tiempo suficiente para alcanzar el estado quasi -estacionario.

\section{Ensayos real izados con la membrana Carbosep M2}

Se realizaron ensayos de ensuciamiento con la membrana Carbosep M2a diferentes PTMs y velocidades tangenciales. Todos los ensayos con la membrana Carbosep M2 se realizaron a una temperatura de $25^{\circ} \mathrm{C}$ y una concentración del alimento de $5 \mathrm{~g} / \mathrm{L}$. 
Las condiciones experimentales consideradas para realizar los ensayos se resumen en la Tabla 6.

Tabla 6. Condiciones experimentales utilizadas en los ensayos de ultrafiltración con las membranas Carbosep M2

\begin{tabular}{lc}
\hline \multicolumn{1}{c}{ Parámetro } & Valores \\
\hline PTM (MPa) & $0.1-0.2-0.3-0.4$ \\
Velocidad tangencial $(\mathrm{m} / \mathrm{s})$ & $1-2-3$ \\
Temperatura $(\stackrel{\circ}{ } \mathrm{C})$ & 25 \\
Concentración del alimento $\left(\mathrm{kg} / \mathrm{m}^{3}\right)$ & 5 \\
\hline
\end{tabular}

Todos los ensayos se realizaron a concentración constante para lo cual se recircularon el rechazo y el permeado al tanque de alimentación.

Se utilizó la misma membrana en todos los experimentos. El protocolo de limpieza de la misma se describe en el apartado 4.7.3.

En algunos ensayos se tomaron muestras de alimento y de permeado para medir su DQO y determinar, de este modo, el índice de rechazo de las membranas.

No fue posible realizar más ensayos con las membranas Carbosep M2 variando más condiciones de operación porque la membrana que se había usado en ensayos anteriores se rompió al sacarla del módulo de membrana. Al intentar sustituirla por otras membranas del mismo tipo se observó que ninguna de ellas proporcionó resultados parecidos a los obtenidos en los ensayos de caracterización de la primera membrana. Por este motivo se descartaron las membranas Carbosep M2, pues no ofrecían resultados comparables. 
Ensayos realizados con la membrana Tami MSKT

Se realizaron un total de 40 ensayos con la membrana Tami MSKT. En 36 de ellos se varió la PTM, la concentración de alimento y la velocidad tangencial, manteniendo una temperatura constante de $25 \circ$ C.

Las condiciones experimentales consideradas para realizar estos ensayos se resumen en la Tabla 7.

Tabla 7. Condiciones experimentales utilizadas en los ensayos de ultrafiltración a temperatura constante con las membranas Tami MSKT

\begin{tabular}{lc}
\hline \multicolumn{1}{c}{ Parámetro } & Valores \\
\hline PTM (MPa) & $0.2-0.3-0.4-0.5$ \\
Velocidad tangencial $(\mathrm{m} / \mathrm{s})$ & $1-2-3$ \\
Temperatura $\left({ }^{\circ} \mathrm{C}\right)$ & 25 \\
Concentración del alimento $\left(\mathrm{kg} / \mathrm{m}^{3}\right)$ & $5-10-15$ \\
\hline
\end{tabular}

En los 4 ensayos restantes se varió la temperatura manteniendo constantes el resto de variables. Se fijó la concentración de alimento en $5 \mathrm{~g} / \mathrm{L}$, la velocidad tangencial en $1 \mathrm{~m} / \mathrm{s}$ y la PTM en $0.5 \mathrm{MPa}$. Los valores de temperatura considerados fueron $15,25,35$ y $40 \stackrel{\circ}{ } \mathrm{C}$.

Finalmente, se realizaron un total de 8 réplicas para comprobar la repetibilidad de los ensayos. Las máxima desviación obtenida fue de un $10 \%$.

Al igual que en el caso de las membranas Carbosep M2, en todos los ensayos se mantuvo la concentración constante y se utilizó la misma membrana. El protocolo de limpieza de la misma se describe en el apartado 4.7.3. 
En los experimentos se tomaron muestras de alimento y de permeado para medir su DQO y determinar, de este modo, el índice de rechazo de las membranasy su evolución con el tiempo.

\subsubsection{Protocolo de limpieza de las membranas de ultrafiltración}

Tras cada ensayo de ensuciamiento se efectuó la limpieza de las membranas, para lo que se utilizó el tanque de limpieza que se muestra en la Figura 9.

El protocolo de limpieza de las membranas Carbosep M2 consta de las siguientes etapas:

1.- A clarado con agua desionizada ( 35 minutos).

2.- Limpieza con una disolución acuosa de $\mathrm{NaOH} 0.2 \%$ (p/p) en agua desionizada (1.5 horas).

3.- A clarado con agua desionizada (35 minutos).

En el caso de las membranas Tami MSKT, la segunda etapa de limpieza se realizó con una disolución acuosa de $\mathrm{NaClO}$ de 250ppm. Para evitar la corrosión del acero se adicionó $\mathrm{NaOH}$ hasta alcanzar un $\mathrm{pH}$ de 11. La primera y la tercera etapa de limpieza de las membranas Tami MSKT fueron iguales a las de las membranas Carbosep M2.

Todas las etapas del protocolo de limpieza se realizaron a una temperatura de $50^{\circ} \mathrm{C}$, una PTM cercana a 0 bar y una velocidad tangencial de $3 \mathrm{~m} / \mathrm{s}$.

La elección de $\mathrm{NaOH}$ como agente de limpieza se debe a que los agentes de ensuciamiento de la membrana son orgánicos, por lo que es aconsejable una limpieza alcalina. El $\mathrm{NaOH}$ es una base relativamente económica, habiéndose realizado además numerosos 
estudios que demuestran su eficacia en la limpieza de membranas (Bird y Bartlett, 2002).

A la vista de que los resultados que se obtenían con el $\mathrm{NaOH}$ no eran satisfactorios en el caso de las membranas Tami MSKT; el $\mathrm{NaOH}$ se sustituyó por $\mathrm{NaClO}$. El $\mathrm{NaClO}$ ha resultado ser efectivo en la limpieza de membranas cerámicas cuyo ensuciamiento se debe a la presencia de materia orgánica (Porter y Porter, 1995; Sulaiman et al., 2001).

Antes de realizar cualquier etapa de limpieza se comprobó previamente que el agua desionizada que se obtiene con la resina de intercambio iónico es de la calidad adecuada, mediante la medida de la conductividad y del $\mathrm{pH}$, de acuerdo con el apartado 4.7.1 de esta Tesis Doctoral.

Una vez finalizado el protocolo de limpieza se vació el tanque y se cargó con agua desionizada para medir la densidad de flujo de permeado, comprobando previamente la calidad del agua del modo indicado. Dicha medida se realizó a una temperatura de $25^{\circ} \mathrm{C}$, una PTM de 3 bar y una velocidad tangencial de $3 \mathrm{~m} / \mathrm{s}$. El objetivo de la misma es comprobar que la duración del proceso de limpieza ha sido suficiente para conseguir recuperar totalmente la permeabilidad inicial dela membrana.

Si la diferencia entre la densidad de flujo de permeado al agua desionizada medida tras la limpieza y la obtenida en los ensayos de caracterización inicial de la membrana, bajo las mismas condiciones experimentales, es superior a error cometido en la determinación experimental de la densidad de flujo de permeado, se vuelve a repetir el protocolo de limpieza las veces que sea necesario. El error relativo cometido en la medida de la densidad de flujo de permeado se calculó del modo que se muestra en el apartado 5.1 de esta Tesis Doctoral y resultó ser igual o inferior a un 11\%. 


\section{Capítulo}

\section{ANÁLISIS DE LOS RESULTADOS Y DISCUSIÓN}

\subsection{CaRACTERIZACIÓN DE LAS MEM BRANAS DE ULTRA FILTRACIÓN}

Los resultados de los ensayos de caracterización de las membranas Carbosep M2 y Tami MSKT se muestran en las Figuras 11 y 12 respectivamente. La evolución de la densidad de flujo de permeado con la presión es lineal de acuerdo con la ecuación de HagenPoiseuille (Ec. 43) que describe el flujo de líquidos a través de medios porosos. Las ecuaciones de ajuste se muestran en la Figura 11 y la Figura 12. La ordenada en el origen debería ser aproximadamente cero. La desviación que presenta respecto del valor cero se debe al error que se comete en la determinación de la densidad de flujo de permeado, que puede ser de hasta un $11 \%$.

$$
J_{P}=\frac{\Delta P}{\mu \cdot R_{m}}
$$




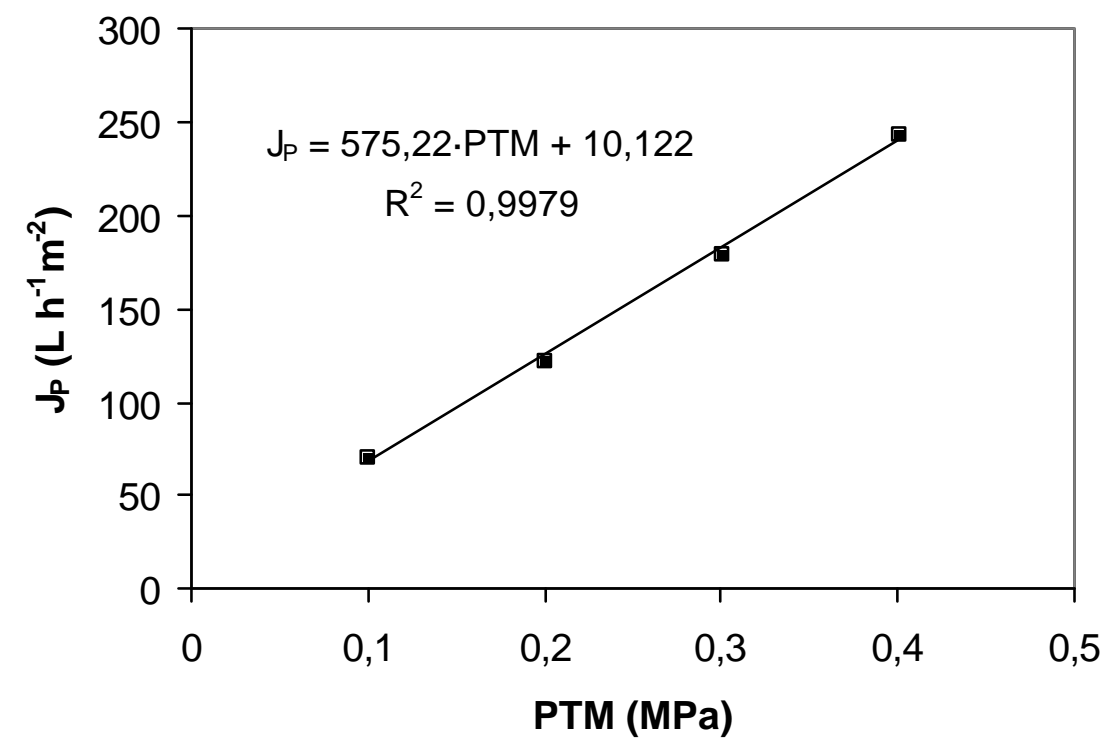

Figura 11. Densidad de flujo de permeado al agua desionizada en función de la presión transmembranal para la membrana Carbosep M2

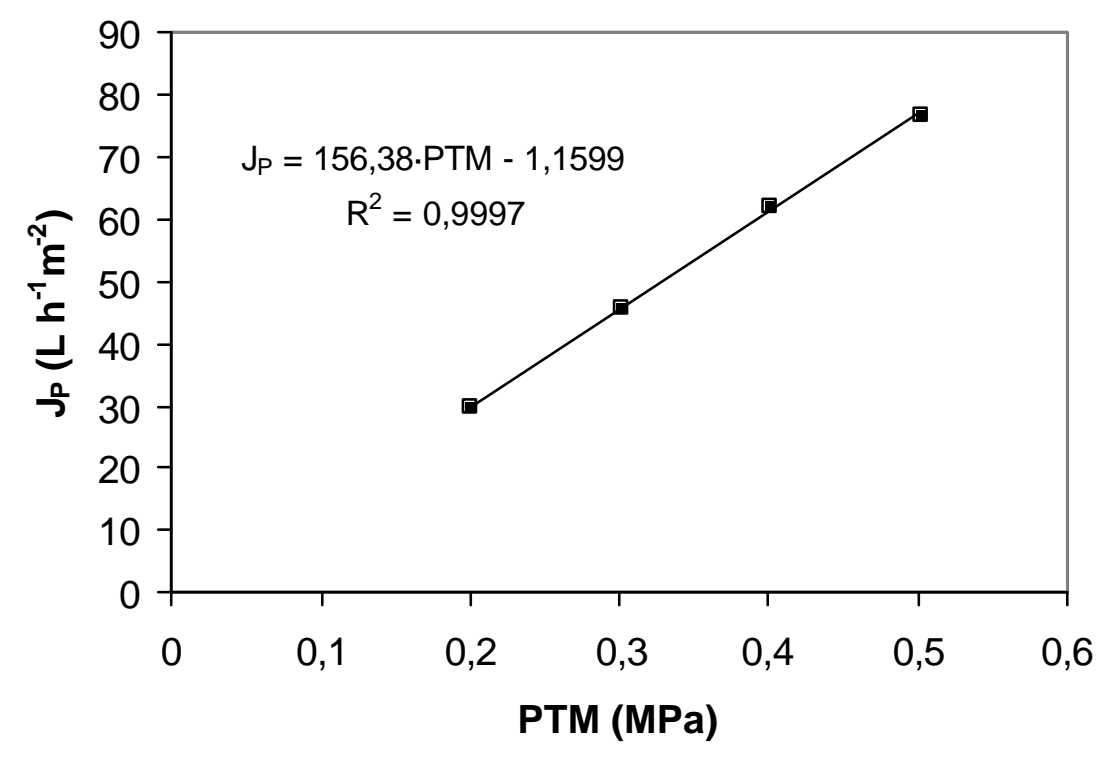

Figura 12. Densidad de flujo de permeado al agua desionizada en función de la presión transmebranal para la membrana Tami MSKT

El error relativo que se comete en la medida de la densidad de flujo de permeado al agua pura se calculó tomando como base los 
trabajos de Daufin et al. (1991) y Daufin et al. (1992). Dicho error se calcula como la suma de los errores relativos cometidos en cada una de las mediciones necesarias para determinar la densidad de flujo de permeado. Estos errores son los derivados del uso de los siguientes equipos de medida: los manómetros para determinar la presión transmembranal, la balanza para pesar el volumen de permeado recogido, el cronómetro para contabilizar el tiempo en el que se recoge una masa determinada de permeado y el sistema de control de temperatura para mantener constante la temperatura en ${ }^{25 \circ} \mathrm{C}$. Por lo tanto, el error relativo en la medida de la densidad de flujo de permeado se determina mediantela Ec. 44.

$$
\frac{\Delta J_{P}}{J_{P}} \leq \frac{\Delta P}{P}+\frac{\Delta m}{m}+\frac{\Delta t}{t}+\frac{\Delta T}{T}
$$

donde:

$$
\begin{gathered}
\frac{\Delta P}{P}=\frac{\Delta P_{e}}{P_{e}}+\frac{\Delta P_{s}}{P_{s}} \leq 6.667 \% \\
\frac{\Delta m}{m} \leq 0.200 \% \\
\frac{\Delta t}{t} \leq 0.036 \% \\
\frac{\Delta T}{T} \leq 4 \%
\end{gathered}
$$

Resultando un error relativo asociado a la medida dela densidad de flujo de permeado al agua pura igual o inferior al $11 \%$.

$$
\frac{\Delta J_{P}}{J_{P}} \leq 10.902 \%
$$




\subsubsection{Determinación de la resistencia intrínseca de la membrana $\left(\mathbf{R}_{\mathrm{m}}\right)$}

Si se considera que la membrana es completamente permeable al agua, la resistencia intrínseca de la misma $\left(R_{m}\right)$ se puede determinar mediante la ecuación de Hagen-Poiseuille (Ec. 43), válida para el flujo de fluidos a través de medios porosos (Cheryan, 1998). Para ello se han ajustado a dicha ecuación los datos experimentales de la densidad de flujo de permeado al agua pura obtenidos para diferentes PTMs (Figuras 11 y 12).

Las resistencias de las membranas así obtenidas resultaron ser de $6.869 \times 10^{12} \mathrm{~m}^{-1}$ para la membrana Carbosep M2 y de $2.527 \times 10^{13} \mathrm{~m}^{-1}$ para la membrana Tami MSKT.

\subsubsection{Determinación de la concentración de PEG en el alimento y en el permeado}

Para calcular el índice de rechazo de la membrana al PEG mediante la Ec. 42 del apartado 4.6.3. es necesario determinar la concentración de PEG en el alimento y en el permeado.

Inicialmente se intentó utilizar la refractometría para determinar la concentración de PEG, pues algunos autores como Prádanos et al. (1995) utilizaron un refractómetro diferencial para la medida de la concentración dePEGs en intervalos de concentración similares a los considerados en esta Tesis Doctoral. Para ello se elaboró una curva de calibrado de índice de refracción frente a concentración de PEG (Figura 13) a partir de disoluciones de PEG de concentración conocida.

Debido a que el índice de refracción varía muy poco con la concentración de PEG y a que el índice de refracción del agua es 1.3325 a $25^{\circ} \mathrm{C}$, valor muy cercano a los que se han obtenido en la 
curva de calibrado, se desestimó la refractometría como método apropiado para determinar concentración de polietilenglicol, ya que el error cometido en la medida es muy elevado.

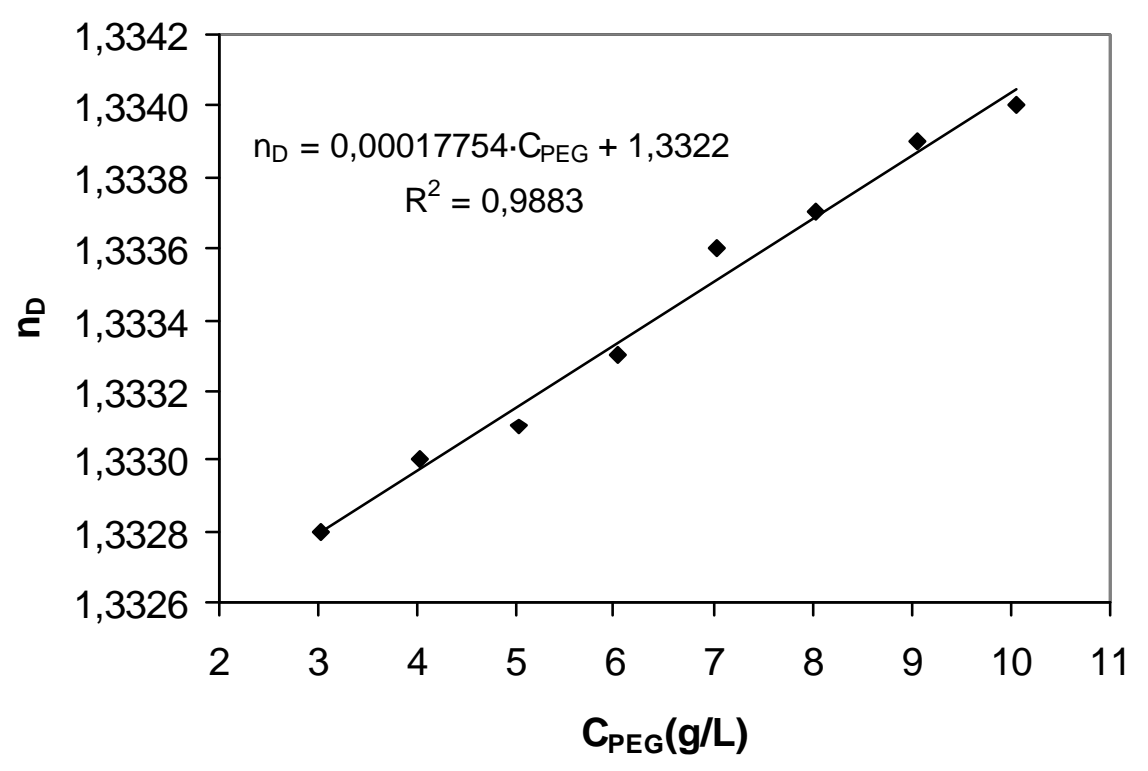

Figura 13. Curva de calibrado de índice de refracción frente a concentración de polietilenglicol

Debido a la imposibilidad de utilizar la refractometría, se optó por medir la DQO tanto en el permeado como en el alimento para determinar el índice de rechazo. Puesto que la DQO es proporcional a la concentración, se puede utilizar para esta finalidad la Ec. 42 sustituyendo las concentraciones por valores de DQO.

Se realizó una curva de calibrado para determinar la concentración de PEG en la alimentación, en el rechazo y en el permeado a partir del valor de la DQO (Figura 14). 


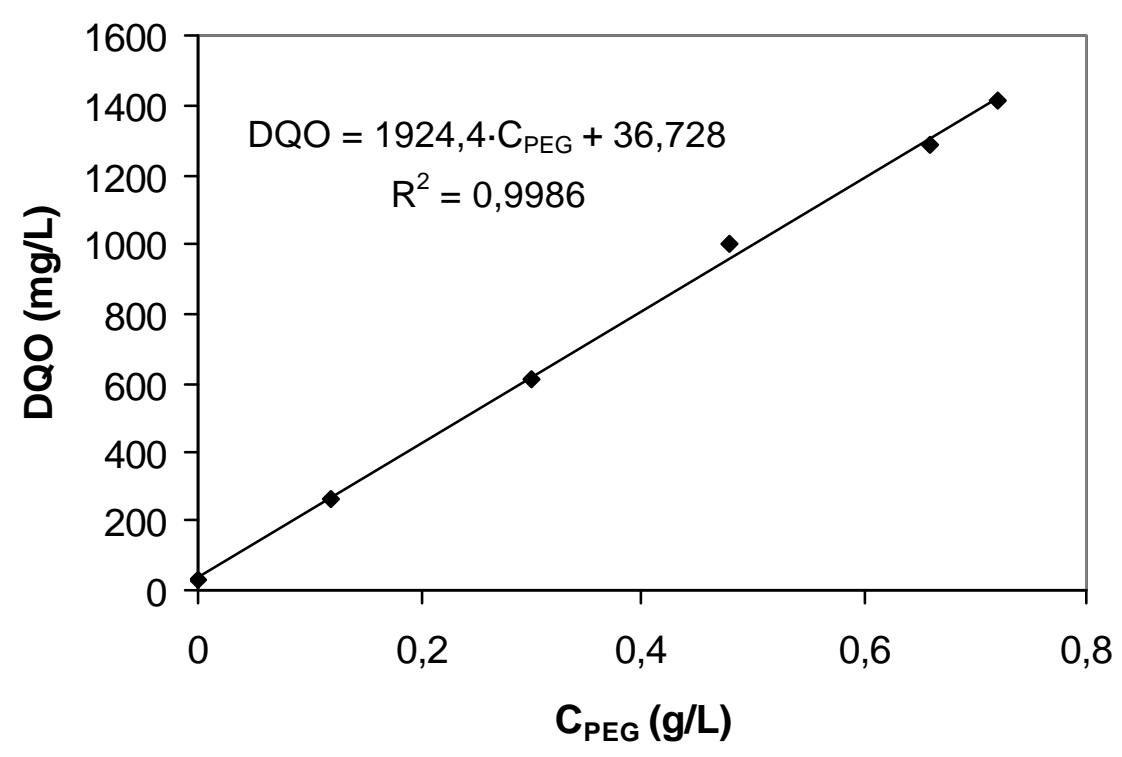

Figura 14. Curva de calibrado de la DQO frente a la concentración de polietilenglicol

\subsection{ATOS DE PARTIDA Y CÁLCULOS PREVIOS}

\subsubsection{Densidad del PEG}

La densidad del polietilenglicol con peso molecular de $35 \mathrm{kDa}$ viene especificada por el fabricante (Merck Schuchardt, Alemania) y es de $1200 \mathrm{~kg} / \mathrm{m}^{3}$.

\subsubsection{Densidad y viscosidad del agua pura a $25^{\circ} \mathrm{C}$}

Los valores de la densidad y la viscosidad dinámica del agua pura a $25^{\circ} \mathrm{C}$ son respectivamente $997.07 \mathrm{~kg} / \mathrm{m}^{3}$ y $8.937 \cdot 10^{-4} \mathrm{~kg} / \mathrm{m} \cdot \mathrm{s}$ (Lide, 2003). La viscosidad cinemática del agua se obtiene a partir de los valores de la densidad y la viscosidad dinámica según la Ec. 50.

$$
v=\frac{\mu}{\rho}
$$




\subsubsection{Radio equivalente del PEG en función de su peso molecular}

Tam y Trembley (1991) correlacionaron el radio de Stokes-Einstein del PEG con su peso molecular según la Ec. 51, en la cual todas las variables vienen expresadas en unidades del sistema internacional.

$$
a_{p}=\left(0.262 \cdot(P M)^{0.5}-0.3\right) \cdot 10^{-10}
$$

La ecuación es válida para PEG en un intervalo de pesos moleculares de 200-40000 Da. Dicha expresión se ha utilizado en numerosas ocasiones (Puhlfür $\beta$ et al., 2000; Möckel et al., 1999).

\subsubsection{Coeficiente de difusión del PEG en función de su peso molecular}

La difusividad del polietilenglicol a $25^{\circ} \mathrm{C}$ se correlaciona con el peso molecular según la Ec. 52 (Pradanos et al., 1995; Cheryan, 1998).

$$
D=9.82 \cdot 10^{-9} \cdot(P M)^{-0.52}
$$

Existen otras ecuaciones que relacionan la difusividad del PEG con su peso molecular (Battacharjee y Datta, 1996; Das Gupta y Bhattacharya, 1990; Sherwood et al., 1975), pero son más inexactas.

\subsubsection{Presión osmótica de una disolución de PEG en agua}

Para calcular la presión osmótica se recomienda en la bibliografía utilizar la ecuación de Flory (Ec. 53) (Bhattacharje y Bhattacharya, 1992b; Ganguly y Bhattacharya 1994; De y Bhattacharya, 1996; Ghose et al., 1999; Ghose et al., 2000; Poddar et al., 1999; etc.). 


$$
\pi=\frac{-R_{G} \cdot T}{V_{1}} \cdot\left[\ln \gamma_{1}+\left(1-\frac{1}{x}\right) \gamma_{2}+x_{1} \cdot \gamma_{2}^{2}\right]
$$

Ec. 53

donde el parámetro x se define en la Ec. 54.

$$
x=\frac{v_{p} \cdot M_{p}}{v_{1} \cdot M_{1}}
$$

y los parámetros $\gamma_{2}$ y $\gamma_{1}$ se calculan por medio de las Ecs. 55 y 56 respectivamente.

$$
\begin{gathered}
\gamma_{2}=\frac{C}{\rho_{P E G}} \\
\gamma_{1}=1-\gamma_{2}
\end{gathered}
$$

El parámetro $x_{1}$ depende del tipo de interacción polímero-disolvente y es de 0.45 para la mezcla PEG-agua.

\subsubsection{Presión transmembranal}

La presión transmembranal se define como la diferencia de presión a través de la membrana. Para el cálculo de la misma se utilizó la siguiente ecuación (Cheryan, 1998):

$$
\Delta P=\frac{P_{e}+P_{s}}{2}-P_{p}
$$




\subsubsection{Equivalencia entre el caudal de alimentación y la velocidad tangencial dentro del módulo de mem brana}

La variable relacionada con la velocidad tangencial que se mide en los ensayos en la planta piloto de ultrafiltración es el caudal de rechazo. Dado que el caudal de permeado es despreciable frente al caudal de alimentación, se puede considerar que el caudal de rechazo es igual al caudal dealimentación.

Considerando esta suposición, se calculó la velocidad tangencial a partir del caudal de alimentación teniendo en cuenta la sección de paso que ofrece la membrana a dicho caudal. La relación entre caudal y velocidad tangencial se muestra en la Figura 15.

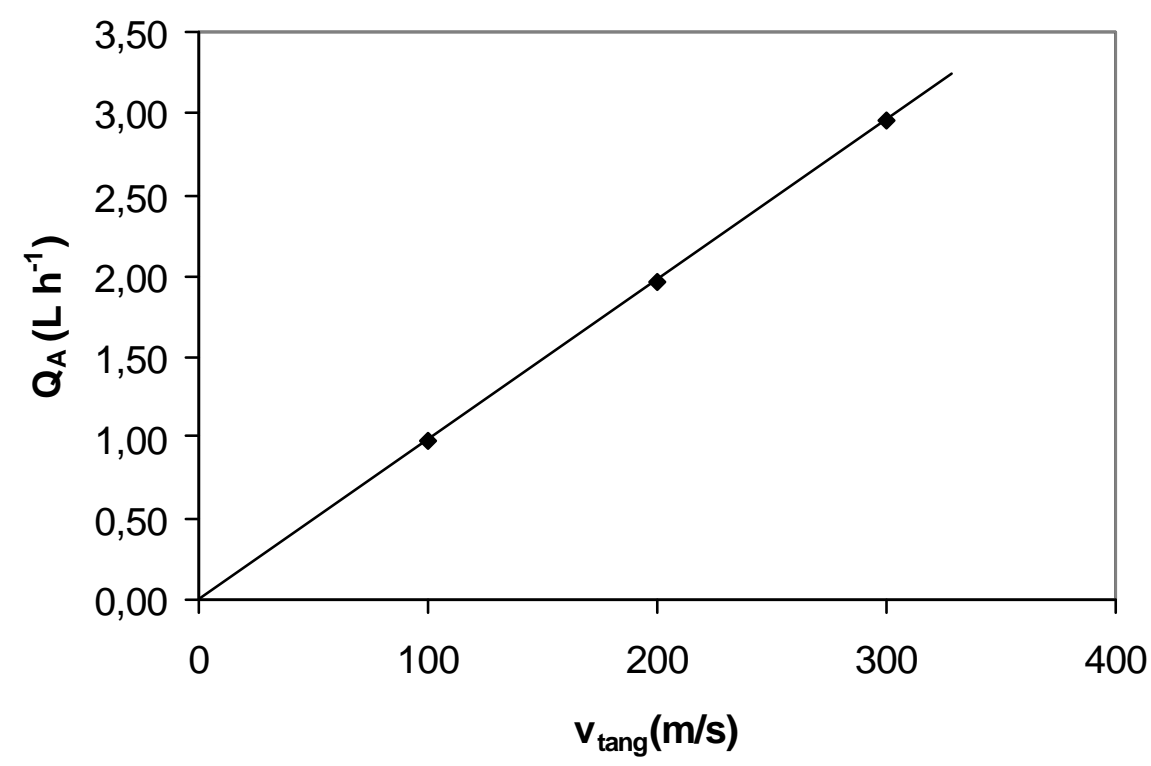

Figura 15. Relación entre el caudal de alimentación y la velocidad tangencial

Calculada de esta forma, la velocidad tangencial para un caudal de $100 \mathrm{~L} / \mathrm{h}$ es de $0.98 \mathrm{~m} / \mathrm{s}$, para un caudal de $200 \mathrm{~L} / \mathrm{h}$ es $1.97 \mathrm{~m} / \mathrm{s}$ y para un caudal de $300 \mathrm{~L} / \mathrm{h}$ es $2.95 \mathrm{~m} / \mathrm{s}$. 


\subsection{ANÁlisis del COMPORTAMIENTO DE LAS MEMBRANAS EN LA ULTRAFILTRACIÓN DE MACROMOLÉCULAS}

\subsubsection{Influencia de la velocidad tangencial en la variación de la densidad de flujo de permeado con el tiempo para la membrana Carbosep M 2}

En la Figura 16 se muestra la influencia de la velocidad tangencial en la variación de la densidad de flujo de permeado con el ti empo para una presión transmembranal de 0.1 MPa. Para esta presión no se observa prácticamente descenso de la densidad de flujo de permeado con el tiempo para ninguna velocidad tangencial ensayada. Tampoco se observa variación apreciable en la densidad de flujo de permeado al inicio del experimento. Este resultado está deacuerdo con el trabajo de Howell (1995), que observóla existencia de una presión transmembranal por debajo de la cual los procesos de ensuciamiento no se manifiestan. A la vista de los resultados experimentales, la presión transmembranal por debajo de la cual los procesos de ensuciamiento no se manifiestan es muy baja, cercana a $0.1 \mathrm{MPa}$.

Sin embargo, la densidad de flujo de permeado para una PTM de $0.1 \mathrm{MPa}$ varía con la velocidad tangencial y únicamente coincide con la densidad de flujo de permeado al agua pura para la velocidad tangencial de $3 \mathrm{~m} / \mathrm{s}$ (Figura 20). Puede considerarse entonces que para esta PTM de 0.1 MPa y las otras velocidades tangenciales (1 y 2 $\mathrm{m} / \mathrm{s}$ ) el fenómeno de polarización por concentración es el responsable de que la densidad de flujo de permeado sea inferior a la del agua pura. Como ya se ha comentado anteriormente dicho fenómeno no se considera ensuciamiento propiamentedicho.

Tal y como era de esperar, un incremento en la velocidad tangencial resulta en una densidad de flujo de permeado estacionaria más elevada. Esto se debe a que al aumentar la velocidad tangencial las moléculas de soluto son más fácilmente arrastradas por el flujo 
convectivo hacia la salida del módulo de membranas, lo cual hace disminuir su concentración sobre la superficie de la membrana y la probabilidad de que se depositen sobrela misma y la ensucien.

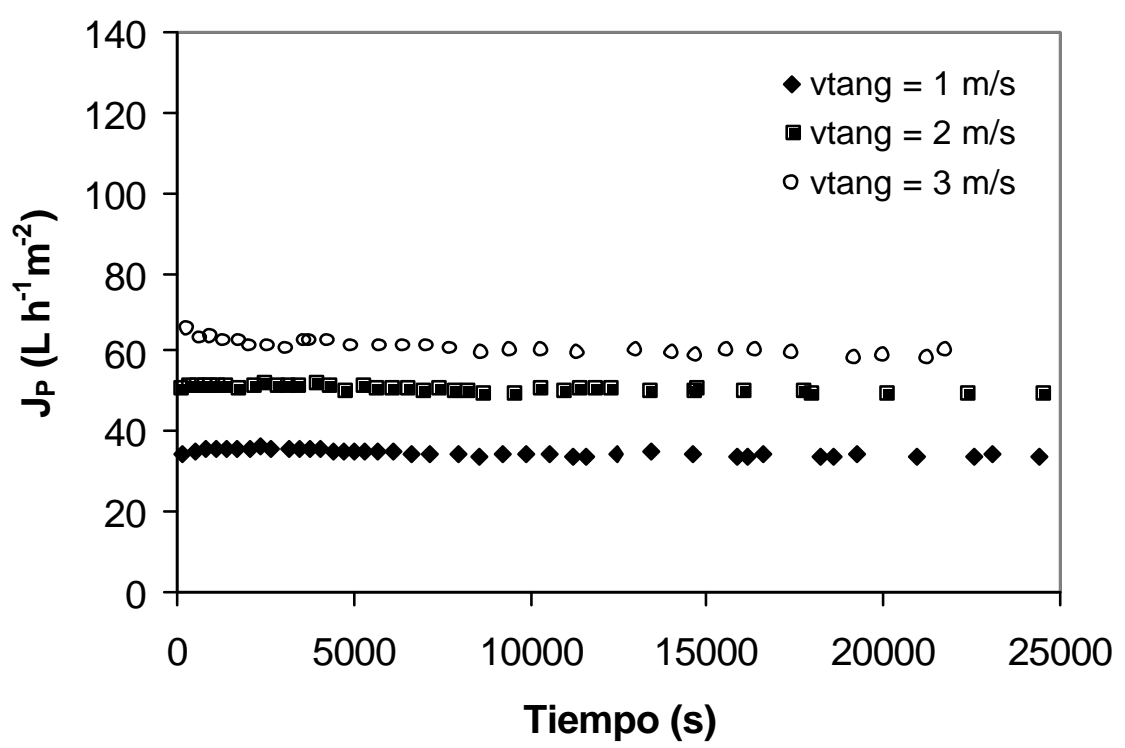

Figura 16. Influencia de la velocidad tangencial en la variación de la densidad de flujo de permeado con el tiempo para una presión transmembranal de 0.1 M Pa para la membrana Carbosep M2.

En la Figura 17 se muestra la influencia de la velocidad tangencial en la variación de la densidad de flujo de permeado con el tiempo para una presión transmembranal de 0.2 MPa. Para esta presión, se observa un ligero descenso de la densidad de flujo de permeado con el tiempo para todas las velocidades tangencial es ensayadas. Esto se debe a que para dicha presión transmembranal la fuerza que impulsa las moléculas hacia la membrana es mayor que para la PTM de $0.1 \mathrm{MPa}$, con lo cual la membrana se ensucia más.

Por otra parte, existe una variación apreciable en la densidad de flujo de permeado al inicio del ensayo para la velocidad tangencial más baja ensayada $(1 \mathrm{~m} / \mathrm{s})$. Para esta velocidad tangencial el ensuciamiento es mayor que para el resto de velocidades tangenciales, ya que el arrastre de moléculas de soluto hacia la 
salida del módulo de membrana es menor. Al inicio del ensayo la membrana pasa de estar completamente limpia a recibir la disolución alimento cargada de moléculas que causan ensuciamiento, produciendo un descenso acusado de la densidad de flujo de permeado.

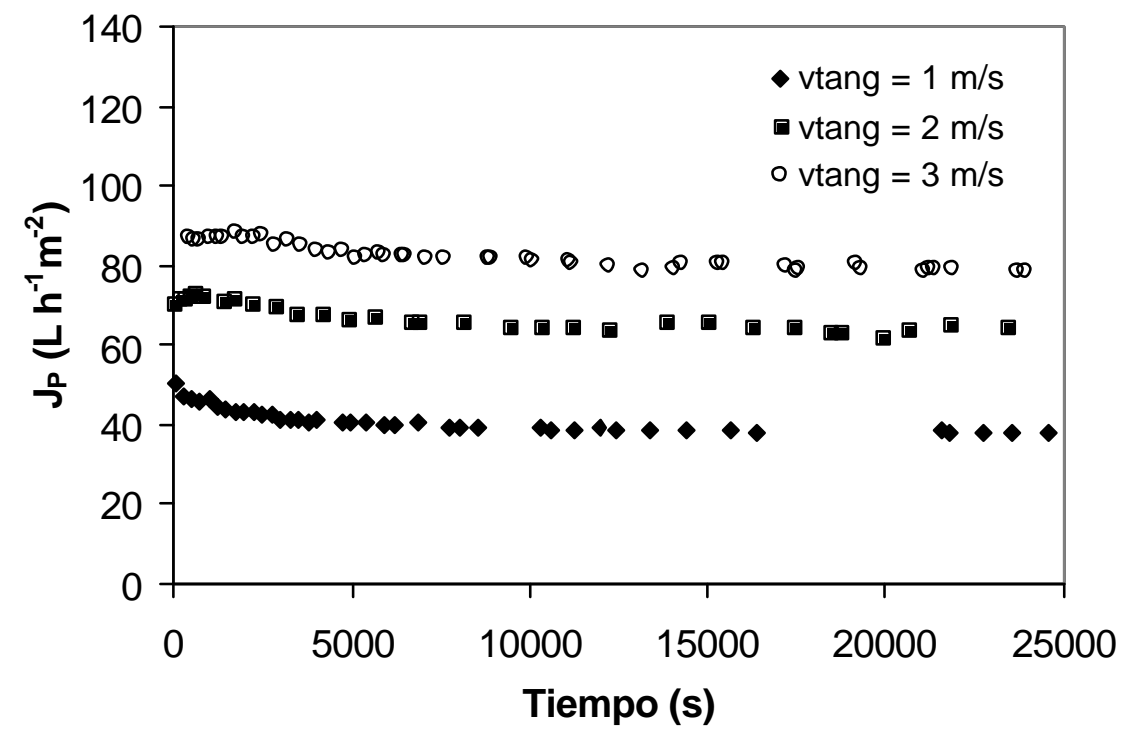

Figura 17. Influencia de la velocidad tangencial en la variación de la densidad de flujo de permeado con el tiempo para una presión transmembranal de 0.2 M Pa para la membrana Carbosep M2

Al igual que en la Figura 16, también en este caso se puede observar como un incremento en la velocidad tangencial resulta en un incremento de la densidad de flujo de permeado estacionaria. El efecto de aumentar en una unidad la velocidad tangencial en el incremento de la densidad de flujo de permeado estacionaria, es mayor para las velocidades tangenciales más bajas. Así en la Figura 17 se puede observar que el incremento de la densidad de flujo de permeado estacionaria es mayor al pasar de una velocidad tangencial de $1 \mathrm{~m} / \mathrm{s}$ a una velocidad tangencial de $2 \mathrm{~m} / \mathrm{s}$, que al pasar de una velocidad tangencial de $2 \mathrm{~m} / \mathrm{s}$ a una velocidad tangencial de $3 \mathrm{~m} / \mathrm{s}$. Esto puede ser debido a que un incremento de una unidad en la velocidad tangencial cuando se emplean 
velocidades tangenciales bajas puede suponer pasar de un proceso en el que se forma capa gel a otro en el que se evita (Cheryan, 1998). Sin embargo, para velocidades tangenciales más elevadas en las que la formación de capa gel no suele ocurrir, dicho incremento sólo supone una reducción de la concentración de soluto en las cercanías dela superficie de la membrana.

En la Figura 18 se muestra la influencia de la velocidad tangencial en la variación de la densidad de flujo de permeado con el tiempo para una presión transmembranal de 0.3 MPa. Para esta presión, e descenso de la densidad de flujo de permeado con el tiempo ya es apreciable para todas las velocidades tangenciales ensayadas. Al comienzo del experimento la variación de la densidad de flujo de permeado es más acusada, sobre todo para la velocidad tangencial más baja ensayada ( $1 \mathrm{~m} / \mathrm{s})$.

Tal y como era de esperar, un incremento en la velocidad tangencial resulta en una densidad de flujo de permeado estacionaria más elevada. Al igual que para la PTMs de 0.1 y $0.2 \mathrm{MPa}$, el efecto de incrementar en una unidad la velocidad tangencial en el aumento de la densidad de flujo de permeado estacionaria es mayor para las velocidades tangenciales más bajas. De este modo en la Figura 18 se puede observar, al igual que en la Figura 16 y en la Figura 17, queel incremento de la densidad de flujo de permeado estacionaria es mayor al pasar de una velocidad tangencial de $1 \mathrm{~m} / \mathrm{s}$ a una velocidad tangencial de $2 \mathrm{~m} / \mathrm{s}$, que al pasar de una velocidad tangencial de $2 \mathrm{~m} / \mathrm{s}$ a una velocidad tangencial de $3 \mathrm{~m} / \mathrm{s}$. 


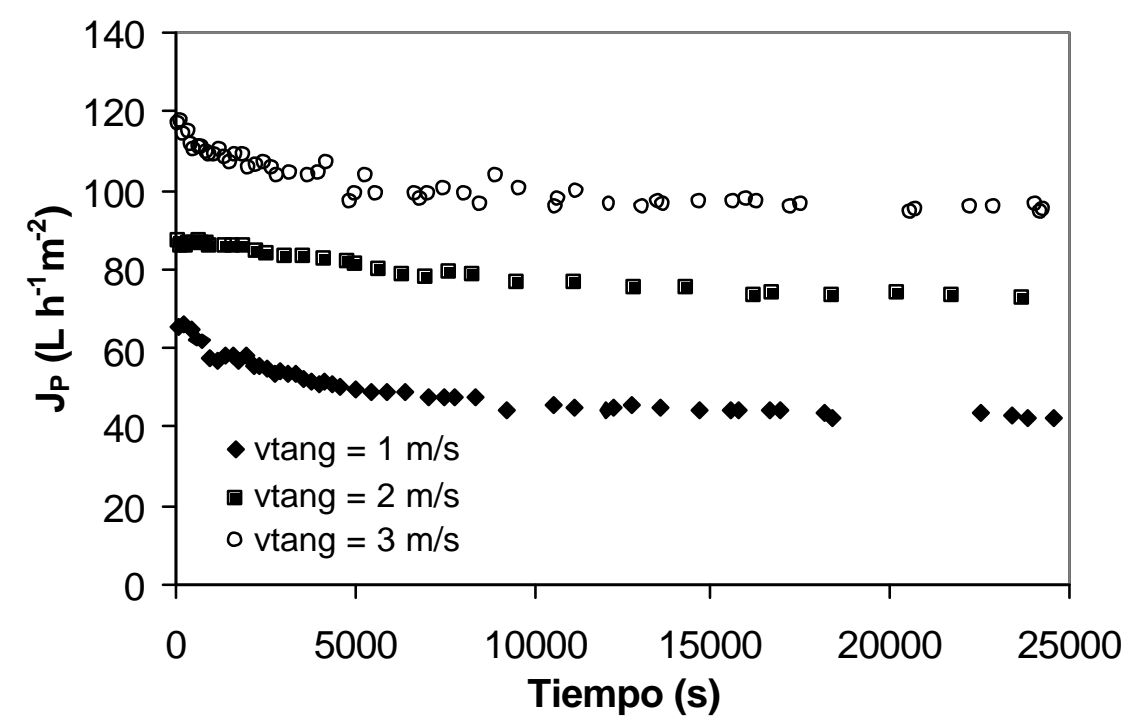

Figura 18. Influencia de la velocidad tangencial en la variación de la densidad de flujo de permeado con el tiempo para una presión transmembranal de 0.3 MPa para la membrana Carbosep M2

En la Figura 19 se muestra la influencia de la velocidad tangencial en la variación de la densidad de flujo de permeado con el tiempo para una presión transmembranal de 0.4 MPa. Para esta presión, el descenso de la densidad de flujo de permeado con el tiempo es notorio para todas las velocidades tangenciales ensayadas, siendo mayor para la velocidad tangencial de $1 \mathrm{~m} / \mathrm{s}$. Al comienzo del experimento la variación de la densidad de flujo de permeado es más acusada, sobre todo para la velocidad tangencial más baja ensayada $(1 \mathrm{~m} / \mathrm{s})$.

Al igual que para las demás PTM consideradas, un incremento en la velocidad tangencial resulta en una densidad de flujo de permeado más elevada. Para una PTM de 0.4 MPa, a diferencia que para el resto de PTMs, el incremento de la densidad de flujo depermeado estacionaria al aumentar en una unidad la velocidad tangencial es aproximadamente el mismo para todas las velocidades tangenciales ensayadas. Para esta PTM el proceso de ultrafiltración está 
controlado por la transferencia de materia para todas las velocidades tangenciales ensayadas, tal y como se observa en la Figura 20.

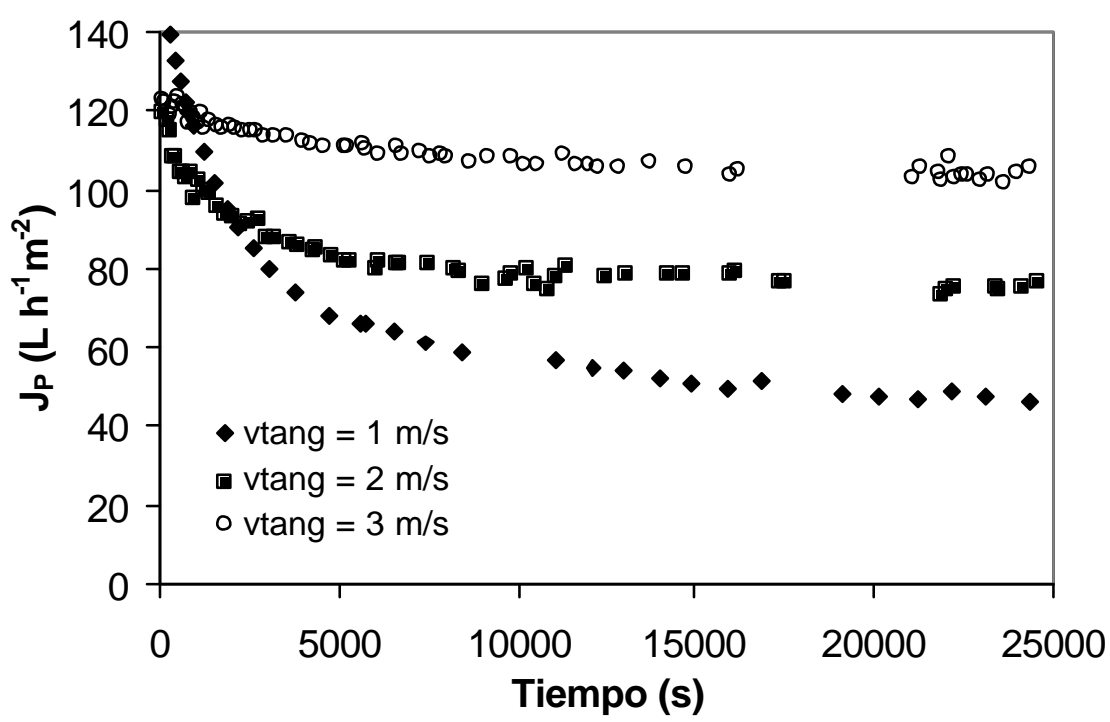

Figura 19. Influencia de la velocidad tangencial en la variación de la densidad de flujo de permeado con el tiempo para una presión transmembranal de $0.4 \mathrm{MPa}$ para la membrana Carbosep M2

Según se observa en la Figura 20, para la PTM más elevada detodos Ios ensayos, 0.4 MPa, y para cualquier velocidad tangencial, 1, 2 y 3 $\mathrm{m} / \mathrm{s}$, el proceso de ultrafiltración está controlado por la transferencia de materia. La fuerza impulsora de las moléculas de soluto y de las moléculas de disolvente hacia la membrana es mayor a elevadas PTMs. Por lo tanto un aumento de la PTM origina una mayor acumulación de las moléculas sobre la superficie de la membrana.

Para la velocidad tangencial de $1 \mathrm{~m} / \mathrm{s}$ la densidad de flujo de permeado varía muy poco con la PTM, lo que indica que el proceso de ultrafiltración se halla en una zona de control por la transferencia de materia. 


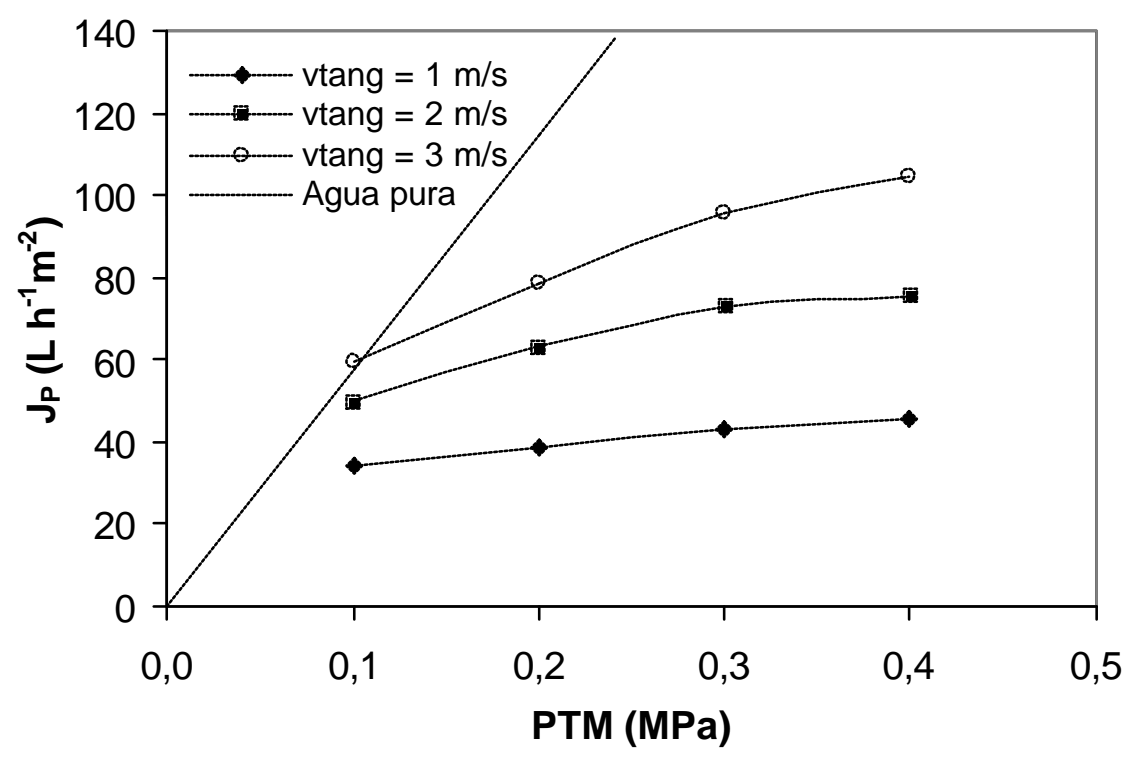

Figura 20. Influencia de la velocidad tangencial en la densidad de flujo de permeado estacionaria para la membrana Carbosep M2.

\subsubsection{Influencia de la velocidad tangencial en la variación de la densidad de flujo de permeado con el tiempo para la membrana Tami MSKT}

En el caso de la membrana Tami MSKT se observó que para PTMs reducidas (Figura 21) la velocidad tangencial no tiene influencia sobre la densidad de flujo de permeado. Por lo tanto, la presión de $0.2 \mathrm{MPa}$ es inferior a la presión transmembranal por debajo de la cual no se producen los fenómenos de ensuciamiento (Howell, 1995). Sin embargo, en la Figura 23 se observa que la densidad de flujo de permeado para una PTM de 0.2 MPa es diferente de la densidad de flujo de permeado al agua pura para esta misma presión. 


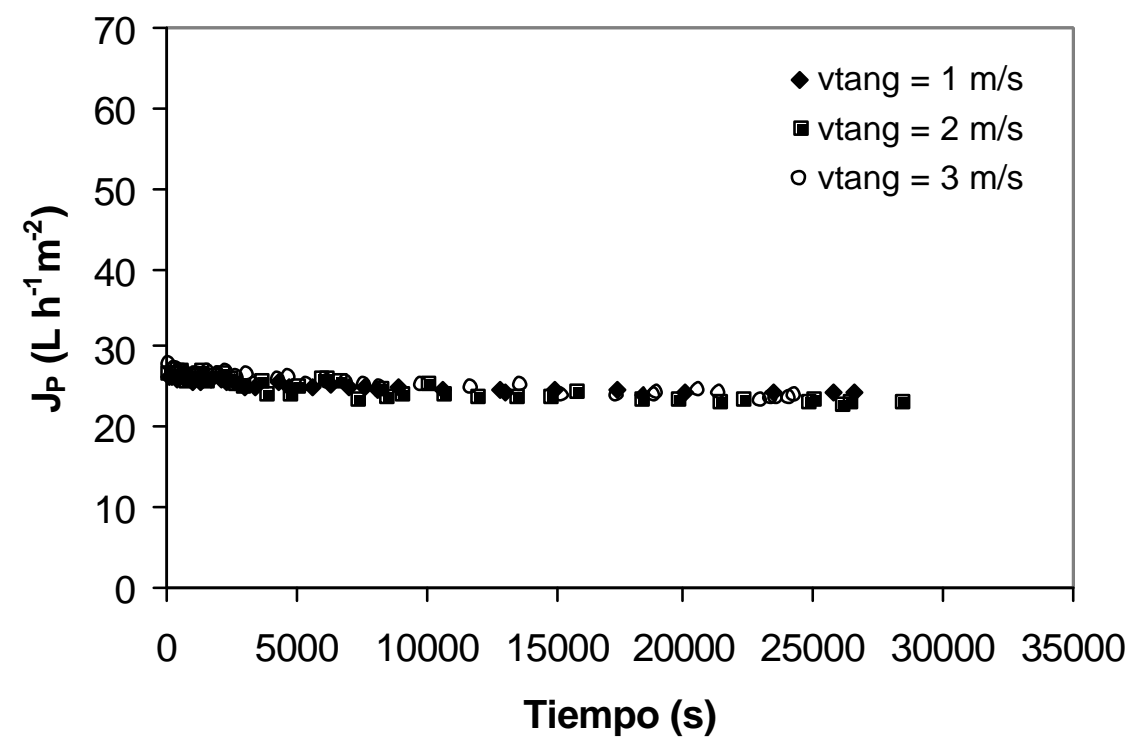

Figura 21. Influencia de la velocidad tangencial en la variación de la densidad de flujo de permeado con el tiempo para una presión transmembranal de $0.2 \mathrm{MPa}$ y una concentración de $5 \mathrm{~g} / \mathrm{L}$ para la membrana Tami MSTK

En la Figura 22 se muestran los resultados obtenidos para una PTM de $0.5 \mathrm{MPa}$. En este caso sí se observaron diferencias entre los valores de la densidad de flujo de permeado obtenidos para las diferentes velocidades tangenciales ensayadas. Al igual que para la membrana Carbosep M2, el incremento en la densidad de flujo de permeado al aumentar la velocidad tangencial de 1 a $2 \mathrm{~m} / \mathrm{s}$ fue superior al incremento observado al aumentar la velocidad tangencial de 2 a $3 \mathrm{~m} / \mathrm{s}$. Esto es debido a que cuando la velocidad tangencial es baja, un incremento en la misma puede suponer la transición entre la existencia de una capa gel consolidada y la no existencia dela misma. 


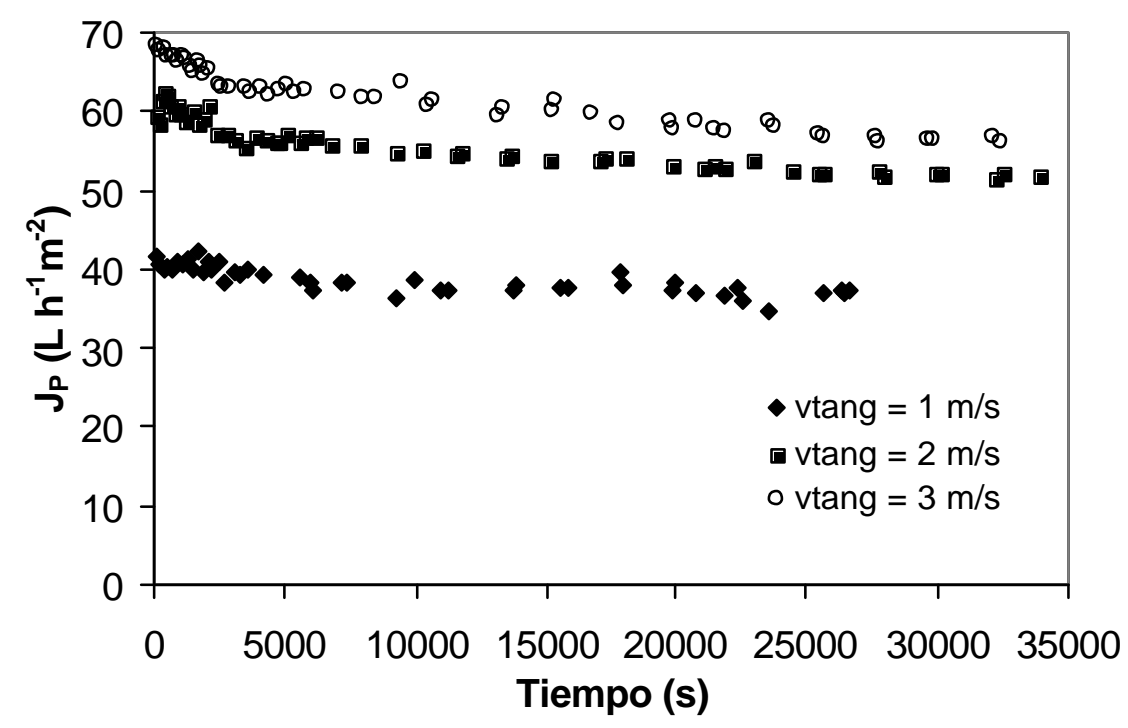

Figura 22. Influencia de la velocidad tangencial en la variación de la densidad de flujo de permeado con el tiempo para una presión transmembranal de $0.5 \mathrm{MPa}$ y una concentración de $5 \mathrm{~g} / \mathrm{L}$ para la membrana Tami MSTK

En la Figura 23 se observa que la densidad de flujo de permeado es la misma para la PTM de 0.2 MPa independientemente del valor de la velocidad tangencial. Para esta PTM y todas las velocidades tangenciales ensayadas el proceso de ultrafiltración está controlado por la PTM.

Cuando la velocidad tangencial es reducida, las moléculas discurren lentamente hacia la salida del módulo de membrana y se depositan sobre la misma a presiones inferiores que para velocidades tangenciales más elevadas. Para la velocidad tangencial de $1 \mathrm{~m} / \mathrm{s}$ y para las PTMs de 0.4 y $0.5 \mathrm{MPa}$ la transferencia de materia controla el proceso de ultrafiltración, obteniéndose el mismo valor de la densidad de flujo de permeado para ambos valores de la PTM, como puede verse en la Figura 23. 
La zona de transición entre el control por la PTM y el control del proceso por la transferencia de materia se produce a PTMs inferiores en el caso de velocidades tangenciales reducidas, como se observa en la Figura 23. Incluso a PTMs altas, las velocidades tangenciales elevadas evitan la acumulación de moléculas de soluto sobre la membrana.

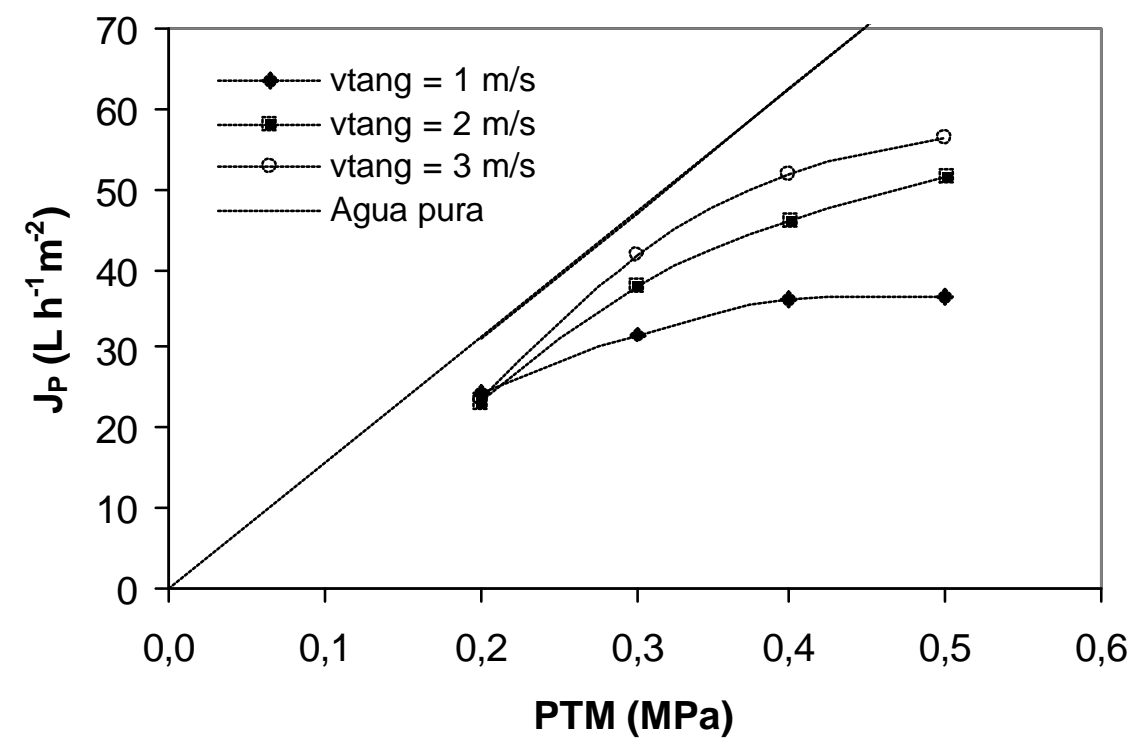

Figura 23. Influencia de la velocidad tangencial en la densidad de flujo de permeado estacionaria para una concentración de $5 \mathrm{~g} / \mathrm{L}$ para la membrana Tami MSTK

En las Figuras 24 a la 26 se muestran los resultados obtenidos cuando la concentración de la alimentación se aumentó a $15 \mathrm{~g} / \mathrm{L}$. Para la PTM de 0.2 MPa (Figura 24), se observó que la densidad de flujo de permeado variaba con la velocidad tangencial, al contrario de lo que ocurría para la concentración de 5 g/ L (Figura 21). En este caso, a aumentar la concentración de soluto en la alimentación se incrementa la probabilidad de que la membrana se ensucie debido a la existencia de más moléculas de soluto en la alimentación capaces de producir ensuciamiento. Por otra parte aumenta la concentración de las moléculas de soluto en las inmediaciones de la membrana, lo que hace que la densidad de flujo de permeado disminuya y que el 
efecto de arrastre de las moléculas de soluto al aumentar la velocidad tangencial sea más acusado.

En este caso, la presión de $0.2 \mathrm{MPa}$ es superior a la presión transmembranal por debajo de la cual no se produce ensuciamiento dela membrana.

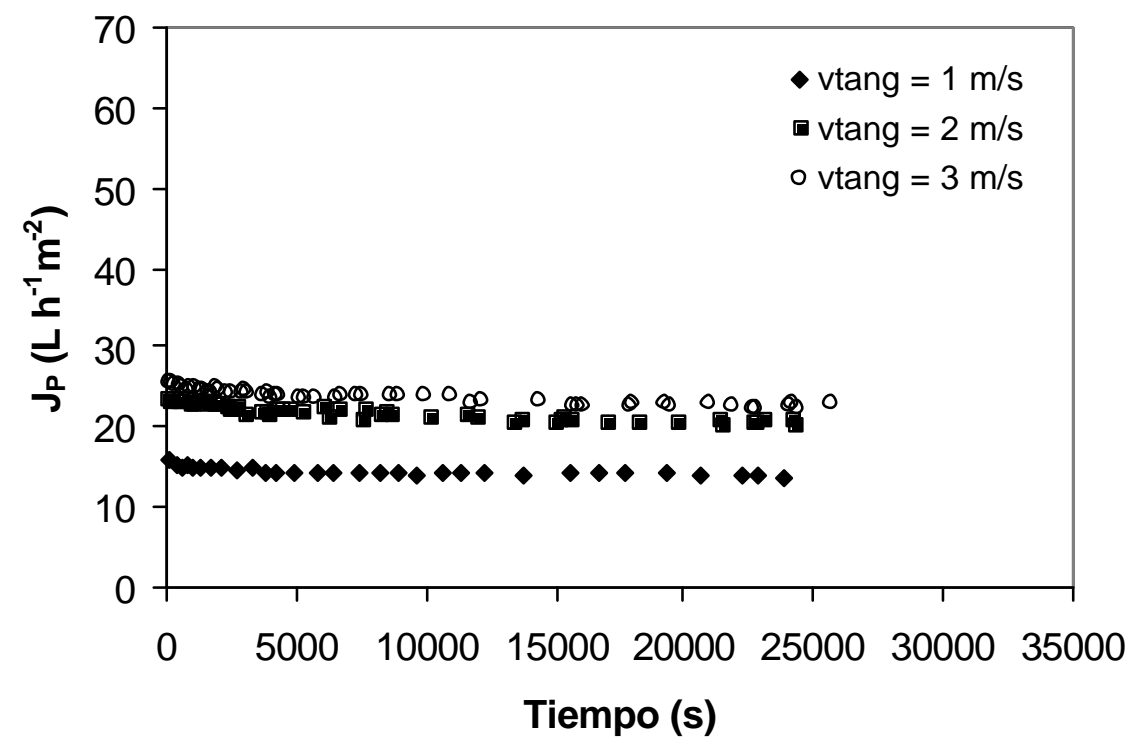

Figura 24. Influencia de la velocidad tangencial en la variación de la densidad de flujo de permeado con el tiempo para una presión transmembranal de $0.2 \mathrm{MPa}$ y una concentración de $15 \mathrm{~g} / \mathrm{L}$ para la membrana Tami MSTK

El mismo comportamiento que tenía lugar para una concentración 5 g/ L y una PTM de $0.5 \mathrm{MPa}$ (Figura 22) se observa también para el caso de una concentración de $15 \mathrm{~g} / \mathrm{L}$ y una PTM de $0.2 \mathrm{MPa}$ (Figura 24) y para el caso de una concentración de $15 \mathrm{~g} / \mathrm{L}$ y una PTM de 0.5 MPa (Figura 25). La variación de la densidad de flujo de permeado con la velocidad tangencial disminuye al aumentar la velocidad tangencial.

Al aumentar la PTM el efecto de la velocidad tangencial sobre la densidad de flujo de permeado es más acusado, como se puede 
observar en la Figura 25, pues al aumentar la PTM también lo hace el aporte de moléculas de soluto hacia la superficie de la membrana.

En todas las condiciones experimentales ensayadas con las membranas Tami MSKT se observó que el descenso de la densidad de flujo de permeado con el tiempo era casi inapreciable, incluso para las condiciones más desfavorables desde el punto de vista del ensuciamiento de la membrana: elevada concentración y PTM (Figura 25). El tamaño de la molécula de soluto es muy superior al tamaño de poro de la membrana, por lo que es difícil que las moléculas de soluto penetren en la membrana y causen un bloqueo delos poros de la misma.

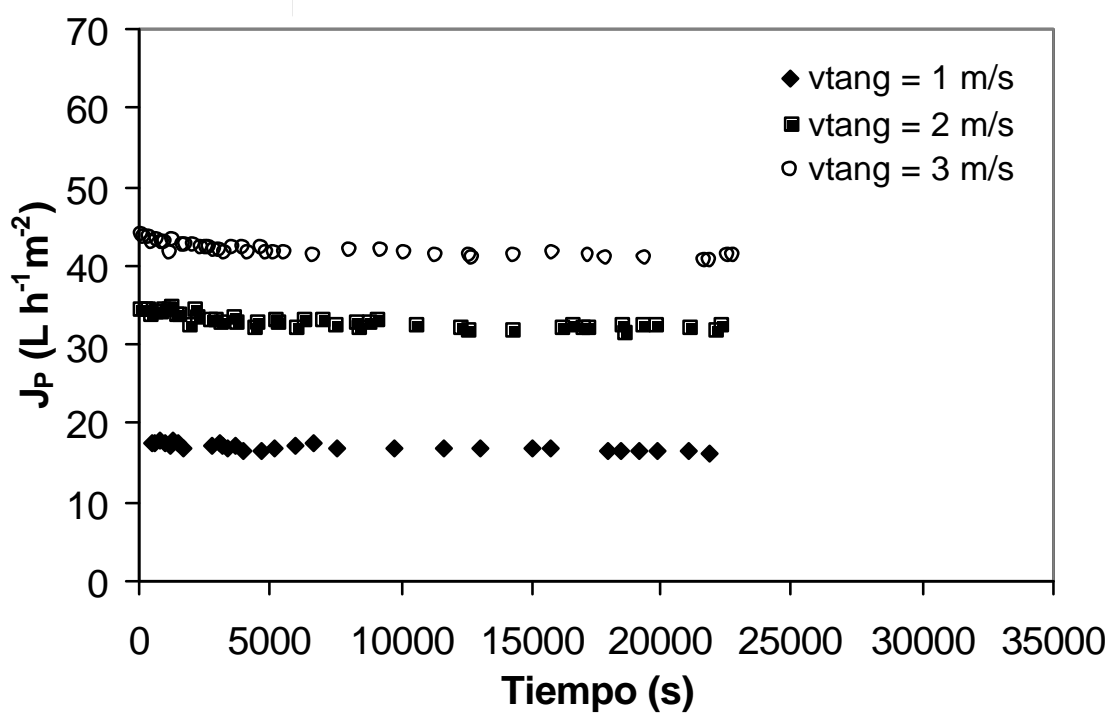

Figura 25. Influencia de la velocidad tangencial en la variación de la densidad de flujo de permeado con el tiempo para una presión transmembranal de $0.5 \mathrm{MPa}$ y una concentración de $15 \mathrm{~g} / \mathrm{L}$ para la membrana Tami MSTK

En la Figura 26 se observa que la densidad de flujo de permeado varía poco con la PTM en comparación con los resultados obtenidos a concentraciones inferiores de soluto en el alimento (Figura 23). Al aumentar la concentración existen más moléculas de soluto capaces 
de depositarse sobre la membrana. A sí, para la concentración de 15 $\mathrm{g} / \mathrm{L}$ y una velocidad tangencial de $1 \mathrm{~m} / \mathrm{s}$ se puede considerar que el proceso está controlado por la transferencia de materia para todas las PTMs consideradas. Para el resto de velocidades tangenciales y todas las PTMs ensayadas el proceso de ultrafiltración se encuentra en la zona de transición entre la zona de control por la PTM y la zona de control por transferencia de materia.

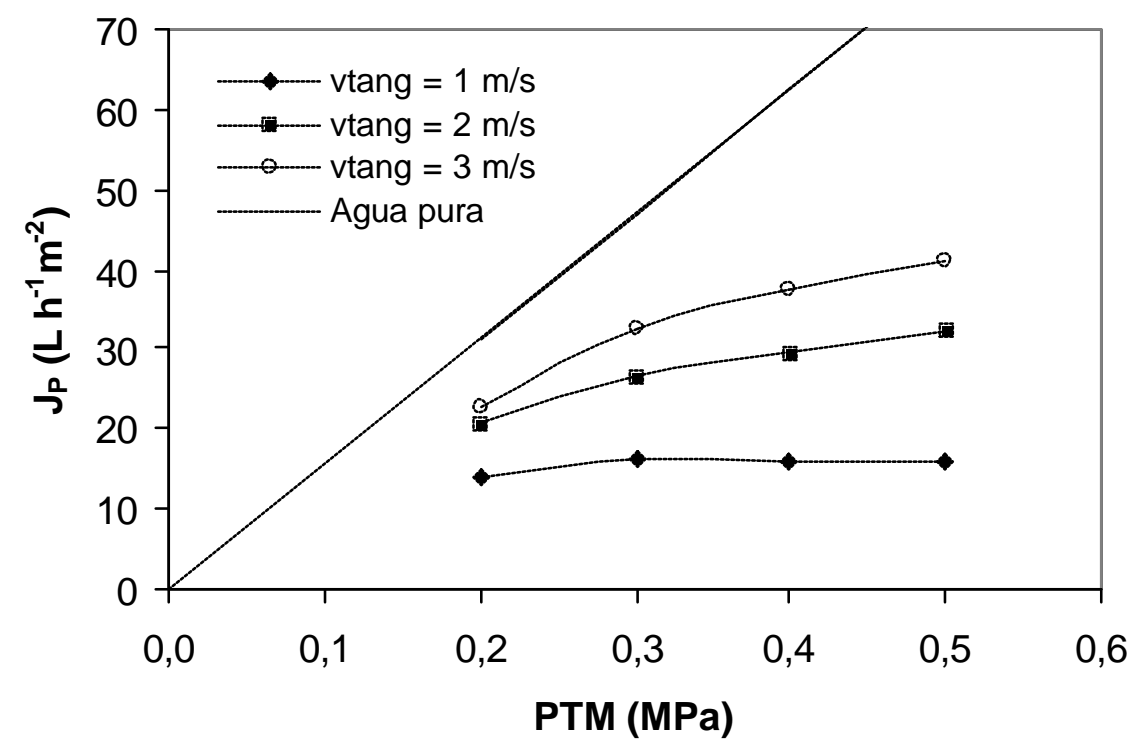

Figura 26. Influencia de la velocidad tangencial en la densidad de flujo de permeado estacionaria para una concentración de $15 \mathrm{~g} / \mathrm{L}$ para la membrana Tami MSTK

\subsubsection{Influencia de la PTM en la variación de la densidad de flujo de permeado con el tiempo para la membrana Carbosep M 2}

En la Figura 27 se muestra la influencia de la presión transmembranal en la variación de la densidad de flujo de permeado con el tiempo para una velocidad tangencial de $1 \mathrm{~m} / \mathrm{s}$. Para esta velocidad tangencial, el descenso de la densidad de flujo de permeado con el tiempo es notorio para las presiones 
transmembranales más elevadas ensayadas ( 0.3 y $0.4 \mathrm{MPa}$ ), siendo muy reducido para las presiones transmembranales más bajas ensayadas ( 0.1 y $0.2 \mathrm{MPa}$ ). Al comienzo del experimento la variación de la densidad de flujo de permeado con el tiempo es más acusada, sobre todo para la presión transmembranal más elevada ensayada (0.4 MPa).

El acusado descenso inicial de la densidad de flujo de permeado con el tiempo puede deberse a un fenómeno de bloqueo de poros. El bloqueo de poros se produce cuando las moléculas de soluto se orientan de forma que puedan penetrar en ellos. Después del bloqueo instantáneo de los poros comienza a formarse la capa gel (Song, 1998a).

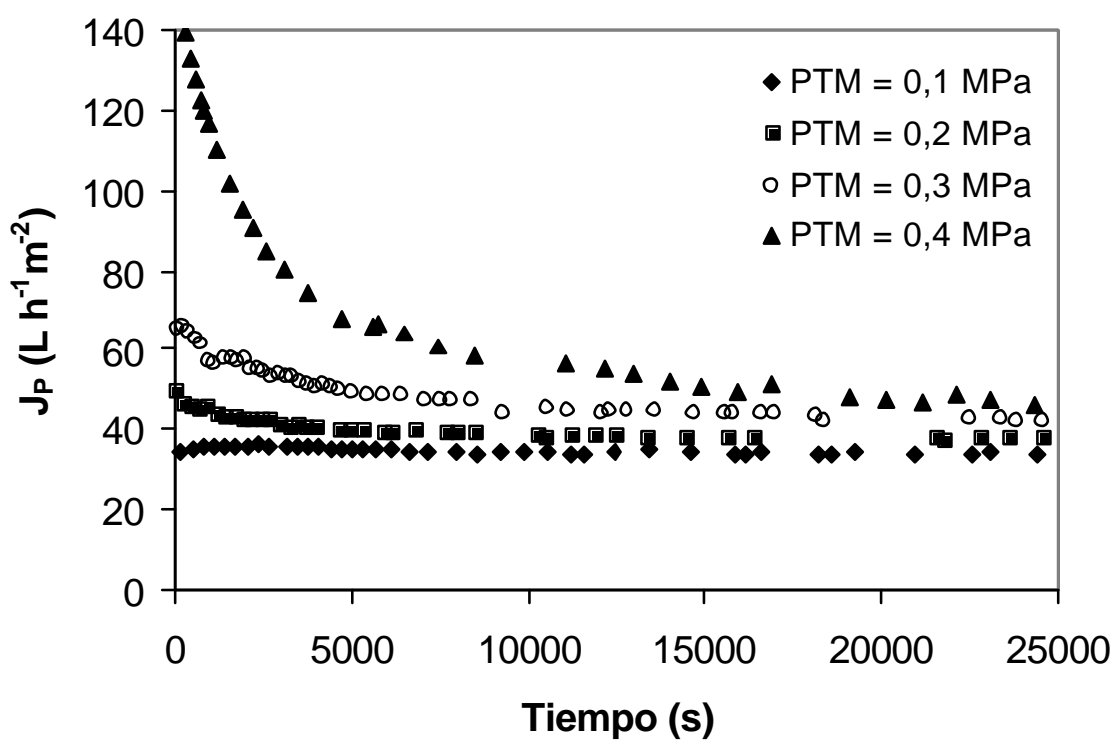

Figura 27. Influencia de la presión transmembranal en la variación de la densidad de flujo de permeado con el tiempo para una velocidad tangencial de $1 \mathrm{~m} / \mathrm{s}$ para la membrana Carbosep M2

Tal y como era de esperar, un incremento en la PTM (la fuerza impulsora del proceso) supone una densidad de flujo de permeado estacionaria más elevada. El incremento de la densidad de flujo de 
permeado estacionaria al aumentar en una unidad la PTM es similar para todas las presiones transmembranales ensayadas. Dicho incremento es muy pequeño, lo cual indica que, para una velocidad tangencial de $1 \mathrm{~m} / \mathrm{s}$, el proceso se halla en una zona muy próxima a la zona de control por transferencia de materia. Esto puede deberse a que para velocidades tangenciales bajas, del orden de $1 \mathrm{~m} / \mathrm{s}$, la capa gel comienza a formarse a PTMs inferiores a las que se formaría para velocidades tangenciales más elevadas.

En la Figura 28 se muestra la influencia de la presión transmembranal en la variación de la densidad de flujo de permeado con el tiempo para una velocidad tangencial de $2 \mathrm{~m} / \mathrm{s}$. Para esta velocidad tangencial, el descenso de la densidad de flujo de permeado con el tiempo es muy acusado para la presión transmembranal más elevada ensayada (0.4 MPa), siendo casi nulo para las presiones transmembranales más bajas ensayadas (0.1 y 0.2 $\mathrm{MPa})$.

Un incremento en la PTM supone una densidad de flujo de permeado estacionaria más elevada, excepto cuando se pasa de una PTM de 0.3 MPa a una PTM de 0.4 MPa; para ambas presiones transmembranales la densidad de flujo de permeado estacionaria es la misma, por lo que el proceso de ultrafiltración ha pasado de estar controlado por la presión a estar controlado por la transferencia de materia. El efecto de incrementar en una unidad la PTM, sobre el aumento de la densidad de flujo de permeado estacionaria, es mayor para las presiones transmembranales más bajas ensayadas (Figura 28), a diferencia de lo que ocurría para la velocidad tangencial de $1 \mathrm{~m} / \mathrm{s}$. 


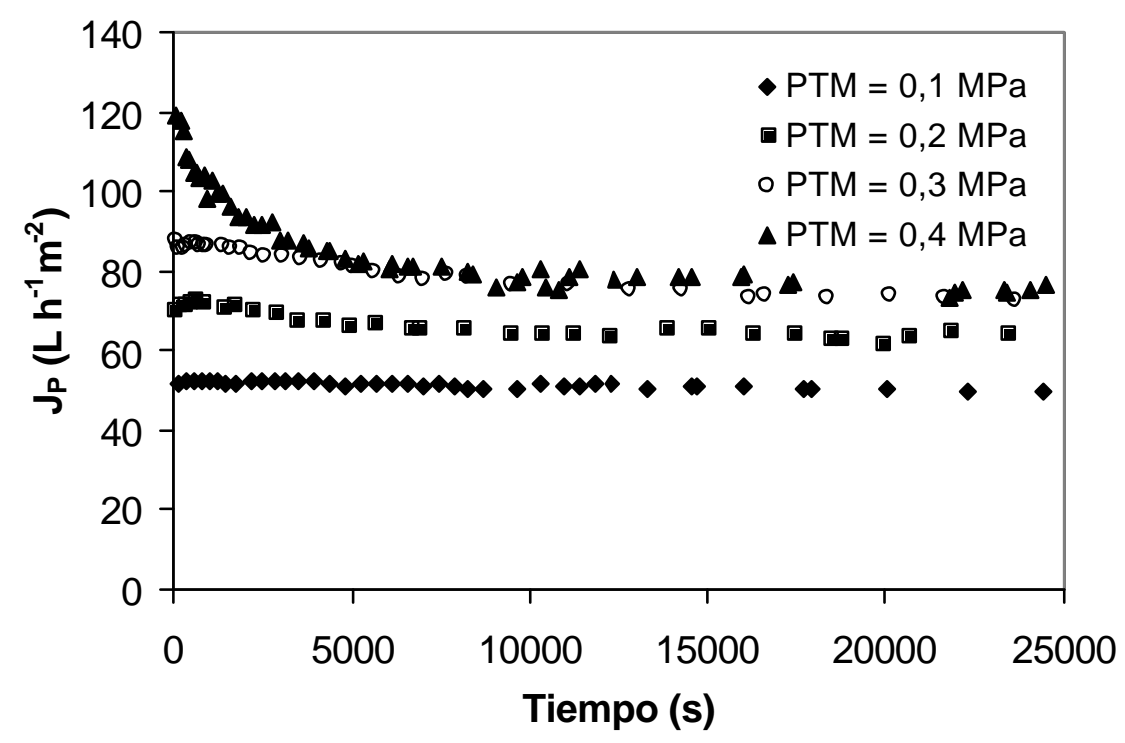

Figura 28. Influencia de la presión transmembranal en la variación de la densidad de flujo de permeado con el tiempo para una velocidad tangencial de $2 \mathrm{~m} / \mathrm{s}$ para la membrana Carbosep M2

En la Figura 29 se muestra la influencia de la presión transmembranal en la variación de la densidad de flujo de permeado con el tiempo para una velocidad tangencial de $3 \mathrm{~m} / \mathrm{s}$. Para esta velocidad tangencial, se observa un ligero descenso de la densidad de flujo de permeado con el tiempo para las presiones transmembranales más elevadas ensayadas ( 0.3 y $0.4 \mathrm{MPa}$ ), siendo prácticamente nulo para las presiones transmembranales más bajas ensayadas (0.1 y $0.2 \mathrm{MPa}$ ). El descenso de la densidad de flujo de permeado con el tiempo es menos notorio que para las velocidades tangenciales inferiores consideradas ( 1 y $2 \mathrm{~m} / \mathrm{s}$ ). Esto puede deberse a que para la velocidad tangencial de $3 \mathrm{~m} / \mathrm{s}$, se produce menos ensuciamiento debido al arrastre de las moléculas de soluto.

Se puede observar en la Figura 29 que un incremento en la PTM supone una densidad de flujo de permeado estacionaria más elevada, como cabría esperar. El efecto de incrementar la PTM sobre 
la densidad de flujo de permeado estacionaria es mayor para las presiones transmembranales más bajas ensayadas. Para estas presiones más bajas el proceso de ultrafiltración está controlado por la presión, mientras que para las presiones más elevadas el proceso pasa a estar controlado por la transferencia de materia.

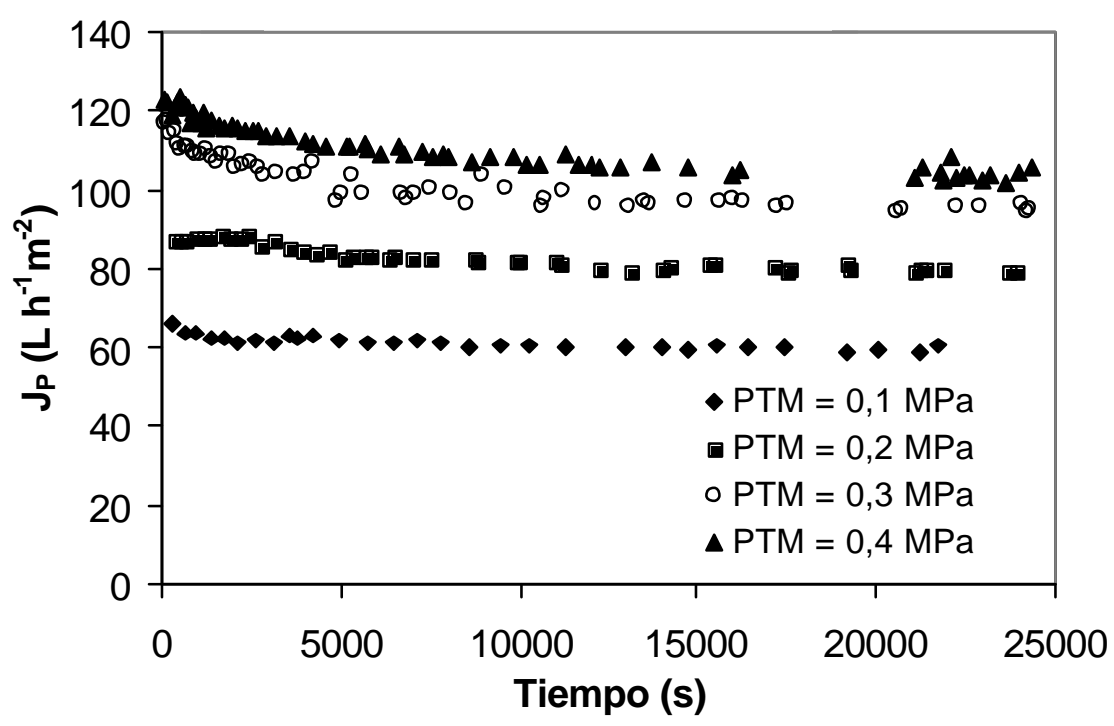

Figura 29. Influencia de la presión transmembranal en la variación de la densidad de flujo de permeado con el tiempo para una velocidad tangencial de $3 \mathrm{~m} / \mathrm{s}$ para la membrana Carbosep M2

Los resultados experimentales obtenidos concuerdan con lo que cabría esperar en todos los casos: la densidad de flujo de permeado disminuye con el tiempo debido al ensuciamiento y aumenta con la velocidad tangencial y la presión transmembranal.

En todos los casos se observó que 7 horas eran suficientes para alcanzar una densidad de flujo de permeado quasi-estacionaria. 


\subsubsection{Influencia de la PTM en la variación de la densidad de flujo de permeado con el tiempo para la membrana Tami MSKT}

Pese a que para todas las condiciones experimentales ensayadas con las membranas Tami MSKT la densidad de flujo de permeado no desciende apreciablemente con el tiempo, los valores de la densidad de flujo de permeado que se obtienen con las disoluciones acuosas de PEG difieren de la densidad de flujo de permeado obtenida con agua pura para la misma PTM y además varían con la velocidad tangencial (Figuras 30 y 31). Esta diferencia en la densidad de flujo de permeado indica que se producen fenómenos de ensuciamiento y de polarización por concentración. La escasa variación de la densidad de flujo de permeado con el tiempo apunta a que el ensuciamiento debe producirse de forma instantánea.

En la Figura 30 se muestran los resultados experimentales obtenidos para una velocidad tangencial de $1 \mathrm{~m} / \mathrm{s}$ y una concentración de 5 $\mathrm{g} / \mathrm{L}$. Se observa que para las PTM s de 0.4 y 0.5 MPa se obtienen los mismos valores de la densidad de flujo de permeado, por lo que para estas condiciones experimentales el proceso de ultrafiltración está controlado por la transferencia de materia.

En la Figura 31 se observa que para elevadas velocidades tangenciales $(3 \mathrm{~m} / \mathrm{s})$ la influencia de la PTM en la densidad de flujo de permeado es mayor, puesto que el mayor arrastre de moléculas de soluto hacia la salida del mód ulo hace que la concentración sobre la superficie de la membrana sea inferior. Por lo tanto, en este caso el proceso no está controlado por la transferencia de materia. 


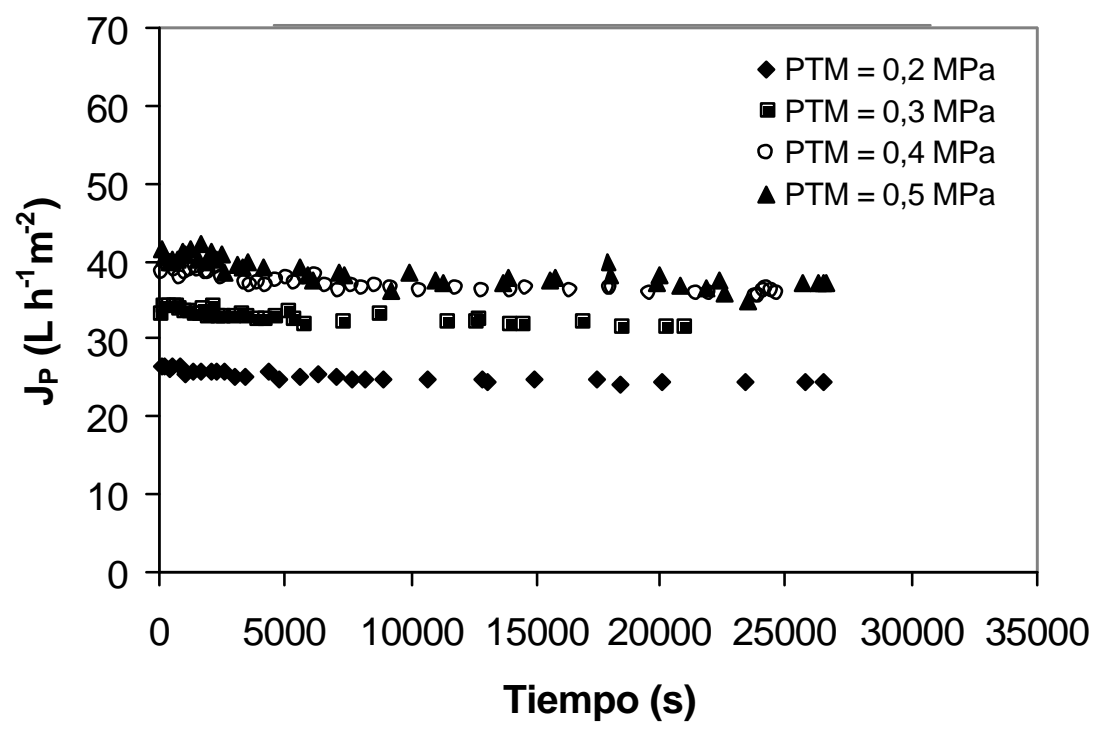

Figura 30. Influencia de la presión transmembranal en la variación de la densidad de flujo de permeado con el tiempo para una velocidad tangencial de $1 \mathrm{~m} / \mathrm{s}$ y una concentración de $5 \mathrm{~g} / \mathrm{L}$ para la membrana Tami MSTK

Para la velocidad tangencial de $3 \mathrm{~m} / \mathrm{s}$ se observa un descenso moderado de la densidad de flujo de permeado con el tiempo en los momentos iniciales de la ultrafiltración. Esto no se observa para la velocidad tangencial de $1 \mathrm{~m} / \mathrm{s}$.

Para bajas velocidades tangenciales y elevadas concentraciones en el alimento (Figura 32), Ia PTM tiene una influencia inapreciable en la densidad de flujo de permeado debido a que el proceso de ultrafiltración se encuentra claramente controlado por la transferencia de materia. La probabilidad de que las moléculas de soluto se depositen sobre la membrana es elevada pues la velocidad tangencial es baja y la concentración elevada. 


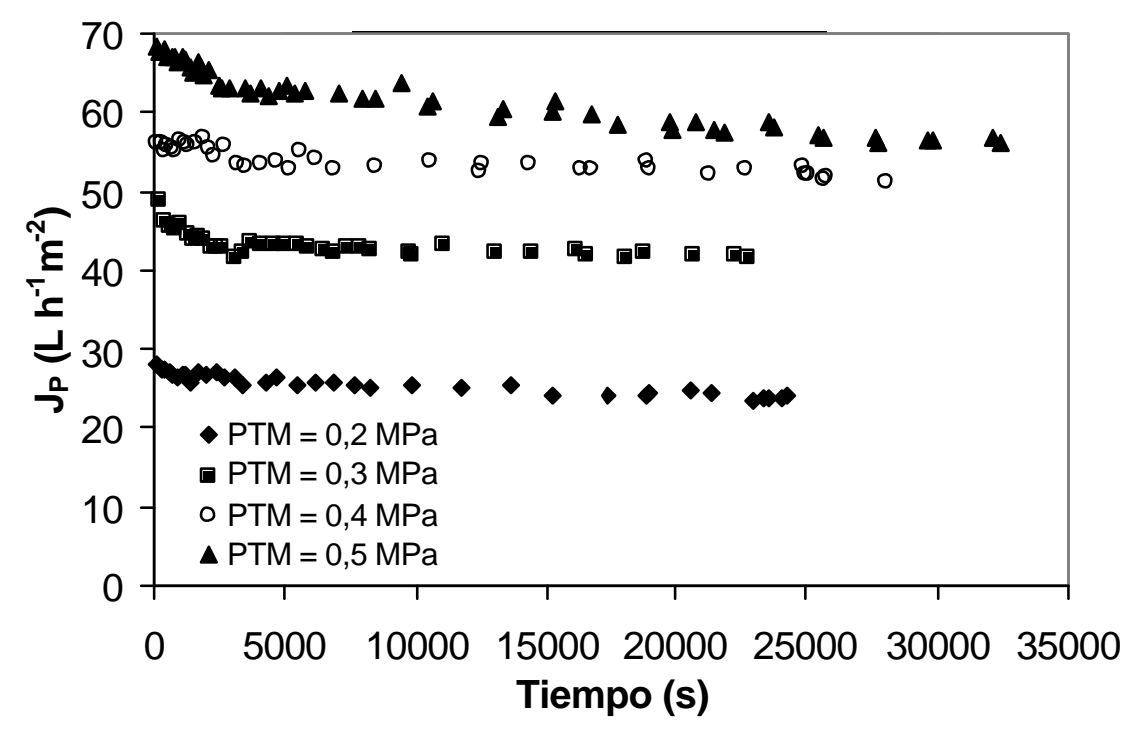

Figura 31. Influencia de la presión transmembranal en la variación de la densidad de flujo de permeado con el tiempo para una velocidad tangencial de $3 \mathrm{~m} / \mathrm{s}$ y una concentración de $5 \mathrm{~g} / \mathrm{L}$ para la membrana Tami MSTK

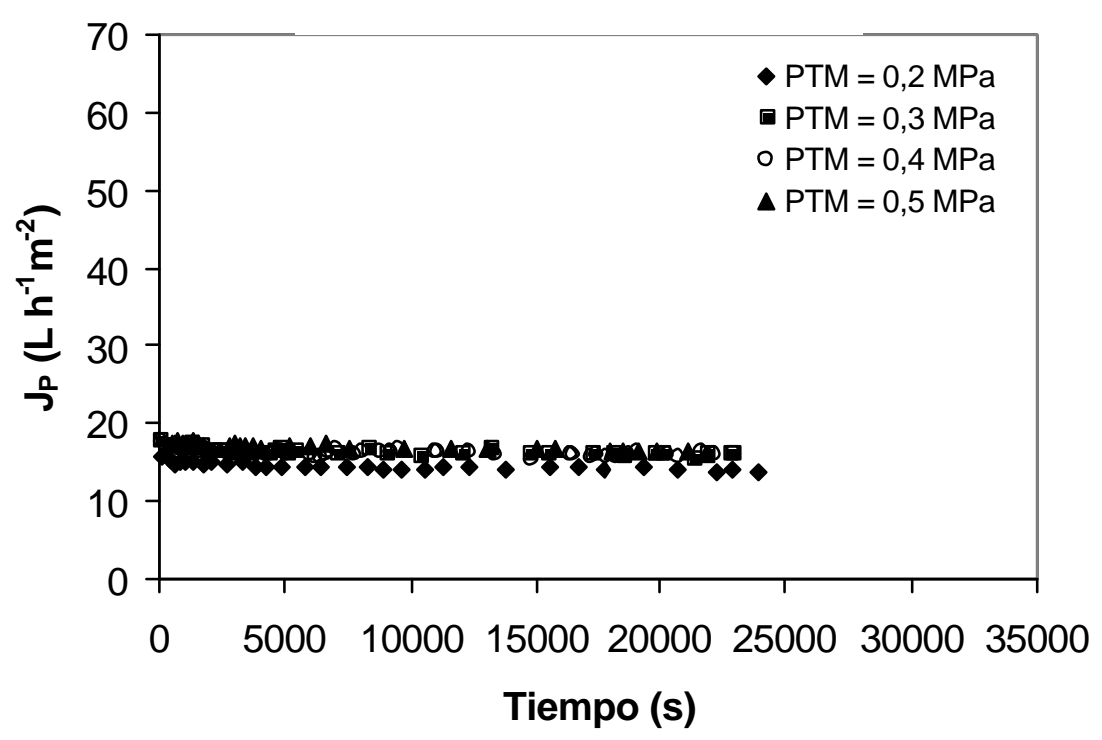

Figura 32. Influencia de la presión transmembranal en la variación de la densidad de flujo de permeado con el tiempo para una velocidad tangencial de $1 \mathrm{~m} / \mathrm{s}$ y una concentración de $15 \mathrm{~g} / \mathrm{L}$ para la membrana Tami MSTK 
Con el incremento de la velocidad tangencial (Figura 33) el proceso de ultrafiltración deja de estar controlado por la transferencia de materia para entrar en la zona de transición entre el control por transferencia de materia y el control por PTM, especialmente para las PTMs más el evadas (0.3, 0.4 y 0.5 MPa). También se observa una disminución muy reducida dela densidad de flujo de permeado con el tiempo, especialmente para la velocidad tangencial de $1 \mathrm{~m} / \mathrm{s}$ (Figura 32).

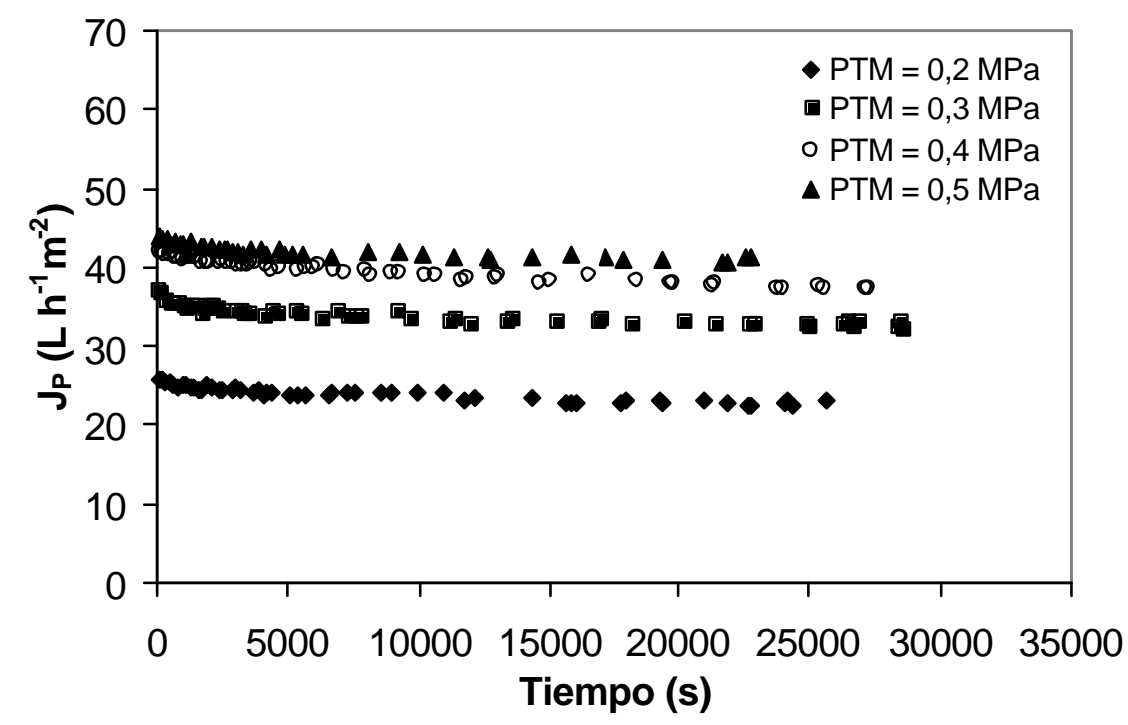

Figura 33. Influencia de la presión transmembranal en la variación de la densidad de flujo de permeado con el tiempo para una velocidad tangencial de $3 \mathrm{~m} / \mathrm{s}$ y una concentración de $15 \mathrm{~g} / \mathrm{L}$ para la membrana Tami MSTK 


\subsubsection{Influencia de la concentración de soluto en la variación de la densidad de flujo de permeado con el tiempo para la membrana Tami MSKT}

Para bajas velocidades tangenciales y elevadas PTMs, un incremento en la concentración del alimento se traduce en una disminución lineal de la densidad de flujo de permeado (Figura 35) debido a que el proceso está controlado por la transferencia de materia, como se puede observar en la Figura 36. En el caso de velocidades tangenciales bajas, las moléculas de soluto discurren lentamente y les da tiempo a depositarse sobre la superficie de la membrana. Además la fuerza de cizalla que podría devolver las moléculas depositadas al seno de la disolución alimento es pequeña.

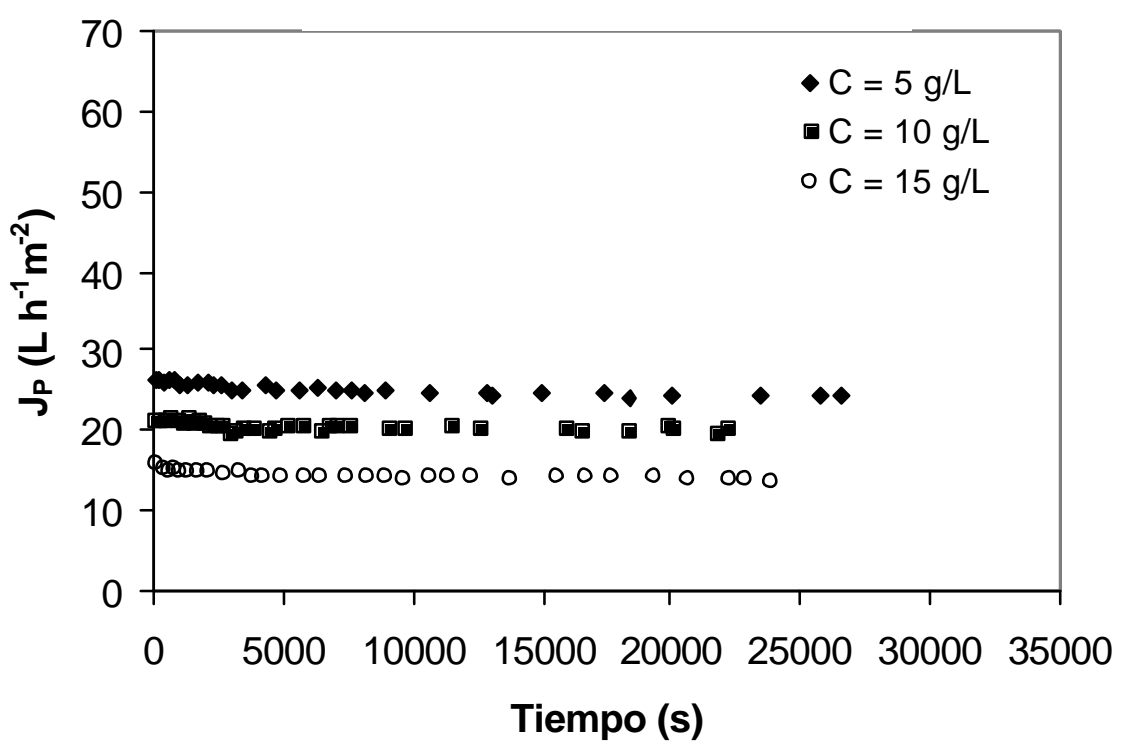

Figura 34. Influencia de la concentración de soluto en la variación de la densidad de flujo de permeado con el tiempo para una velocidad tangencial de $1 \mathrm{~m} / \mathrm{s}$ y una presión transmembranal de 0.2 MPa para la membrana Tami MSTK

Cuando las PTMs son elevadas, el flujo convectivo de moléculas de soluto hacia la superficie de la membrana es mayor y se acentúa el fenómeno de polarización por concentración. Se observa que para 
elevadas PTMs (Figura 35) la variación de la concentración de soluto tiene más influencia sobre la densidad de flujo de permeado que en el caso de bajas PTMs (Figura 34).

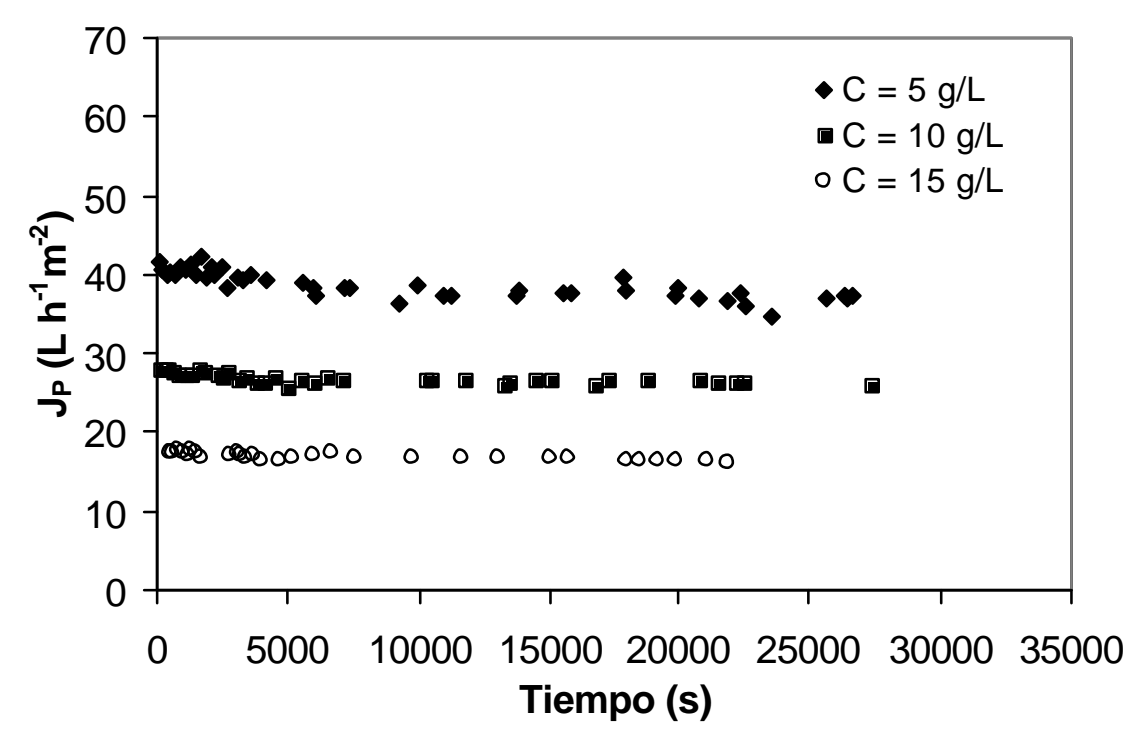

Figura 35. Influencia de la concentración de soluto en la variación de la densidad de flujo de permeado con el tiempo para una velocidad tangencial de $1 \mathrm{~m} / \mathrm{s}$ y una presión transmembranal de 0.5 MPa para la membrana Tami MSTK

Pese a que no se observa un descenso de la densidad de flujo de permeado con el tiempo (Figura 35), las condiciones de operación de $1 \mathrm{~m} / \mathrm{s}$ y $0.5 \mathrm{MPa}$ deben ser aquellas para las cuales se obtiene un ensuciamiento máximo de la membrana. Bajo estas condiciones existe un claro control del proceso de ultrafiltración por la transferencia de materia (Figura 36). Para la velocidad tangencial de $1 \mathrm{~m} / \mathrm{s}$ y las tres concentraciones de soluto ensayadas, la densidad de flujo de permeado resultó ser la misma para las presiones transmembranales de 0.4 y $0.5 \mathrm{MPa}$.

Cuando el proceso está controlado por la transferencia de materia la influencia de la concentración de soluto sobre la densidad de flujo de permeado es lineal (Figura 36). Sin embargo no ocurre lo mismo 
cuando el proceso de ultrafiltración está controlado por la PTM o se halla en la zona de transición entre el control por transferencia de materia y el control por la PTM. En la Figura 36 se observa que para una velocidad tangencial de $1 \mathrm{~m} / \mathrm{s}$, concentraciones de 5, 10 y 15 $\mathrm{g} / \mathrm{L}$ y bajas PTM s el proceso no está controlado por la transferencia de materia, al no observarse una influencia de tipo lineal de la concentración de soluto en el alimento sobre la densidad de flujo de permeado.

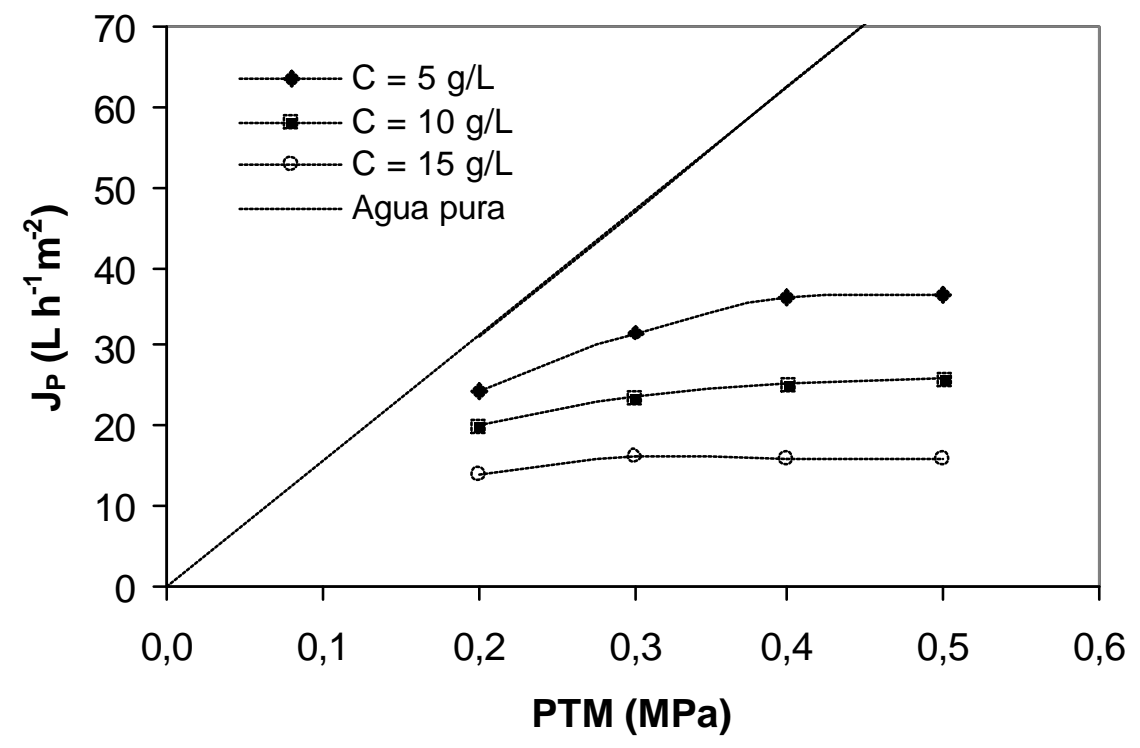

Figura 36. Influencia de la concentración de soluto en la densidad de flujo de permeado estacionaria para una velocidad tangencial de $1 \mathrm{~m} / \mathrm{s}$ para la membrana Tami MSTK

Para elevadas velocidades tangenciales y bajas PTMs la concentración de soluto en la disolución alimento no tiene influencia sobre la densidad de flujo de permeado (Figura 37). En estas condiciones el ensuciamiento es mínimo y el proceso está controlado por la PTM. 


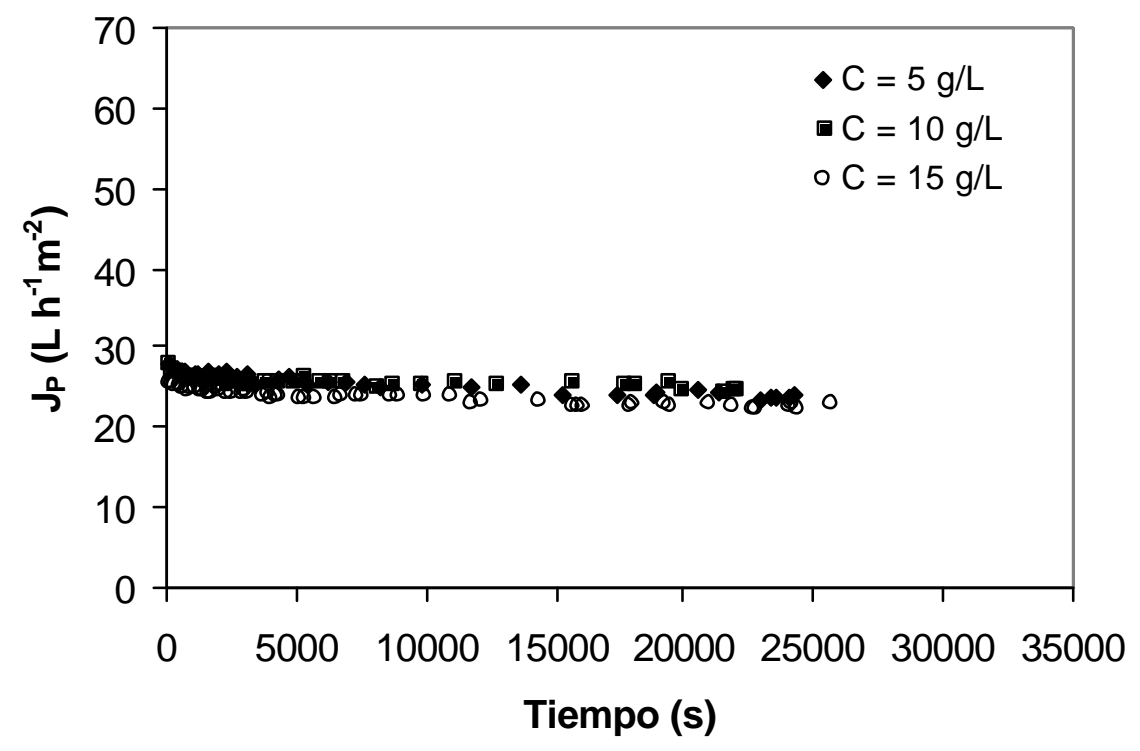

Figura 37. Influencia de la concentración de soluto en la variación de la densidad de flujo de permeado con el tiempo para una velocidad tangencial de $3 \mathrm{~m} / \mathrm{s}$ y una presión transmembranal de 0.2 M Pa para la membrana Tami MSTK

Al igual que para una velocidad tangencial de $1 \mathrm{~m} / \mathrm{s}$ (Figura 34 y Figura 35), con el aumento de la PTM, la concentración de soluto en el alimento tiene más influencia en la densidad de flujo de permeado (Figura 37 y Figura 38). Cuando las PTMs son bajas el ensuciamiento que puede provocar un aumento de concentración de soluto en la disolución alimento es menor, puesto que también es menor el aporte de moléculas de soluto hacia la membrana.

Para elevadas velocidades tangenciales y elevadas PTMs el proceso sigue estando controlado por la PTM o se halla en la zona de transición entre el control por la transferencia de materia y el control por la PTM. La densidad de flujo de permeado no disminuye de forma lineal al aumentar de la concentración de soluto (Figura 38). El paso de una concentración de soluto de $10 \mathrm{~g} / \mathrm{L}$ a $15 \mathrm{~g} / \mathrm{L}$ tiene una influencia más marcada en la disminución dela densidad de flujo de permeado que el paso de una concentración de $5 \mathrm{~g} / \mathrm{L}$ a una 
concentración de $10 \mathrm{~g} / \mathrm{L}$. Esto se debe a que para elevadas velocidades tangenciales el ensuciamiento no es notorio si la concentración de soluto en la disolución alimento no es significativa.

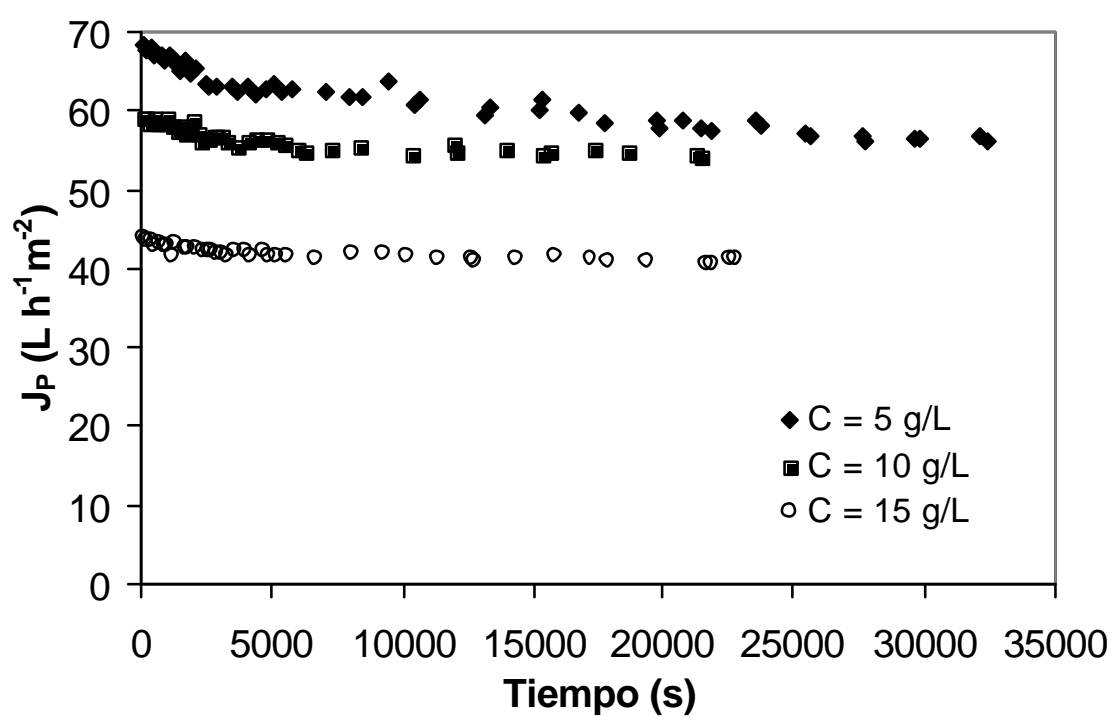

Figura 38. Influencia de la concentración de soluto en la variación de la densidad de flujo de permeado con el tiempo para una velocidad tangencial de $3 \mathrm{~m} / \mathrm{s}$ y una presión transmembranal de 0.5 MPa para la membrana Tami MSTK

En la Figura 39 se observa que para una velocidad tangencial de 3 $\mathrm{m} / \mathrm{s}$ y una PTM de $0.3,0.4$ y $0.5 \mathrm{MPa}$ el proceso de ultrafiltración se halla en la zona de transición entre el control por la PTM y el control por la transferencia materia. Una elevada velocidad tangencial reduce la tendencia de las moléculas de soluto a depositarse sobre la superficie de la membrana debido a que su tiempo de residencia en el módulo de membrana es pequeño y a que las fuerzas de cizalla devuelven al seno de la disolución alimento gran parte de las moléculas de soluto que se hayan podido depositar sobre la membrana. 


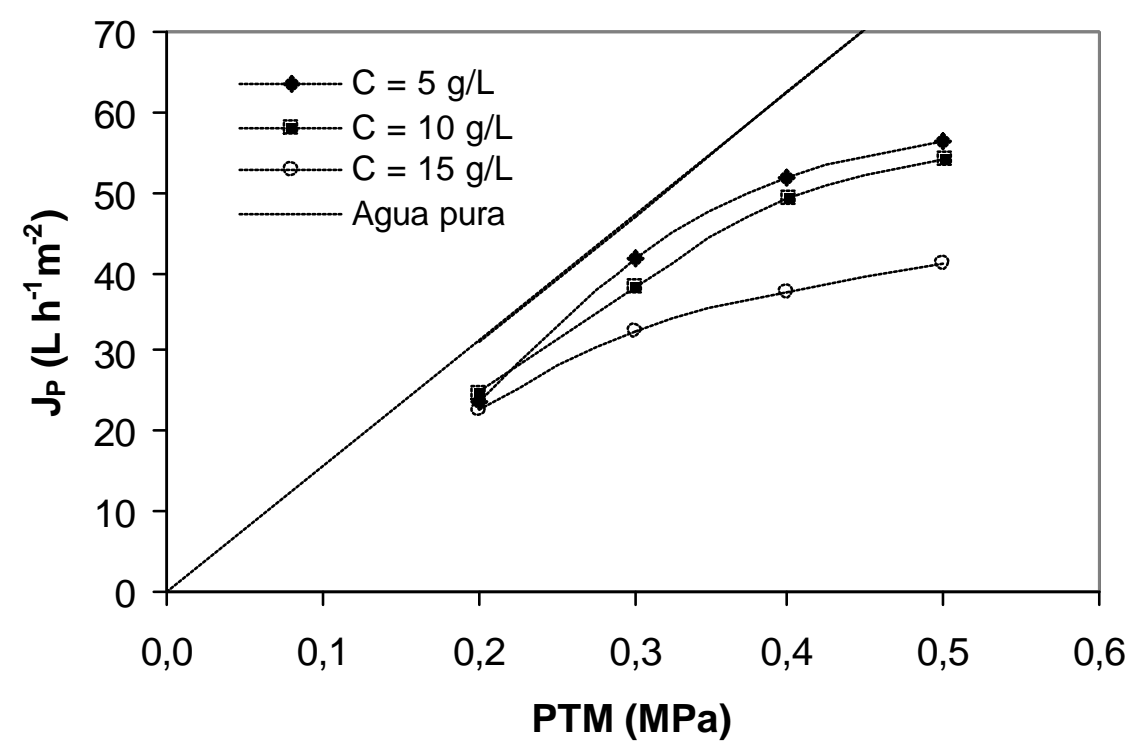

Figura 39. Influencia de la concentración de soluto en la densidad de flujo de permeado estacionaria para una velocidad tangencial de $3 \mathrm{~m} / \mathrm{s}$ para la membrana Tami MSTK

5.3.6. Influencia de la temperatura en la variación de la densidad de flujo de permeado con el tiempo para la membrana Tami MSKT

La influencia de la temperatura en la variación de la densidad de flujo de permeado con el tiempo para la membrana Tami MSTK se muestra en la Figura 40. La densidad de flujo de permeado se incrementa al aumentar la temperatura. Dicho incremento es debido a una disminución de la viscosidad conforme aumenta la temperatura. 


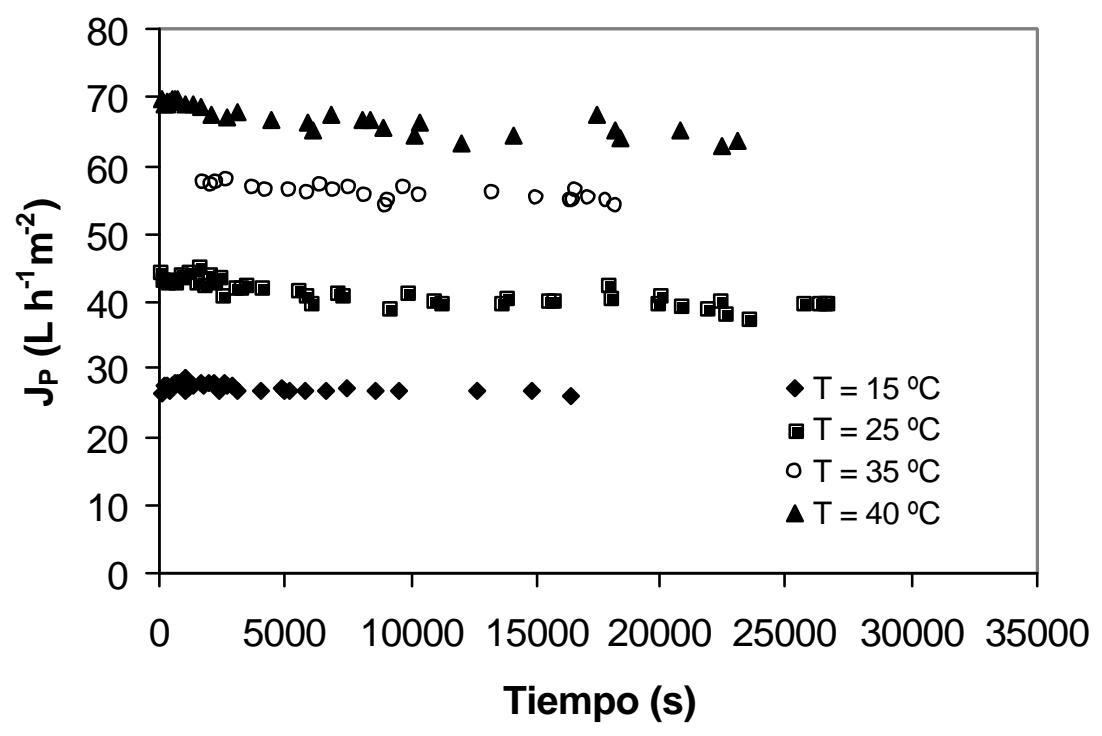

Figura 40. Influencia de la temperatura en la variación de la densidad de flujo de permeado con el tiempo para una concentración de soluto de $5 \mathrm{~g} / \mathrm{L}$, una velocidad tangencial de $1 \mathrm{~m} / \mathrm{s}$ y una presión transmembranal de $0.5 \mathrm{MPa}$ para la membrana Tami MSTK

\subsection{7. Índice de rechazo de la membrana al PEG}

El índice de rechazo (R) se calcula de acuerdo con la Ec. 42 del apartado 4.6.3.

En el caso de las membranas Carbosep M2 se calculó el índice de rechazo en dos experimentos elegidos al azar para comprobar el paso o no de PEG a través de la membrana. Los valores obtenidos fueron un $86.3 \%$ y un $85.9 \%$ de índice de rechazo, constantándose quealgunas moléculas de polietilenglicol atravesaban la membrana.

El paso de moléculas de PEG a través de la membrana Carbosep M2, pese a tener un peso molecular ( $35 \mathrm{kDa}$ ) mayor que el umbral de corte molecular de la membrana (15 kDa), se debe a que las 
moléculas de polietilenglicol no son esféricas sino que presentan una morfología alargada. También es debido a la influencia de la distribución de pesos moleculares del PEG usado en los ensayos.

En el caso de las membranas Tami MSKT, el índice de rechazo obtenido fue siempre superior al obtenido con las membranas Carbosep M2, puesto que dichas membranas presentan un umbral de corte molecular de $5 \mathrm{kDa}$, inferior al de las membranas Carbosep M2.

Para las membranas Tami MSKT, en la mayoría de las condiciones experimentales probadas el índice de rechazo fue superior a 97\%. Los únicos valores de rechazo inferiores se obtuvieron a la velocidad tangencial de $1 \mathrm{~m} / \mathrm{s}$, como puede verse en las Figuras 41 a la 45.

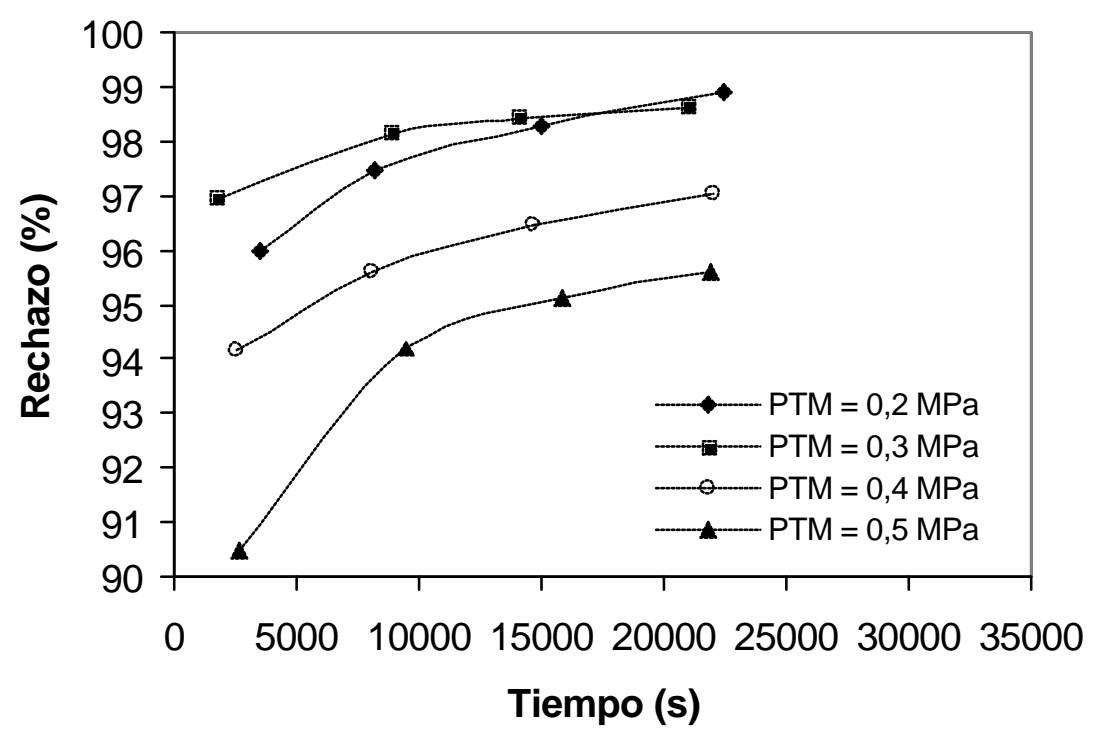

Figura 41. Influencia de la presión transmembranal en la variación de rechazo con el tiempo para una velocidad tangencial de $1 \mathrm{~m} / \mathrm{s}$ y una concentración de $5 \mathrm{~g} / \mathrm{L}$ para la membrana Tami MSTK

Tal y como se observa en las Figuras 41 y 42, cuando la velocidad tangencial es menor, la influencia de la presión en el índice de rechazo es más significativa. Cuando las velocidades tangenciales 
son muy bajas, las moléculas de soluto discurren lentamente y, por lo tanto, bajo el efecto de la PTM, las moléculas tienen tiempo de orientarse y atravesar la membrana.

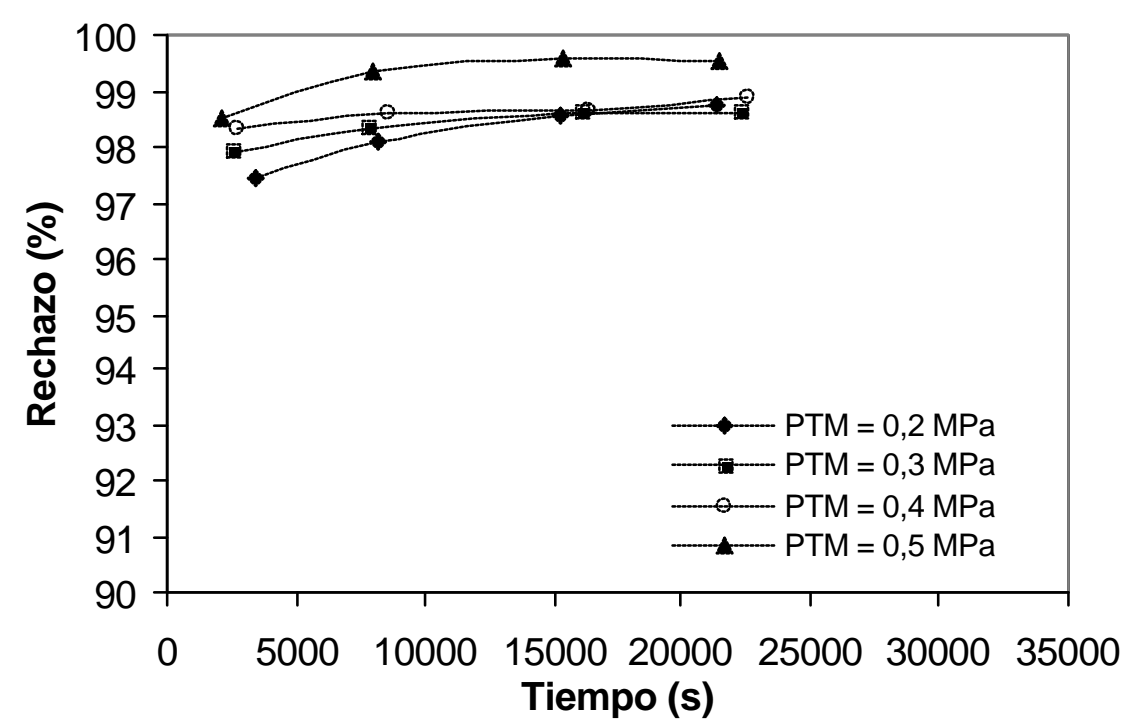

Figura 42. Influencia de la presión transmembranal en la variación del rechazo con el tiempo para una velocidad tangencial de $3 \mathrm{~m} / \mathrm{s}$ y una concentración de $5 \mathrm{~g} / \mathrm{L}$ para la membrana Tami MSTK

Por otra parte al aumentar la velocidad tangencial, el índice de rechazo a las moléculas de soluto aumenta (Figura 41 y Figura 42). Con el incremento de la velocidad tangencial la concentración de moléculas de soluto en las inmediaciones de la superficie de la membrana es menor y por lo tanto el flujo de soluto a través de la membrana disminuye.

El incremento de la presión transmembranal causa un incremento de la concentración de soluto en la superficie de la membrana y puede dar lugar a dos efectos contrapuestos en el índice de rechazo dependiendo de si existe o no formación de capa gel. Si existe formación de capa gel, dicha capa actúa como una resistencia adicional que hace disminuir el flujo de disolvente a través de la membrana en mayor medida que el de soluto, disminuyendo el 
índice de rechazo al soluto. Si no se forma capa gel, el flujo de disolvente a través de la membrana aumenta más de lo que lo hace el flujo de soluto, con lo cual el índice de rechazo al soluto aumenta.

Para una velocidad tangencial de $1 \mathrm{~m} / \mathrm{s}$, una concentración de soluto de $5 \mathrm{~g} / \mathrm{L}$ y una PTM de 0.4 y 0.5 bar, la formación de capa gel puede ser responsable de que el índice de rechazo al soluto disminuya la aumentar la PTM (Figura 41 y Figura 43).

En cambio, para una velocidad tangencial de $3 \mathrm{~m} / \mathrm{s}$, el índice de rechazo aumenta al incrementar la PTM, pues es menos probable la formación capa gel en este caso (Figura 42 y Figura 43).

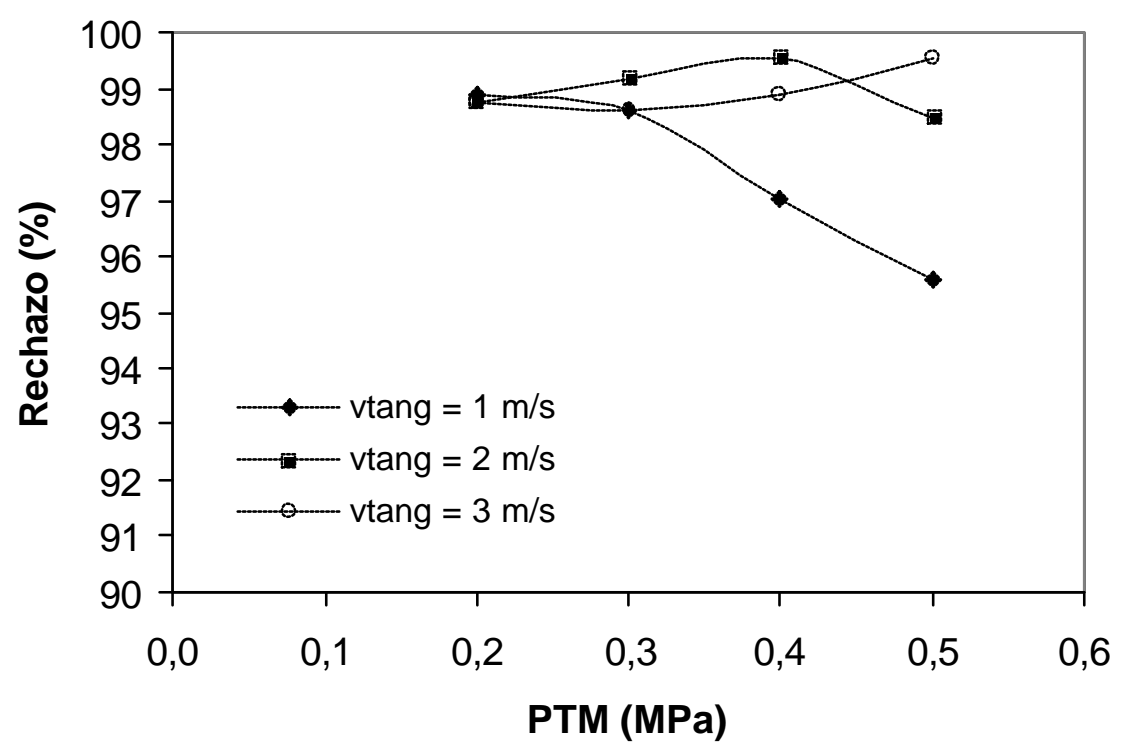

Figura 43. Influencia de la velocidad tangencial y de la presión transmembranal en e rechazo en estado estacionario para una concentración de $5 \mathrm{~g} / \mathrm{L}$ para la membrana Tami MSTK

En todos los casos el índice de rechazo aumenta con el tiempo. Esto se debe a que la disminución del flujo de permeado debido al ensuciamiento es inferior a la disminución del flujo de soluto. 


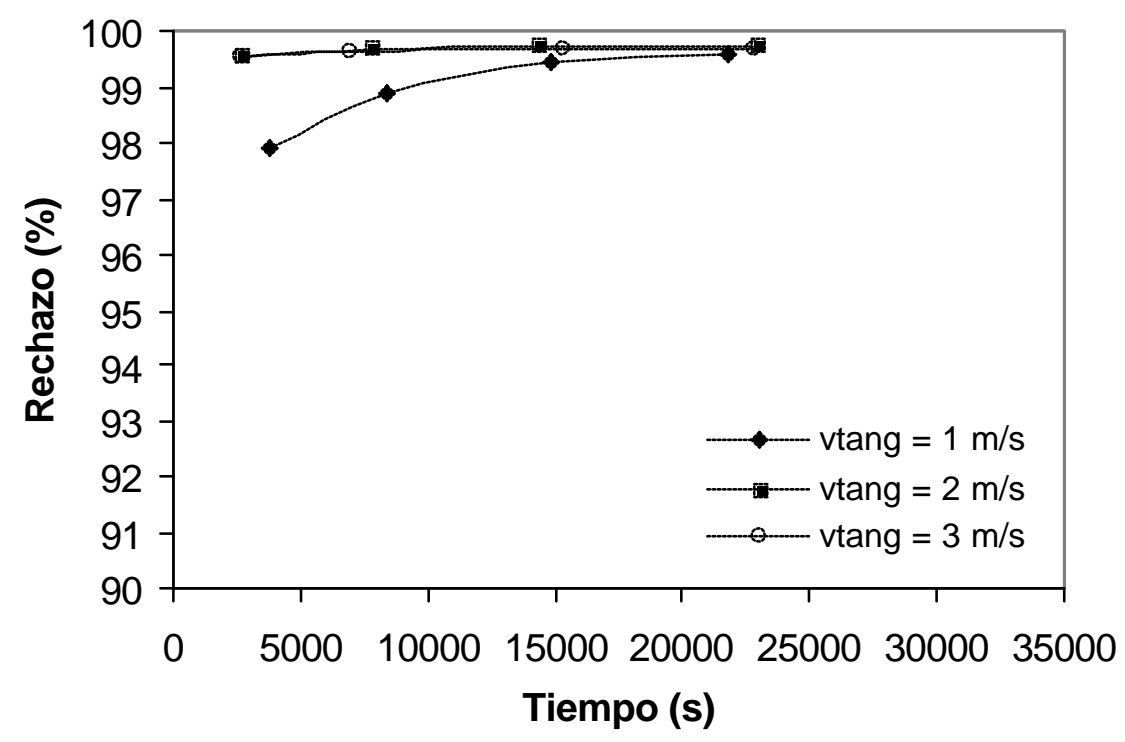

Figura 44. Influencia de la velocidad tangencial en la variación del rechazo con el tiempo para una presión transmembranal de 0.3 MPa y una concentración de $15 \mathrm{~g} / \mathrm{L}$ para la membrana Tami MSTK

Como ya se comentó anteriormente, un incremento en la velocidad tangencial causa un incremento en el índice de rechazo al soluto, puesto que disminuye la concentración de soluto en las cercanías de la membrana. Esta influencia es más marcada cuando la velocidad tangencial pasa de no ser suficientemente elevada para evitar que se forme la capa gel $(1 \mathrm{~m} / \mathrm{s})$ a serlo $(2 \mathrm{~m} / \mathrm{s}) \mathrm{y}$, por lo tanto, evita que el soluto se concentre en las cercanías de la membrana y pueda difundir fácilmente (Figura 44).

Los índices de rechazo más bajos se obtuvieron para la velocidad tangencial de $1 \mathrm{~m} / \mathrm{s}$ y la PTM de $0.5 \mathrm{MPa}$ para los tres valores de concentración ensayados. 


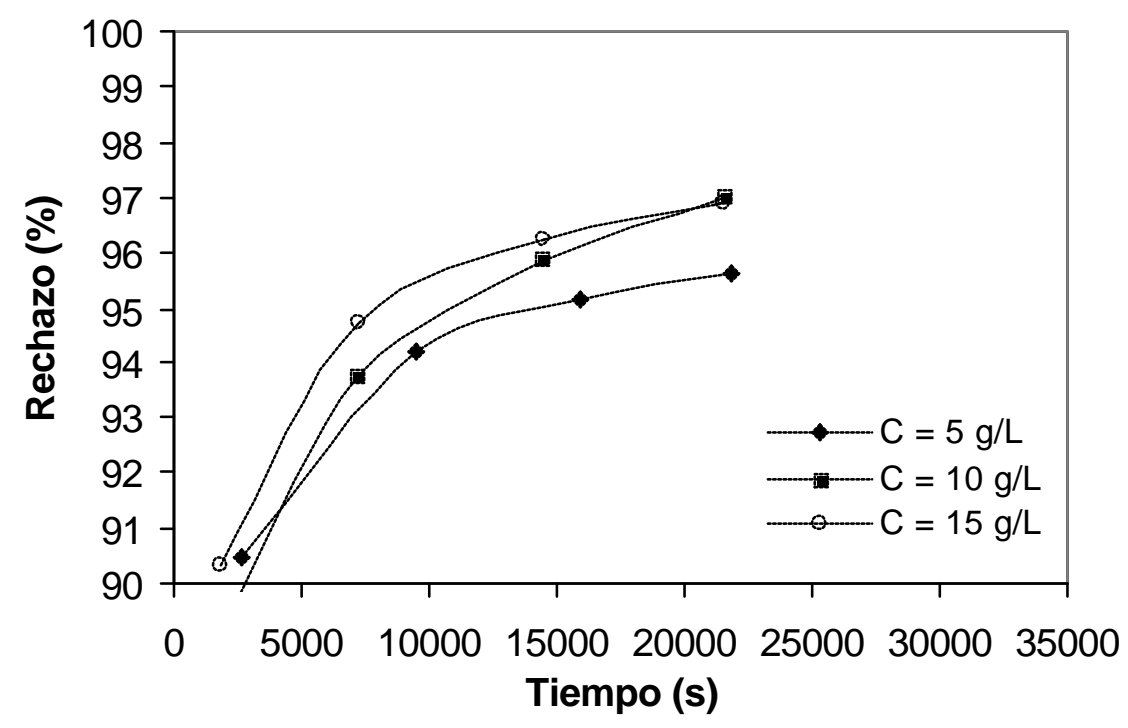

Figura 45. Influencia de la concentración de soluto en la variación del rechazo con el tiempo para una velocidad tangencial de $1 \mathrm{~m} / \mathrm{s}$ y una presión transmembranal de $0.5 \mathrm{MPa}$ para la membrana Tami MSTK

Para todas las condiciones de operación ensayadas se observó que el índice de rechazo aumenta al incrementar la concentración de soluto en la alimentación (Figura 45). Un incremento en la concentración de soluto en la alimentación da lugar a un aumento de la concentración de soluto en la superficie de la membrana y, por tanto, del ensuciamiento de la membrana, el cual causa una disminución en el flujo de permeado que resultó ser inferior a la disminución en la densidad deflujo de soluto. 


\subsection{A PLICACIÓN DE MODELOS DINÁMICOS DE ULTRAFILTRACIÓN NO EMPÍRICOS}

\subsubsection{Modelo de aplicación de la teoría de la ultrafiltración transversal en el caso dinámico.}

Como ya se mencionó en el apartado 3.1.1, este modelo se ha aplicado en la bibliografía calculando todos sus parámetros mediante ajuste empírico, una vez obtenidos los resultados mediante experimentación. En esta Tesis, sin embargo, se ha realizado la simulación del modelo de forma completamente teórica sin utilizar ningún dato experimental.

Las simulaciones se han realizado utilizando la ecuación fundamental del modelo (Ec. 1). Para el cálculo de los parámetros del modelo se han utilizado al gunas de las ecuaciones referidas en el apartado 3.1.6. Para el cálculo de la resistencia específica de la capa gel se ha empleado la Ec. 18. Asimismo, para el cálculo de la concentración de soluto cercana a la superficie de la membrana se utilizaron las Ecs. 19 a la 21.

Los resultados predichos por el modelo se comparan con los resultados experimentales en las Figuras 46 a la 48.

En la Figura 46 se comparan las predicciones del modelo con los resultados experimentales para una velocidad tangencial de $1 \mathrm{~m} / \mathrm{s}$. En este caso, el modelo predice valores de la densidad de flujo de permeado estacionaria inferiores a los valores experimentales. Esto puede ser debido a que el modelo fue desarrollado para la ultrafiltración transversal, y por lo tanto predice más ensuciamiento que el que corresponde a la ultrafiltración tangencial. Sin embargo, la forma de la curva de descenso de la densidad de flujo de permeado con el tiempo estimada a partir del modelo es similar a la que se obtiene en los ensayos experimentales. 


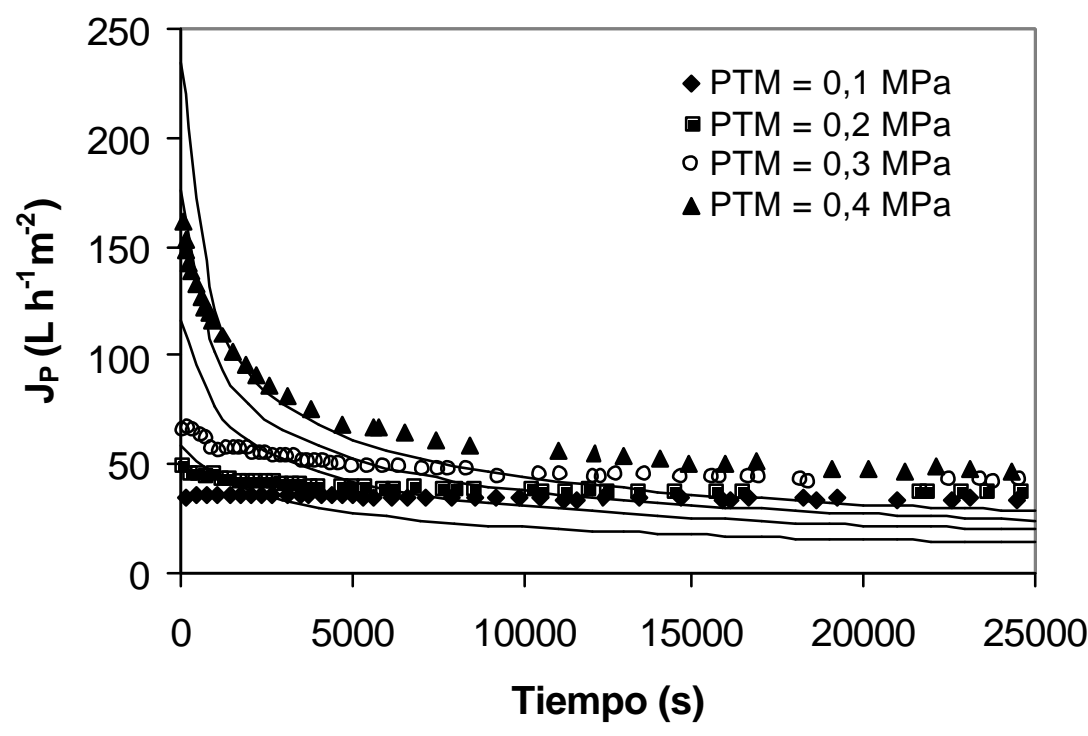

Figura 46. Comparación entre los datos experimentales y las predicciones del modelo que se describe en el apartado 3.1.1 para una velocidad tangencial de $1 \mathrm{~m}$ / s y una concentración de $5 \mathrm{~g} / \mathrm{L}$ para la membrana Carbosep M 2

La comparación entre las predicciones del modelo y los resultados experimentales para una velocidad tangencial de $2 \mathrm{~m} / \mathrm{s}$ se muestra en la Figura 47.

Para esta velocidad tangencial, el modelo predice valores de la densidad de flujo de permeado estacionaria muy inferiores a los valores experimentales. Esto puede ser debido a que, para una velocidad tangencial de $2 \mathrm{~m} / \mathrm{s}$, puede aparecer un mecanismo de ensuciamiento distinto del de formación de capa gel, que no ha sido tenido en cuenta por el modelo y que produce un ensuciamiento menos severo. Este razonamiento concuerda con los resultados obtenidos por Davis (1992). 


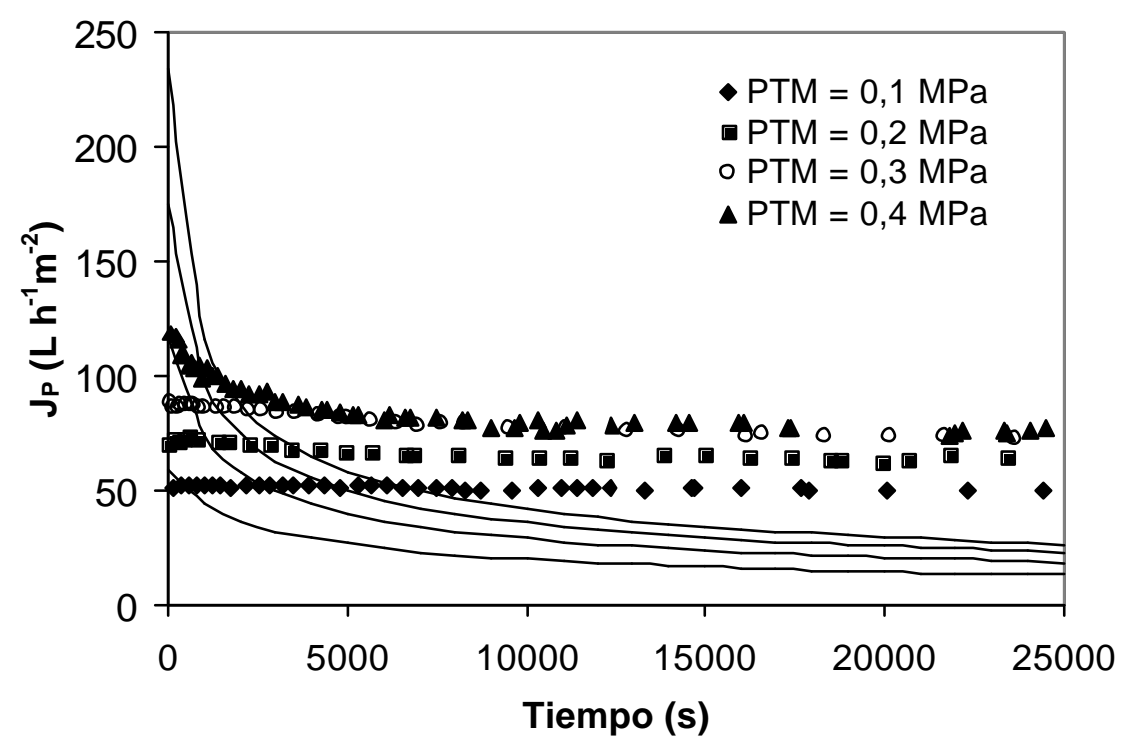

Figura 47. Comparación entre los datos experimentales y las predicciones del modelo que se describe en el apartado 3.1.1 para una velocidad tangencial de $2 \mathrm{~m} / \mathrm{s}$ y una concentración de $5 \mathrm{~g} / \mathrm{L}$ para la membrana Carbosep M2

Según Davis (1992), durante la ultrafiltración tangencial las moléculas potencial mente formadoras de capa gel se depositan en la superficie de la membrana para formar dicha capa, excepto en condiciones extremas (elevada velocidad tangencial, baja presión transmembranal, baja concentración en el alimento), para las cuales las moléculas son arrastradas por el flujo tangencial del rechazo hacia la salida del módulo de membranas. En estas condiciones $\mathrm{e}$ aporte de moléculas hacia la superficie de la membrana causado por el flujo de permeado es contrarrestado por el arrastre de las mismas hacia la salida del módulo debido al flujo tangencial. Según se observa en los resultados experimentales, puede que la velocidad tangencial de $2 \mathrm{~m} / \mathrm{s}$ sea demasiado elevada para producirse la formación de capa gel.

Por otra parte, la forma de la curva de descenso de la densidad de flujo de permeado predicha por el modelo con el tiempo difiere de 
la que se obtiene en los ensayos experimentales, de forma que el modelo predice un ensuciamiento más intenso del que realmente se produce.

La Figura 48 muestra las predicciones del modelo y los resultados experimentales para una velocidad tangencial de $3 \mathrm{~m} / \mathrm{s}$.

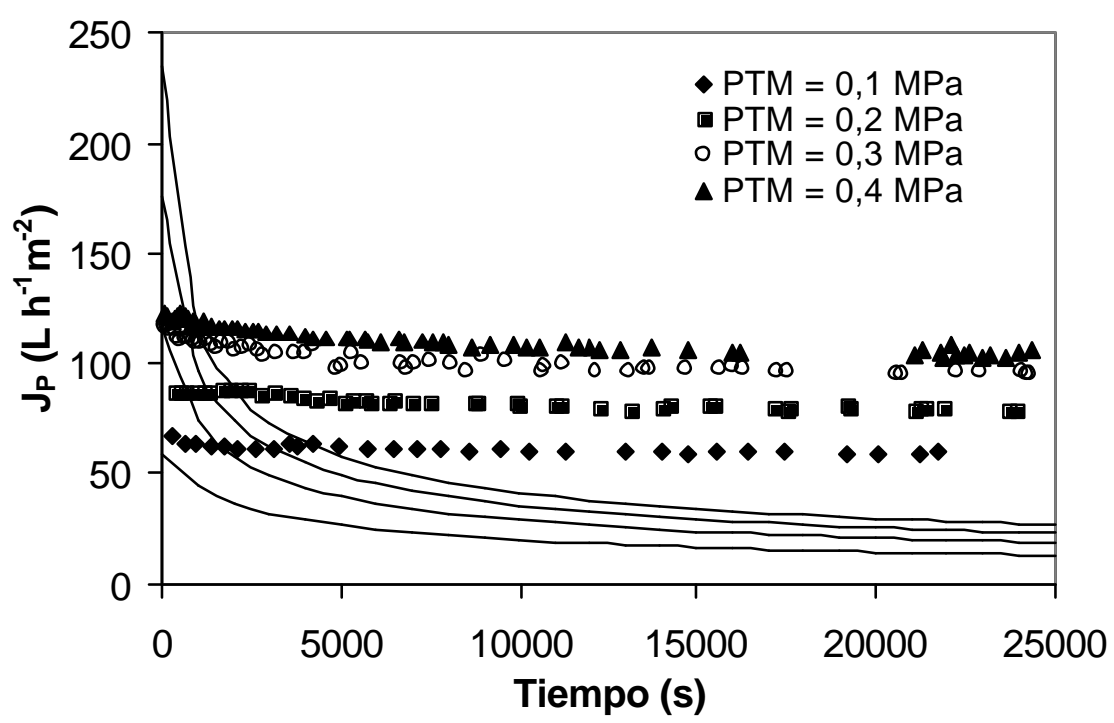

Figura 48. Comparación entre los datos experimentales y las predicciones del modelo que se describe en el apartado 3.1.1 para una velocidad tangencial de $3 \mathrm{~m} / \mathrm{s}$ y una concentración de $5 \mathrm{~g} / \mathrm{L}$ para la membrana Carbosep M2

Para esta vel ocidad tangencial, el modelo predice valores de la densidad de flujo de permeado estacionaria todavía mucho más reducidos con respecto a los valores experimentales que lo que se había observado para la velocidad tangencial de $2 \mathrm{~m} / \mathrm{s}$. Esta discrepancia entre las predicciones del modelo y los resultados experimentales puede ser debida a que, para una velocidad tangencial de $3 \mathrm{~m} / \mathrm{s}$, el mecanismo de ensuciamiento principal no es el de formación de capa gel, sino otro mecanismo que produce un ensuciamiento menos severo. 
La forma de la curva predicha por el modelo para el descenso de la densidad de flujo de permeado con el tiempo difiere, al igual que ocurría para la velocidad tangencial de $2 \mathrm{~m} / \mathrm{s}$, de la que se obtiene en los ensayos experimentales. El modelo predice un ensuciamiento más acusado del que realmente se produce.

El modelo sólo predice resultados aceptables para la velocidad tangencial de $1 \mathrm{~m} / \mathrm{s}$.

En general, no se observa diferencia apreciable entre las curvas predichas para diferentes velocidades tangenciales. Esto puede estar relacionado con el hecho de que el modelo fue inicialmente desarrollado para la ultrafiltración transversal y, en este caso, ha sido aplicado en la ultrafiltración tangencial. Sin embargo, la aplicación de modelos de ultrafiltración transversal en la ultrafiltración tangencial ha sido una constante en la literatura (Tracey y Davis, 1994; Kelly y Zydney, 1995).

Las desviaciones del modelo respecto de los resultados experimentales pueden deberse a que algunas de las hipótesis del modelo no son acertadas para las condiciones experimentales ensayadas. Por ejemplo, el rechazo al paso de moléculas de soluto no es total, como se demuestra en el apartado 5.3.7 de esta Tesis Doctoral , y el mecanismo de ensuciamiento de la membrana puede que no sea únicamente la formación de capa gel.

\subsubsection{Modelo de difusión inducido por cizalla aplicado en el caso de la ultrafiltración dinámica}

Las simulaciones de la evolución de la densidad de flujo de permeado con el tiempo se han realizado utilizando la ecuación fundamental del modelo (Ec. 2). Para calcular los parámetros del modelo se han utilizado: la Ec. 3 para el cálculo de la resistencia de la capa gel adimensional, la Ec. 17 para el cálculo de la resistencia específica de la capa gel y las Ecs. 19 a la 21 para calcular la 
concentración de soluto cercana a la superficie de la membrana. Dichas ecuaciones se han descrito en el apartado 3.1.6.

En las Figuras 49 a la 51 se comparan los resultados predichos por $\mathrm{e}$ model o con los resultados experimentales obtenidos.

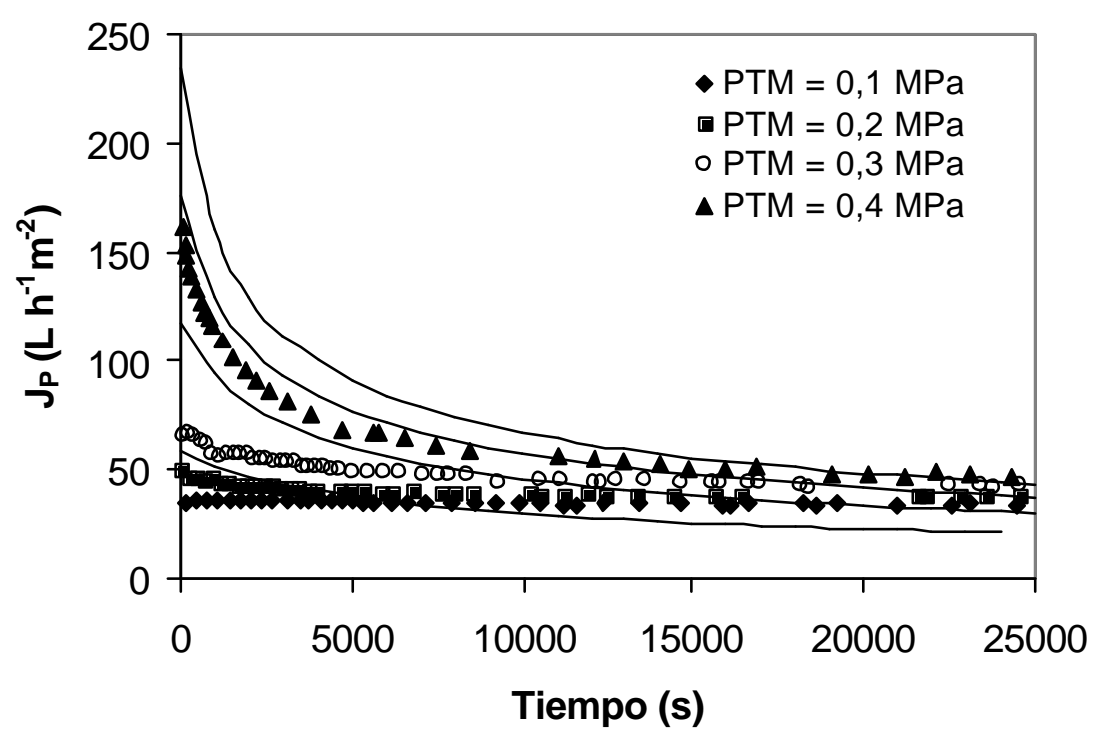

Figura 49. Comparación entre los datos experimentales y las predicciones del modelo que se describe en el apartado 3.1.2 para una velocidad tangencial de $1 \mathrm{~m} / \mathrm{s}$ y una concentración de $5 \mathrm{~g} / \mathrm{L}$ para la membrana Carbosep M 2

En la Figura 49 se muestran las predicciones del modelo junto con los resultados experimentales obtenidos para una velocidad tangencial de $1 \mathrm{~m} / \mathrm{s}$. Las densidades de flujo de permeado estacionarias que predice el modelo para esta velocidad tangencial se aproximan mucho a los valores experimentales, quedando ligeramente por debajo de los mismos. A demás, la forma dela curva de descenso de la densidad de flujo de permeado con el tiempo que predice el modelo es muy parecida a la que se obtiene en los ensayos experimentales. 
La comparación entre las predicciones del modelo y los resultados experimentales para una velocidad tangencial de $2 \mathrm{~m} / \mathrm{s}$ se muestra en la Figura 50. En este caso hay más discrepancias entre las densidades de flujo de permeado predichas por el modelo y las experimentales que para la velocidad tangencial de $1 \mathrm{~m} / \mathrm{s}$. Sin embargo, puede observarse que el modelo predice los cambios que se producen en la densidad de flujo de permeado conforme aumenta la PTM, al pasar de estar el proceso controlado por la presión a estar controlado por la transferencia de materia. De este modo, la diferencia entre las densidades de flujo de permeado a distintas presiones se reduce conforme aumenta la PTM.

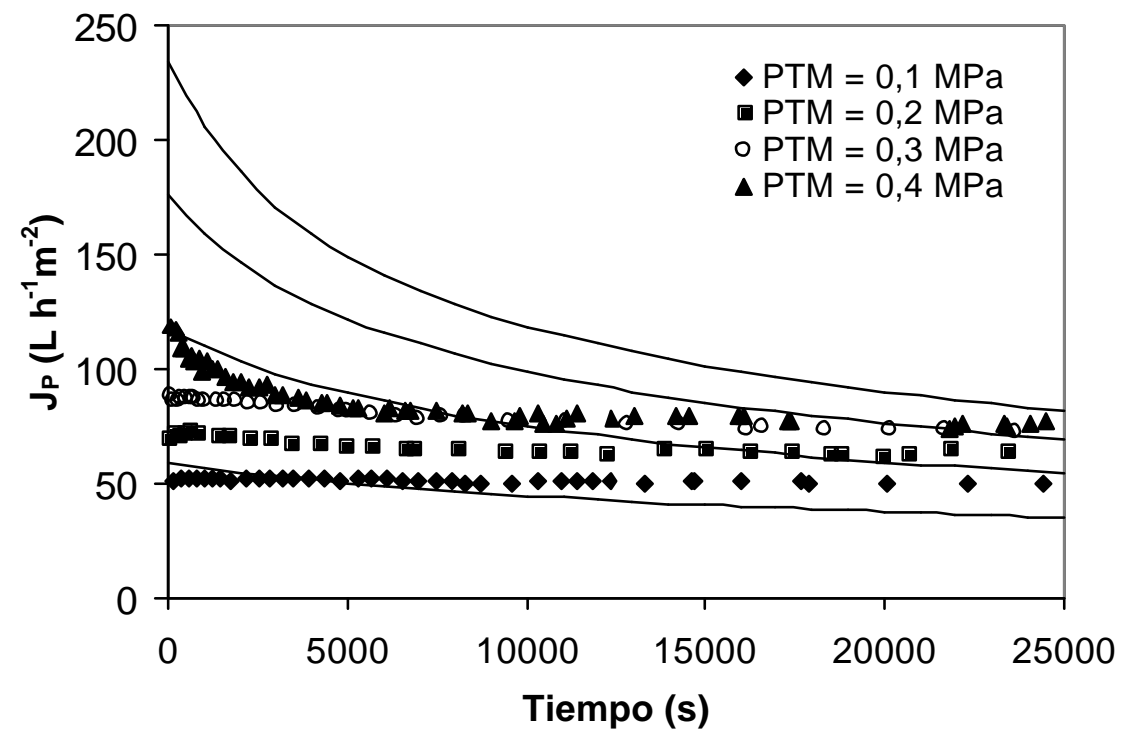

Figura 50. Comparación entre los datos experimentales y las predicciones del modelo que se describe en el apartado 3.1.2 para una velocidad tangencial de $2 \mathrm{~m} / \mathrm{s}$ y una concentración de $5 \mathrm{~g} / \mathrm{L}$ para la membrana Carbosep M 2

En cuanto a la forma de las curvas de descenso de la densidad de flujo de permeado con el tiempo que predice el modelo, no se aprecian demasiadas diferencias respecto de las que se obtuvieron en los ensayos experimentales para PTMs bajas. Sin embargo, para tiempos de operación reducidos, el modelo predice menos 
ensuciamiento que el observado experimentalmente, pues por medio del modelo se estimaron valores de la densidad de flujo de permeado más elevados que los obtenidos en los ensayos experimentales.

En la Figura 51 se muestran las predicciones del modelo y los resultados experimentales para una velocidad tangencial de $3 \mathrm{~m} / \mathrm{s}$. Del mismo modo que para la velocidad tangencial de $2 \mathrm{~m} / \mathrm{s}$, en este caso, las predicciones del modelo en cuanto a la densidad de flujo de permeado estacionaria no son tan buenas como para la velocidad tangencial de $1 \mathrm{~m} / \mathrm{s}$. No obstante, para la velocidad tangencial de 3 $\mathrm{m} / \mathrm{s}$, también se observa que el modelo predice el cambio que se produce en la densidad de flujo de permeado al aumentar la PTM y pasar de estar el proceso controlado por la presión a estar controlado por la transferencia de materia.

La forma de la curva de descenso de la densidad de flujo de permeado con el tiempo estimada por medio del modelo difiere de la que se obtiene en los ensayos experimentales para elevadas PTMs. Para la velocidad tangencial de $3 \mathrm{~m} / \mathrm{s}$, el descenso dela densidad de flujo de permeado con el tiempo que se observó en los ensayos experimentales fue muy reducido. Sin embargo, las curvas predichas por el modelo reflejan un descenso de la densidad de flujo de permeado mucho más acusado debido a que se considera un mecanismo de ensuciamiento progresivo de la membrana.

Al igual que en el caso de la velocidad tangencial de $2 \mathrm{~m} / \mathrm{s}$, el modelo predice menos ensuciamiento que el observado experimentalmente para tiempos cortos de operación, ya que las densidades de flujo de permeado estimadas son más elevadas que las experimentales. 


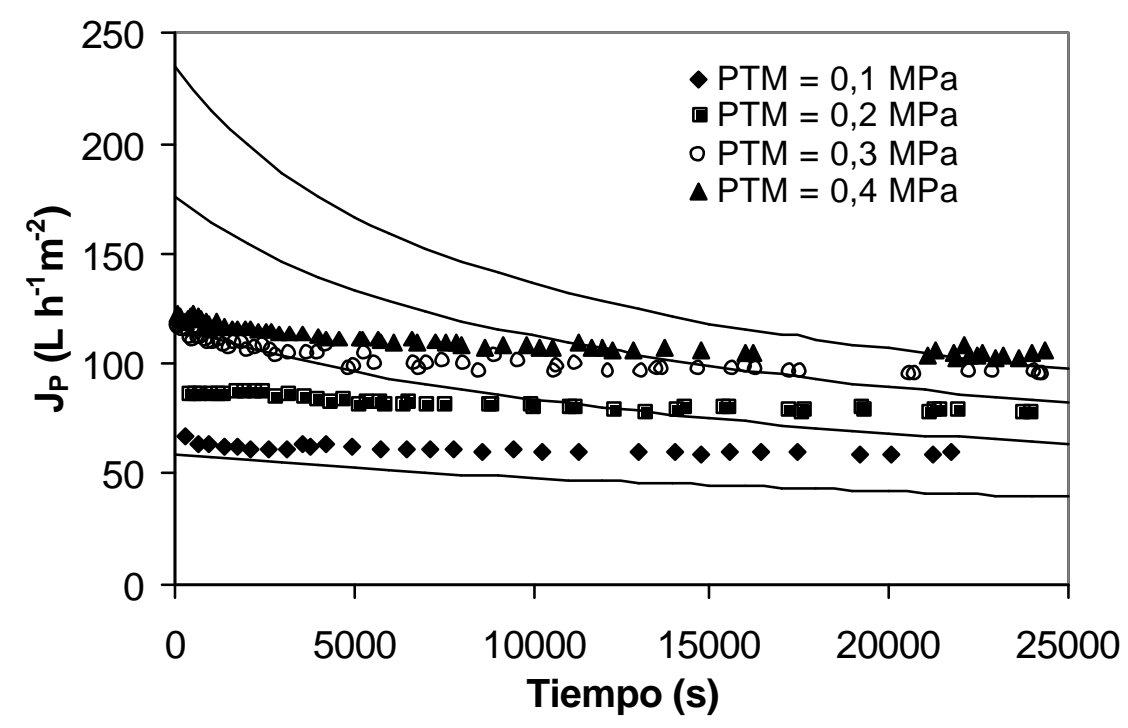

Figura 51. Comparación entre los datos experimentales y las predicciones del modelo que se describe en el apartado 3.1.2 para una velocidad tangencial de $3 \mathrm{~m} / \mathrm{s}$ y una concentración de $5 \mathrm{~g} / \mathrm{L}$ para la membrana Carbosep M2

El modelo predice aceptablemente el valor de la densidad de flujo de permeado estacionaria para todas las velocidades tangenciales ensayadas. Para periodos cortos de operación, el modelo predice para todas las condiciones experimentales ensayadas menos ensuciamiento que el observado experimentalmente.

Las diferencias entre las predicciones del modelo y los resultados experimentales obtenidos en los ensayos en la planta piloto pueden deberse a que varias de las hipótesis del modelo no son adecuadas para las condiciones experimentales ensayadas. Por ejemplo, el rechazo al paso de moléculas de soluto no es total. 


\subsubsection{Modelo dinámico de Song para la ultrafiltración tangencial}

Para simular la evolución de la densidad de flujo de permeado con el tiempo por medio de este modelo se utilizó la Ec. 4. Para calcular los parámetros del modelo se utilizaron varias de las ecuaciones descritas en el apartado 3.1.6. Para el cálculo de la resistencia específica de la capa gel se utilizó la Ec. 12. Por otra parte, la concentración de soluto cercana a la superficie de la membrana se calculó por medio de las Ecs. 19 a la 21. La influencia de la velocidad tangencial en el Modelo dinámico de Song para la ultrafiltración tangencial se considera a través de la concentración en la capa gel según la Ec. 19. La presión transmembranal crítica para la aparición de fenómenos de ensuciamiento se calculó mediante la Ec. 5. Finalmente, para el cálculo del número crítico de filtración se utilizó Ia Ec. 6. El valor de estos parámetros depende de las condiciones de operación. Los valores más elevados que se obtuvieron fueron 0.0051 para el número de filtración crítico y 43.404 Pa para la presión transmembranal crítica.

En las Figuras 52 a la 54 se comparan los resultados predichos por el modelo con los resultados experimentales.

En la Figura 52 se comparan las predicciones del modelo con los resultados experimentales para una velocidad tangencial de $1 \mathrm{~m} / \mathrm{s}$. Los valores de la densidad de flujo de permeado estacionaria estimados por medio del modelo son muy similares a los valores experimentales. Para las PTMs de 0.3 y $0.4 \mathrm{MPa}$ los resultados predichos son ligeramente superiores a los experimental es, mientras que para la PTM de 0.2 MPa, la densidad de flujo de permeado estacionaria predicha coincide prácticamente con la experimental. Para la PTM de 0.1 MPa, la densidad de flujo de permeado estacionaria estimada con el modelo es ligeramente inferior a la experimental. Además, la forma de la curva de descenso de la densidad de flujo de permeado con el tiempo predicha por el 
modelo es similar a la que se obtuvo en los ensayos experimentales. Sin embargo, para tiempos de operación reducidos, el modelo predice menos ensuciamiento del observado experimentalmente Esto puede ser debido a haber despreciado el fenómeno de taponamiento de poros.

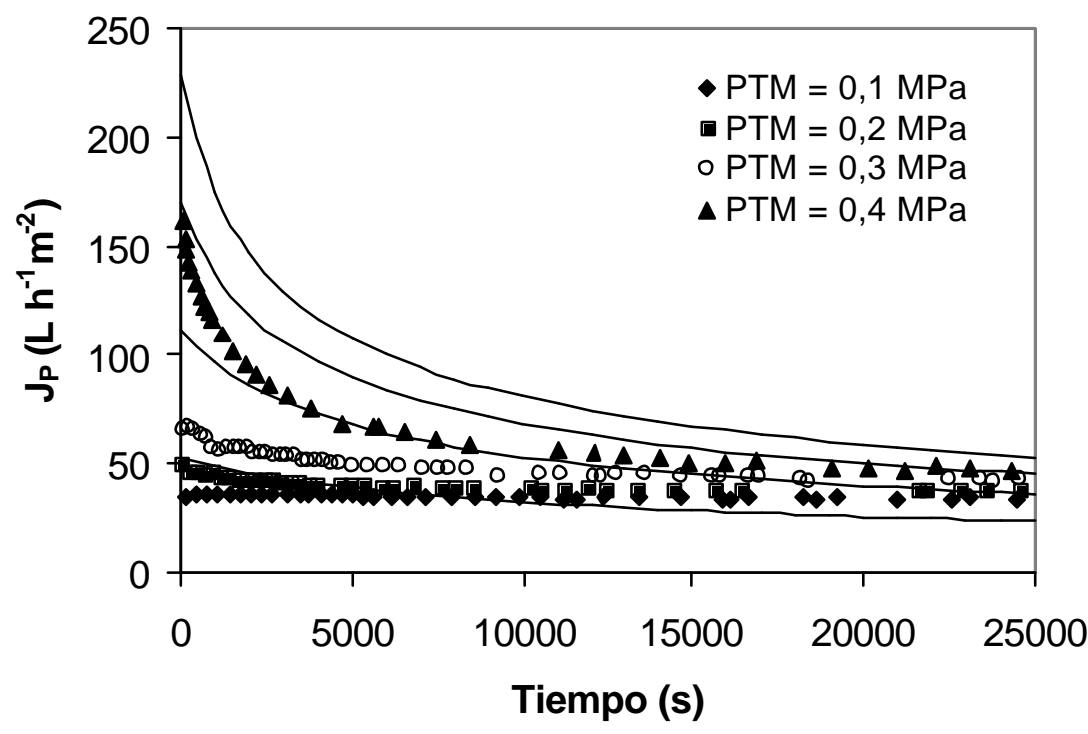

Figura 52. Comparación entre los datos experimentales y las predicciones del modelo que se describe en el apartado 3.1.3 para una velocidad tangencial de $1 \mathrm{~m} / \mathrm{s}$ y una concentración de $5 \mathrm{~g} / \mathrm{L}$ para la membrana Carbosep M 2

La comparación entre las predicciones del modelo y los resultados experimentales para una velocidad tangencial de $2 \mathrm{~m} / \mathrm{s}$ se muestra en la Figura 53. En este caso, las predicciones del modelo para la densidad de flujo de permeado estacionaria no son tan buenas como para la velocidad tangencial de $1 \mathrm{~m} / \mathrm{s}$, obteniéndose valores inferiores a los experimentales. Esto se debe a que, para una velocidad tangencial más elevada, de $2 \mathrm{~m} / \mathrm{s}$, el mecanismo de ensuciamiento ya no es probablemente la formación de capa gel.

No obstante, el modelo predice el cambio que se produce en la densidad de flujo de permeado al aumentar la PTM y pasar de estar 
el proceso controlado por la presión a estar controlado por la transferencia de materia. De este modo, la diferencia entre las densidades de flujo de permeado a distintas presiones se reduce conforme aumenta la PTM. Sin embargo, la diferencia entre las densidades de flujo de permeado que predice el modelo es inferior a la observada experimentalmente.

Por otra parte, la forma de la curva de descenso de la densidad de flujo de permeado con el tiempo predicha por el modelo difiere notablemente de la que se obtuvo en los ensayos experimentales. El descenso inicial de la densidad de flujo de permeado estimado por medio del modelo es mucho más acusado de lo que se observó experimentalmente.

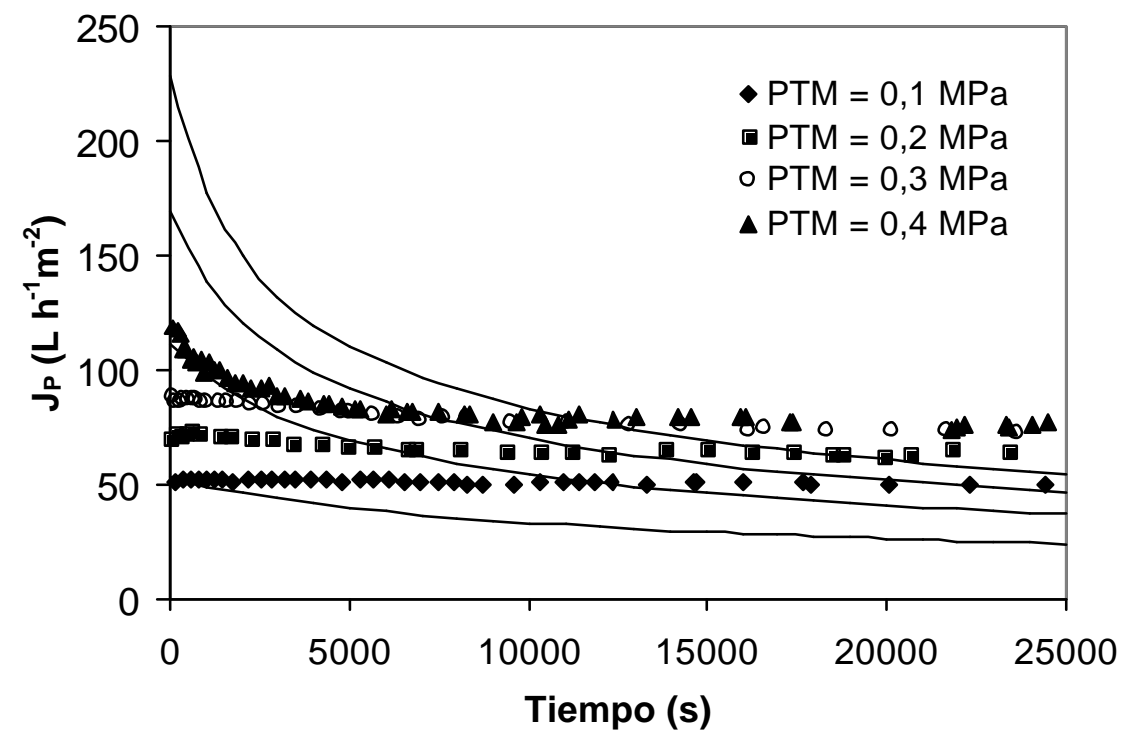

Figura 53. Comparación entre los datos experimentales y las predicciones del modelo que se describe en el apartado 3.1.3 para una velocidad tangencial de $2 \mathrm{~m} / \mathrm{s}$ y una concentración de $5 \mathrm{~g} / \mathrm{L}$ para la membrana Carbosep M 2

Para periodos largos de operación, cercanos al estacionario, el modelo predice un ensuciamiento más intenso del que se obtuvo en los ensayos experimentales. Sin embargo, para tiempos de operación 
cortos, el modelo predice menos ensuciamiento del que se observó experimentalmente.

En la Figura 54 se comparan los resultados predichos por el modelo con los resultados experimentales para una velocidad tangencial de $3 \mathrm{~m} / \mathrm{s}$. Para esta velocidad tangencial, los valores de la densidad de flujo de permeado estacionaria estimados por medio del modelo difieren mucho más de los resultados experimentales incluso que para la velocidad tangencial de $2 \mathrm{~m} / \mathrm{s}$.

Pese a esto, para la velocidad tangencial de $3 \mathrm{~m} / \mathrm{s}$, también se observa que el modelo considera el cambio que se produce en la densidad de flujo de permeado al aumentar la PTM y pasar de estar el proceso controlado por la presión a estar controlado por la transferencia de materia.

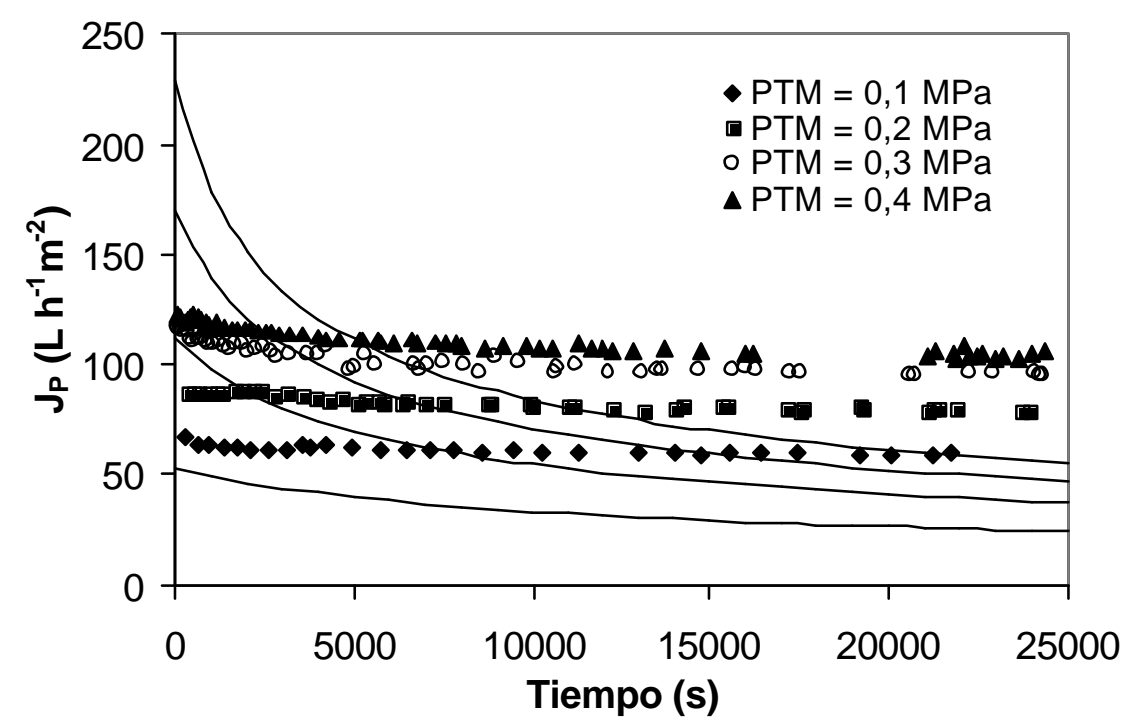

Figura 54. Comparación entre los datos experimentales y las predicciones del modelo que se describe en el apartado 3.1.3 para una velocidad tangencial de $3 \mathrm{~m} / \mathrm{s}$ y una concentración de $5 \mathrm{~g} / \mathrm{L}$ para la membrana Carbosep M2 
En esta ocasión, la forma de la curva de descenso de la densidad de flujo de permeado con el tiempo predicha por el modelo difiere de la que se obtuvo en los ensayos experimentales. Para la velocidad tangencial de $3 \mathrm{~m} / \mathrm{s}$ no se observó descenso apreciable de la densidad de flujo de permeado con \& tiempo experimentalmente Sin embargo, las curvas estimadas a partir del modelo sí reflejan un descenso acusado de la densidad de flujo de permeado debido a que se considera un mecanismo de ensuciamiento progresivo de la membrana.

Al igual que en el caso de la velocidad tangencial de $2 \mathrm{~m} / \mathrm{s}$, para periodos largos de operación cercanos al estacionario, el modelo predice un ensuciamiento más severo que el observado experimentalmente.

Para periodos cortos de operación, las densidades de flujo de permeado estimadas por medio del modelo son más elevadas que las obtenidas en los ensayos experimentales y por lo tanto, el modelo predice menos ensuciamiento que el observado.

Las predicciones de la densidad de flujo de permeado que realiza el modelo únicamente son aceptables para la velocidad tangencial de 1 $\mathrm{m} / \mathrm{s}$. En el caso de tiempos de operación reducidos, el modelo predice en todos los casos menos ensuciamiento que el observado experimentalmente.

A pesar de que uno de los parámetros del modelo es la velocidad tangencial, no existe una diferencia apreciable entre las curvas estimadas para diferentes velocidades tangenciales. Esto puede ser debido a que el modelo supone que las moléculas depositadas en la capa gel no pueden ser nuevamente impulsadas hacia la capa de polarización por concentración y a que la velocidad de formación del depósito es independiente de la velocidad de cizalla, y por tanto, también lo es de la velocidad tangencial. 
Las discrepancias entre las predicciones del model o y los resultados experimentales pueden deberse a que al gunas hipótesis del modelo no son adecuadas para las condiciones experimentales ensayadas. Por ejemplo, el rechazo al paso de moléculas de soluto no es total.

Por otra parte, con el modelo se obtienen peores predicciones para tiempos de operación cortos. Esto puede deberse a que se han supuesto condiciones de estado estacionario para estimar la concentración de soluto en las proximidades de la superficie de la membrana.

\subsubsection{Modelo dinámico de B hattacharjee y Bhattacharya para la ultrafiltración controlada por la presión osmótica 0 por la capa gel indistintamente}

Este modelo fue desarrollado por Bhattacharje y Bhattacharya (1992a), quienes calcularon los parámetros del mismo de forma empírica. Sin embargo, en este trabajo, los parámetros del model o se calcularon de forma teórica, sin necesidad de recurrir a la experimentación.

Para realizar las simulaciones de la densidad de flujo de permeado frente al tiempo se utilizó la ecuación fundamental del modelo (Ec. 8). Para calcular los parámetros del modelo se utilizaron algunas de las ecuaciones descritas en el apartado 3.1.6. Para el cálculo de la resistencia específica de la capa gel se empleó la Ec. 13. Asimismo, la concentración de soluto cercana a la superficie de la membrana se calculó por medio delas Ecs. 19 a la 21.

En la presente Tesis Doctoral, al aplicar este modelo se ha despreciado la resistencia debida a la adsorción. Según Zhang et al. (2003), la máxima adsorción de PEG sobre superficies de $\mathrm{ZrO}_{2}$ es de $0.20 \mathrm{mg} / \mathrm{m}^{2}$. Hamieh et al. (2000) midieron la adsorción de PEG sobre $\mathrm{TiO}_{2}$, obteniendo valores siempre inferiores a $0.10 \mathrm{mg} / \mathrm{m}^{2} . \mathrm{Si}$ 
se supone que el tamaño molecular del PEG es lo suficientemente elevado para no ser capaz de penetrar a través de los poros de la membrana, teniendo en cuenta que la superficie activa de la membrana es de $35.5 \mathrm{~cm}^{2}$, la resistencia de adsorción que puede ofrecer el PEG adsorbido sobre la membrana es despreciable.

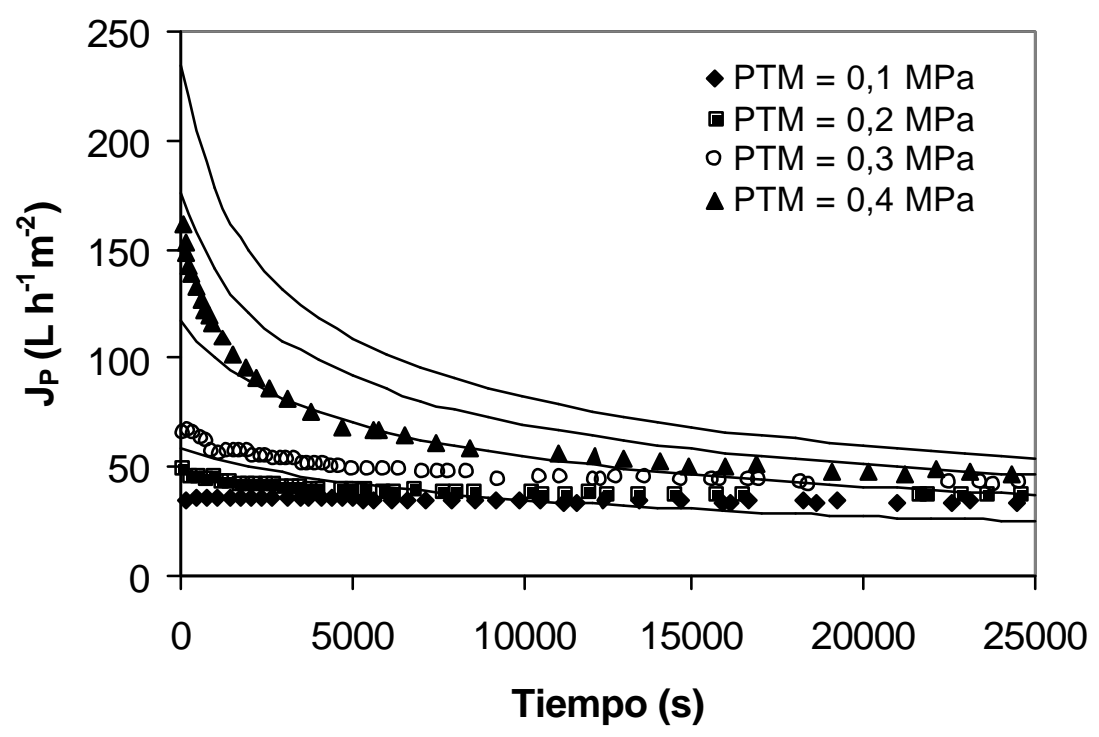

Figura 55. Comparación entre los datos experimentales y las predicciones del modelo que se describe en el apartado 3.1.4 para una velocidad tangencial de $1 \mathrm{~m} / \mathrm{s}$ y una concentración de $5 \mathrm{~g} / \mathrm{L}$ para la membrana Carbosep M 2

Según Mulder (2000), la concentración en la capa gel no es constante y depende de la concentración del alimento y de la velocidad tangencial. De todas las condiciones experimental es ensayadas para la membrana Carbosep M2, la máxima concentración en la capa gel se alcanzará para la velocidad tangencial más baja $(1 \mathrm{~m} / \mathrm{s})$ y se puede calcular por medio de la Ec. 19. Para esa concentración en la capa gel, la presión osmótica calculada mediante la Ec. 53 es de 571 Pa. Este valor de la presión osmótica es lo suficientemente bajo para poder despreciar también en el modelo el valor la resistencia osmótica. 
Los resultados predichos por este modelo se comparan con los resultados experimentales en las Figuras 55 a la 57.

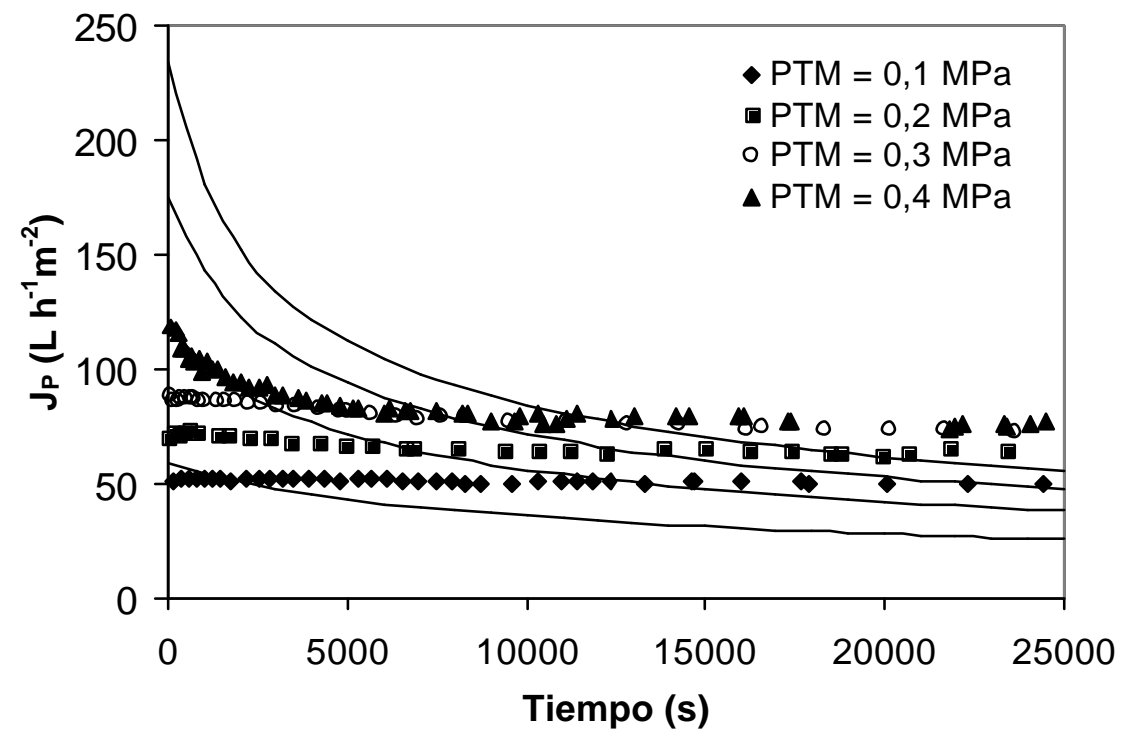

Figura 56. Comparación entre los datos experimentales y las predicciones del modelo que se describe en el apartado 3.1.4 para una velocidad tangencial de $2 \mathrm{~m} / \mathrm{s}$ y una concentración de $5 \mathrm{~g} / \mathrm{L}$ para la membrana Carbosep M 2

En la Figura 55 se muestran las densidades de flujo de permeado estimadas por el modelo y los resultados experimentales obtenidos para una velocidad tangencial de $1 \mathrm{~m} / \mathrm{s}$. En la Figura $56 \mathrm{se}$ comparan las predicciones del modelo con los resultados experimentales para una velocidad tangencial de $2 \mathrm{~m} / \mathrm{s} . \mathrm{Y}$ en la Figura 57 se representan los resultados predichos por el modelo y los experimentales para una velocidad tangencial de $3 \mathrm{~m} / \mathrm{s}$. 


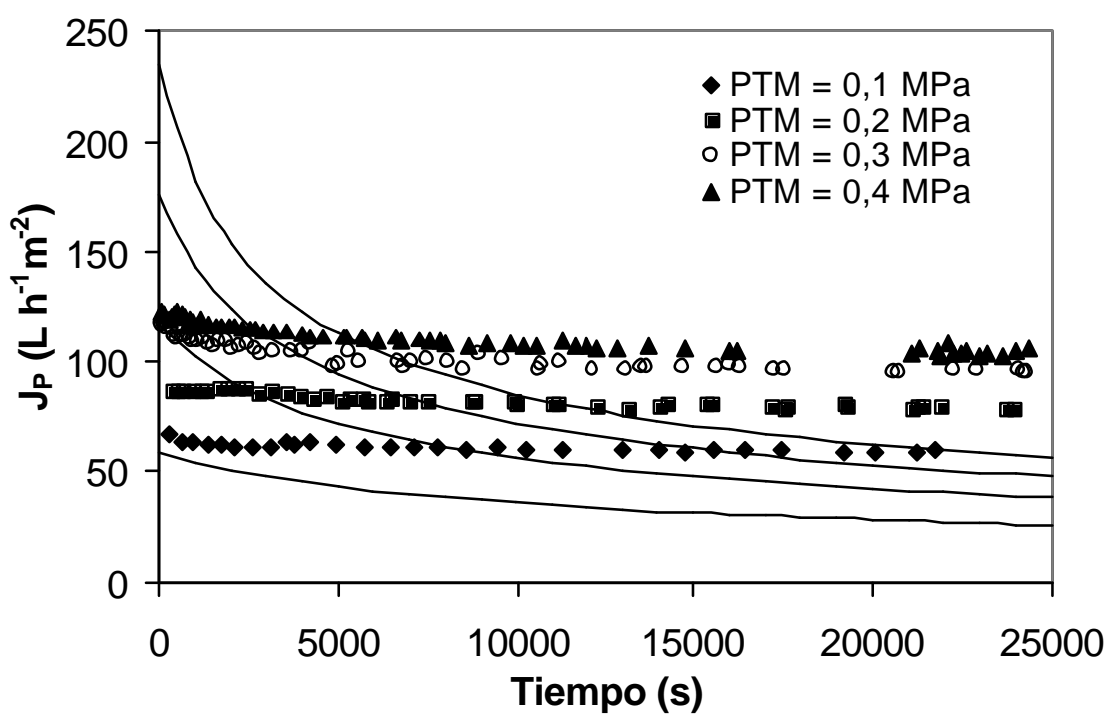

Figura 57. Comparación entre los datos experimentales y las predicciones del modelo que se describe en el apartado 3.1.4 para una velocidad tangencial de $3 \mathrm{~m} / \mathrm{s}$ y una concentración de $5 \mathrm{~g} / \mathrm{L}$ para la membrana Carbosep M2

Las predicciones obtenidas por medio de este modelo son muy similares a las obtenidas con el Modelo dinámico de Song para la ultrafiltración tangencial. En el Modelo dinámico de Song para la ultrafiltración tangencial, el valor dela presión transmembranal crítica mínima necesaria para la aparición de fenómenos de ensuciamiento es muy reducido y despreciable frente a la PTM. Por otra parte, en el M odelo dinámico de Bhattacharjee y Bhattacharya para la ultrafiltración controlada por la presión osmótica o por la capa gel indistintamente, al despreciar tanto la resistencia de adsorción como la resistencia osmótica se obtiene una ecuación muy parecida a la del Modelo dinámico de Song para la ultrafiltración tangencial. Esta puede ser la razón de la similitud entre los resultados predichos por ambos modelos. 


\subsubsection{Modelo dinámico que combina el bloqueo de poros y la formación de capa gel}

Tal como se expuso en el apartado 3.1.5, en la bibliografía se ha aplicado este modelo calculando todos sus parámetros de forma empírica a partir de los resultados experimentales. Sin embargo, en esta Tesis Doctoral, los parámetros del modelo se calcularon de forma teórica sin necesidad de recurrir a la experimentación.

Para calcular los parámetros del modelo se utilizaron algunas de las ecuaciones descritas en el apartado 3.1.6. El cálculo de la resistencia específica de la capa gel se efectuó por medio de la Ec. 13. Para calcular la concentración de soluto en las proximidades de la superficie de la membrana se utilizaron las Ecs. 19 a la 21.

En la simulación se ha supuesto que la resistencia inicial de la capa gel es muy baja y, por tanto, despreciable También se ha supuesto que todo el soluto presente en la alimentación contribuye al crecimiento de la capa gel y forma grandes agregados. En realidad, la propia molécula de soluto, por su gran tamaño molecular, puede ser considerada del tamaño de un agregado.

En las Figuras 58 a la 60 se comparan los resultados experimentales con las predicciones del modelo.

En la Figura 58 se comparan las densidades de flujo de permeado estimadas por medio del modelo con las experimentales para una velocidad tangencial de $1 \mathrm{~m} / \mathrm{s}$. Los valores de la densidad de flujo de permeado estacionaria predichos por el modelo son inferiores a los valores experimentales. Sin embargo, la forma de la curva de descenso de la densidad de flujo de permeado con el tiempo estimada por medio del modelo es similar a la obtenida en los ensayos experimentales. 


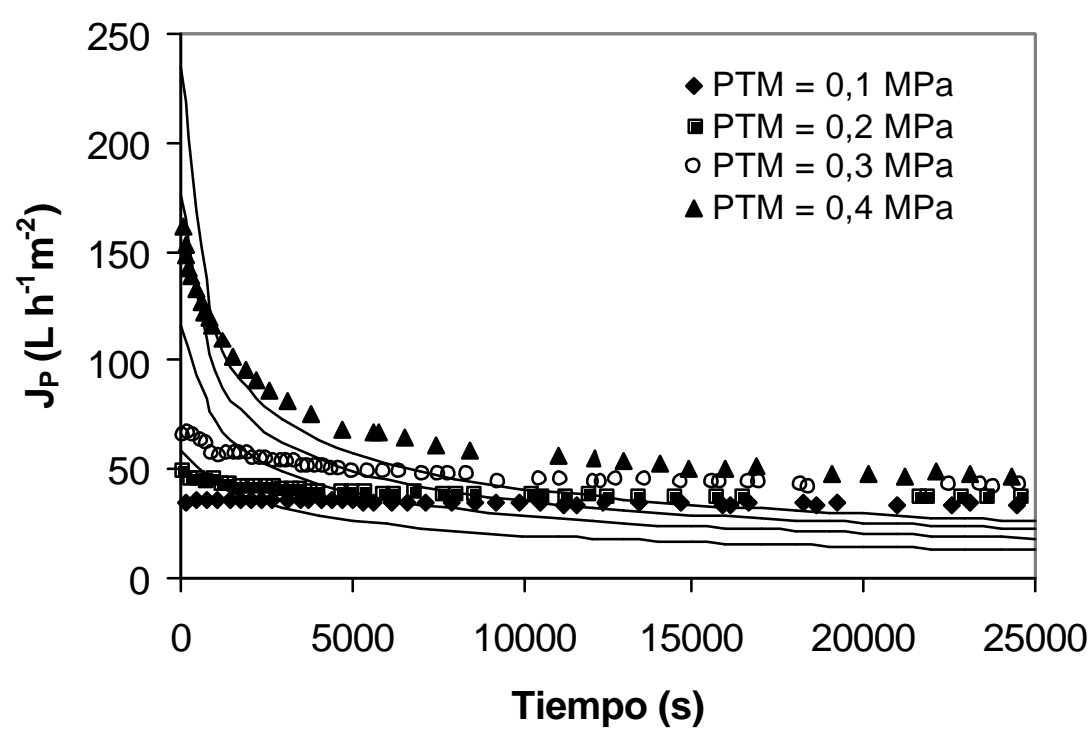

Figura 58. Comparación entre los datos experimentales y las predicciones del modelo que se describe en el apartado 3.1.5 para una velocidad tangencial de $1 \mathrm{~m} / \mathrm{s}$ y una concentración de $5 \mathrm{~g} / \mathrm{L}$ para la membrana Carbosep M 2

La comparación entre los resultados predichos por el modelo y los experimentales para una velocidad tangencial de $2 \mathrm{~m} / \mathrm{s}$ se muestra en la Figura 59. Las predicciones del modelo para la densidad de flujo de permeado estacionaria presentan una desviación respecto de los valores experimentales mayor a la obtenida para la velocidad tangencial de $1 \mathrm{~m} / \mathrm{s}$.

De acuerdo con los resultados predichos por este modelo, la diferencia entre las densidades de flujo de permeado que se obtienen a distintas presiones disminuye al aumentar la PTM; aunque no en la misma proporción que lo hacen los resultados experimentales. Por lo tanto, el modelo no predice adecuadamente el cambio que se produce en la densidad de flujo de permeado al pasar de estar el proceso controlado por la presión a estar controlado por la transferencia de materia. 


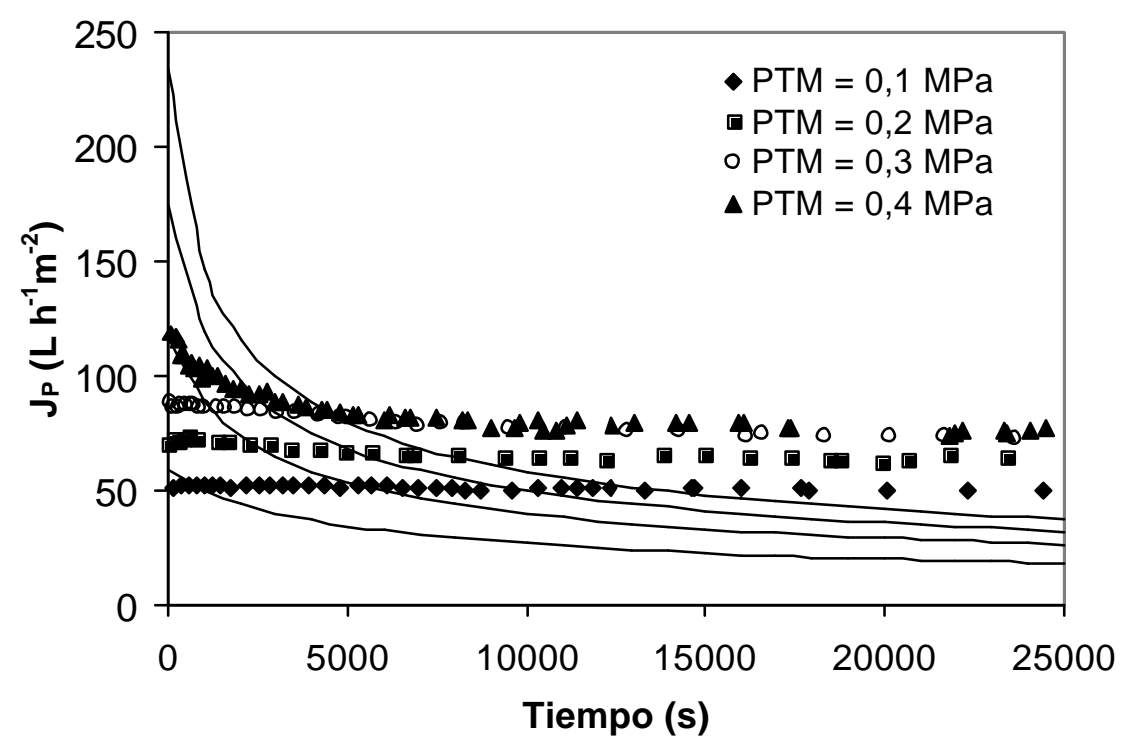

Figura 59. Comparación entre los datos experimentales y las predicciones del modelo que se describe en el apartado 3.1.5 para una velocidad tangencial de $2 \mathrm{~m} / \mathrm{s}$ y una concentración de $5 \mathrm{~g} / \mathrm{L}$ para la membrana Carbosep M 2

Por otro lado, la forma de la curva de descenso de la densidad de flujo de permeado con el tiempo estimada por medio del modelo difiere notablemente de la que se obtiene en los ensayos experimentales. El modelo predice un descenso inicial de la densidad de flujo de permeado más acusado de lo que se observa experimentalmente.

En la Figura 60 se muestran las predicciones del modelo y los resultados experimentales para una velocidad tangencial de $3 \mathrm{~m} / \mathrm{s}$. Para esta velocidad tangencial, las predicciones del modelo para la densidad de flujo de permeado estacionaria presentan una desviación respecto de los valores experimentales similar a la obtenida para las anteriores velocidades tangencial es ( 1 y $2 \mathrm{~m} / \mathrm{s}$ ).

Para la velocidad tangencial de $3 \mathrm{~m} / \mathrm{s}$ también se observa que el modelo no predice adecuadamente el cambio que se produce en la 
densidad de flujo de permeado con la PTM al pasar de estar el proceso controlado por la presión a estar controlado por la transferencia de materia.

Para esta velocidad tangencial , la forma de curva de descenso de la densidad de flujo de permeado con el tiempo estimada por medio del modelo es distinta de la que se obtiene en los ensayos experimentales. En los ensayos experimentales casi no se observó descenso de la densidad de flujo de permeado con el tiempo. Sin embargo, las curvas obtenidas con el modelo sí muestran un descenso notable de la densidad de flujo de permeado al considerar un mecanismo deensuciamiento progresivo de la membrana.

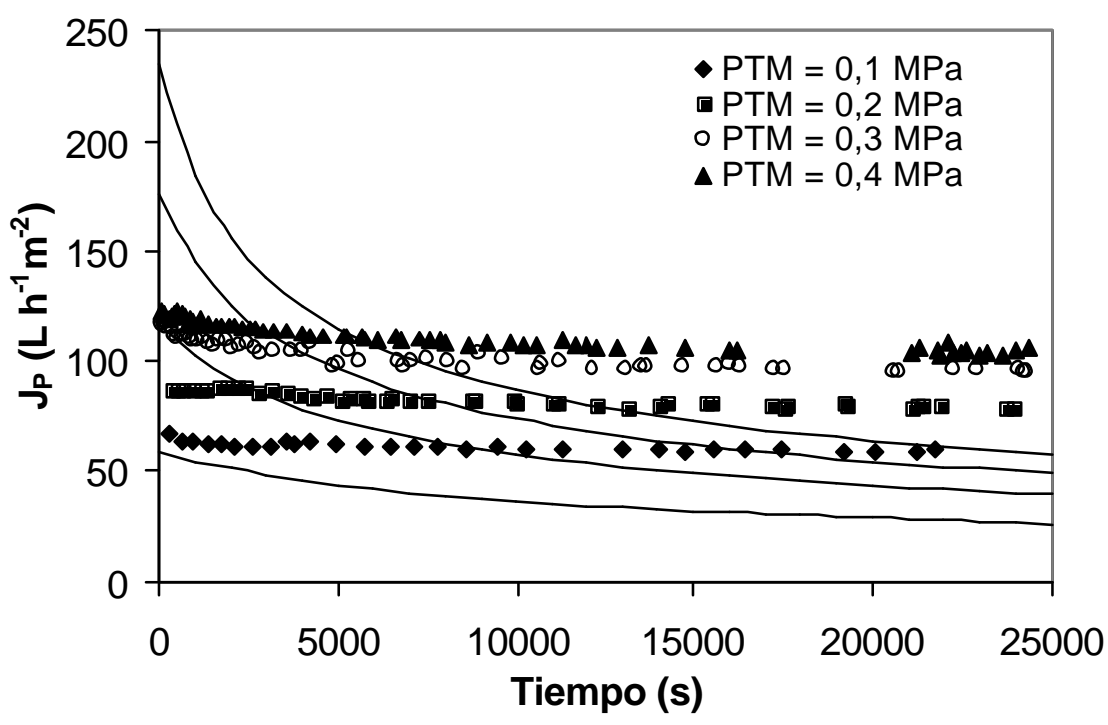

Figura 60. Comparación entre los datos experimentales y las predicciones del modelo que se describe en el apartado 3.1.5 para una velocidad tangencial de $3 \mathrm{~m} / \mathrm{s}$ y una concentración de $5 \mathrm{~g} / \mathrm{L}$ para la membrana Carbosep M2

Al igual que para el resto de velocidades tangencial es ensayadas, el modelo predice un ensuciamiento más acusado que el observado experimentalmente para tiempos de operación largos, cercanos al estacionario. Sin embargo, para tiempos de operación reducidos e 
modelo predice un ensuciamiento inferior al obtenido en los ensayos.

Este modelo contempla simultáneamente dos procesos de ensuciamiento: taponamiento de poros y formación de capa gel.

Según el modelo, para tiempos de operación cortos, el proceso de ensuciamiento está dominado por el fenómeno de taponamiento de los poros. Por ello, para tiempos reducidos el modelo predice un descenso de la densidad de flujo de permeado con el tiempo detipo exponencial, que corresponde a este mecanismo de ensuciamiento. Sin embargo, para velocidades tangenciales elevadas y PTMs reducidas en los resultados experimentales no se observa este descenso exponencial. Por lo tanto, es muy probable que para esas condiciones experimentales no se produzcan fenómenos de taponamiento de poros. De ahí la discrepancia entre las predicciones del modelo y los resultados experimentales para tiempos de operación reducidos. Estas discrepancias se ven acentuadas al haber supuesto condiciones de estado estacionario para realizar la estimación de la concentración en las proximidades de la superficie de la membrana.

El modelo no realiza predicciones de la densidad de flujo de permeado aceptables para ninguna de las velocidades tangenciales ensayadas. La ausencia de fenómenos de taponamiento de poros bajo determinadas condiciones experimentales, junto con la posibilidad de que la capa gel se forme en un tiempo muy corto pueden ser la causa de la discrepancia entre el modelo y los resultados experimentales para las diferentes velocidades tangenciales.

Por otra parte, las desviaciones del modelo respecto de los resultados experimentales pueden deberse también a que otras de las hipótesis del modelo no son acertadas para las condiciones experimentales ensayadas. Por ejemplo, el rechazo al paso de 
moléculas de soluto no es total. Además el modelo considera que el bloqueo de poros es parcial de modo que sigue existiendo una densidad de flujo de permeado a través de los poros parcialmente bloqueados. Puede ocurrir que al gunos poros se taponen totalmente y no exista flujo a través de los mismos puesto que las moléculas de soluto tienen un tamaño muy superior a los poros de la membrana. A simismo, la capa gel se puede formar sobre toda la superficiedela membrana en vez de solamente sobre la superficie de la membrana previamente bloqueada.

\subsubsection{Conclusiones de la aplicación teórica de los modelos dinámicos de ultrafiltración no empíricos}

Los resultados experimentales obtenidos con la aplicación teórica de los modelos dinámicos de ultrafiltración no empíricos permiten concluir lo siguiente:

- No existe un modelo dinámico no empírico que describa cuantitativamente la dinámica de los procesos de ultrafiltración para todas las condiciones de operación ensayadas. Esto es debido a que algunas de las hipótesis consideradas por los modelos (el único mecanismo de ensuciamiento es la formación de capa gel, el rechazo de la membrana a las moléculas de soluto es total, etc.) no son ciertas para las condiciones experimentales ensayadas. También puede deberse a errores en la estimación de los parámetros de los modelos de forma teórica.

- Todos los modelos consideran la formación de capa gel el mecanismo principal de ensuciamiento en los procesos de ultrafiltración tangencial de macromoléculas. Por este motivo el mejor ajuste entre los resultados predichos por los modelos y los resultados experimentales se obtuvo para la velocidad tangencial de $1 \mathrm{~m} / \mathrm{s}$, pues es para la que es más probable que 
se produzca la formación de capa gel sobre la superficie de la membrana.

- El M odelo de difusión inducido por cizalla aplicado en el caso de la ultrafiltración dinámica es el que mejor predice la densidad de flujo de permeado estacionaria para todas las velocidades tangenciales ensayadas. La forma de la curva de descenso de la densidad de flujo de permeado con el tiempo para todas las velocidades tangenciales es aceptable.

- El M odelo dinámico de Song para la ultrafiltración tangencial y el Modelo dinámico de Bhattacharjee y Bhattacharya para la ultrafiltración controlada por la presión osmótica o por la capa gel indistintamente no reflejan la influencia de la velocidad tangencial sobrela densidad de flujo de permeado.

- El M odel o dinámico que combina el bloqueo de poros y la formación de capa gel, junto con el Modelo de aplicación de la teoría de la ultrafiltración transversal en el caso dinámico, son los únicos modelos que no predicen aceptablemente la densidad de flujo de permeado estacionaria para ninguna las velocidades tangenciales ensayadas.

\subsubsection{Modelo de difusión inducido por cizalla aplicado en el caso de la ultrafiltración dinámica con estimación empírica de la concentración en la capa gel}

El Modelo de difusión inducido por cizalla aplicado en el caso de la ultrafiltración dinámica junto con el Modelo dinámico de Song para la ultrafiltración tangencial son los modelos no empíricos que mejor predicen la variación de la densidad de flujo de permeado con el tiempo, sobre todo para la velocidad tangencial más reducida ensayada ( $1 \mathrm{~m} / \mathrm{s})$, para la cual es más probable que se forme capa gel. Por ello se seleccionaron ambos modelos con el objetivo de 
aplicarlos estimando empíricamente la concentración en la capa gel y comparar los resultados con los obtenidos cuando se aplicaron de forma teórica. El M odelo de difusión inducido por cizalla aplicado en el caso de la ultrafiltración dinámica se aplicó de forma teórica en el apartado 5.4.2. En las Figuras 61 a la 66 se muestran las predicciones de dicho modelo estimando la concentración en la capa gel a partir de los datos experimentales de la densidad de flujo de permeado estacionario mediante la Ec. 19.

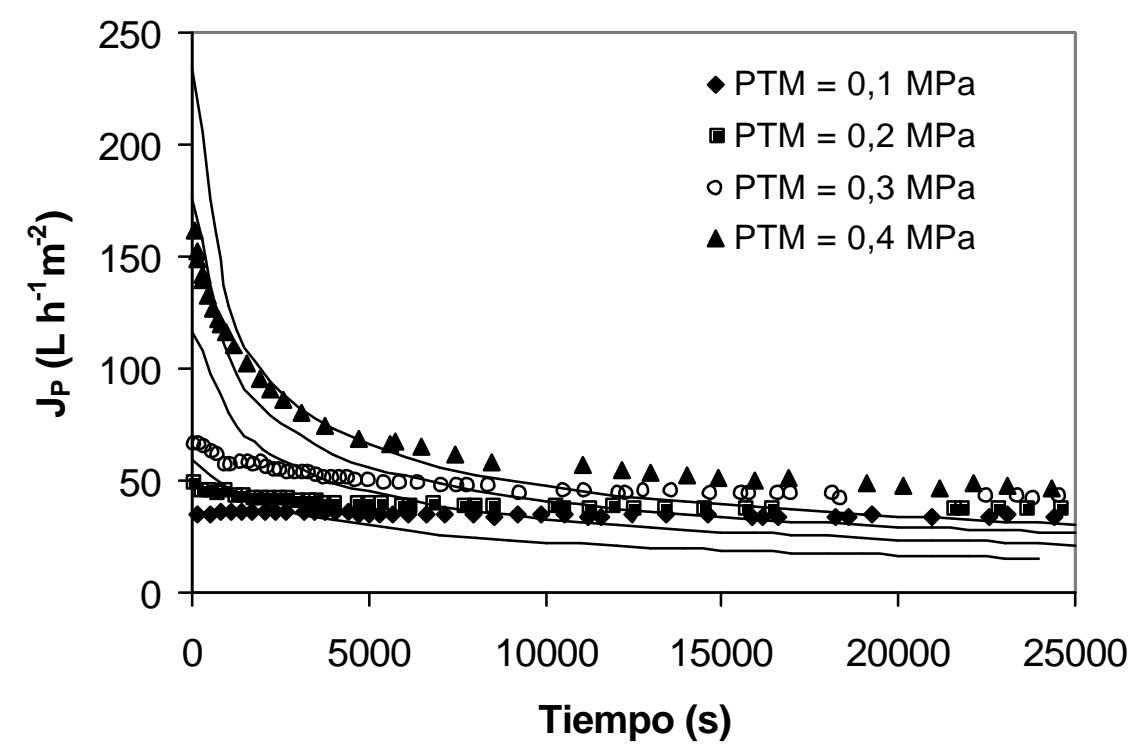

Figura 61. Comparación entre los datos experimentales y las predicciones del modelo que se describe en el apartado 3.1.2 cuando la concentración de la capa gel se estima de forma empírica para una velocidad tangencial de $1 \mathrm{~m} / \mathrm{s}$ y una concentración de $5 \mathrm{~g} / \mathrm{L}$ para la membrana Carbosep M 2

Si se comparan las Figuras 61 y 62 con las Figuras 49 y 51 se observa que cuando el M odelo de difusión inducido por cizalla aplicado en el caso de la ultrafiltración dinámica se aplica de forma totalmente teórica, el ensuciamiento que predice es menor que cuando se ha estimado la concentración en la capa gel de forma empírica. En este último caso, además, los valores de la densidad de flujo de permeado predichos por el modelo se ajustan peor a los resultados experimentales. 


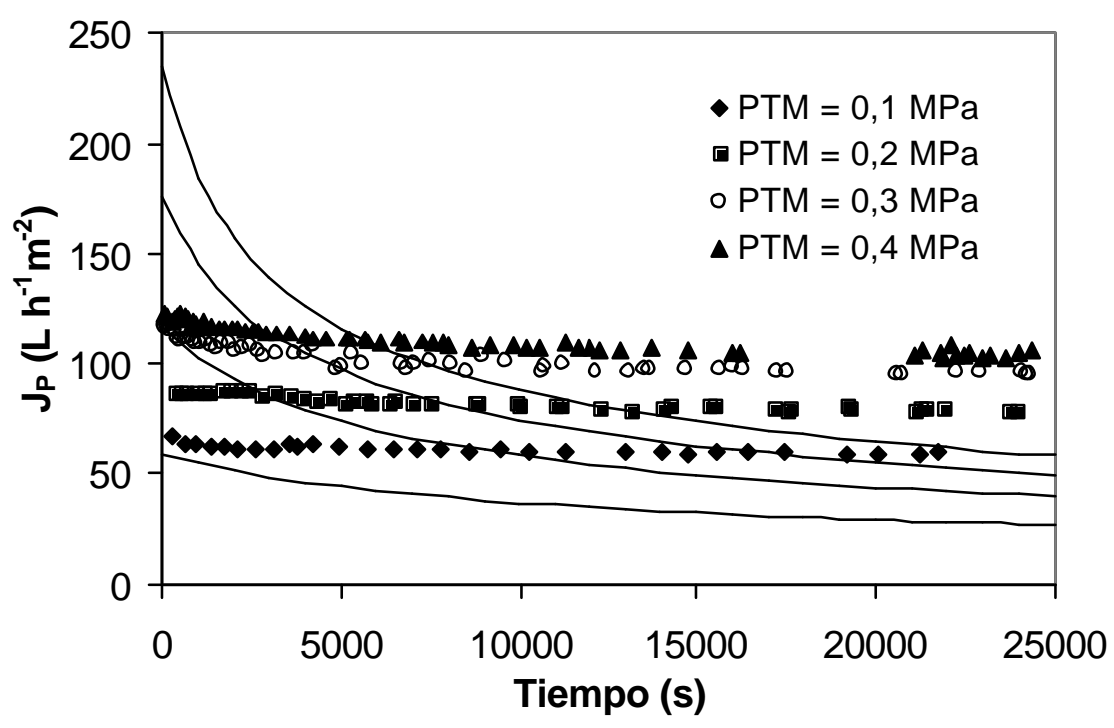

Figura 62. Comparación entre los datos experimentales y las predicciones del modelo que se describe en el apartado 3.1.2 cuando la concentración de la capa gel se estima de forma empírica para una velocidad tangencial de $3 \mathrm{~m} / \mathrm{s}$ y una concentración de $5 \mathrm{~g} / \mathrm{L}$ para la membrana Carbosep M 2

En las Figuras 63 a la 66 se comparan los resultados experimentales con los predichos por el modelo para la membrana Tami MSKT.

Comparando las Figuras 63 y 64 con las Figuras 61 y 62 se observa que, para las mismas condiciones experimentales, el Modelo de difusión inducido por cizalla aplicado en el caso de la ultrafiltración dinámica realiza mejores predicciones de la densidad de flujo de permeado estacionaria en el caso de las membranas Tami MSKT que en el caso de las membranas Carbosep M2. La cantidad de moléculas que contribuyen a la formación de la capa gel en el caso de las membranas Carbosep M2 es menor que en el caso de las membranas Tami MSKT ya que la membrana Carbosep M2 rechaza menos moléculas que la membrana Tami MSKT, según se indicó en el apartado 5.3.7. 


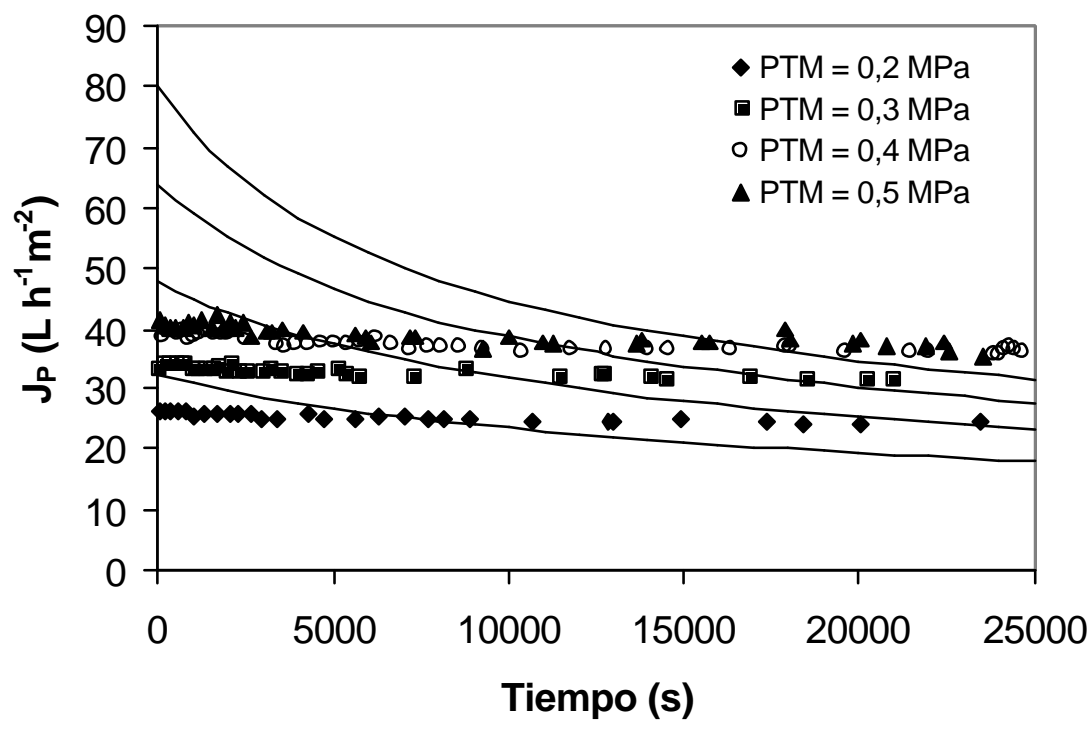

Figura 63. Comparación entre los datos experimentales y las predicciones del modelo que se describe en el apartado 3.1.2 cuando la concentración de la capa gel se estima de forma empírica para una velocidad tangencial de $1 \mathrm{~m} / \mathrm{s}$ y una concentración de $5 \mathrm{~g} / \mathrm{L}$ para la membrana Tami MSKT

El Modelo de difusión inducido por cizalla aplicado en el caso de la ultrafiltración dinámica predice mejor la densidad de flujo de permeado cuando la membrana se ensucia poco durante el proceso de ultrafiltración (Figura 64). En dichas condiciones, la diferencia entre la densidad de flujo de permeado al agua pura y la densidad de flujo de permeado obtenida con la disolución al imento no es muy pronunciada. Cuando el ensuciamiento es notorio, las predicciones que realiza el modelo son mucho peores (Figura 63). 


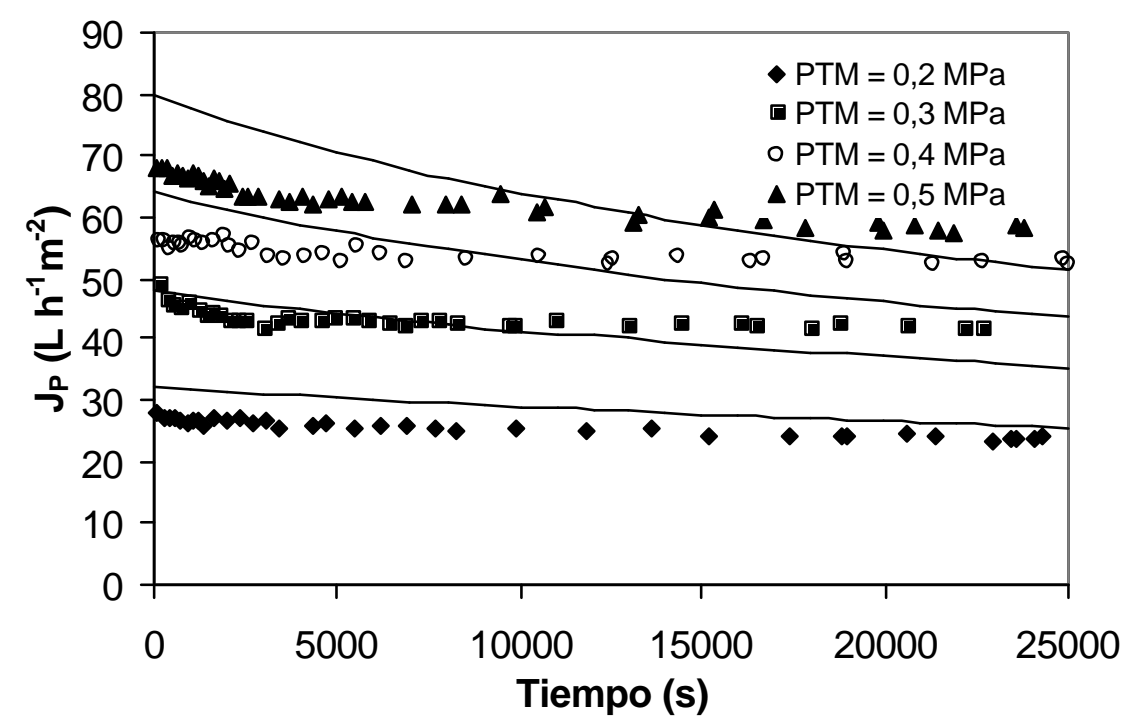

Figura 64. Comparación entre los datos experimentales y las predicciones del modelo que se describe en el apartado 3.1.2 cuando la concentración de la capa gel se estima de forma empírica para una velocidad tangencial de $3 \mathrm{~m} / \mathrm{s}$ y una concentración de $5 \mathrm{~g} / \mathrm{L}$ para la membrana Tami MSKT

En las Figuras 65 y 66 se muestran los resultados obtenidos con concentraciones más elevadas de soluto ( $15 \mathrm{~g} / \mathrm{L}$ ). 


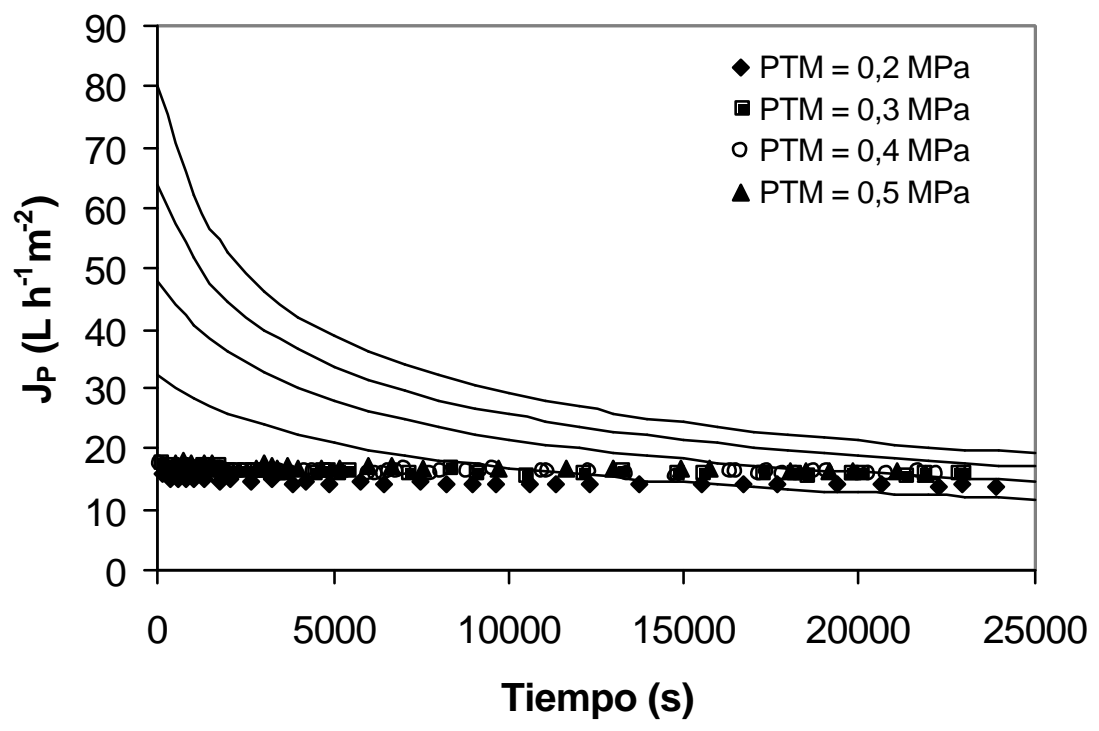

Figura 65. Comparación entre los datos experimentales y las predicciones del modelo que se describe en el apartado 3.1.2 cuando la concentración de la capa gel se estima de forma empírica para una velocidad tangencial de $1 \mathrm{~m} / \mathrm{s}$ y una concentración de $15 \mathrm{~g} / \mathrm{L}$ para la membrana Tami MSKT

En las condiciones más favorables para la formación de capa gel: elevadas concentraciones de la disolución alimento y bajas velocidades tangenciales (Figura 65), las predicciones no son mejores que cuando las condiciones de operación son menos favorables para el desarrollo de la capa gel (Figura 66). 


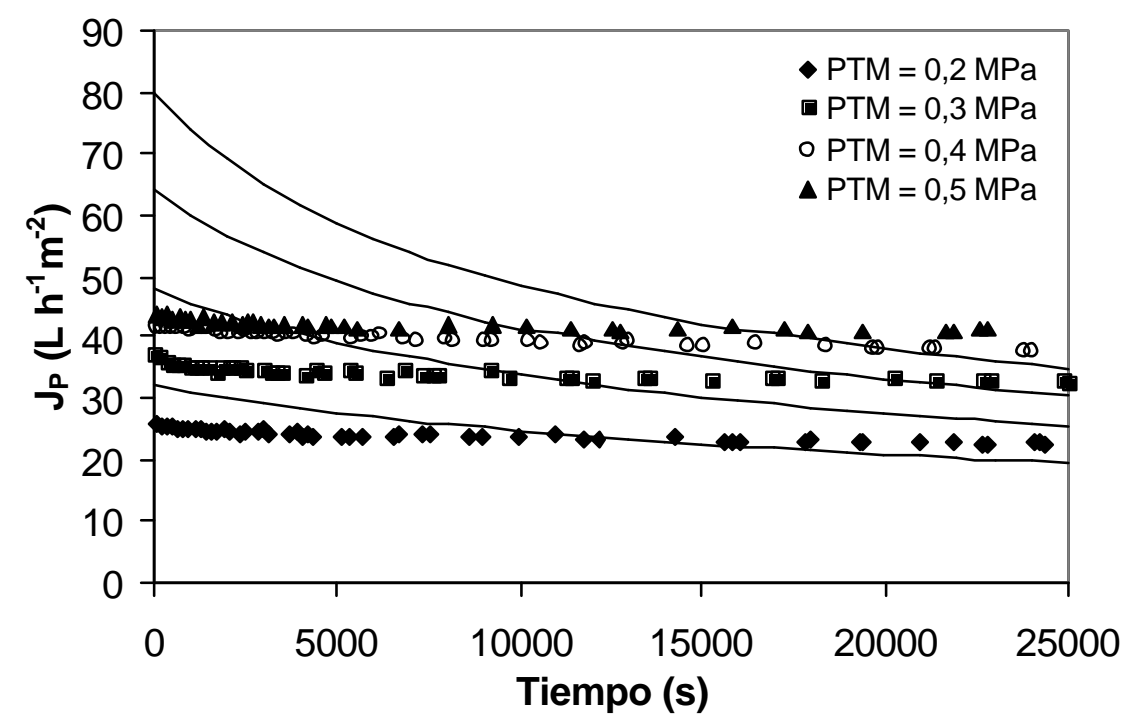

Figura 66. Comparación entre los datos experimentales y las predicciones del modelo que se describe en el apartado 3.1.2 cuando la concentración de la capa gel se estima de forma empírica para una velocidad tangencial de $3 \mathrm{~m} / \mathrm{s}$ y una concentración de $15 \mathrm{~g} / \mathrm{L}$ para la membrana Tami MSKT

\subsubsection{Modelo dinámico de Song para la ultrafiltración tangencial con estimación empírica de la concentración en la capa gel}

El M odelo dinámico de Song para la ultrafiltración tangencial junto con el M odelo dinámico de Bhattacharjee y Bhattacharya para la ultrafiltración controlada por la presión osmótica o por la capa gel indistintamente son dos de los modelos no empíricos que mejor predicen la variación de la densidad de flujo de permeado con el tiempo. Con ambos modelos se obtienen predicciones muy similares entre sí. En las Figuras 67 a la 69 se muestran las predicciones del M odelo dinámico de Song para la ultrafiltración tangencial cuando la concentración en la capa gel se ha estimado a partir de los datos experimentales de la densidad de flujo de permeado estacionario mediantela Ec. 19. En el 
apartado 5.4 .3 se muestran los resultados predichos por el modelo cuando éste se aplica de manera total mente teórica.

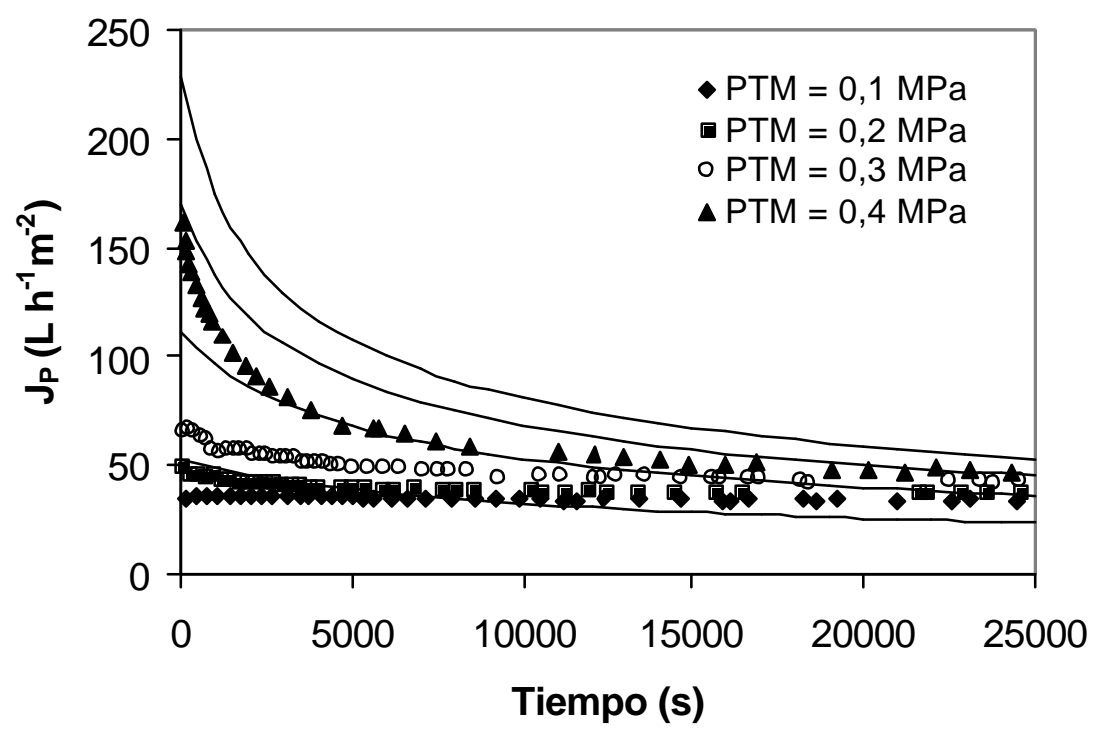

Figura 67. Comparación entre los datos experimentales y las predicciones del modelo que se describe en el apartado 3.1.3 cuando la concentración de la capa gel se estima de forma empírica para una velocidad tangencial de $1 \mathrm{~m} / \mathrm{s}$ y una concentración de $5 \mathrm{~g} / \mathrm{L}$ para la membrana Carbosep M 2

Dado que las predicciones del Modelo dinámico de Song para la ultrafiltración tangencial no reflejan la influencia de la velocidad tangencial en la densidad de flujo de permeado, sólo se muestran en este apartado los resultados obtenidos para una velocidad tangencial. Se escoge una velocidad tangencial de $1 \mathrm{~m} / \mathrm{s}$ puesto que de todas las velocidades tangenciales ensayadas es aquella para la cual es más probable que se forme capa gel y por tanto es aquella para la cual el modelo debería funcionar mejor.

Para la membrana Carbosep M2, las predicciones del modelo cuando la concentración en la capa gel se estima de forma empírica (Figura 67) coinciden con las predicciones obtenidas anteriormente (Figura 52) cuando se estima la concentración en la capa gel de 
forma teórica. Esto se debe a que el modelo no refleja la influencia de la concentración de la capa gel en los resultados predichos por el mismo.

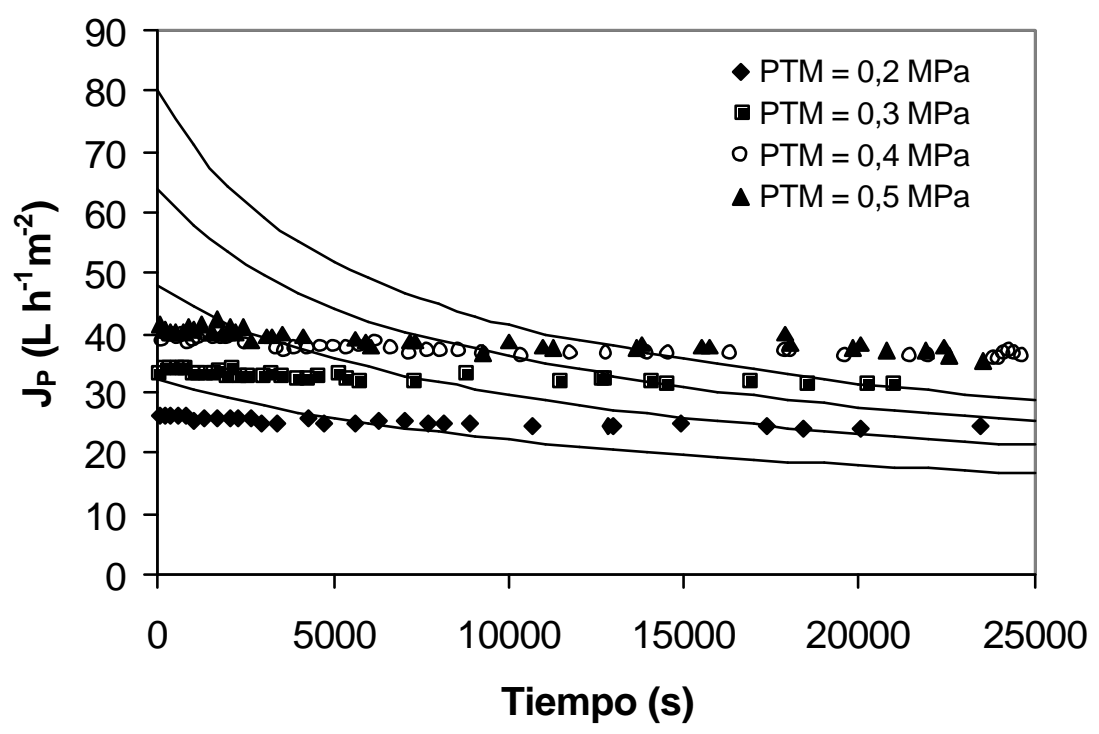

Figura 68. Comparación entre los datos experimentales y las predicciones del modelo que se describe en el apartado 3.1.3 cuando la concentración de la capa gel se estima de forma empírica para una velocidad tangencial de $1 \mathrm{~m} / \mathrm{s}$ y una concentración de $5 \mathrm{~g} / \mathrm{L}$ para la membrana Tami MSKT

En el caso de la membrana Tami MSKT, no se obtienen buenos resultados para ninguna de las concentraciones de alimento ensayadas (Figura 68 y Figura 69). Esto se debe a que el modelo no es adecuado cuando la densidad de flujo de permeado varía poco con el tiempo. El modelo predice en todos los casos una disminución acusada de la densidad de flujo de permeado con el tiempo, mientras que los datos experimentales muestran muy poca variación de la densidad de flujo de permeado con el tiempo. 


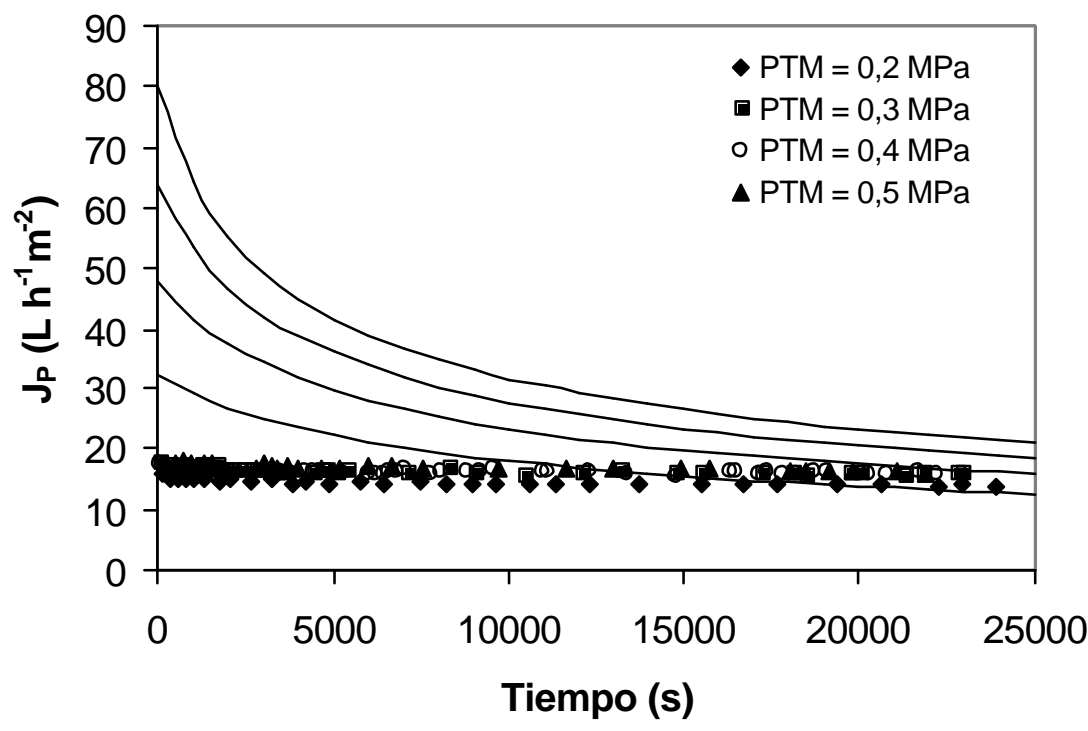

Figura 69. Comparación entre los datos experimentales y las predicciones del modelo que se describe en el apartado 3.1.3 cuando la concentración de la capa gel se estima de forma empírica para una velocidad tangencial de $1 \mathrm{~m} / \mathrm{s}$ y una concentración de $15 \mathrm{~g} / \mathrm{L}$ para la membrana Tami MSKT

Si se compara la Figura 68 con la Figura 69, se observa que, del mismo modo que muestran los datos experimentales, al aumentar la concentración de la disolución alimento el modelo predice densidades de flujo de permeado más parecidas entre sí para las distintas PTMs. Sin embargo, para la concentración de la disolución alimento más alta ensayada (Figura 69) los resultados experimentales obtenidos para las distintas PTMs coinciden, no lográndose esta coincidencia en los resultados predichos por el modelo. 


\subsubsection{Conclusiones de la aplicación de los modelos dinámicos de ultrafiltración no empíricos cuando la concentración en la capa gel se estima de forma empírica}

Los resultados experimentales obtenidos con los modelos dinámicos de ultrafiltración no empíricos cuando la concentración en la capa gel se estima deforma empírica permiten concluir lo siguiente:

- El valor de la densidad de flujo de permeado predicho por el Modelo de difusión inducido por cizalla aplicado en el caso de la ultrafiltración dinámica cuando la concentración en la capa gel se estima de forma empírica no se ajusta más al valor experimental que cuando dicha concentración se estima de forma teórica.

- Cuando la concentración en la capa gel se estima de forma empírica, los valores de la densidad de flujo de permeado predichos por el M odelo dinámico de Song para la ultrafiltración tangencial son similares a los obtenidos cuando dicho parámetro se estima teóricamente, no logrando ninguna mejora en el grado de ajuste a los resultados experimentales.

- Ninguno de los modelos no empíricos que se han analizado en esta Tesis Doctoral predice de manera precisa la densidad de flujo de permeado, incluso cuando se estima de manera empírica la concentración en la capa gel. Por ello se debe investigar la posibilidad de aplicar otros modelos dinámicos que no sean totalmente teóricos. 


\subsection{APLICACIÓN DE MOdELOS DINÁMICOS DE ULTRAFILTRACIÓN SEMI-EM PÍRICOS}

\subsubsection{R esultados de la aplicación de los M odelos de Hermia}

Los M odelos de Hermia fueron desarrollados para flujo transversal a la membrana y han sido aplicados en el caso de flujo tangencial.

\section{Modelo de bloqueo completo de poros $(n=2)$}

Este modelo considera que las moléculas de soluto presentes en la disolución alimento son de mayor tamaño que los poros de la membrana, de forma que no pueden atravesarla. Sin embargo, en el apartado 5.3.7 se hace referencia a un índice de rechazo de la membrana al PEG próximo al $86 \%$ bajo las condiciones experimentales ensayadas.

Para la velocidad tangencial de $1 \mathrm{~m} / \mathrm{s}$ (Figura 70), el ajuste del Modelo de bloqueo completo de poros a los datos experimentales es bueno en el caso de 0.1 MPa, aceptable en el caso de 0.2 y $0.3 \mathrm{MPa}$ y muy malo en el caso de $0.4 \mathrm{MPa}$.

A velocidades tangenciales mayores, $2 \mathrm{~m} / \mathrm{s}$ (Figura 71), se vuelve a obtener un ajuste del $\mathrm{M}$ odelo de bloqueo completo de poros a los datos experimentales bueno en el caso de 0.1 MPa, aceptable en el caso de 0.2 y $0.3 \mathrm{MPa}$ y muy malo en el caso de $0.4 \mathrm{MPa}$. 


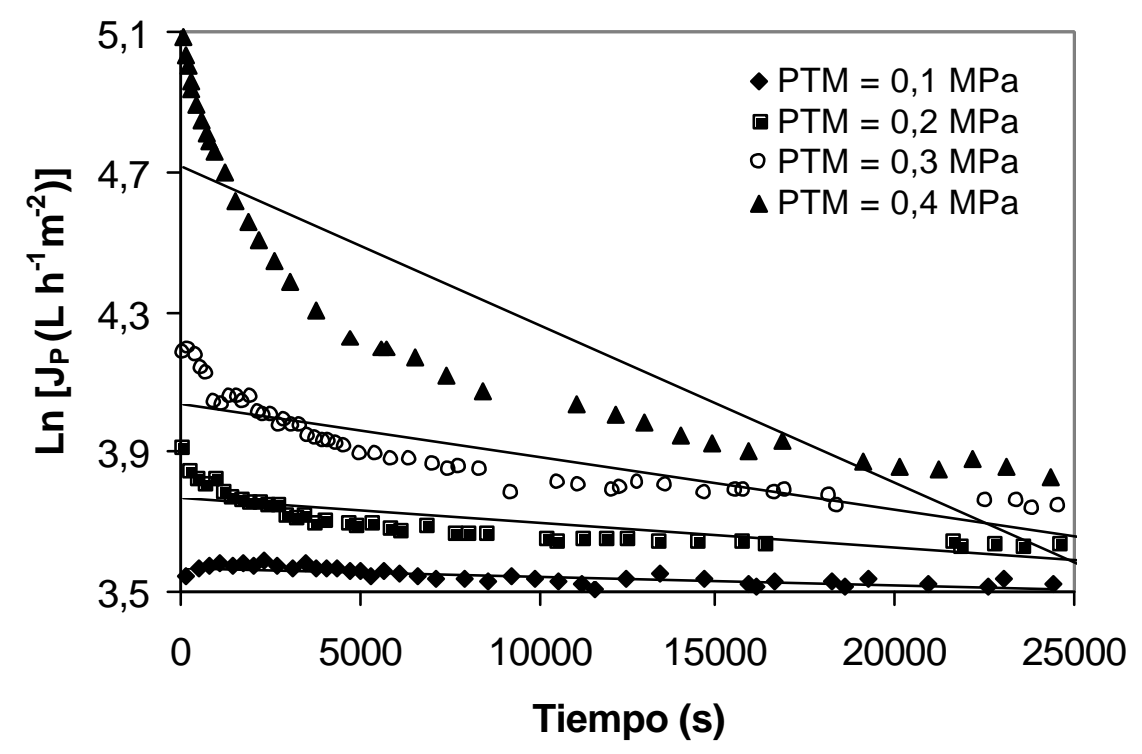

Figura 70. Ajuste empírico del M odelo de bloqueo completo de poros para una velocidad tangencial de $1 \mathrm{~m} / \mathrm{s}$ y una concentración de 5g/ L para la membrana Carbosep M2

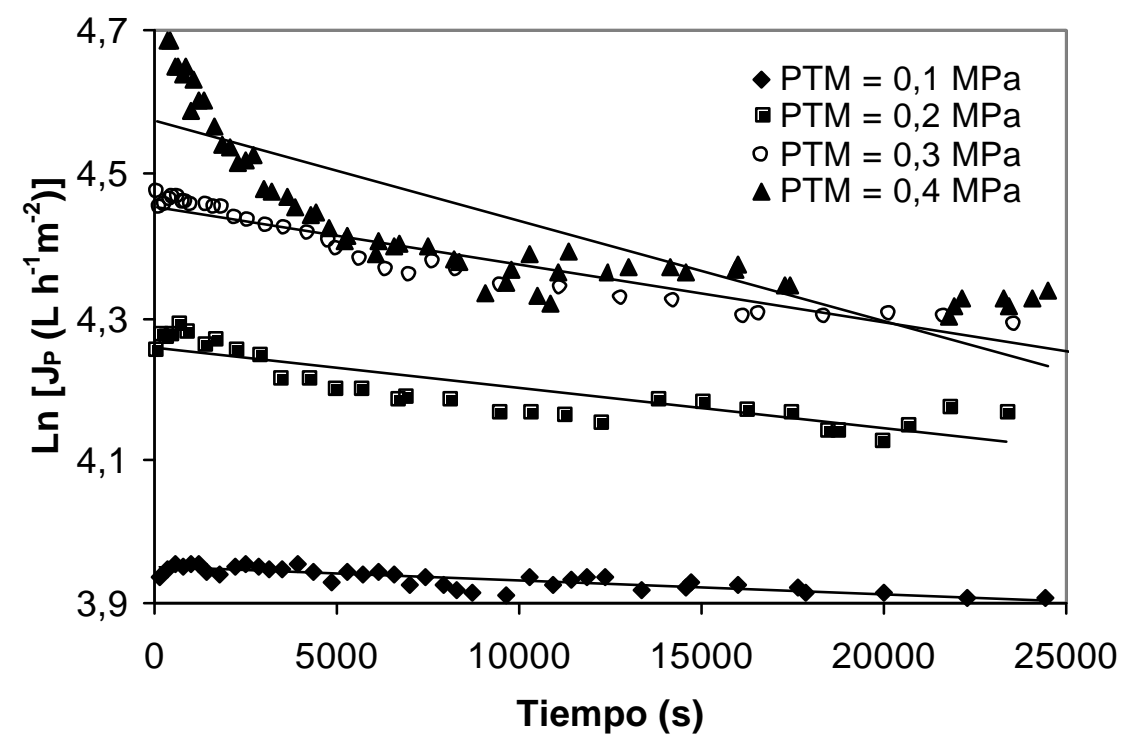

Figura 71. Ajuste empírico del M odelo de bloqueo completo de poros para una velocidad tangencial de $2 \mathrm{~m} / \mathrm{s}$ y una concentración de $5 \mathrm{~g} / \mathrm{L}$ para la membrana Carbosep M2 
Para la velocidad tangencial de $3 \mathrm{~m} / \mathrm{s}$ (Figura 72), para la que se observa quela densidad de flujo de permeado varía muy poco con el tiempo, el ajuste del M odel o de bloqueo completo de poros a los datos experimentales es bueno para todas las PTMs.

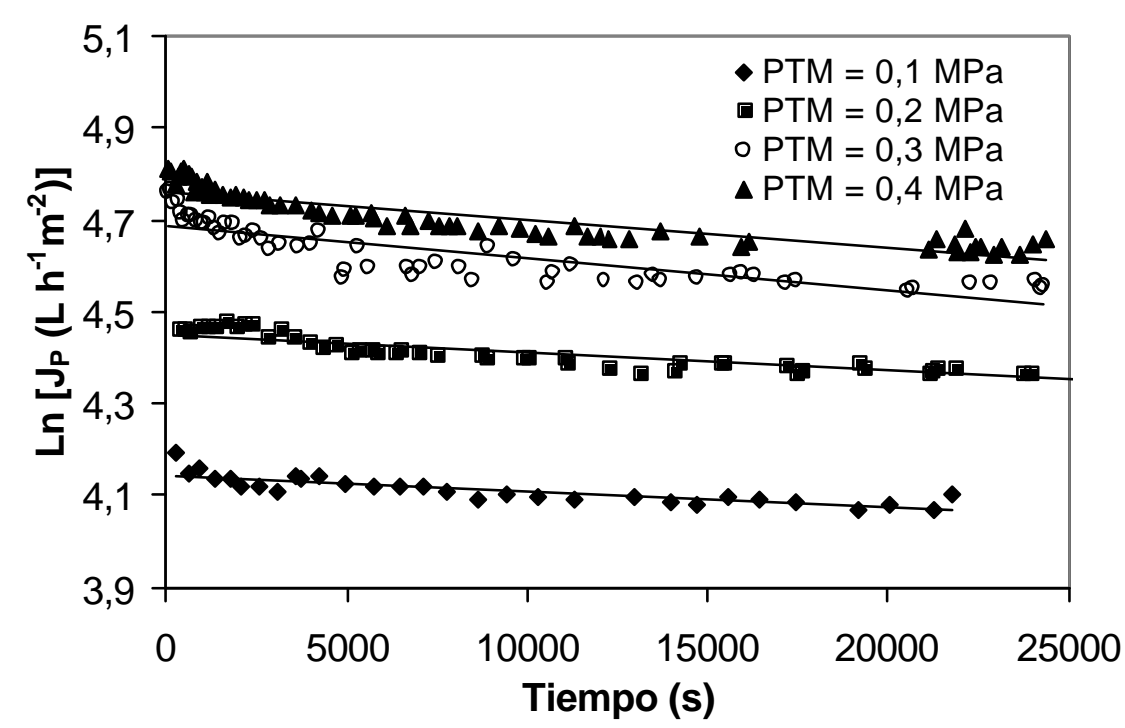

Figura 72. Ajuste empírico del M odelo de bloqueo completo de poros para una velocidad tangencial de $3 \mathrm{~m} / \mathrm{s}$ y una concentración de $5 \mathrm{~g} / \mathrm{L}$ para la membrana Carbosep M2

Model o de bloqueo intermedio de poros $(n=1)$

El M odelo de bloqueo intermedio de poros considera que el tamaño de los poros de la membrana es similar al tamaño de las moléculas de soluto, produciéndose una obstrucción de la entrada de los poros sin que se bloqueen completamente en todos los casos. Esta situación puede equipararse a la que se obtiene en los ensayos experimentales, pues las moléculas de soluto no son rechazadas en su totalidad por la membrana. Ésta puede ser una de las causas de que el $\mathrm{M}$ odel o de bloqueo intermedio de poros se ajuste mejor a los datos experimentales que el $\mathrm{M}$ odel o de bloqueo completo de poros. 
El M odelo de bloqueo intermedio deporos describe una situación más real que el $M$ odelo de bloqueo completo de poros puesto que considera que las moléculas de soluto se pueden depositar unas sobre otras de forma que la probabilidad de que una molécula de soluto bloquee un poro disminuye con el tiempo.

Cuando la velocidad tangencial es de $1 \mathrm{~m} / \mathrm{s}$, el M odelo de bloqueo intermedio de poros se ajusta bien a los datos experimentales para una PTM 0.1 MPa (Figura 73). Sin embargo el ajuste no es tan bueno en el caso de 0.2, 0.3 MPa y 0.4 MPa.

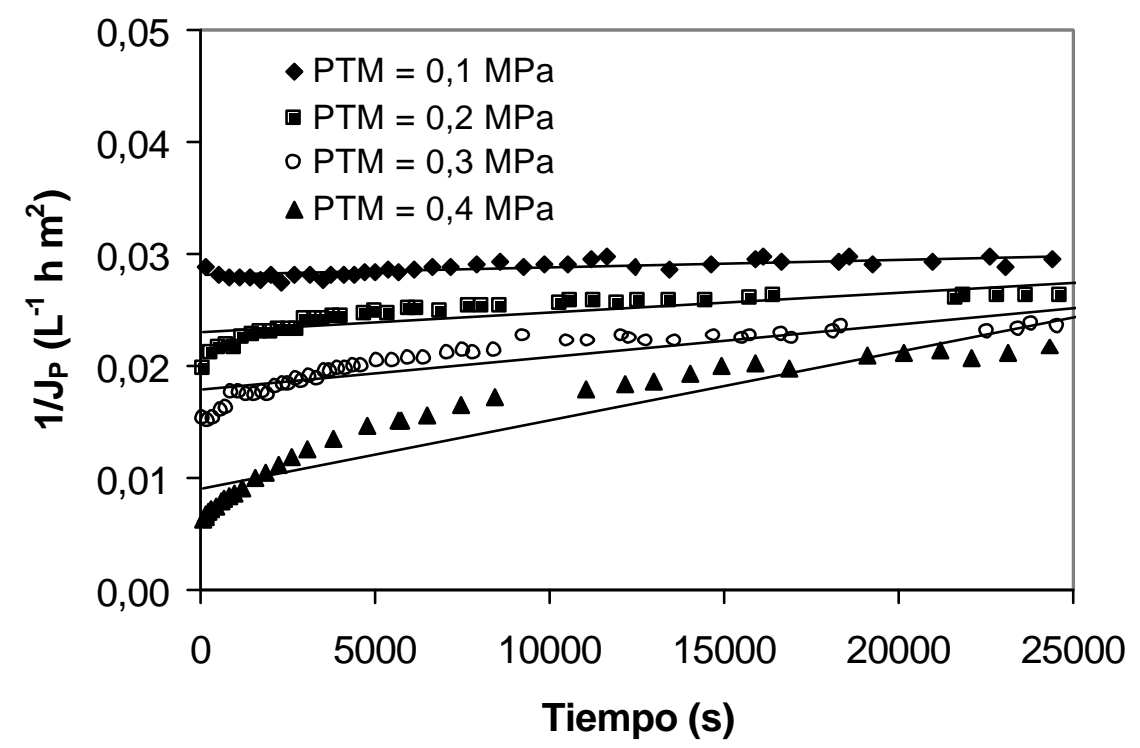

Figura 73. Ajuste empírico del M odelo de bloqueo intermedio de poros para una velocidad tangencial de $1 \mathrm{~m} / \mathrm{s}$ y una concentración de $5 \mathrm{~g} / \mathrm{L}$ para la membrana Carbosep M2

Para la velocidad tangencial de $2 \mathrm{~m} / \mathrm{s}$, e M odelo de bloqueo intermedio de poros se ajusta bien a los datos experimentales cuando la PTM es de $0.1,0.2$ y $0.3 \mathrm{MPa}$. Los peores resultados se obtienen para la PTM de 0.4 MPa (Figura 74). 


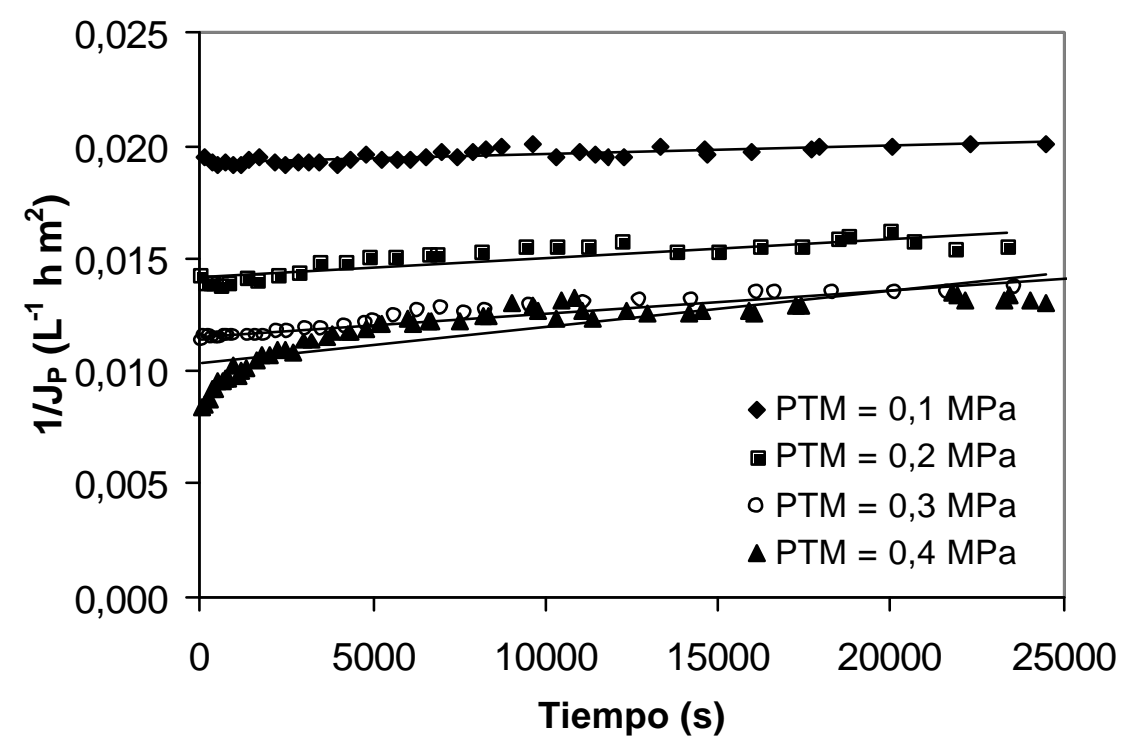

Figura 74. Ajuste empírico del M odel o de bloqueo intermedio de poros para una velocidad tangencial de $2 \mathrm{~m} / \mathrm{s}$ y una concentración de $5 \mathrm{~g} / \mathrm{L}$ para la membrana Carbosep M2

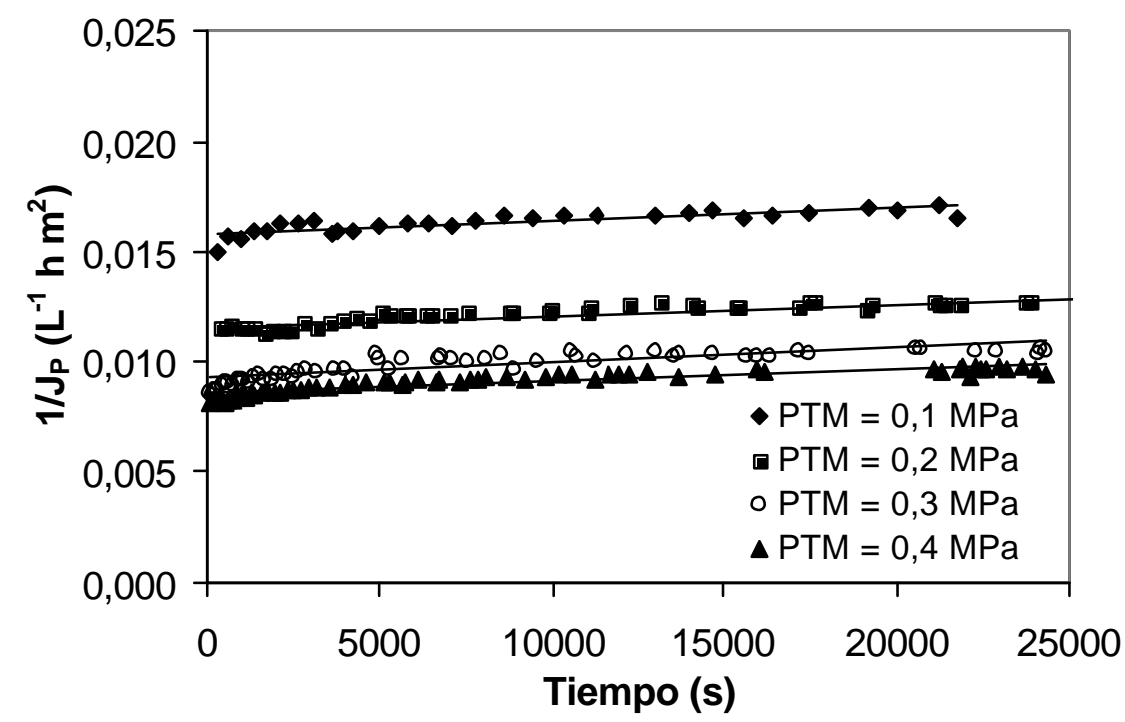

Figura 75. Ajuste empírico del M odel o de bloqueo intermedio de poros para una velocidad tangencial de $3 \mathrm{~m} / \mathrm{s}$ y una concentración de $5 \mathrm{~g} / \mathrm{L}$ para la membrana Carbosep M2 
Cuando la velocidad tangencial es de $3 \mathrm{~m} / \mathrm{s}$, el ajuste del M odelo de bloqueo intermedio de poros a los datos experimentales es bueno para todas las PTMs ensayadas (Figura 75).

\section{Modelo de bloqueo estándar de poros ( $n=3 / 2)$}

En el M odelo de bloqueo estándar de poros el tamaño de las moléculas de soluto se considera inferior al de los poros de la membrana, produciéndose un bloqueo interno de los mismos. El ajuste del modelo a los datos experimentales es malo debido a que bajo las condiciones experimentales ensayadas la mayoría de moléculas no atraviesan la membrana hacia el lado del permeado, siendo su tamaño muy superior al de los poros de la membrana.

El Modelo de bloqueo estándar de poros se ajusta bien para una velocidad tangencial de $1 \mathrm{~m}$ / s y una PTM de 0.1 MPa (Figura 76). Para PTMs superiores el ajuste es peor, siendo muy malo en el caso de 0.4 MPa.

Cuando la velocidad tangencial es de $2 \mathrm{~m} / \mathrm{s}$ (Figura 77), el M odelo de bloqueo estándar de poros se ajusta bien a los datos experimentales cuando la densidad de flujo de permeado varía muy poco con el tiempo. Este es el caso de la PTM de 0.1 MPa. Para PTMs mayores, 0.2 y $0.3 \mathrm{MPa}$, el ajuste es aceptable y muy malo en el caso de 0.4 $\mathrm{MPa}$. 


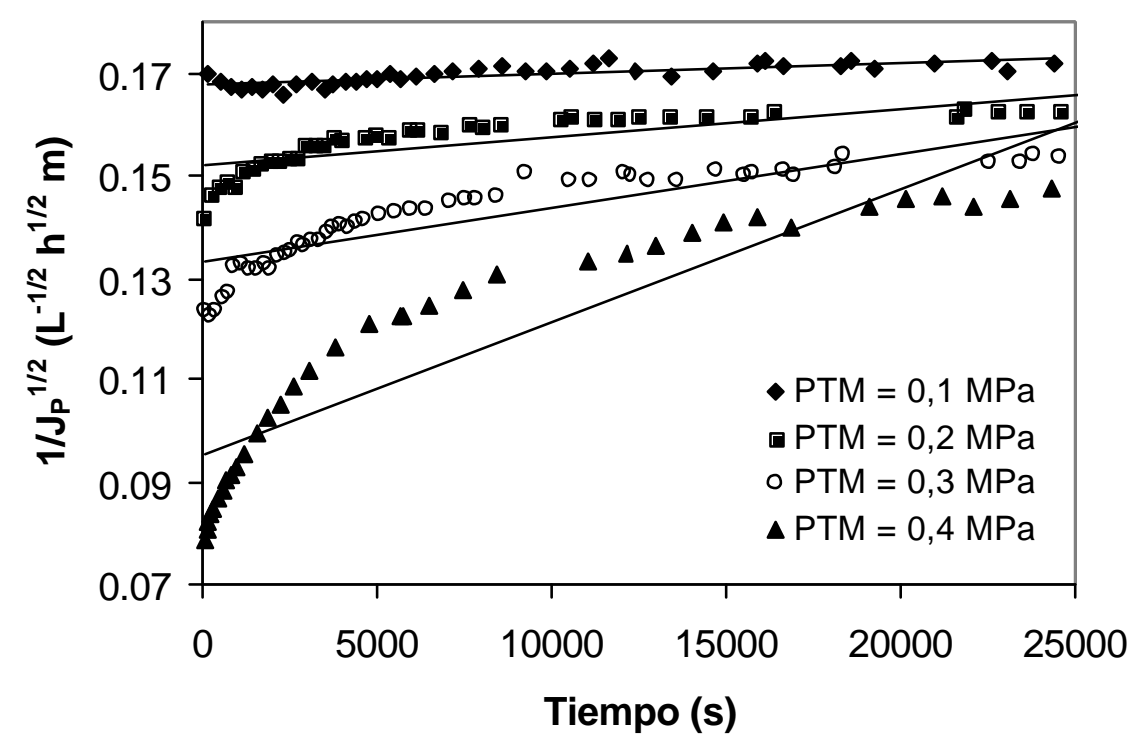

Figura 76. Ajuste empírico del M odelo de bloqueo estándar de poros para una velocidad tangencial de $1 \mathrm{~m} / \mathrm{s}$ y una concentración de 5g/ L para la membrana Carbosep M2

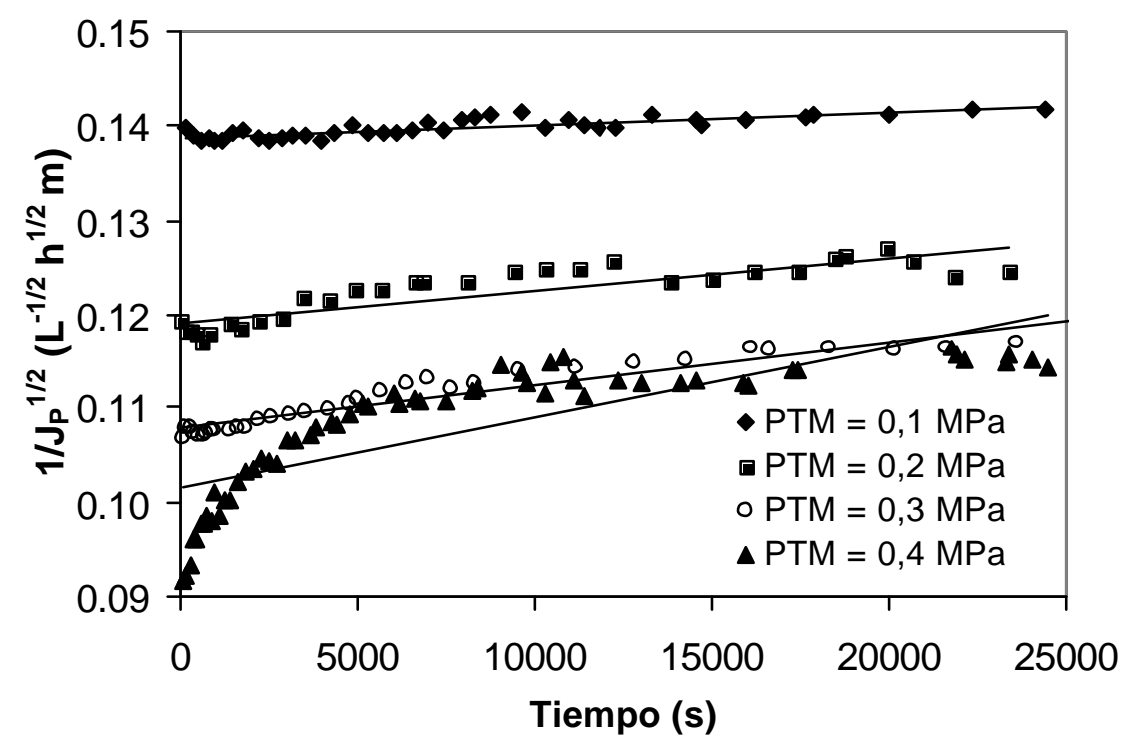

Figura 77. Ajuste empírico del M odelo de bloqueo estándar de poros para una velocidad tangencial de $2 \mathrm{~m} / \mathrm{s}$ y una concentración de $5 \mathrm{~g} / \mathrm{L}$ para la membrana Carbosep M2 
Para la velocidad tangencial de $3 \mathrm{~m} / \mathrm{s}$ y todas las PTMs ensayadas (Figura 78), el ajuste del Modelo de bloqueo estándar de poros a los datos experimentales es bueno.

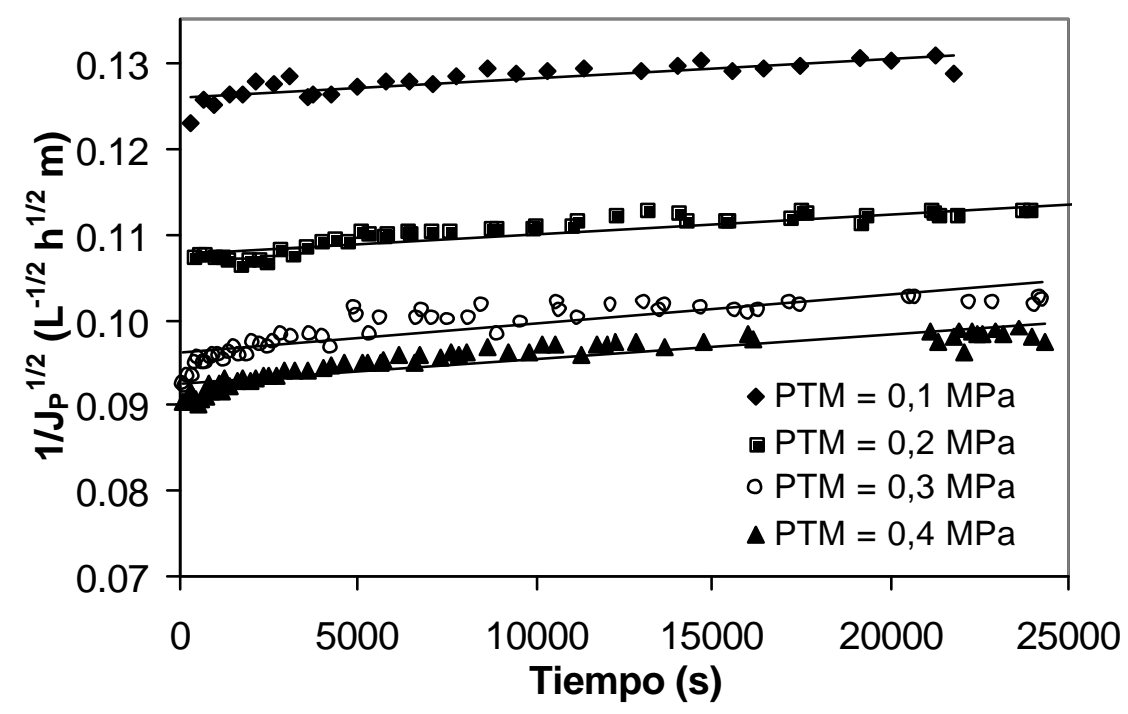

Figura 78. Ajuste empírico del M odelo de bloqueo estándar de poros para una velocidad tangencial de $3 \mathrm{~m} / \mathrm{s}$ y una concentración de $5 \mathrm{~g} / \mathrm{L}$ para la membrana Carbosep M2

Modelo de formación de torta $(n=0)$

EI M odelo de formación de torta considera que las moléculas de soluto son mucho más grandes que el poro y no penetran en él. Se obtiene un buen ajuste del modelo a los datos experimentales debido a que la mayor parte de las moléculas de PEG son rechazadas por la membrana bajo las condiciones experimentales ensayadas.

Para la velocidad tangencial de $1 \mathrm{~m} / \mathrm{s}$, el ajuste del Modelo de formación de torta a los datos experimentales es bueno en el caso de 0.1 MPa. Los resultados obtenidos con PTMs superiores no son del todo insatisfactorios (Figura 79). 


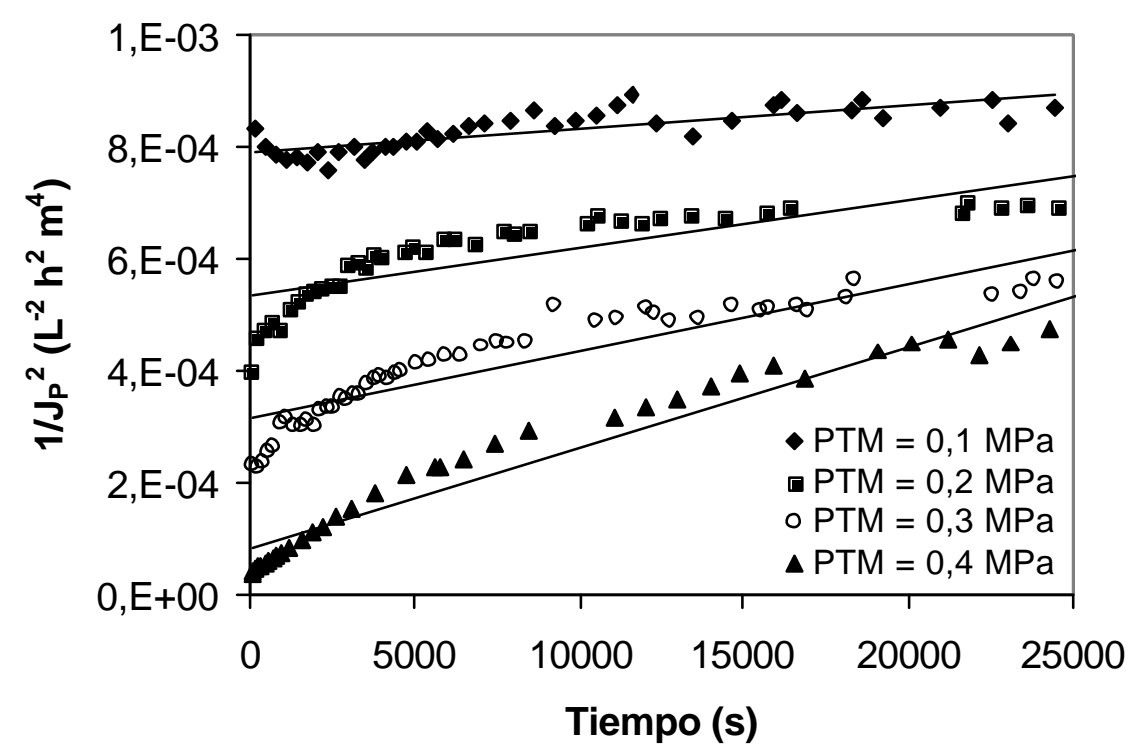

Figura 79. Ajuste empírico del Modelo de formación de torta para una velocidad tangencial de $1 \mathrm{~m} / \mathrm{s}$ y una concentración de $5 \mathrm{~g} / \mathrm{L}$ para la membrana Carbosep M2

El ajuste del M odelo de formación de torta a los datos experimentales para la velocidad tangencial de $2 \mathrm{~m} / \mathrm{s}$ es bueno en la mayoría de las condiciones experimentales ensayadas, 0.1, 0.2 y $0.3 \mathrm{MPa}$ (Figura 80), no siendo tan bueno en el caso de 0.4 M Pa.

Al igual que con los anteriores modelos, para la velocidad tangencial de $3 \mathrm{~m} / \mathrm{s}$, el ajuste del M odelo de formación de torta a los datos experimentales es bueno para todas las PTMs ensayadas (Figura 81). 


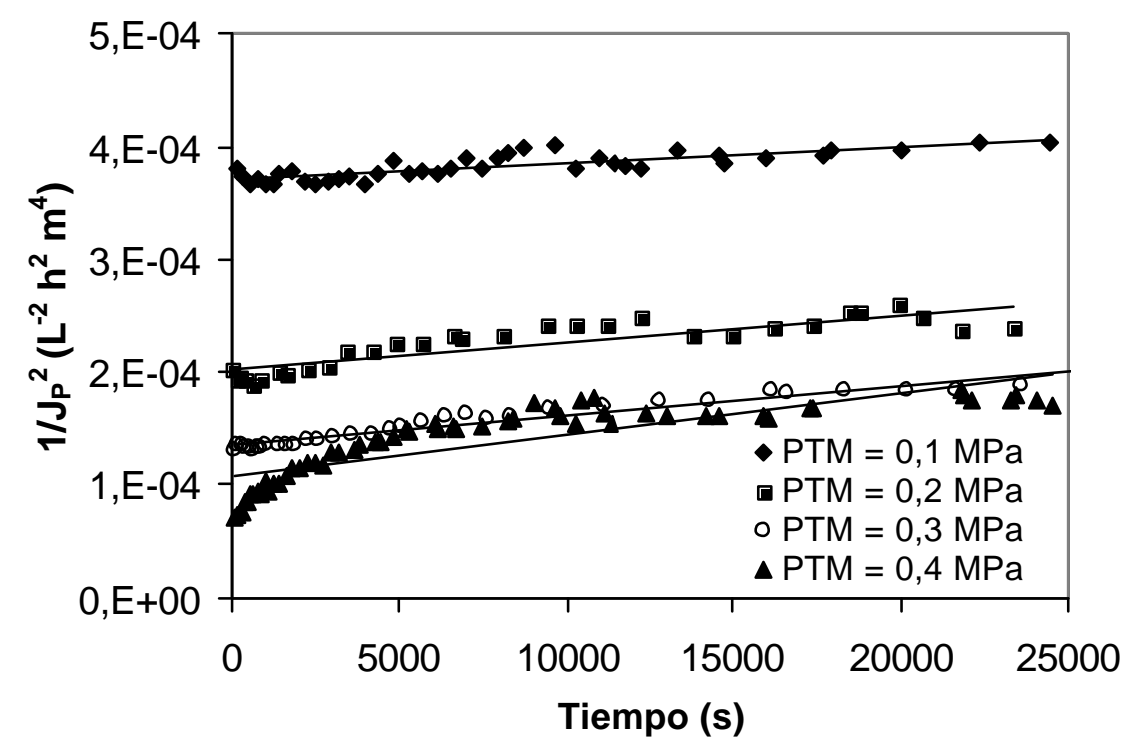

Figura 80. Ajuste empírico del Modelo de formación de torta para una velocidad tangencial de $2 \mathrm{~m} / \mathrm{s}$ y una concentración de $5 \mathrm{~g} / \mathrm{L}$ para la membrana Carbosep M2

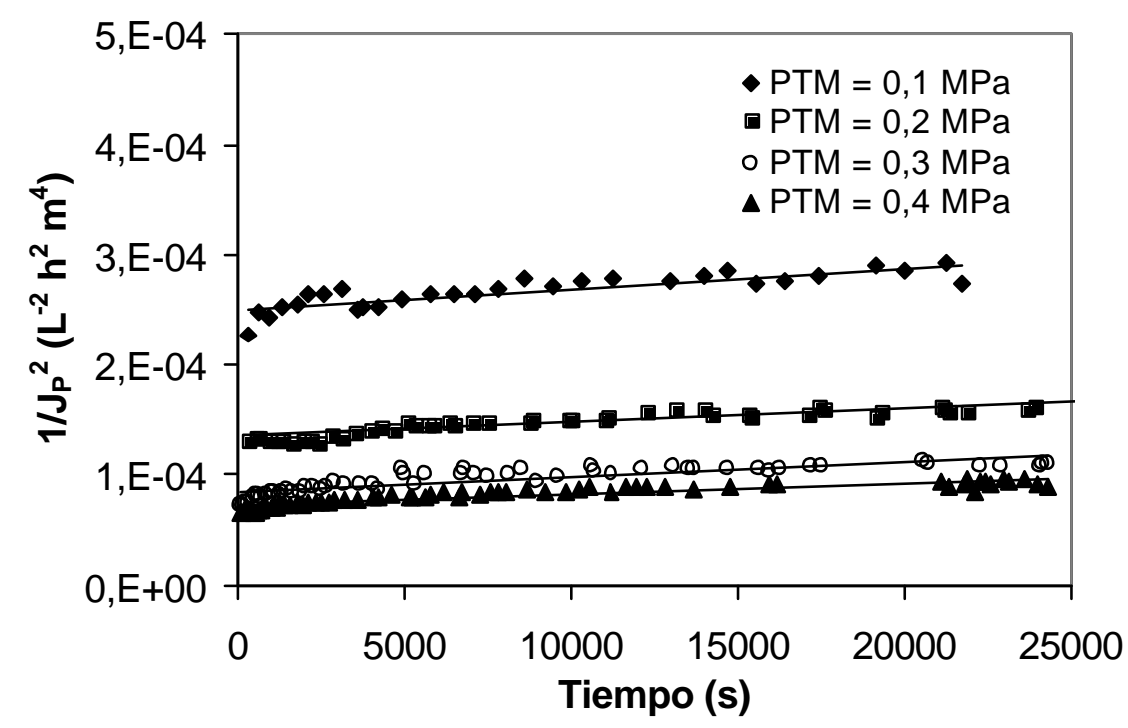

Figura 81. Ajuste empírico del Modelo de formación de torta para una velocidad tangencial de $3 \mathrm{~m} / \mathrm{s}$ y una concentración de $5 \mathrm{~g} / \mathrm{L}$ para la membrana Carbosep M2 
Comparación entre los distintos M odel os de H ermia y conclusiones

En la Tabla 8 se muestran los val ores del error cuadrático medio, R22, para ajustes de los Modelos de Hermia a los datos experimentales obtenidos en los ensayos de ultrafiltración realizados en planta piloto. En la mayoría de los casos los valores del error cuadrático medio se encuentran por debajo de 0.9. La causa principal de que el error cuadrático medio esté por debajo de 0.9 es que los M odelos de Hermia consideran filtración frontal.

Tabla 8. Error cuadrático medio de los ajustes de los M odel os de H ermia a los datos experimentales obtenidos con la membrana Carbosep M2

\begin{tabular}{c|c|cccc}
\hline $\begin{array}{c}\text { Velocidad } \\
\text { tangencial } \\
(\mathrm{m} / \mathrm{s})\end{array}$ & $\begin{array}{c}\text { PTM } \\
\text { (MPa) }\end{array}$ & $\begin{array}{c}\text { Bloqueo } \\
\text { completo }\end{array}$ & $\begin{array}{c}\text { Bloqueo } \\
\text { intermedio }\end{array}$ & $\begin{array}{c}\text { Bloqueo } \\
\text { estándar }\end{array}$ & Capa gel \\
\hline \multirow{3}{*}{1} & 0.1 & 0.636 & 0.638 & 0.637 & 0.639 \\
& 0.2 & 0.621 & 0.648 & 0.635 & 0.675 \\
& 0.3 & 0.750 & 0.792 & 0.772 & 0.829 \\
& 0.4 & 0.787 & 0.883 & 0.838 & 0.947 \\
& 0.1 & 0.679 & 0.680 & 0.680 & 0.681 \\
& 0.2 & 0.755 & 0.760 & 0.758 & 0.765 \\
& 0.3 & 0.913 & 0.923 & 0.918 & 0.933 \\
& 0.4 & 0.631 & 0.669 & 0.650 & 0.704 \\
\hline 3 & 0.1 & 0.700 & 0.710 & 0.705 & 0.719 \\
& 0.2 & 0.799 & 0.806 & 0.802 & 0.813 \\
& 0.3 & 0.709 & 0.723 & 0.716 & 0.736 \\
& 0.4 & 0.793 & 0.806 & 0.800 & 0.819 \\
\hline
\end{tabular}

Si se comparan los valores de $\mathrm{R}^{2}$ de un mismo modelo para distintas condiciones experimentales se observa que no siempre las rectas de ajuste que corresponden a un $\mathrm{R}^{2}$ mayor se ajustan mejor a los resultados experimentales (Gu, 2004). Por ejemplo, en la Tabla 8 se 
observa que, para el $\mathrm{M}$ odelo de bloqueo completo de poros, $\mathrm{R}^{2}$ es mayor en el caso de $1 \mathrm{~m} / \mathrm{s}$ y $0.4 \mathrm{MPa}$ que en el caso de $1 \mathrm{~m} / \mathrm{s}$ y $0.1 \mathrm{MPa}$. Sin embargo en la Figura 70 se observa que el ajuste es mejor para 0.1MPa que en el caso de 0.4 MPa. Lo mismo ocurre para todos los modelos en la mayoría de las condiciones experimentales ensayadas. Por lo tanto, parece adecuado comparar los valores de ${ }^{2}$ para los distintos Modelos de Hermia y bajo unas condiciones experimentales fijas de PTM y de velocidad tangencial, y no para un modelo determinado y diferentes condiciones experimentales.

A tendiendo a los valores de $\mathrm{R}^{2}$ de la Tabla 8 se concluye lo siguiente:

- No siempre las rectas de ajuste que corresponden a un $\mathrm{R}^{2}$ mayor se ajustan mejor a los resultados experimentales. Los valores de $\mathrm{R}^{2}$ deben analizarse con precaución, comparando los diferentes modelos para unas condiciones experimentales fijas.

- Para todas las condiciones experimentales ensayadas el modelo que presenta un $\mathrm{R}^{2}$ mayor es el $\mathrm{M}$ odelo de formación de torta, seguido del M odelo de bloqueo intermedio de poros.

- Según la Tabla 8, cuando el proceso de ultrafiltración está controlado por la transferencia de materia (0.3 y $0.4 \mathrm{MPa}$ y velocidades tangenciales de 1 y $2 \mathrm{~m} / \mathrm{s}$, Figura 20) el valor de $\mathrm{R}^{2}$ es mayor que cuando el proceso está controlado por la PTM, i.e. para el resto de condiciones de operación.

Mediante la observación de las Figuras 70 a la 81 del presente apartado de esta Tesis Doctoral puede concluirse lo siguiente:

- Para todos los modelos el ajuste es mejor cuando la densidad de flujo de permeado varía poco con el tiempo (velocidad tangencial de $3 \mathrm{~m} / \mathrm{s}$ para PTMs de $0.1,0.2,0.3$ y $0.4 \mathrm{MPa}$ y 
velocidades tangenciales de 1 y $2 \mathrm{~m} / \mathrm{s}$ para una PTM de 0.1 $\mathrm{MPa})$.

- Sólo para los ensayos en los que la densidad de flujo de permeado desciende apreciablemente con el tiempo se puede escoger el modelo más apropiado. Por tanto, para los ensayos realizados con las membranas Tami MSKT no puede escogerse el modelo más apropiado, ya que los ajustes son buenos en todos los casos.

- El M odelo de bloqueo intermedio de poros es el que mejor se ajusta a los resultados experimentales para todas las condiciones experimentales ensayadas.

- Los resultados predichos por el Modelo de formación de torta presentan un grado de ajuste a los resultados experimentales análogo al mostrado por el $\mathrm{M}$ odelo de bloqueo intermedio de poros para 1 y $2 \mathrm{~m} / \mathrm{s}$ y $0.4 \mathrm{MPa}$, condiciones para las cuales la formación de capa gel es más probable.

\subsubsection{Resultados de la aplicación de los Modelos de Hermia adaptados para flujo tangencial}

Modelo de bloqueo completo de poros para flujo tangencial $\left(\mathrm{n}_{\underline{c F}}=2\right)$

El ajuste del M odelo de bloqueo completo de poros para flujo tangencial es bueno para todas las condiciones de operación ensayadas Figuras 82 a la 84). Los peores resultados se obtienen para una velocidad tangencial de $1 \mathrm{~m} / \mathrm{s}$ y una PTM de 0.4 MPa (Figura 82). Esto se debe a que para velocidades tangenciales reducidas y elevadas PTMs el paso de moléculas de soluto a través de la membrana es máximo, tal y como se comentó en el apartado 5.3.7 de la presente Tesis Doctoral. Sin embargo, el M odelo de bloqueo completo de poros para flujo 
tangencial considera que las moléculas de soluto son de mayor tamaño que los por os de la membrana y no pueden atravesarla.

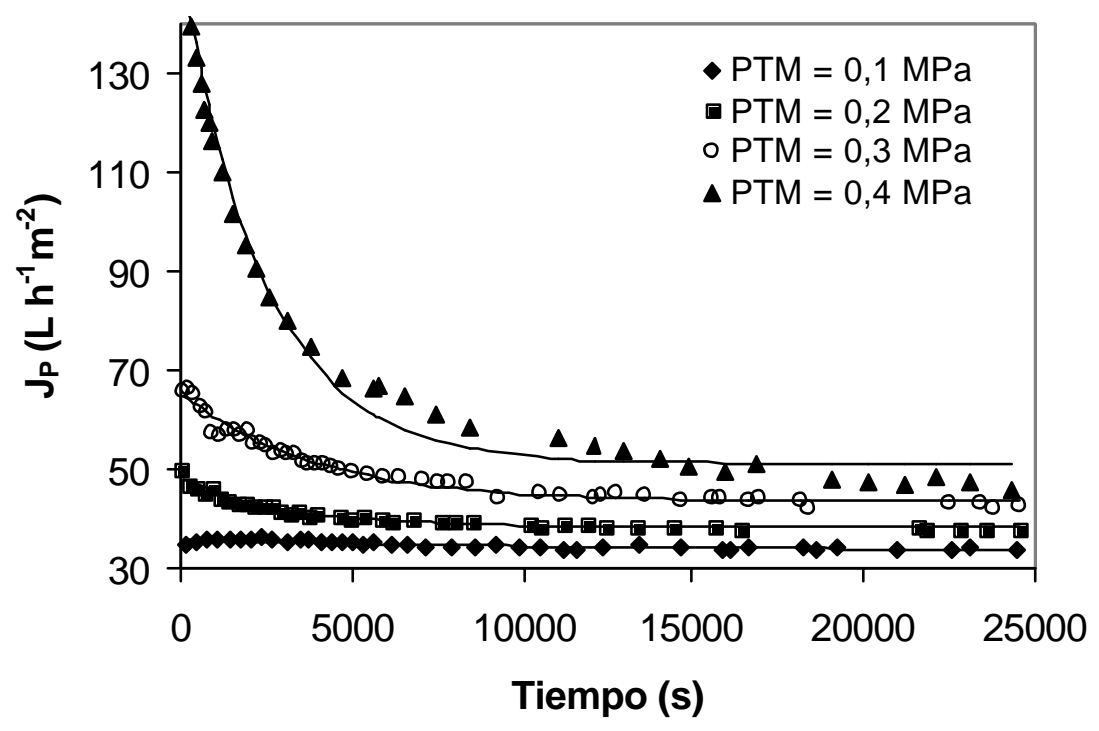

Figura 82. Ajuste empírico del Modelo de bloqueo completo de poros adaptado para flujo tangencial para una velocidad tangencial de $1 \mathrm{~m} / \mathrm{s}$ y una concentración de $5 \mathrm{~g} / \mathrm{L}$ para la membrana Carbosep M2

El ajuste de los modelos a los datos experimentales ha mejorado notablemente al realizar la adaptación para flujo tangencial de los mismos. Comparando la Figura 82 con la Figura 70 se observa un mejor ajuste del Modelo de bloqueo completo de poros para flujo tangencial respecto al $\mathrm{M}$ odelo de bloqueo completo de poros para una velocidad tangencial de $1 \mathrm{~m} / \mathrm{s}$ y todas las PTMs ensayadas.

Para la velocidad tangencial de $2 \mathrm{~m} / \mathrm{s}$, el ajuste del M odel o de bloqueo completo de poros para flujo tangencial también mejora respecto al M odelo de bloqueo completo de poros, especialmente para las PTMs de 0.4 y $0.3 \mathrm{MPa}$ (Figuras 83 y 71). Para la velocidad tangencial de 3 $\mathrm{m} / \mathrm{s}$ (Figuras 84 y 72) no se observa mejoría debido a que el ajuste ya era suficientemente bueno para el $M$ odelo de bloqueo completo de poros desarrollado para la filtración transversal 


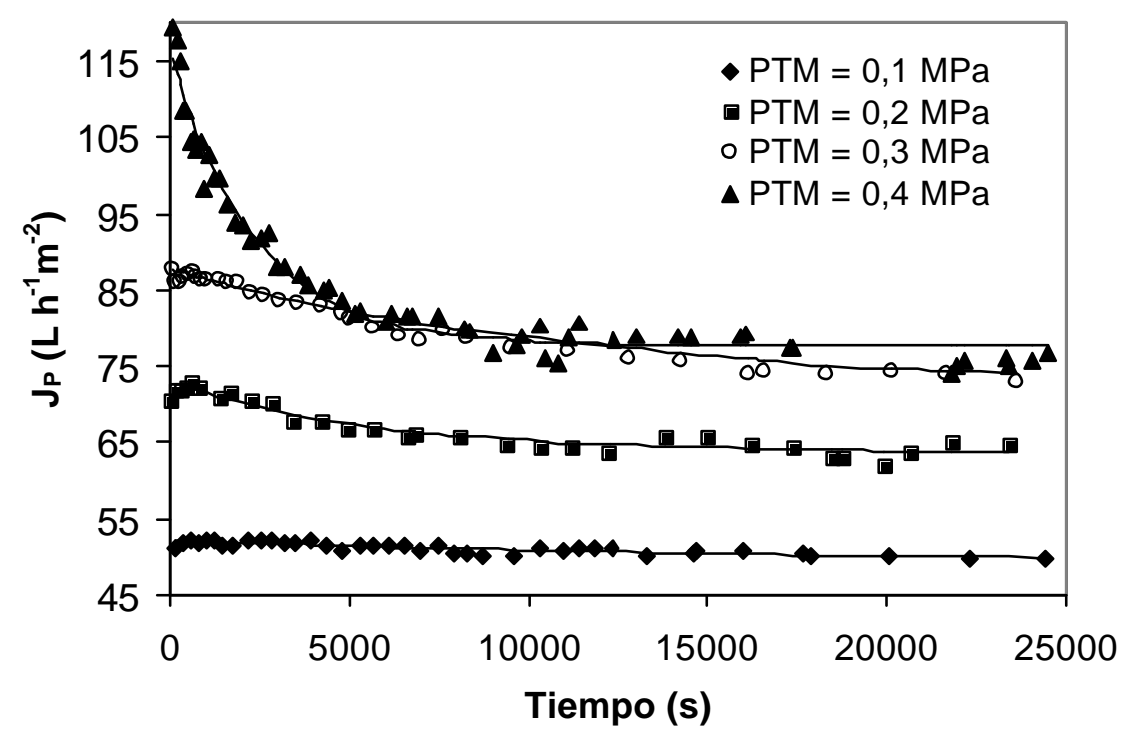

Figura 83. Ajuste empírico del Modelo de bloqueo completo de poros adaptado para flujo tangencial para una velocidad tangencial de $2 \mathrm{~m} / \mathrm{s}$ y una concentración de $5 \mathrm{~g} / \mathrm{L}$ para la membrana Carbosep M2

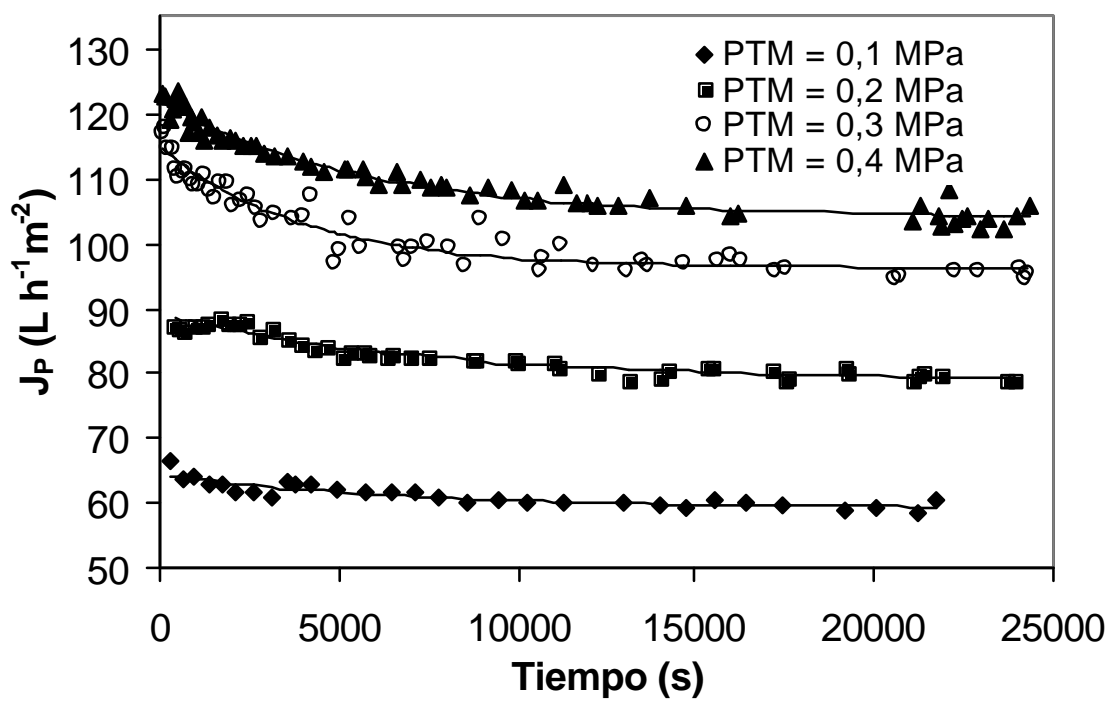

Figura 84. Ajuste empírico del Modelo de bloqueo completo de poros adaptado para flujo tangencial para una velocidad tangencial de $3 \mathrm{~m} / \mathrm{s}$ y una concentración de $5 \mathrm{~g} / \mathrm{L}$ para la membrana Carbosep M2 
Modelo de bloqueo intermedio de poros para flujo tangencial $\left(\mathrm{n}_{\mathrm{CF}}=\right.$ 1)

El M odelo de bloqueo intermedio de poros para flujo tangencial seajusta bien a los resultados experimentales para todas las condiciones de operación ensayadas sin excepción (Figuras 85 a la 87), incluso para las condiciones experimentales en las que el Modelo de bloqueo completo de poros para flujo tangencial se ajustaba peor $(1 \mathrm{~m} / \mathrm{s}$ y 0.4 $\mathrm{MPa})$.

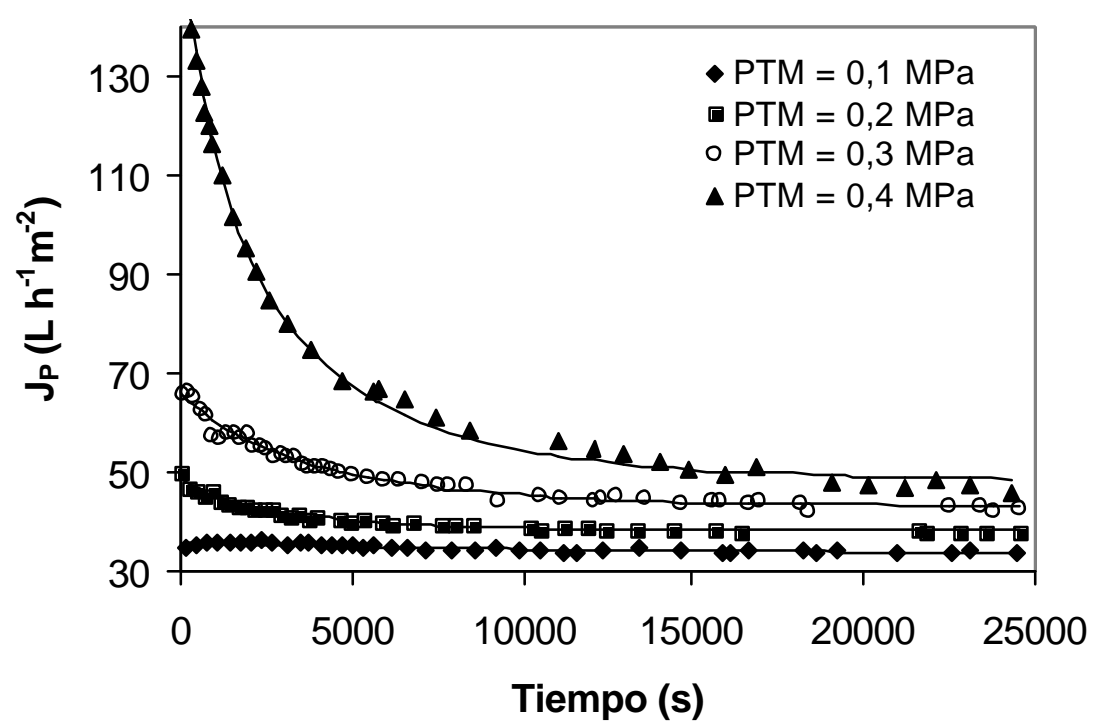

Figura 85. Ajuste empírico del Modelo de bloqueo intermedio de poros adaptado para flujo tangencial para una velocidad tangencial de $1 \mathrm{~m} / \mathrm{s}$ y una concentración de $5 \mathrm{~g} / \mathrm{L}$ para la membrana Carbosep M2

Las razones por las cuales el M odelo de bloqueo intermedio de poros para flujo tangencial proporciona mejores resultados que el Modelo de bloqueo completo de poros para flujo tangencial ya han sido expuestas en el apartado 5.5.1 de esta Tesis Doctoral. 
Al igual que para el $M$ odelo de bloqueo completo de poros para flujo tangencial, el M odelo de bloqueo intermedio de poros para flujo tangencial se ajusta mejor a los datos experimentales que su equivalente para flujo transversal, especialmente en el caso de las velocidades tangenciales de 1 y $2 \mathrm{~m} / \mathrm{s}$ (Figuras 85 y 86 ) pues para la velocidad tangencial de $3 \mathrm{~m} / \mathrm{s}$ (Figura 87) el ajuste ya era bueno antes de realizar la adaptación del modelo al flujo tangencial (Figura 75).

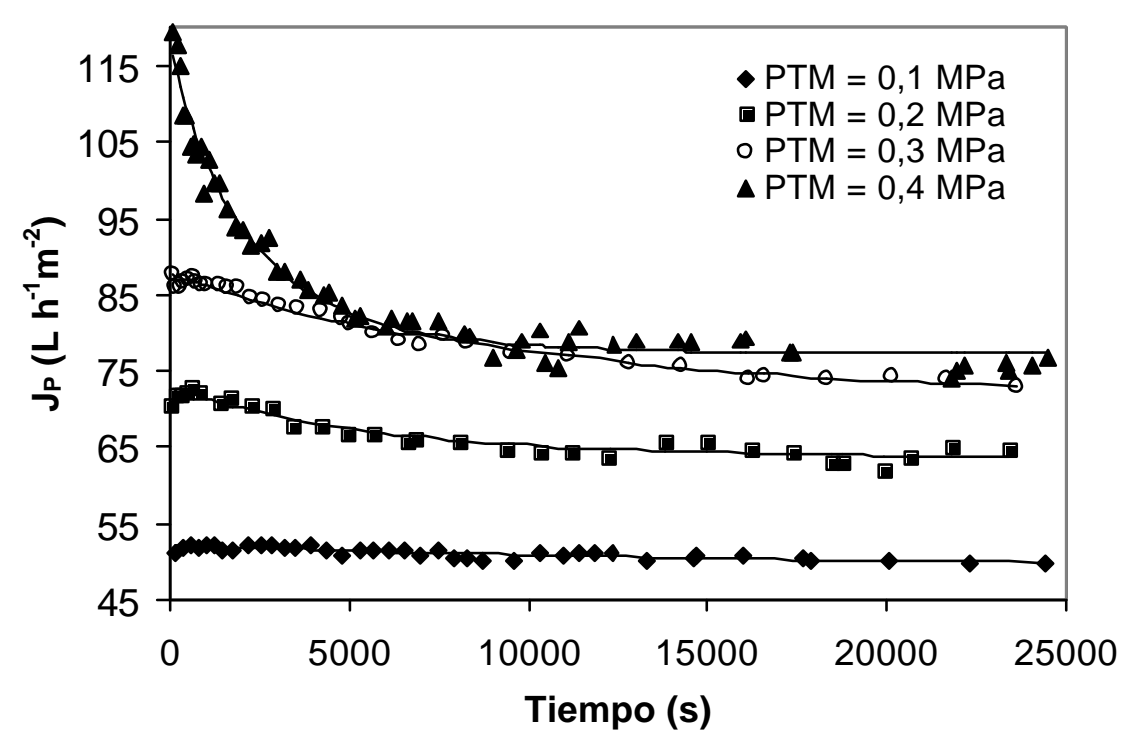

Figura 86. Ajuste empírico del Modelo de bloqueo intermedio de poros adaptado para flujo tangencial para una velocidad tangencial de $2 \mathrm{~m} / \mathrm{s}$ y una concentración de $5 \mathrm{~g} / \mathrm{L}$ para la membrana Carbosep M2 


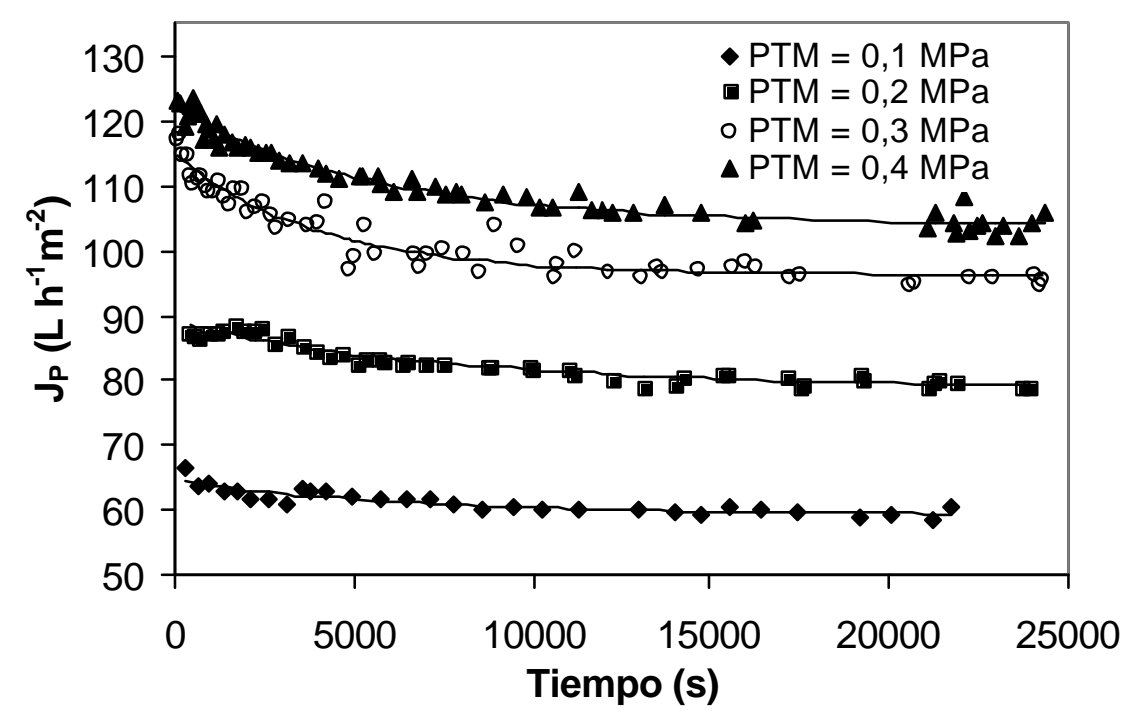

Figura 87. Ajuste empírico del Modelo de bloqueo intermedio de poros adaptado para flujo tangencial para una velocidad tangencial de $3 \mathrm{~m} / \mathrm{s}$ y una concentración de $5 \mathrm{~g} / \mathrm{L}$ para la membrana Carbosep M2

Modelo de bloqueo estándar de poros para flujo tangencial ( $\mathrm{n}_{\mathrm{CF}}=$ 3/ 2)

El M odelo de bloqueo estándar de poros para flujo tangencial no se ajusta bien a los resultados experimentales para la mayoría de las condiciones de operación ensayadas (Figuras 88 a la 90). Los peores ajustes se obtuvieron para una velocidad tangencial de $1 \mathrm{~m} / \mathrm{s}$ y una PTM de 0.4 MPa (Figura 88) y para una velocidad tangencial de 2 $\mathrm{m} /$ sy una PTM de 0.4 MPa (Figura 89). 


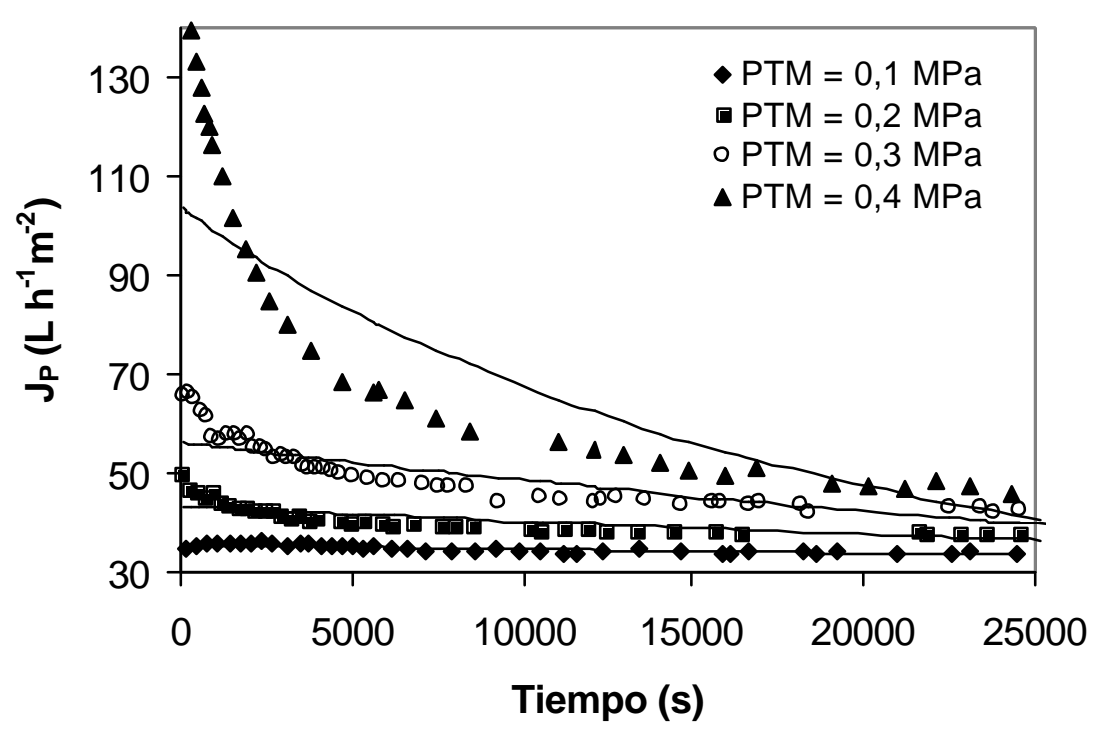

Figura 88. Ajuste empírico del Modelo de bloqueo estándar de poros adaptado para flujo tangencial para una velocidad tangencial de $1 \mathrm{~m} / \mathrm{s}$ y una concentración de $5 \mathrm{~g} / \mathrm{L}$ para la membrana Carbosep M2

Los mejores ajustes del modelo a los resultados experimentales se obtienen bajo las condiciones de operación para las cuales la densidad de flujo de permeado varía muy poco con el tiempo. Estas condiciones se cumplen para la velocidad tangencial de $1 \mathrm{~m} / \mathrm{s}$ y la PTM de 0.1 MPa (Figura 88); para la velocidad tangencial de $2 \mathrm{~m} / \mathrm{s}$ y las PTM s de 0.1 y $0.2 \mathrm{M} \mathrm{Pa}$ (Figura 89) y para la velocidad tangencial de $3 \mathrm{~m} /$ s y las PTM s de0.1 y $0.2 \mathrm{MPa}$ (Figura 90). 


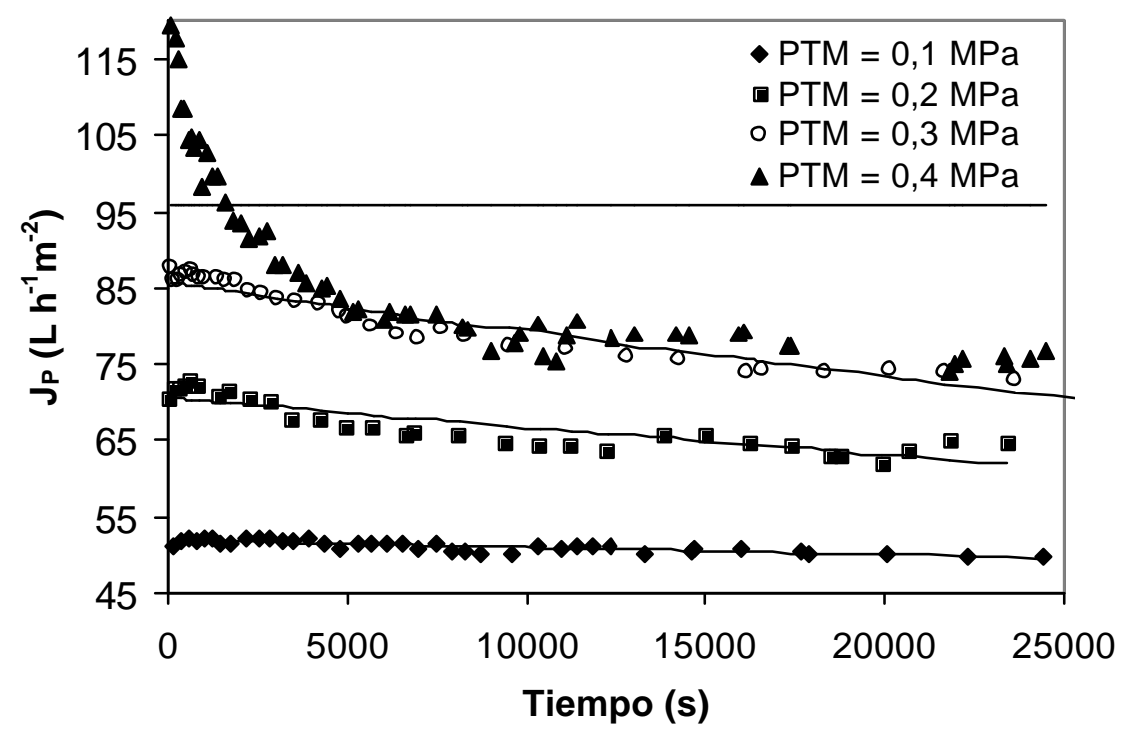

Figura 89. Ajuste empírico del Modelo de bloqueo estándar de poros adaptado para flujo tangencial para una velocidad tangencial de $2 \mathrm{~m} / \mathrm{s}$ y una concentración de $5 \mathrm{~g} / \mathrm{L}$ para la membrana Carbosep M2

Debido a que el modelo contempla un bloqueo interno de los poros, la velocidad tangencial no afecta a los resultados y la precisión del ajuste del M odelo de bloqueo estándar de poros para flujo tangencial es equiparable a la del M odelo de bloqueo estándar de poros para flujo transversal, haciéndose extensibles los comentarios sobre dicho modelo que se han recogido en el apartado 5.5.1 de esta Tesis Doctoral. 


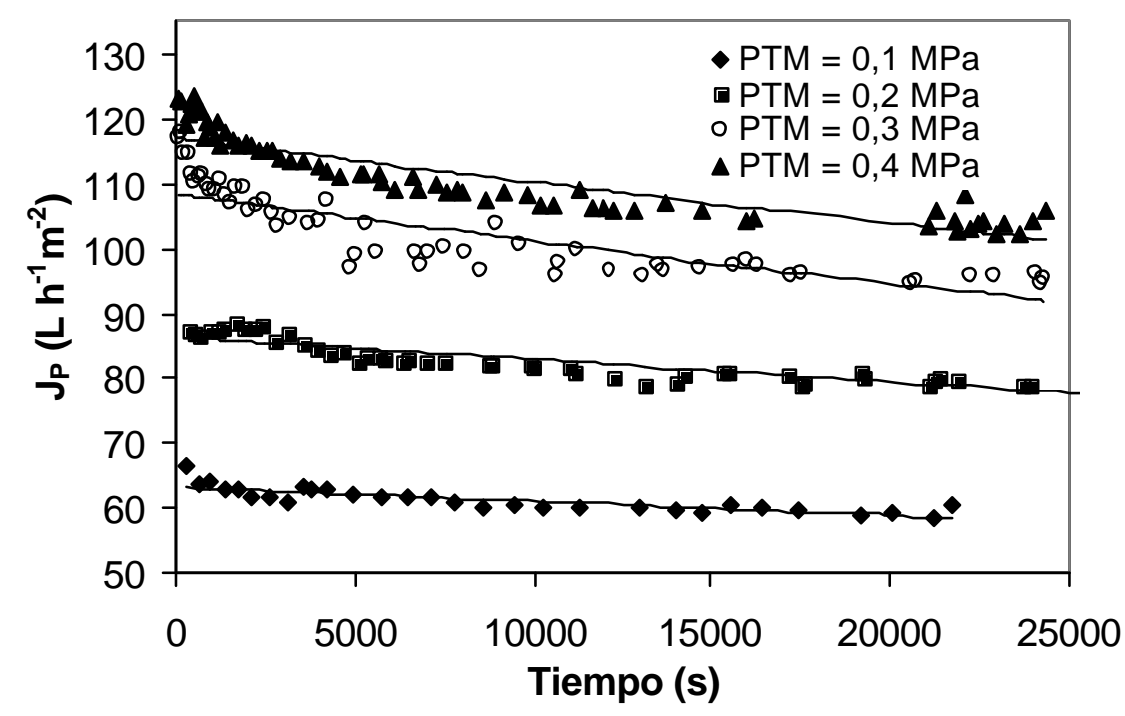

Figura 90. Ajuste empírico del Modelo de bloqueo estándar de poros adaptado para flujo tangencial para una velocidad tangencial de $3 \mathrm{~m} / \mathrm{s}$ y una concentración de $5 \mathrm{~g} / \mathrm{L}$ para la membrana Carbosep M2

Modelo de formación de capa gel para flujo tangencial $\left(\mathrm{n}_{\mathrm{CF}}=0\right)$

El ajuste del Modelo de formación de capa gel para flujo tangencial es bueno para todas las condiciones de operación ensayadas Figuras 91 a la 93) excepto para la velocidad tangencial de $2 \mathrm{~m} / \mathrm{s}$ y la PTM de 0.4 MPa (Figura 92). Cuando la densidad de flujo de permeado varía poco con el tiempo se obtienen buenos resultados con cualquiera de los modelos. Las variaciones más apreciables en la densidad de flujo de permeado con el tiempo se producen para una PTM de $0.4 \mathrm{MPa}$ y unas velocidades tangenciales de 1 y $2 \mathrm{~m} / \mathrm{s}$. El ajuste del Modelo de formación de capa gel para flujo tangencial es excelente para una PTM de 0.4 M Pa y una velocidad tangencial de 1 $\mathrm{m} / \mathrm{s}$ (Figura 91). Sin embargo es peor para una PTM de 0.4 MPa y una velocidad tangencial de $2 \mathrm{~m} / \mathrm{s}$ (Figura 92). Esto se debe a que estas últimas condiciones son menos apropiadas para la formación de capa gel al ser la velocidad tangencial más elevada. 


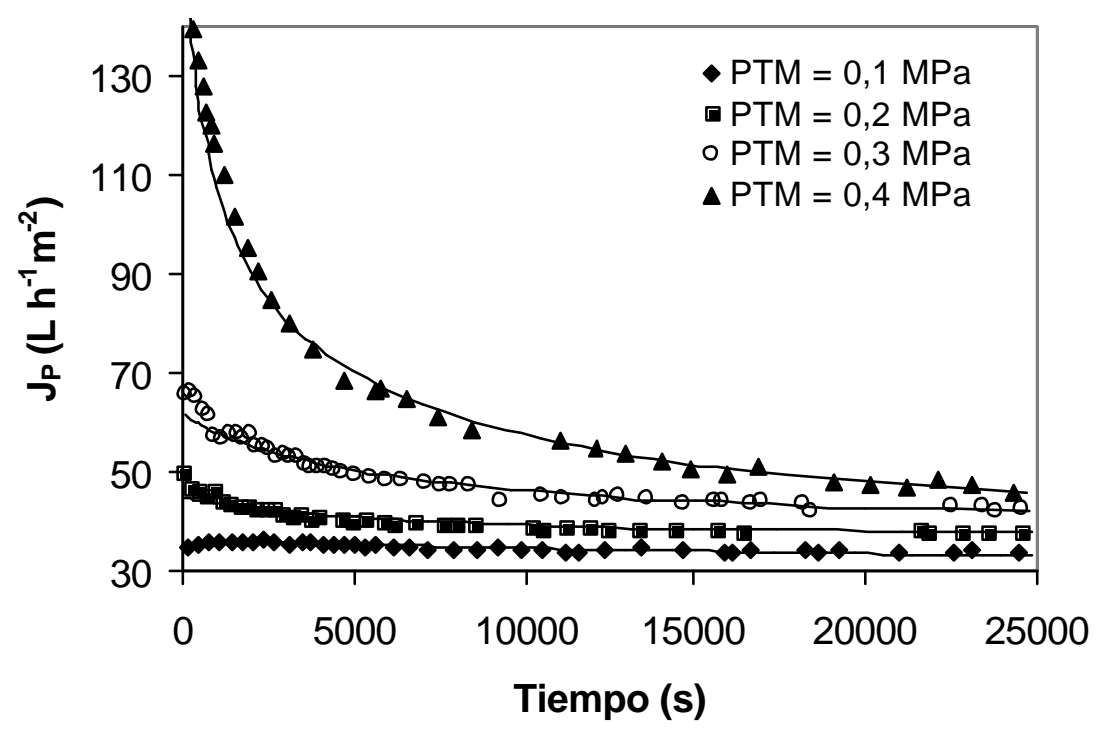

Figura 91. Ajuste empírico del M odelo de formación de capa gel adaptado para flujo tangencial para una velocidad tangencial de $1 \mathrm{~m} / \mathrm{s}$ y una concentración de $5 \mathrm{~g} / \mathrm{L}$ para la membrana Carbosep M2

Al realizar la adaptación para flujo tangencial del Modelo de formación de capa gel, e ajuste del modelo a los datos experimentales ha mejorado respecto del ajuste del M odelo de formación de capa gel para flujo transversal para la velocidad tangencial de $1 \mathrm{~m} / \mathrm{s}$ y la PTM de 0.4 MPa (Figura 91 y Figura 79). Sin embargo, comparando la Figura 92 con la Figura 80 y la Figura 92 con la Figura 81, se observa que para el resto de las condiciones experimentales ensayadas no ha habido mejoría alguna en el ajuste al realizar la adaptación del M odelo de formación de capa gel para flujo tangencial. 


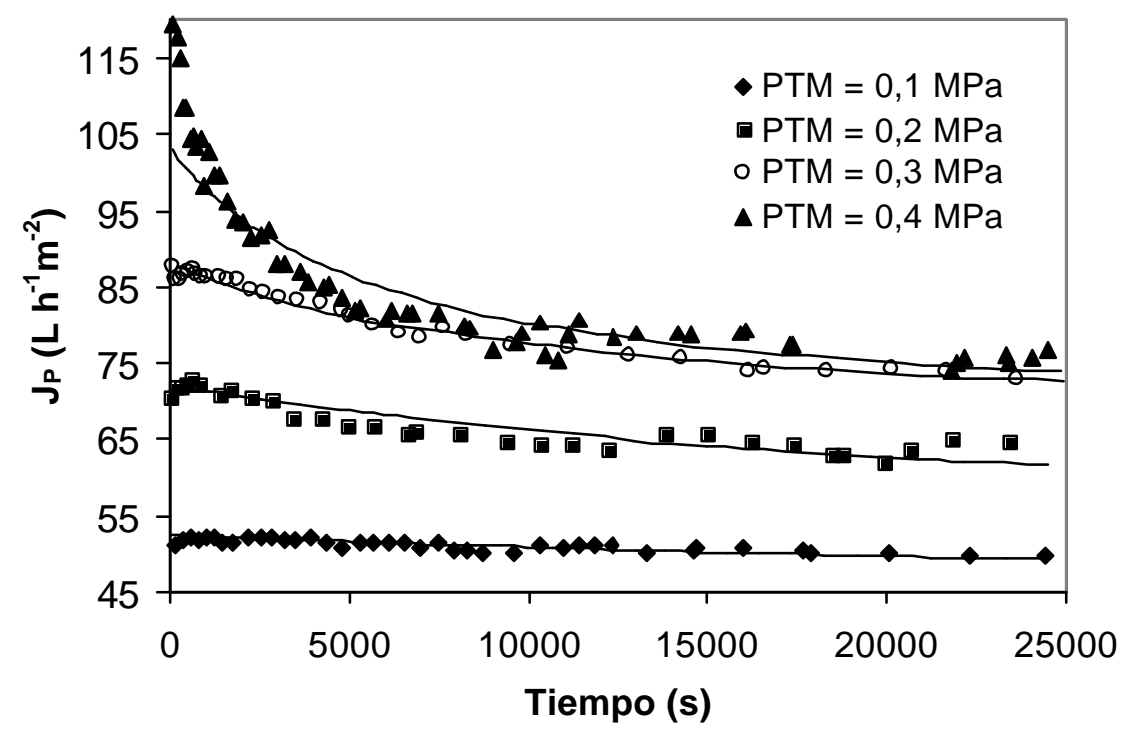

Figura 92. Ajuste empírico del M odelo de formación de capa gel adaptado para flujo tangencial para una velocidad tangencial de $2 \mathrm{~m} / \mathrm{s}$ y una concentración de $5 \mathrm{~g} / \mathrm{L}$ para la membrana Carbosep M2

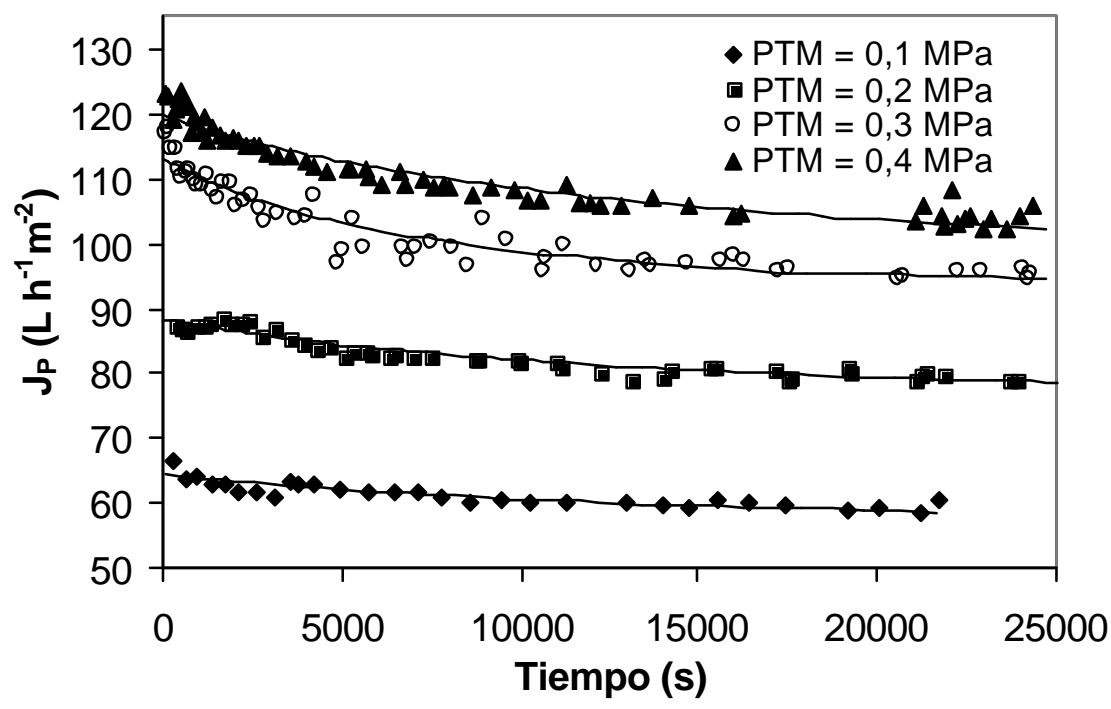

Figura 93. Ajuste empírico del M odelo de formación de capa gel adaptado para flujo tangencial para una velocidad tangencial de $3 \mathrm{~m} / \mathrm{s}$ y una concentración de $5 \mathrm{~g} / \mathrm{L}$ para la membrana Carbosep M2 
Conclusiones derivadas de la comparación entre los distintos $\mathrm{M}$ odelos de $\mathrm{H}$ ermia adaptados para flujo tangencial

A partir de los resultados mostrados en las Figuras 82 a la 93 del apartado 5.5.2 de esta Tesis Doctoral se concluyelo siguiente:

- Al igual que para los M odelos de H ermia, para todos los M odelos de Hermia adaptados para flujo tangencial el ajuste es mejor cuando la densidad de flujo de permeado varía poco con el tiempo. Por este motivo los ajustes de los modelos a los resultados experimentales obtenidos con las membranas Tami MSKT fueron buenos en todos los casos, por lo que no ha sido posible seleccionar el modelo más adecuado en este caso.

- El M odelo de bloqueo estándar de poros para flujo tangencial es el que peor se ajusta a los datos experimentales.

- Todos los modelos exceptuando el M odelo de bloqueo estándar de poros para flujo tangencial se ajustan bien a los datos experimentales para las siguientes condiciones de operación: velocidad tangencial de $3 \mathrm{~m} / \mathrm{s}$ para PTM s de $0.1,0.2,0.3$ y 0.4 MPa y velocidades tangenciales de 1 y $2 \mathrm{~m} / \mathrm{s}$ para una PTM de $0.1,0.2$ y $0.3 \mathrm{MPa}$. Dichas condiciones experimentales tienen en común que la variación de la densidad de flujo de permeado con el tiempo es pequeña.

- Sólo para los ensayos en los que el descenso de la densidad de flujo de permeado con el tiempo es considerable se logra seleccionar el modelo más apropiado.

- El M odelo de bloqueo intermedio de poros para flujo tangencial se ajusta bien a los datos experimentales para todas las condiciones ensayadas. 
- Para 1 m/ s y 0.4 MPa el M odelo de formación de capa gel para flujo tangencial presenta un grado de ajuste a los resultados experimentales análogo al mostrado por el M odelo de bloqueo intermedio de poros para flujo tangencial.

- Para $1 \mathrm{~m} / \mathrm{s}$ y $0.3 \mathrm{MPa}$, para $2 \mathrm{~m} / \mathrm{s}$ y 0.2 y $0.4 \mathrm{MPa}$ y para 3 $\mathrm{m} / \mathrm{s}$ y 0.3 y $0.4 \mathrm{MPa}$ el grado de ajuste del M odelo de bloqueo completo de poros para flujo tangencial a los resultados experimentales es muy similar al observado para e M odelo de bloqueo intermedio de poros para flujo tangencial.

- Comparando las Figuras 82 a la 93 del apartado 5.5.2 con las Figuras 70 a la 81 del apartado 5.5.1, para todos los M odelos de $\mathrm{H}$ ermia adaptados para flujo tangencial excepto para el M odelo de bloqueo estándar de poros los ajustes a los resultados experimentales obtenidos mejoran respecto a los obtenidos con los M odelos de Hermia para flujo transversal. El M odelo de bloqueo estándar de poros no se ve afectado por el proceso de adaptación para flujo tangencial, tal y como se indicó en el apartado 3.2.2 de esta Tesis Doctoral.

\subsubsection{Resultados de la aplicación de los Modelos de Hermia adaptados para flujo tangencial calculando teóricamente sus parámetros}

Los M odelos de Hermia adaptados para flujo tangencial se aplicaron también a partir de dos únicos valores experimentales: la densidad de flujo de permeado estacionaria, Jpss, y la densidad de flujo de permeado inicial , Jo , tal y como se indicó en el apartado 3.2.3 deesta Tesis Doctoral. Los resultados obtenidos se compararon con los datos experimentales obtenidos con las membranas Carbosep M2. La aplicación de los modelos a las membranas Tami MSKT no aporta información sobre la adecuación de los modelos a las condiciones experimentales ensayadas puesto que la variación de la 
densidad de flujo de permeado con el tiempo no es significativa y en este caso todos los modelos se adaptan bien a los resultados experimentales.

Modelo de bloqueo completo de poros para flujo tangencial $\left(\mathrm{n}_{\underline{C F}}=2\right)$

Para la velocidad tangencial de $1 \mathrm{~m} / \mathrm{s}$ (Figura 94), el M odelo de bloqueo completo de poros para flujo tangencial realiza malas predicciones para la PTM de 0.4 MPa. Para estas condiciones experimentales es más probable que se forme capa gel y que, por lo tanto, unas moléculas se depositen sobre otras. Esta situación no la contempla el modelo. Para el resto de PTMs las predicciones son buenas.

Comparando la Figura 94 con la Figura 82 se observa que para la velocidad tangencial de $1 \mathrm{~m} / \mathrm{s}$ y todas las PTMs ensayadas se obtienen mejores resultados cuando el M odelo de bloqueo completo de poros para flujo tangencial se ajusta empíricamente que cuando sus parámetros se calculan de forma teórica. Esta diferencia es más acusada para la PTM de 0.4 MPa. También se observa que los resultados son igual de buenos para la PTM de 0.1 MPa debido a que en este caso la variación de la densidad de flujo de permeado con el tiempo es muy pequeña. 


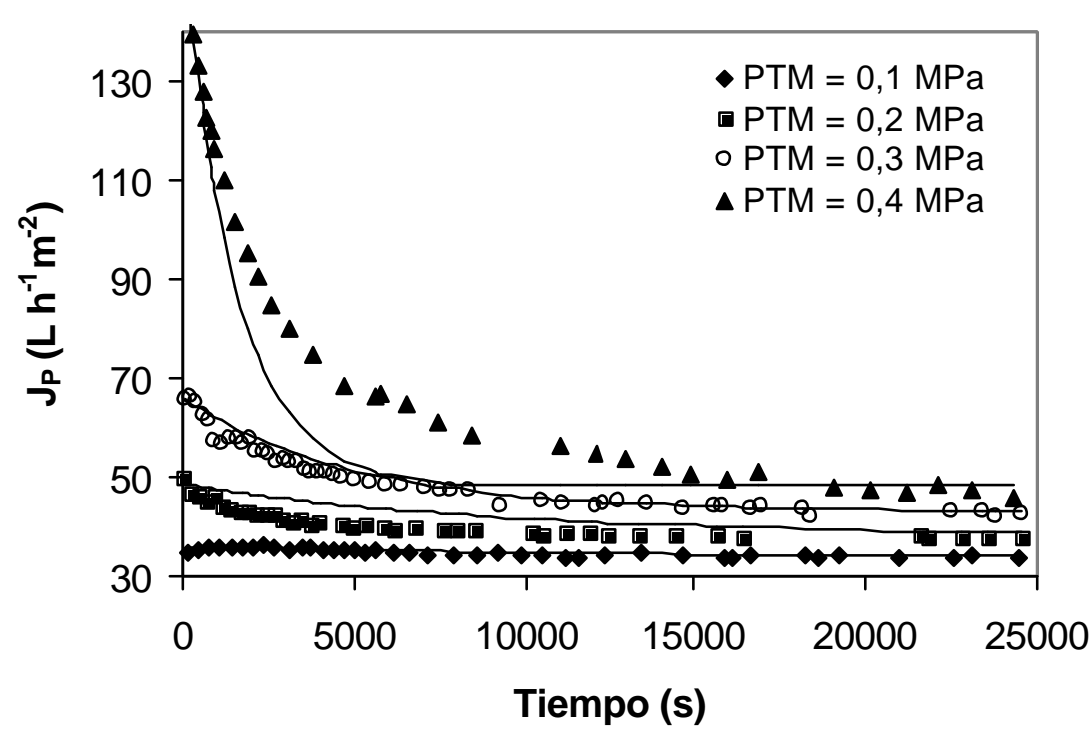

Figura 94. Comparación entre los datos experimentales y las predicciones del M odelo de bloqueo completo de poros adaptado para flujo tangencial para una velocidad tangencial de $1 \mathrm{~m} / \mathrm{s}$ y una concentración de $5 \mathrm{~g} / \mathrm{L}$ para la membrana Carbosep M2

Cuando la velocidad tangencial es de $2 \mathrm{~m} / \mathrm{s}$ (Figura 95), las predicciones que realiza el $\mathrm{M}$ odelo de bloqueo completo de poros para flujo tangencial son buenas para todas las PTMs, aunque el peor ajuste a los resultados experimentales se obtiene para la PTM de 0.3 MPa. Para dicha PTM, además, se obtienen peores resultados en este caso que cuando se realiza un ajuste totalmente empírico de los parámetros del modelo (Figura 83). Para el resto de PTMs los resultados son igual de buenos en ambos casos. 


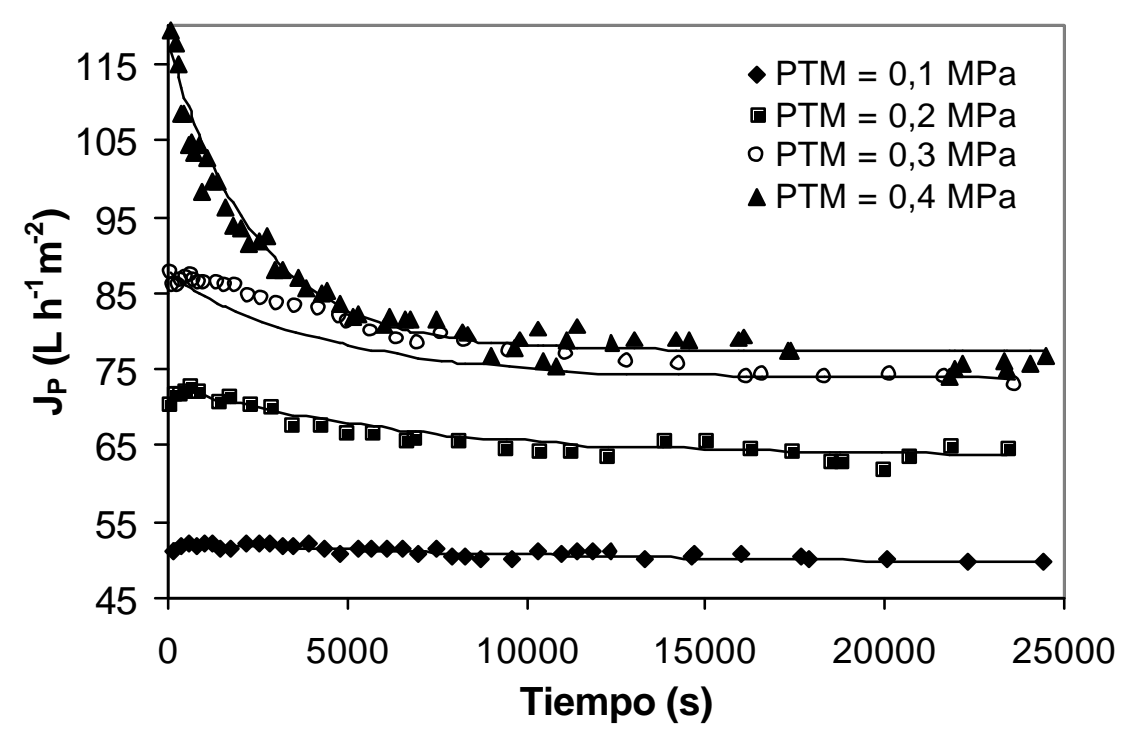

Figura 95. Comparación entre los datos experimentales y las predicciones del M odelo de bloqueo completo de poros adaptado para flujo tangencial para una velocidad tangencial de $2 \mathrm{~m} / \mathrm{s}$ y una concentración de $5 \mathrm{~g} / \mathrm{L}$ para la membrana Carbosep M2

Para la velocidad tangencial de $3 \mathrm{~m} / \mathrm{s}$ (Figura 96), se obtienen buenas predicciones para todas las PTMs ensayadas. El peor ajustea los resultados experimentales se observó para la PTM de 0.4 MPa. Al realizar una comparación entre el ajuste totalmente empírico del M odelo de bloqueo completo de poros para flujo tangencial (Figura 84) y las predicciones del mismo cuando se calculan sus parámetros de forma teórica para la velocidad tangencial de $3 \mathrm{~m} / \mathrm{s}$ (Figura 96) se observa que las predicciones teóricas son peores en este último caso que cuando el ajuste es totalmente empírico para la PTM de 0.4 MPa. 


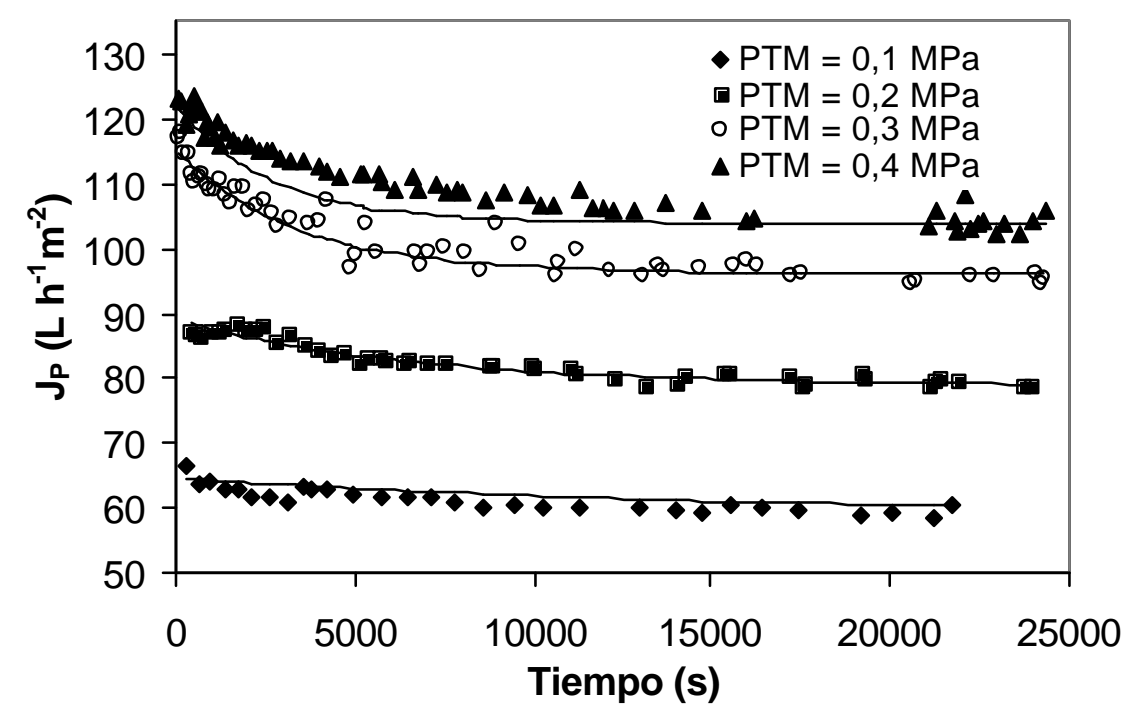

Figura 96. Comparación entre los datos experimentales y las predicciones del Modelo de bloqueo completo de poros adaptado para flujo tangencial para una velocidad tangencial de $3 \mathrm{~m} / \mathrm{s}$ y una concentración de $5 \mathrm{~g} / \mathrm{L}$ para la membrana Carbosep M2

Modelo de bloqueo intermedio de poros para flujo tangencial $\mathrm{n}_{\mathrm{CF}}=$ 1)

Las predicciones que realiza el M odelo de bloqueo intermedio de poros para flujo tangencial para la velocidad tangencial de $1 \mathrm{~m} / \mathrm{s}$ son buenas para todas las PTM s ensayadas (Figura 97).

Las predicciones son ligeramente peores en este caso que cuando se realiza el ajuste empírico (Figura 85). Cuando la densidad de flujo de permeado no varía apreciablemente con el tiempo, condiciones de ensayo de $1 \mathrm{~m} / \mathrm{s}$ y $0.1 \mathrm{MPa}$, los resultados predichos por el modelo son iguales en ambos casos. 


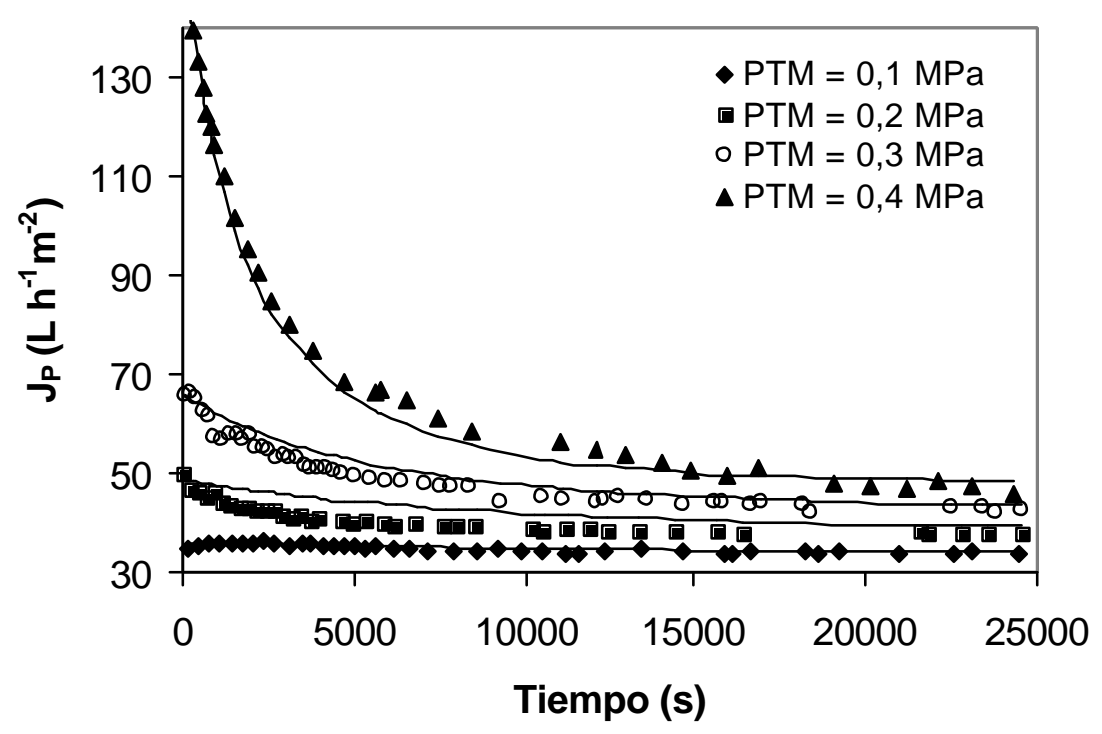

Figura 97. Comparación entre los datos experimentales y las predicciones del $M$ odelo de bloqueo intermedio de poros adaptado para flujo tangencial para una velocidad tangencial de $1 \mathrm{~m} / \mathrm{s}$ y una concentración de $5 \mathrm{~g} / \mathrm{L}$ para la membrana Carbosep M2

En las condiciones más favorables para que el proceso de ultrafiltración esté controlado por la transferencia de materia y para que se forme capa gel, $1 \mathrm{~m} / \mathrm{s}$ y $0.4 \mathrm{MPa}$, el Modelo de bloqueo intermedio de poros para flujo tangencial (Figura 97) proporciona mejores resultados que el $\mathrm{M}$ odelo de bloqueo completo de poros para flujo tangencial (Figura 94). Cuando los parámetros de los modelos se ajustan de manera empírica ocurre lo mismo (Figuras 82 y 85). Para estas condiciones de operación el índice de rechazo al soluto es menor que para cualquiera de las otras condiciones de operación, tal y como se indicó en el apartado 5.3.7 de esta Tesis Doctoral. En el $M$ odelo de bloqueo intermedio de poros para flujo tangencial el tamaño de las moléculas de soluto se considera similar al tamaño de los poros de la membrana, mientras que en el Modelo de bloqueo completo de poros para flujo tangencial las moléculas de soluto son de mayor tamaño que los poros de la membrana. Por tanto, el M odelo de bloqueo intermedio de poros para flujo tangencial representa mejor la 
situación de paso de moléculas a través de la membrana que el M odelo de bloqueo completo de poros para flujo tangencial.

Para la velocidad tangencial de $2 \mathrm{~m} / \mathrm{s}$ (Figura 98) se obtienen buenas predicciones para todas las PTMs ensayadas observándose el peor ajuste a los resultados experimentales para la PTM de 0.3 $\mathrm{MPa}$. Al comparar las predicciones obtenidas en este caso con las obtenidas mediante ajuste empírico (Figura 86) se observa un peor ajuste a los resultados experimentales para las PTMs de 0.3 y 0.4 MPa cuando se calculan teóricamente los parámetros del modelo.

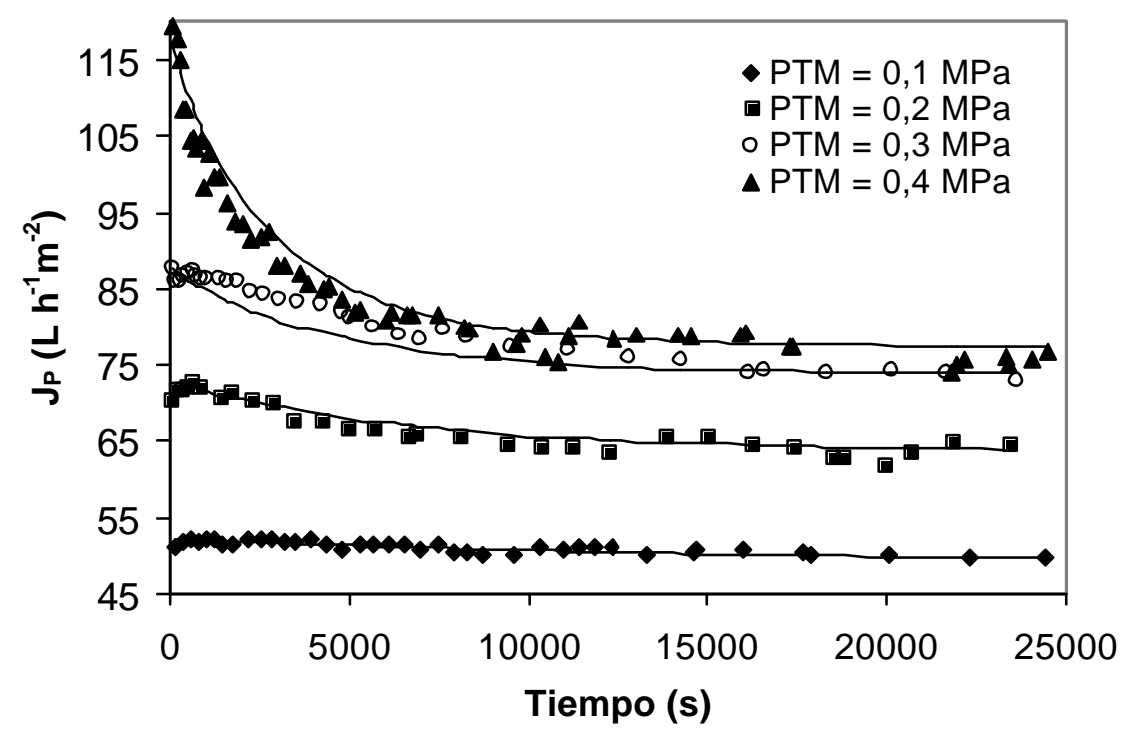

Figura 98. Comparación entre los datos experimentales y las predicciones del $M$ odelo de bloqueo intermedio de poros adaptado para flujo tangencial para una velocidad tangencial de $2 \mathrm{~m} / \mathrm{s}$ y una concentración de $5 \mathrm{~g} / \mathrm{L}$ para la membrana Carbosep M2

Las predicciones que realiza el M odelo de bloqueo intermedio de poros para flujo tangencial para la velocidad tangencial de $3 \mathrm{~m} / \mathrm{s}$ son buenas para todas las PTMs ensayadas, obsevándose no obstante el peor ajuste a los datos experimentales para la PTM de $0.4 \mathrm{MPa}$ (Figura 99). Para esta PTM los resultados obtenidos son también 
peores que los que se obtuvieron cuando se realizó un ajuste empírico del modelo (Figura 87).

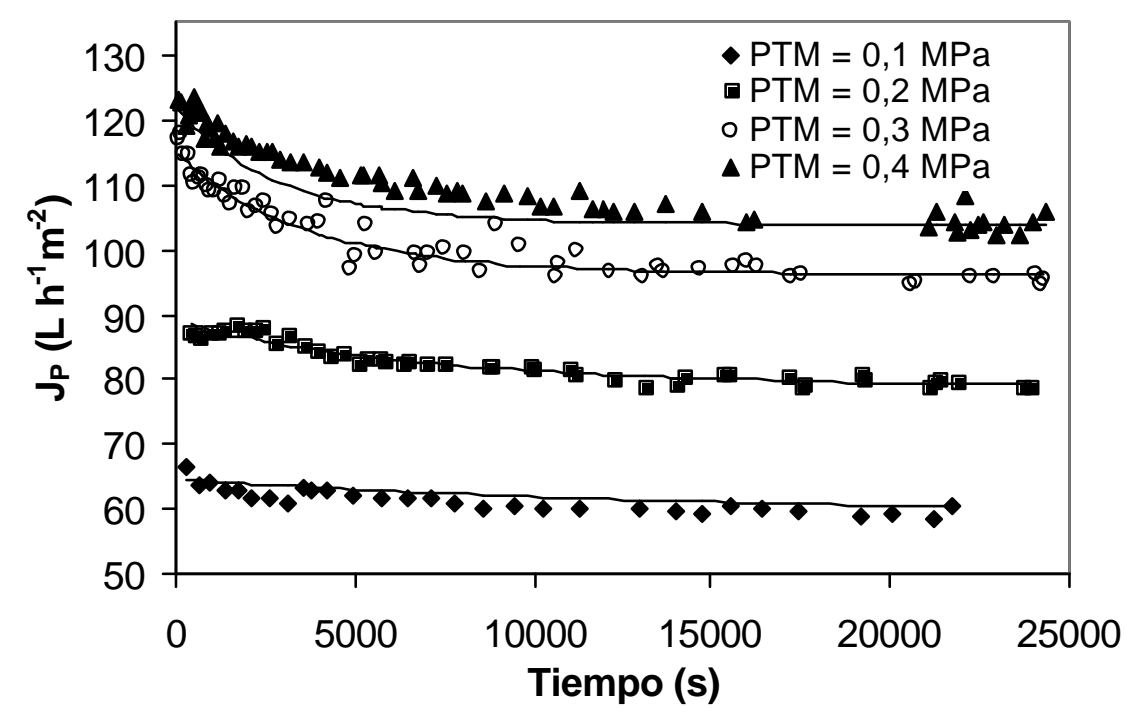

Figura 99. Comparación entre los datos experimentales y las predicciones del $M$ odelo de bloqueo intermedio de poros adaptado para flujo tangencial para una velocidad tangencial de $3 \mathrm{~m} / \mathrm{s}$ y una concentración de $5 \mathrm{~g} / \mathrm{L}$ para la membrana Carbosep M2

Cuando la velocidad tangencial es $1 \mathrm{~m}$ / s y la PTM es 0.3 MPa y para una velocidad tangencial de $2 \mathrm{~m} / \mathrm{s}$ y una PTM de $0.4 \mathrm{MPa}$, el M odelo de bloqueo completo de poros para flujo tangencial (Figuras 94 y 95) proporciona resultados mejores que el $\mathrm{M}$ odel o de bloqueo intermedio de poros para flujo tangencial (Figuras 97 y 98). Sin embargo las diferencias no son muy significativas. En ambos casos la desviación de las predicciones de los modelos respecto de los resultados experimentales es inferior al error experimental que se comete en la medida de la densidad de flujo de permeado. 
Conclusiones derivadas de la comparación entre los distintos M odelos de Hermia adaptados para flujo tangencial que han sido aplicados mediantela estimación teórica de sus parámetros

- Cuando se estiman los parámetros de los M odelos de Hermia adaptados para flujo tangencial de forma teórica se obtienen resultados ligeramente peores que cuando se realiza un ajuste total mente empírico.

- Al igual que para los ajustes totalmente empíricos de los M odelos de Hermia adaptados para flujo tangencial, cuando se estiman de forma teórica los parámetros de dichos modelos el ajuste es mejor cuando la densidad de flujo de permeado varía poco con el tiempo.

- El Modelo de bloqueo intermedio de poros para flujo tangencial realiza buenas predicciones para todas las condiciones experimentales ensayadas, obteniéndose el peor grado de ajuste a los resultados experimentales para una velocidad tangencial de $2 \mathrm{~m} / \mathrm{s}$ y una PTM de $0.3 \mathrm{MPa}$.

- El M odelo de bloqueo completo de poros para flujo tangencial realiza buenas predicciones para todas las condiciones experimentales ensayadas, excepto para una velocidad tangencial de $1 \mathrm{~m} / \mathrm{s}$ y una PTM de $0.4 \mathrm{MPa}$ y para una velocidad tangencial de $2 \mathrm{~m} / \mathrm{s}$ y una PTM de $0.3 \mathrm{MPa}$.

\subsubsection{A nálisis de los parámetros de los modelos}

En las tablas 9 a la 13 serecogen los valores de los parámetros de los modelos dinámicos de ultrafiltración semi-empíricos considerados en el apartado 3.2 de esta Tesis Doctoral. Los parámetros que se muestran se obtuvieron al ajustar a dichos modelos los resultados experimentales obtenidos con la membrana Carbosep M2. 
Asimismo, se comparan los valores de las densidades de flujo de permeado inicial y estacionaria resultantes del ajuste de los modelos con las experimentales.

A tendiendo al significado físico y a la definición de los parámetros de los modelos que se han descrito en el apartado 3.2, éstos deben tomar valores más elevados cuanto mayor es el ensuciamiento delas membranas de ultrafiltración.

Tabla 9. Parámetros resultantes de la aplicación de los M odel os de H ermia en el caso de la membrana Carbosep M2.

\begin{tabular}{|c|c|c|c|c|c|}
\hline $\begin{array}{l}\text { PTM } \\
\text { (MPa) }\end{array}$ & $\begin{array}{c}\text { Velocidad } \\
\text { tangencial } \\
(\mathrm{m} / \mathrm{s})\end{array}$ & $\begin{array}{c}K_{c^{\prime}} 10^{6} \\
\left(s^{-1}\right)\end{array}$ & $\begin{array}{c}K_{i} \\
\left(m^{-1}\right)\end{array}$ & $\begin{array}{c}\mathrm{K}_{\mathrm{e}} \cdot 10^{4} \\
\left(\mathrm{~s}^{-0.5} \cdot \mathrm{m}^{-0.5}\right)\end{array}$ & $\begin{array}{c}\mathrm{K}_{\mathrm{cg}} \cdot 10^{-4} \\
\left(\mathrm{~s} \cdot \mathrm{m}^{-2}\right)\end{array}$ \\
\hline \multirow{3}{*}{0.1} & 1 & 2.47 & 0.26 & 3.98 & 5.31 \\
\hline & 2 & 1.86 & 0.13 & 2.47 & 1.85 \\
\hline & 3 & 3.50 & 0.21 & 4.24 & 2.41 \\
\hline \multirow{3}{*}{0.2} & 1 & 7.11 & 0.62 & 10.51 & 10.89 \\
\hline & 2 & 5.63 & 0.30 & 6.50 & 3.22 \\
\hline & 3 & 4.22 & 0.18 & 4.40 & 1.60 \\
\hline \multirow{3}{*}{0.3} & 1 & 15.03 & 1.09 & 20.17 & 15.84 \\
\hline & 2 & 8.13 & 0.37 & 8.64 & 3.34 \\
\hline & 3 & 6.99 & 0.24 & 6.53 & 1.71 \\
\hline \multirow{3}{*}{0.4} & 1 & 45.26 & 2.22 & 49.56 & 23.51 \\
\hline & 2 & 14.13 & 0.58 & 14.25 & 4.75 \\
\hline & 3 & 6.00 & 0.19 & 5.40 & 1.27 \\
\hline
\end{tabular}

En la Tabla 9 se muestran los parámetros resultantes de la aplicación de los M odel os de H ermia para flujo transversal. Para PTMs bajas (0.1 $\mathrm{MPa}$ ) el ensuciamiento es muy reducido. Por este motivo los valores de los parámetros son pequeños y no se han observado diferencias significativas entre los valores de los parámetros obtenidos a distintas velocidades tangenciales. Sin embargo, para presiones transmembranales elevadas estas diferencias son más acusadas. 
Conforme aumenta la velocidad tangencial el ensucimiento de las membranas es menor y los valores que toman los parámetros de los modelos son reducidos, tal y como era de esperar. También se puede observar que, en general, para una misma velocidad tangencial, los valores de los parámetros aumentan al aumentar la PTM, indicando un mayor ensuciamiento. Dicho efecto es más acusado para las velocidades tangenciales más bajas.

Tabla 10. Parámetros resultantes de la aplicación de los M odel os de H ermia adaptados para flujo tangencial en el caso de la membrana Carbosep M2.

\begin{tabular}{|c|c|c|c|c|c|}
\hline $\begin{array}{l}\text { PTM } \\
\text { (MPa) }\end{array}$ & $\begin{array}{c}\text { Velocidad } \\
\text { tangencial } \\
(\mathrm{m} / \mathrm{s})\end{array}$ & $\begin{array}{c}\mathrm{K}_{\mathrm{ccF}} \\
\text { ajustado } \\
\left(\mathrm{m}^{-1}\right)\end{array}$ & $\begin{array}{c}\mathrm{K}_{\mathrm{iCF}} \\
\text { ajustado } \\
\left(\mathrm{m}^{-1}\right)\end{array}$ & $\begin{array}{c}\mathrm{K}_{\mathrm{iCF}} \text { y } \mathrm{K}_{\mathrm{CCF}} \\
\text { teóricos } \\
\left(\mathrm{m}^{-1}\right)\end{array}$ & $\begin{array}{c}\mathrm{K}_{\mathrm{cgCF}} \cdot 10^{-5} \\
\text { ajustado } \\
\left(\mathrm{s} \cdot \mathrm{m}^{-2}\right)\end{array}$ \\
\hline \multirow{3}{*}{0.1} & 1 & 9.90 & 9.86 & 6.61 & 2.23 \\
\hline & 2 & 4.13 & 4.09 & 4.97 & 1.24 \\
\hline & 3 & 8.92 & 9.26 & 4.06 & 2.32 \\
\hline \multirow{3}{*}{0.2} & 1 & 26.62 & 29.32 & 8.60 & 12.49 \\
\hline & 2 & 8.95 & 9.24 & 7.79 & 1.15 \\
\hline & 3 & 5.58 & 5.72 & 6.30 & 1.46 \\
\hline \multirow{3}{*}{0.3} & 1 & 14.39 & 16.57 & 11.15 & 7.84 \\
\hline & 2 & 4.08 & 4.09 & 9.77 & 1.95 \\
\hline & 3 & 8.01 & 8.55 & 9.40 & 1.71 \\
\hline \multirow{3}{*}{0.4} & 1 & 9.77 & 13.41 & 14.79 & 6.05 \\
\hline & 2 & 12.85 & 15.17 & 12.04 & 2.57 \\
\hline & 3 & 5.30 & 5.59 & 11.22 & 0.81 \\
\hline
\end{tabular}

En la Tabla 10 se muestran los parámetros resultantes de la aplicación de los M odelos de Hermia adaptados para flujo tangencial. Cuando los parámetros de los model os se cal culan mediante ajustea los datos experimentales se observa que su valor disminuye al aumentar la velocidad tangencial en casi todos los casos. Sin embargo, no se observó una tendencia clara en cuanto a la variación de los parámetros con la PTM. Por otra parte, cuando los 
parámetros de los modelos se calculan teóricamente se puede observar que los valores de los parámetros aumentan con la presión transmembranal y disminuyen con la velocidad tangencial, es decir, en aquellas condiciones en las que se espera un mayor ensuciamiento dela membrana.

Tabla 11. Comparación entre las densidades de flujo de permeado iniciales obtenidas experimentalmente con la membrana Carbosep M 2 y las resultantes de la aplicación de los M odelos de Hermia.

\begin{tabular}{|c|c|c|c|c|c|c|}
\hline \multirow{2}{*}{$\begin{array}{l}\text { PTM } \\
\text { (MPa) }\end{array}$} & \multirow{2}{*}{$\begin{array}{c}\text { Velocidad } \\
\text { tangencial } \\
(\mathrm{m} / \mathrm{s})\end{array}$} & \multicolumn{5}{|c|}{ Densidades de flujo de permeado $\left(L \cdot h^{-1} \cdot m^{-2}\right)$} \\
\hline & & $\begin{array}{l}\text { Bloqueo } \\
\text { completo }\end{array}$ & $\begin{array}{c}\text { Bloqueo } \\
\text { intermedio }\end{array}$ & $\begin{array}{l}\text { Bloqueo } \\
\text { estándar }\end{array}$ & Torta & $\begin{array}{l}\text { Experi- } \\
\text { mental }\end{array}$ \\
\hline \multirow{3}{*}{0.1} & 1 & 35.51 & 35.51 & 35.52 & 35.51 & 34.62 \\
\hline & 2 & 51.90 & 51.92 & 51.91 & 51.91 & 51.20 \\
\hline & 3 & 63.06 & 63.05 & 63.09 & 63.06 & 63.04 \\
\hline \multirow{3}{*}{0.2} & 1 & $43.28 *$ & 43.23* & 43.28* & 43.19* & 49.99 \\
\hline & 2 & 70.49 & 70.47 & 70.50 & 70.48 & 70.56 \\
\hline & 3 & 86.15 & 86.13 & 86.21 & 86.16 & 86.10 \\
\hline \multirow{3}{*}{0.3} & 1 & $56.50^{*}$ & $56.47 *$ & $56.45^{*}$ & $56.49 *$ & 65.46 \\
\hline & 2 & 85.91 & 85.98 & 85.89 & 86.07 & 87.72 \\
\hline & 3 & 108.64 & 108.58 & 108.60 & 108.53 & 116.95 \\
\hline \multirow{3}{*}{0.4} & 1 & 111.49* & $110.12 *$ & $110.57^{*}$ & 111.68* & 161.70 \\
\hline & 2 & 97.01* & $96.53 *$ & 96.68* & 96.18* & 119.33 \\
\hline & 3 & 117.11 & 117.11 & 117.10 & 117.12 & 122.87 \\
\hline
\end{tabular}

En la Tabla 11 se muestran los valores de las densidades de flujo de permeado iniciales obtenidas experimentalmente y los valores resultantes de la aplicación de los Modelos de Hermia para flujo transversal. Las diferencias entre los valores experimentales y los calculados son, en su mayoría, inferiores al error experimental cometido en la determinación de la densidad de flujo de permeado, el cual se ha calculado en el apartado 5.1 de esta Tesis Doctoral y resultó ser menor o igual al $11 \%$. Los valores que aparecen en la 
Tabla 11 marcados con un asterisco se desvían más de un $11 \%$ del valor experimental correspondiente. Dicha desviación fue ligeramente superior al $11 \%$ en todos los casos, excepto para la PTM de $0.4 \mathrm{MPa}$ y la velocidad tangencial de $1 \mathrm{~m} / \mathrm{s}$, para la que resultó ser del orden del $30 \%$. Estas diferencias entre los valores de la densidad de flujo de permeado inicial ajustados y los valores experiemtales son debidas a las dificultades para medir la densidad de flujo de permeado en los instantes inciales del ensayo de ultrafiltración.

Tabla 12. Comparación entre las densidades de flujo de permeado iniciales obtenidas experimentalemente con la membrana Carbosep M 2 y las resultantes de la aplicación de los M odelos de $\mathrm{H}$ ermia adaptados para flujo tangencial.

\begin{tabular}{|c|c|c|c|c|c|}
\hline \multirow{2}{*}{$\begin{array}{l}\text { PTM } \\
\text { (MPa) }\end{array}$} & \multirow{2}{*}{$\begin{array}{c}\text { Velocidad } \\
\text { tangencial } \\
(\mathrm{m} / \mathrm{s})\end{array}$} & \multicolumn{4}{|c|}{ Densidades de flujo de permeado $\left(L \cdot h^{-1} \cdot m^{-2}\right)$} \\
\hline & & $\begin{array}{l}\text { Bloqueo } \\
\text { completo }\end{array}$ & $\begin{array}{c}\text { Bloqueo } \\
\text { intermedio }\end{array}$ & Capa gel & $\begin{array}{l}\text { Experi- } \\
\text { mental }\end{array}$ \\
\hline \multirow{3}{*}{0.1} & 1 & 35.90 & 35.90 & 36.08 & 34.62 \\
\hline & 2 & 52.17 & 52.18 & 52.45 & 51.20 \\
\hline & 3 & 64.42 & 64.46 & 64.29 & 63.04 \\
\hline \multirow{3}{*}{0.2} & 1 & 48.28 & 48.49 & 44.79 & 49.99 \\
\hline & 2 & 72.77 & 72.80 & 72.04 & 70.56 \\
\hline & 3 & 88.76 & 88.80 & 88.03 & 86.10 \\
\hline \multirow{3}{*}{0.3} & 1 & 65.24 & 65.89 & 61.54 & 65.46 \\
\hline & 2 & 87.79 & 87.83 & 88.24 & 87.72 \\
\hline & 3 & 114.88 & 115.10 & 113.23 & 116.95 \\
\hline \multirow{3}{*}{0.4} & 1 & 153.41 & 159.34 & 163.36 & 161.70 \\
\hline & 2 & 115.95 & 117.32 & 103.16* & 119.33 \\
\hline & 3 & 121.86 & 122.03 & 119.72 & 122.87 \\
\hline
\end{tabular}

En la Tabla 12 se muestran los valores de las densidades de flujo de permeado iniciales obtenidas experimental mente y las resultantes de la aplicación de los Modelos de Hermia adaptados para flujo 
tangencial. Las diferencias entre los valores experimentales y los estimados son inferiores al error experimental cometido en la determinación de la densidad de flujo de permeado excepto para el $M$ odelo de formación de capa gel adaptado para flujo tangencial para la PTM de $0.4 \mathrm{MPa}$ y la velocidad tangencial de $2 \mathrm{~m} / \mathrm{s}$. En este caso la desviación entreel valor experimental y el ajustado es de un $13.5 \%$. Los valores de las densidades de flujo de permeado inicial son más parecidas a los resultados experimentales en el caso de los M odelos de $\mathrm{H}$ ermia adaptados para flujo tangencial que en el caso de los M odelos de H ermia para flujo transversal, como se esperaba.

Tabla 13. Comparación entre las densidades de flujo de permeado estacionarias obtenidas experimentalmente con la membrana Carbosep M 2 y las resultantes de la aplicación de los M odelos de H ermia adaptados para flujo tangencial.

\begin{tabular}{|c|c|c|c|c|c|}
\hline \multirow{2}{*}{$\begin{array}{l}\text { PTM } \\
\text { (MPa) }\end{array}$} & \multirow{2}{*}{$\begin{array}{c}\text { Velocidad } \\
\text { tangencial } \\
(\mathrm{m} / \mathrm{s})\end{array}$} & \multicolumn{4}{|c|}{ Densidades de flujo de permeado $\left(\mathrm{L} \cdot \mathrm{h}^{-1} \cdot \mathrm{m}^{-2}\right)$} \\
\hline & & $\begin{array}{l}\text { Bloqueo } \\
\text { completo }\end{array}$ & $\begin{array}{c}\text { Bloqueo } \\
\text { intermedio }\end{array}$ & Capa gel & $\begin{array}{l}\text { Experi- } \\
\text { mental }\end{array}$ \\
\hline \multirow{3}{*}{0.1} & 1 & 33.56 & 33.53 & 27.85 & 34.07 \\
\hline & 2 & 49.23 & 49.17 & 45.11 & 49.96 \\
\hline & 3 & 59.17 & 59.15 & 56.49 & 59.13 \\
\hline \multirow{3}{*}{0.2} & 1 & 38.38 & 38.32 & 37.62 & 38.25 \\
\hline & 2 & 63.53 & 63.49 & 53.66 & 62.89 \\
\hline & 3 & 78.78 & 78.66 & 76.39 & 79.09 \\
\hline \multirow{3}{*}{0.3} & 1 & 43.36 & 43.03 & 40.99 & 42.96 \\
\hline & 2 & 71.24 & 70.60 & 70.24 & 73.01 \\
\hline & 3 & 96.37 & 96.24 & 93.65 & 95.62 \\
\hline \multirow{3}{*}{0.4} & 1 & 51.07 & 48.12 & 41.48 & 45.71 \\
\hline & 2 & 77.51 & 77.18 & 72.25 & 75.69 \\
\hline & 3 & 104.09 & 103.95 & 98.58 & 104.55 \\
\hline
\end{tabular}

En la Tabla 13 se muestran las densidades de flujo de permeado estacionaria experimental y la resultante del ajuste de los M odel os de Hermia adaptados para flujo tangencial. Las diferencias entre los 
valores experimentales y los ajustados son siempre inferiores al error experimental cometido en la determinación de la densidad de flujo de permeado. 


\section{Capítulo}

\section{CONCLUSIONES}

Los resultados experimentales obtenidos en la presente Tesis Doctoral permiten concluir lo siguiente:

- No existe un modelo dinámico no empírico que describa adecuadamente la dinámica de los procesos de ultrafiltración para diferentes condiciones de operación y para el cual se obtengan buenas predicciones.

- Todos los modelos teóricos analizados consideran que el principal mecanismo de ensuciamiento es la formación de capa gel. Por este motivo las mejores predicciones se obtienen para velocidades tangenciales reducidas y elevadas presiones transmembranales, que son las condiciones experimentales para las que la capa gel es más probable que se forme.

- De todos los modelos teóricos analizados, los modelos que realizan las mejores predicciones para bajas velocidades tangenciales son el Modelo de difusión inducido por cizalla aplicado en el caso de la ultrafiltración dinámica, el M odelo dinámico de Song para la ultrafiltración tangencial y el M odelo dinámico de B hattacharjee y B hattacharya para la ultrafiltración controlada por la presión osmótica o por la capa gel indistintamente. 
- El M odelo dinámico de Song para la ultrafiltración tangencial y el Modelo dinámico de Bhattacharjee y Bhattacharya para la ultrafiltración controlada por la presión osmótica o por la capa gel indistintamente no reflejan la influencia de la velocidad tangencial en la densidad de flujo de permeado.

- El modelo teórico que realiza las mejores predicciones para velocidades tangenciales elevadas es el Modelo de difusión inducido por cizalla aplicado en el caso de la ultrafiltración dinámica.

- Las mejoras en las predicciones obtenidas con los modelos teóricos cuando la concentración en la capa gel se estima de forma empírica no son significativas.

- Para todos los modelos semi-empíricos: M odelos de Hermia y M odelos de Hermia adaptados para flujo tangencial, tanto en el caso de que se hayan estimado empíricamente los parámetros como en el caso de que se hayan calculado teóricamente, el ajuste es mejor cuando la variación de la densidad de flujo de permeado con el tiempo no es significativa. De este modo, sólo para los ensayos en los queel descenso dela densidad deflujo de permeado con el tiempo es considerable se logra seleccionar el modelo semi-empírico más apropiado.

- Para todos los M odelos de H ermia adaptados para flujo tangencial los ajustes obtenidos mejoran respecto a los obtenidos con los M odelos de Hermia convencionales exceptuando el Modelo de bloqueo estándar de poros. Este modelo no se ve afectado por el proceso de adaptación para flujo tangencial y es aquel para el que peor se ajustan los resultados predichos a los datos experimentales.

- El M odelo de bloqueo intermedio de poros para flujo tangencial se ajusta bien a los datos experimentales para todas las condiciones ensayadas. 
- Para $1 \mathrm{~m} / \mathrm{s}$ y $0.4 \mathrm{MPa}$ el M odelo de formación de capa gel para flujo tangencial se ajusta tan bien a los resultados experimentales como el Modelo de bloqueo intermedio de poros para flujo tangencial, pues éstas son las condiciones para las que la formación de capa gel es más probable.

- Para $1 \mathrm{~m} / \mathrm{s}$ y $0.3 \mathrm{MPa}$, para $2 \mathrm{~m} / \mathrm{s}$ y 0.2 y $0.4 \mathrm{MPa}$ y para 3 $\mathrm{m} / \mathrm{s}$ y 0.3 y $0.4 \mathrm{MPa}$ el M odel o de bloqueo intermedio de poros para flujo tangencial se ajusta tan bien como el Modelo de bloqueo completo de poros para flujo tangencial a los datos experimentales.

- Cuando se calculan los parámetros de los M odelos de Hermia adaptados para flujo tangencial de forma teórica se obtienen resultados ligeramente peores que cuando se realiza un ajuste empírico.

- El M odelo de bloqueo intermedio de poros para flujo tangencial con cálculo teórico de los parámetros realiza buenas predicciones para todas las condi ciones experimentales ensayadas.

- El M odelo de bloqueo completo de poros para flujo tangencial con cálculo teórico de los parámetros del mismo realiza buenas predicciones para todas las condiciones experimentales ensayadas, excepto para una velocidad tangencial de $1 \mathrm{~m} / \mathrm{s}$ y una PTM de 0.4 MPa.

- En el caso de los M odelos de Hermia para flujo transversal, así como en el caso de la estimación teórica de los parámetros de los M odel os de H ermia adaptados para flujo tangencial, se observó que los valores de los parámetros de los modelos siguen una variación con la PTM y la velocidad tangencial que está de acuerdo con su significado físico. 
- Los resultados predichos por los modelos semi-empíricos, incluso cuando los parámetros de los mismos se estiman de forma teórica, se asemejan más a los datos experimentales que las mejores predicciones obtenidas con los model os teóricos.

- De todos los modelos teóricos y semi-empíricos analizados en esta Tesis Doctoral, el modelo más apropiado para describir los fenómenos de ensuciamiento en los procesos de ultrafiltración de macromoléculas para las condiciones experimentales ensayadas es el $M$ odelo de bloqueo intermedio de poros para flujo tangencial. 


\section{NOTACIÓN}

\section{NOTACIÓN}

a

A

$\mathrm{A}_{0}$

$a_{p}$

$A_{\text {poro }}$

C

$\mathrm{C}_{\mathrm{m}}$

$\mathrm{C}_{\mathrm{g}}$

$\mathrm{C}_{\mathrm{gv}}$

$\mathrm{C}_{\mathrm{V}}$

$\mathrm{C}_{0}$

Cov

$C_{p}$

D

$D_{h}$

$D_{\text {int }}$

$\mathrm{f}$

$f^{\prime}$

Jo $\quad-$ densidad de flujo de permeado inicial $(\mathrm{m} / \mathrm{s})$

$J_{\mathrm{P}}$

- resistencia específica de la capa gel $(\mathrm{m} / \mathrm{kg})$

- área de membrana $\left(\mathrm{m}^{2}\right)$

- superficie porosa de la membrana $\left(\mathrm{m}^{2}\right)$

- radio de la molécula de polietilenglicol ( $\mathrm{m}$ )

- área superficial de los poros dela membrana $\left(\mathrm{m}^{2}\right)$

- concentración $\left(\mathrm{kg} / \mathrm{m}^{3}\right)$

- concentración del soluto sobre la superficie de la membrana $\left(\mathrm{kg} / \mathrm{m}^{3}\right)$

- concentración del soluto en la capa gel $\left(\mathrm{kg} / \mathrm{m}^{3}\right)$

- concentración del soluto en la capa gel ( $\mathrm{v} / \mathrm{v}$ )

- concentración del soluto ( $\mathrm{v} / \mathrm{v}$ )

- concentración del soluto en el alimento $\left(\mathrm{kg} / \mathrm{m}^{3}\right)$

- concentración del soluto en el alimento $(\mathrm{v} / \mathrm{v})$

- concentración del soluto en el permeado $\left(\mathrm{kg} / \mathrm{m}^{3}\right)$

- difusividad del soluto $\left(\mathrm{m}^{2} / \mathrm{s}\right)$

- diámetro hidráulico de paso de la alimentación por la membrana $(\mathrm{m})$

- diámetro interno de la membrana $(\mathrm{m})$

- fracción de soluto que está presente en la disolución como grandes agregados (adimensional)

- cantidad fraccional de soluto que contribuye al crecimiento de la capa gel (adimensional)

- densidad de flujo de permeado $(\mathrm{m} / \mathrm{s})$ 
$\int_{\text {Pss }} \quad-$ densidad de flujo de permeado en condiciones de estado estacionario $(\mathrm{m} / \mathrm{s})$

$\mathrm{K} \quad-$ constante de la Ec. 22 (unidades en función del parámetro $n$ en la Ec. 22)

$\mathrm{K}_{\mathrm{A}} \quad$ - parámetro de las Ecs. 24 y 26 en el M odel o de bloqueo estándar de poros y en el M odelo de bloqueo intermedio de poros que representa la superficie de membrana bloqueada por unidad de vol umen total permeado a través de la membrana $\left(\mathrm{m}^{-1}\right)$

$\mathrm{K}_{\mathrm{B}} \quad$ - parámetro de la Ec. 28 en el M odel o de bloqueo estándar de poros que representa la disminución del área transversal de los poros por unidad de volumen de permeado filtrado $\left(\mathrm{m}^{-1}\right)$

$\mathrm{K}_{c}-$ constante de la Ec. 23 correspondienteal M odelo de bloqueo completo de poros ( seg-1) $^{-1}$

$\mathrm{K}_{\mathrm{cCF}}-$ constante de la Ec. 32 correspondienteal M odelo de bloqueo completo de poros para flujo tangencial $\left(\mathrm{m}^{-1}\right)$

$\mathrm{K}_{\mathrm{CF}} \quad$ - coeficientefenomenológico - constantedela Ec. 31 que depende del mecanismo de ensuciamiento (unidades en función del parámetro $\mathrm{n}_{\mathrm{CF}}$ en la Ec. 31)

$\mathrm{K}_{\mathrm{cg}} \quad$ - constante de la Ec. 29 correspondienteal M odelo de formación de torta (seg/ $\mathrm{m}^{2}$ )

$\mathrm{K}_{\mathrm{cgCF}}-$ constante de la Ec. 34 correspondienteal M odelo de formación de capa gel para flujo tangencial (seg/ $\mathrm{m}^{2}$ )

$\mathrm{K}_{\text {cgcF }}^{\prime} \quad$ - constante de filtración dela Ec. 40 en el M odelo de formación de capa gel para flujo tangencial que relaciona la masa de capa gel con el volumen de permeado filtrado $\left(\mathrm{kg} / \mathrm{m}^{3}\right)$

$\mathrm{K}_{\mathrm{D}} \quad-$ parámetro dela Ec. 30 en el M odelo de formación de torta que representa el área de capa gel por unidad de volumen de permeado filtrado $\left(\mathrm{m}^{-1}\right)$

$\mathrm{K}_{\mathrm{e}} \quad$ - constante de la Ec. 27 correspondienteal M odelo de bloqueo estándar de poros ( $\left.\mathrm{m}^{-1 / 2} \mathrm{seg}^{-1 / 2}\right)$

$\mathrm{K}_{\mathrm{i}} \quad$ - constante de la Ec. 25 correspondienteal M odelo de bloqueo intermedio de poros $\left(\mathrm{m}^{-1}\right)$ 


\begin{tabular}{|c|c|}
\hline $\mathrm{K}_{\mathrm{iCF}}$ & $\begin{array}{l}\text { - constante de la Ec. } 33 \text { correspondienteal M odelo de } \\
\text { bloqueo intermedio de poros para flujo tangencial }\left(\mathrm{m}^{-1}\right)\end{array}$ \\
\hline $\mathrm{k}_{\mathrm{TM}}$ & - coeficiente de transferencia de materia $(\mathrm{m} / \mathrm{s})$ \\
\hline k & - constante de Boltzman (J/ K) \\
\hline $\mathrm{L}$ & - longitud de la membrana (m) \\
\hline m & - masa $(\mathrm{kg})$ \\
\hline$n$ & $\begin{array}{l}\text { - constante de la Ec. } 22 \text { que depende del mecanismo de } \\
\text { ensuciamiento (adimensional) }\end{array}$ \\
\hline $\mathrm{n}_{\mathrm{CF}}$ & $\begin{array}{l}\text { - constante de la Ec. } 31 \text { que depende del mecanismo de } \\
\text { ensuciamiento (adimensional) }\end{array}$ \\
\hline$M_{\text {agg }}$ & - masa de una molécula de soluto (kg/ molécula) \\
\hline$M_{1}$ & - peso molecular del disolvente $(\mathrm{kg} / \mathrm{mol})$ \\
\hline$M_{p}$ & - peso molecular del polímero $(\mathrm{kg} / \mathrm{mol})$ \\
\hline$n_{D}$ & - índice de refracción (adimensional) \\
\hline $\mathrm{N}_{\mathrm{Fc}}$ & - número crítico de filtración (adimensional) \\
\hline$P$ & - presión (Pa) \\
\hline$\Delta \mathrm{P}$ & - presión transmembranal $(\mathrm{Pa})$ \\
\hline$\Delta \mathrm{P}_{\mathrm{c}}$ & $\begin{array}{l}\text { - presión crítica para la aparición de fenómenos de } \\
\text { ensuciamiento }(\mathrm{Pa})\end{array}$ \\
\hline $\mathrm{Pe}_{\mathrm{e}}$ & - presión de entrada al módulo de membranas (Pa) \\
\hline$P_{m}$ & - coeficiente de permeabilidad $\left(\mathrm{m}^{2}\right)$ \\
\hline$P_{p}$ & - presión en el permeado (Pa) \\
\hline$P_{s}$ & - presión de salida del módulo de membranas (Pa) \\
\hline$Q_{A}$ & - caudal dealimento ( $\left.\mathrm{m}^{3} / \mathrm{s}\right)$ \\
\hline $\mathrm{R}$ & — índice de rechazo (adimensional) \\
\hline $\mathrm{R}_{\mathrm{a}}$ & - resistencia debida a fenómenos de adsorción $\left(\mathrm{m}^{-1}\right)$ \\
\hline $\mathrm{R}_{\mathrm{bm}}$ & - resistencia de la membrana bloqueada $\left(\mathrm{m}^{-1}\right)$ \\
\hline$r_{c}$ & - resistencia específica de la capa gel $\left(\mathrm{kg} / \mathrm{m}^{3} \mathrm{~s}\right)$ \\
\hline $\mathrm{R}_{c}$ & - resistencia específica de la capa gel en la Ec. $14\left(\mathrm{~m}^{-2}\right)$ \\
\hline$R_{c}^{\prime}$ & - resistencia específica de la capa gel en la Ec. $18\left(\mathrm{~m}^{-2}\right)$ \\
\hline $\mathrm{R}_{\mathrm{co}}$ & - resistencia inicial de la capa gel $\left(\mathrm{m}^{-1}\right)$ \\
\hline $\mathrm{Re}$ & - Número de Reynolds (adimensional) \\
\hline $\mathrm{R}_{\mathrm{g}}$ & - resistencia de la capa gel $\left(\mathrm{m}^{-1}\right)$ \\
\hline $\mathrm{R}_{\mathrm{G}}$ & - constante de los gases ideales $(\mathrm{J} / \mathrm{K}$ mol $)$ \\
\hline $\mathrm{R}_{\mathrm{m}}$ & - resistencia de la membrana $\left(\mathrm{m}^{-1}\right)$ \\
\hline
\end{tabular}


$\mathrm{R}_{\text {osm }}$

$\mathrm{S}_{\mathrm{A}}$

SC

So

t

T

V

$\mathrm{V}_{1}$

$v_{1}$

$V_{p}$

$V_{p}$

$\mathrm{V}_{\text {tang }}$

$\mathrm{X}$

$x_{1}$

$X_{m}$

- resistencia debida a fenómenos de presión osmótica $\left(\mathrm{m}^{-1}\right)$

- sección de paso del caudal de alimento a través dela membrana $\left(\mathrm{m}^{2}\right)$

- Número de Schmidt (adimensional)

- área superficial por unidad de volumen de soluto o de agregado de moléculas de soluto en el caso de que se forme $\left(\mathrm{m}^{-1}\right)$

- tiempo (s)

- temperatura $(\mathrm{K})$

- volumen $\left(\mathrm{m}^{3}\right)$

- volumen específico del disolvente $\left(\mathrm{m}^{3} / \mathrm{mol}\right)$

- volumen específico del disolvente $\left(\mathrm{m}^{3} / \mathrm{kg}\right)$

- volumen acumulado de permeado $\left(\mathrm{m}^{3}\right)$

- volumen específico del polímero $\left(\mathrm{m}^{3} / \mathrm{kg}\right)$

- velocidad tangencial $(\mathrm{m} / \mathrm{s})$

- parámetro definido en la Ec. 54 (adimensional)

- parámetro que depende de la interacción disolventepolímero (adimensional)

- fracción másica de soluto sobre la superficie de membrana (adimensional)

\section{Letras griegas}

$\alpha$

$\beta$

$\varepsilon$

$\gamma$

$\gamma_{1}$

$\gamma_{2}$

$\mu$

$v$

$\pi$
- parámetro de bloqueo de poros $\left(\mathrm{m}^{2} / \mathrm{kg}\right)$

- relación entre la resistencia de la capa gel y la resistencia de la membrana definida por la Ec. 3 (adimensional)

- porosidad de la capa gel (adimensional)

- velocidad decizalla $\left(\mathrm{s}^{-1}\right)$

- parámetro definido en la Ec. 56 (adimensional)

- parámetro definido en la Ec. 55 (adimensional)

- viscosidad dinámica $(\mathrm{kg} / \mathrm{ms})$

- viscosidad cinemática $\left(\mathrm{m}^{2} / \mathrm{s}\right)$

- presión osmótica (Pa) 
$\theta$

$\theta_{\mathrm{g}}$

$\rho$

$\rho_{m}$

$\rho_{\mathrm{g}}$

$\rho_{P E G}$

$\rho_{\mathrm{s}}$

$\psi$
- parámetro definido en la Ec. 7 (adimensional)

- parámetro definido en laEc. 7 (adimensional)

- densidad $\left(\mathrm{kg} / \mathrm{m}^{3}\right)$

- densidad de la disolución alimento que se encuentra sobre la superficie de la membrana $\left(\mathrm{kg} / \mathrm{m}^{3}\right)$

- densidad de la capa gel $\left(\mathrm{kg} / \mathrm{m}^{3}\right)$

- densidad del PEG $\left(\mathrm{kg} / \mathrm{m}^{3}\right)$

- densidad del soluto $\left(\mathrm{kg} / \mathrm{m}^{3}\right)$

- factor de forma del soluto (adimensional)

\section{Abreviaturas}

ASTM - American Society for Testing and Materials

AWWA - American Water Works Association

BA - bomba dealimentación

D - diálisis

DQO - demanda química de oxígeno

ED - electrodiálisis

EPA - Environmental Protection Agency

$\mathrm{F} \quad-$ filtro

HPLC - cromatografía líquida de alta resolución

ISO - International Organization for Standardization

M - manómetro

MF - microfiltración

NF - nanofiltración

OI - ósmosis inversa

PEG - polietilenglicol

PG - permeación de gases

PM - peso molecular

PTM - presión transmembranal

PV - pervaporación

SCT - sistema de control de temperatura

$\mathrm{SL} \quad$ - sistema de lavado

SRL - sistema de retro-lavado

TT - sensor de temperatura 
UF - ultrafiltración

UPV - Universidad Politécnica de Valencia

VA - válvula dealivio 


\section{REFERENCIAS}

\section{REFERENCIAS}

A merican National Standards Institute (2001): Standard M ethod of Test for $\mathrm{V}$ iscosity of Transparent and O paque Liquids. Washington.

AWWA Research Foundation (1998): Tratamiento del agua por procesos de membrana: principios, procesos y aplicaciones. McGraw-Hill, Madrid.

Belfort, G.; Davis, R.H. y Zydney, A.L. (1994): “The behaviour of suspensions and macromolecular solutions in crossflow ultrafiltration", Journal of M embrane Science, Vol. 96, pp. 1-58

Bes, M .A. (2003): Reutilización de aguas residuales de la industria textil aplicando conjuntamente tratamiento físico-químico y procesos de membranas, Tesis Doctoral, Universidad Politécnica de Valencia.

Bhattacharjee, S. y Bhattacharya, P.K. (1992a): "Flux decline behaviour with low molecular weight solutes during ultrafiltration in an unstirred batch cell", Journal of M embrane Science, Vol. 72, pp. 149-161

Bhattacharjee, S. y Bhattacharya, P.K. (1992b): “Prediction of limiting flux in ultrafiltration of kraft black liquor", Journal of M embrane Science, Vol. 72, pp. 137-147 
Bhattacharjee, C. y Datta, S. (1996): “Analysis of mass transfer during ultrafiltration of PEG-6000 in a continuous stirred cell: effect of back transport", J Jurnal of M embraneScience, Vol. 119, pp. 39-46

Bhattacharjee, C. y Datta, S. (2003): “Analysis of polarized layer resistance during ultrafiltration of PEG-6000: an approach based on filtration theory", Separation and Purification Technology, Vol. 33, pp. 115-126

Bhattacharya, P.K.; A garwal, S.; De, S. y Rama Gopal, U.V.S. (2001): "Ultrafiltration of sugar cane juice for recovery of sugar: analysis of flux and retention", Separation and Purification Technology, Vol. 21, pp. 247-259

Bird, M.R. y Bartlett, M. (2002): “Measuring and modelling flux recovery during chemical cleaning of MF membranes for the processing of whey protein concentrate", Journal of Food Engineering, Vol. 53, pp. 143-152

Bowen, W.R.; Calvo, J.I. y Hernández, A. (1995): "Steps of membrane blocking in flux decline during protein microfiltration", Journal of M embraneScience, Vol. 101, pp. 153-165

Castro, R.C.; Monbouquette, H.G. y Cohen, Y. (2000): “Shearinduced permeability changes in a polymer grafted silica membrane", J Jurnal of M embrane Science, Vol. 179, pp. 207-220

Cheryan, M. (1998): Ultrafiltration and microfiltration handbook. Second edition. CRC Press, New York.

Costa, J. (1985): O btención de membranas de ultrafiltración a partir de polímeros comerciales, y su aplicación al tratamiento de aguas residuales de pinturas cataforéticas, Tesis Doctoral, Universidad Politécnica de Valencia. 
Daufin, G.; Merin, U.; Kerhervé, F.L.; Labbé, J.P.; Quémerais, A. y Bousser, C. (1991): "Cleaning of inorganic membranes after whey and milk ultrafiltration", Biotechnology and Bioengineering, Vol. 38, pp. 82-89

Daufin, G.; Merin, U.; Kerherve, F.L.; Labbe, J.P.; Quemerais, A. y Bousser, C. (1992): "Efficiency of cleaning agents for an inorganic membrane after milk ultrafiltration", Journal of Dairy Research, Vol. 59, pp. 29-38

Davis, R.H. (1992): “Modeling of fouling of crossflow microfiltration membranes", Separation and Purification M ethods, Vol. 21, pp. 75-126

Das Gupta, S. y Bhattacharya, P.K. (1990): “Comparative limiting flux analysis of black liquor and polyethylene glycol in ultrafiltration", Chemical Engineering Communications, Vol. 93, pp. 193-210

De, S. y Bhattacharya, P.K. (1996): “Flux prediction of black liquor in crossflow ultrafiltration using low and high rejecting membranes", Journal of M embrane Science, Vol. 109, pp. 109-123

De, S. y Bhattacharya, P.K. (1997): “Modeling of ultrafiltration process for a two-component aqueous solution of low and high (gel forming) molecular weight solutes", Journal of Membrane Science, Vol. 136, pp. 57-69

de Barros, S.T.D.; Andrade, C.M.G.; Mendes, E.S. y Peres, L. (2003): "Study of fouling mechanism in pineapple juice clarification by ultrafiltration", Journal of M embrane Science, Vol. 215, pp. 213-224

Field, R.W.; Wu, D.; Howell, J.A. y Gupta, B.B. (1995): “Critical flux concept for microfiltration fouling", J ournal of M embrane Science, Vol. 100, pp. 259-272 
Ganguly, S. y Bhattacharya, P.K. (1994): “Development of concentration profile and prediction of flux for ultrafiltration in radial cross-flow cell", Journal of M embrane Science, Vol. 97, pp. 185198

Ghose, S.; Battacharjee, C. y Datta, S. (2000): "Simulation of unstirred batch ultrafiltration process based on a reversible pore plugging mode", Journal of M embrane Science, Vol. 169, pp. 29-38

Ghose, S.; Poddar, A.; Datta, S. y Battacharjee, C. (1999): “N umerical simulation of an unstirred batch ultrafiltration process based on the boundary layer concept", Separation and Purification Technology, Vol. 16, pp. 75-81

Gozálvez, J.M. (1998): Fabricación de membranas de acetato de celulosa aptas para ósmosis inversa y nanofiltración mediante el método de inversión de fase, Tesis Doctoral, Universidad Politécnica de Valencia.

Gu, Z. (2004): A cross-sample Incomparability of $R^{2} s$ and Additional Evidence on $V$ alue Relevance Changes Over Time [Working paper]. Carnegie Mellon University, Pittsburgh.

Hamieh, T.; Siffert, B. y M 'Pandou, A. (2000): “Thickness of nonionic polymer layers carried by inorganic adsorbents in the case of the $\mathrm{TiO}_{2}$ - poly ethylenglycol system", A dvanced Powder Technology, Vol. 11, pp. 271-277

Hermia, J. (1982): “Constant pressure blocking filtration laws Application to power-law non-newtonian fluids", Transactions of the Institution of Chemical Engineers, Vol.60, pp. 183-187

Hlavacek, M. y Bouchet, F. (1993): “Constant flowrate blocking laws and an example of their application to dead-end microfiltration of protein solutions", J ournal of M embrane Science, Vol. 82, pp. 285-295 
Ho, C-C. y Zydney A.L. (2000): “A combined pore blockage and cake filtration model for protein fouling during microfiltration", Journal of Colloid and Interface Science, Vol. 232, pp. 389-399

Howell, J.A. (1995): "Sub-critical flux operation of microfiltration", Journal of M embraneScience, Vol. 107, pp. 165-171

Hwang, K-J. y Lin T-T. (2002): “Effect of morphology of polymeric membrane on the performance of cross-flow microfiltration", Journal of M embrane Science, Vol. 199, pp. 41-52

International Organization for Standardization (2002): Standard 15705: W ater quality [D etermination of the chemical oxygen demand index (ST-COD)] Small-scale sealed-tube method. Ginebra.

International Organization for Standardization (2001): Crude petroleum and liquid petroleum products -Llaboratory determination of density - H ydrometer method. Ginebra.

Jacob, S. y Jaffrin, M.Y. (2000): "Purification of brown cane sugar solutions by ultrafiltration with ceramic membranes: investigation of membrane fouling", Separation Science and Technology, Vol. 35, pp. 989-1010

Kelly, S.T. y Zydney, A.L. (1995): “Mechanisms for BSA fouling during microfiltration", Journal of M embrane Science, Vol. 107, pp. $115-127$

Koltuniewicz, A.B. y Field, R.W. (1996): "Process factors during removal of oil-in-water emulsions with cross-flow microfiltration", Desalination, Vol. 105, pp. 79-89 
Krishnan, M.; Kalogerakis, N.; Behie, L.A. y Mehrotra, A.K. (1994): "Separation of monoclonal IgM antibodies using tangential flow ultrafiltration", Canadian Journal of Chemical Engineering, Vol. 72, pp. 982-990.

Lee, S.; Kim, J. y Lee, C.H. (1999): “Analysis of $\mathrm{CaSO}_{4}$ scale formation mechanism in various nanofiltration modules", Journal of M embraneScience, Vol. 163, pp. 63-74

Lide, D.R. (2003): CRC Handbook of Chemistry and Physics. 83rd edition. CRC Press LLC, N ew York.

Lim, A.L. y Bai, R. (2003): “Membrane fouling and cleaning in microfiltration of activated sludge wastewater", Journal of M embrane Science, Vol. 216, pp. 279-290

Madaeni , S.S.; Fane, A.G. y Grohmann, G.S. (1995): “Virus removal from water and wastewater using membranes", Journal of M embrane Science, Vol. 102, pp. 65-75

Meindersma, G.W.; Augeraud, J. y Vergossen, F.H.P. (1997): "Separation of a biocatalyst with ultrafiltration or filtration after bioconversion", Journal of M embrane Science, Vol. 125, pp. 333-349

Mendoza, J.A. (2000): A plicación de la ultrafiltración al tratamiento de las aguas residuales de apelambrado en una industria de curtidos. A nálisis y selección del protocolo de limpieza, Tesis Doctoral, Universidad Politécnica de Valencia.

Mikulášek, P; Dolecek, P.; Šmídová, D. y Pospíšil, P. (2004): "Crossflow microfiltration of mineral dispersions using ceramic membranes", D esalination, Vol. 163, pp. 333-343 
Möckel, D.; Staude, E. y Guiver, M.D. (1999): "Static protein adsorption, ultrafiltration behaviour and cleanability of hydrophilized polysulfone membranes", Journal of M embrane Science, Vol. 158, pp. 63-75

Mohammadi, T.; Kazemimoghadam, M. y Saadabadi, M. (2003): "M odeling of membrane fouling and flux decline in reverse osmosis during separation of oil in water emulsions", D esalination, Vol. 157, pp. 369-375

Molinari, R.; Glagliardi, R. y Drioli, E. (1995): “Methodology for estimating saving of primary energy with membrane operations in industrial processes", D esalination, Vol. 100, pp. 125-137

Mulder, M. (2000): Basic principles of membrane technology. Second edition. Kluwer Academic, Dordrecht.

Palacio, L.; Ho, C-C.; Prádanos, P.; Hernández, A. y Zydney, A.L. (2003): "Fouling with protein mixtures in microfiltration: BSAlysozyme and BSA-pepsin", Journal of M embrane Science, Vol. 222, pp. $41-51$

Parnham, C.S. y Davis, R.H. (1996): "Protein recovery from bacterial cell debris using crossflow microfiltration with backpulsing", Journal of M embrane Science, Vol. 118, pp. 259-268

Poddar, A.; Bhattacharjee, C. y Datta, S. (1999): "Simulation of unstirred batch ultrafiltration system based on analytical solution of boundary layer equation", Separation Science and Technology, Vol. 34, pp. $2485-2500$

Porter, J.J. y Porter, R.S. (1995): “Filtration studies of selected anionic dyes using asymmetric titanium dioxide membranes on porous stainless-steel tubes", Journal of M embrane Science, Vol. 101, pp. 67-81 
Prádanos, P.; Arribas, J.I. y Hernández, A. (1995): “Mass transfer coefficient and retention of PEGs in low pressure cross-flow ultrafiltration through asymetric membranes", Journal of M embrane Science, Vol. 99, pp. 1-20

Puhlfür $\beta$, P.; Voigt, A.; Weber, R. y Morbe, M. (2000): “Microporous $\mathrm{TiO}_{2}$ membranes with a cut off $<500 \mathrm{Da}$ ", Journal of Membrane Science, Vol. 174, pp. 123-133

Sherwood, T.K.; Pigford, R.L. y Wilke, C.R. (1975): M ass transfer. Mc Graw Hill, New York.

Song, L. (1998a): “Flux decline in crossflow microfiltration and ultrafiltration: mechanisms and modeling of membrane fouling", Journal of M embrane Science, Vol. 139 pp. 183-200

Song, L. (1998b): “A new model for the prediction of the limiting flux in ultrafiltration", Journal of M embrane Science, Vol. 144 pp. 173185

Song, L. y Elimelech, M (1995): "Theory of concentration polarization in crossflow filtration", Journal of the Chemical Society. Faraday Transactions, Vol. 91 pp. 3389-3398

Sulaiman, M.Z.; Sulaiman, N.M. y A bdellah, B. (2001): “Prediction of dynamic permeate flux during cross-flow ultrafiltration of polyethylene glycol using concentration polarization-gel layer model", J ournal of M embrane Science, Vol. 189 pp. 151-165

Tam, C. y Trembley, A. (1991): “Membrane pore characterization comparison between single and multicomponent solute probe techniques", Journal of M embraneScience, Vol. 57 pp. 271-287 
Taniguchi, M.; Kilduff, J.E. y Belfort, G. (2003): “Modes of natural organic matter fouling during ultrafiltration", Environmental Science and Technology, Vol. 37 pp. 1676-1683

Todisco, S.; Peña, L.; Drioli, E. y Tallarico, P. (1996): “Analysis of the fouling mechanism in microfiltration of orange juice", J ournal of Food Processing and Preservation, Vol. 20 pp. 453-466

Tracey, E.M. y Davis, R.H. (1994): “Protein fouling of track-etched polycarbonate microfiltration membranes", Journal of Membrane Science, Vol. 167 pp. 104-116

Vincent, M.C. (2004): M odelling flux decline in crossflow ultrafiltration [comunicación presentada en la sexta edición del congreso N etwork Young Membrains]. Hamburgo, Alemania.

Vincent, M .C.; Lora, J.; Álvarez, Sy Bergantiños, E. (2004): M embrane fouling in the ultrafiltration of wastewater from the textile industry: dynamic modelling [comunicación presentada en el congreso Euromembrane]. Hamburgo, A lemania.

Vincent, M.C.; Álvarez, S. y Lora, J. (2005a): Crossflow ultrafiltration of cake forming solutes: a non-steady state model [comunicación presentada en el congreso Desalination and the Environment]. Santa Margherita Ligure, Italia.

Vincent, M.C.; Álvarez, S.; Lora, J y Bergantiños, E. (2005b): Prediction of flux decline in the ultrafiltration of macromolecules [comunicación presentada en el congreso International Congress on Membranes and Membrane Processes]. Seoul, Corea. 
Vincent, M.C.; Álvarez, S.; Lora, J y Bergantiños, E. (2005c): A pplication of a dynamic model for prediction of flux decline in the ultrafiltration of macromolecules [comunicación presentada en el congreso Membrane Science and Technology Conference of the Visegrad Countries]. Polanica Zrój, Polonia.

Vincent, M.C.; Álvarez, S.; Lora, J y Bergantiños, E. (2005d): Modelado dinámico aplicado a la ultrafiltración de macromoléculas [comunicación presentada en el quinto Congreso Iberoamericano de Ciencia y Tecnología de Membranas]. Valencia, España.

Vincent, M.C.; Lora, J.; Álvarez, S y Bergantiños, E. (2005e): "Métodos de limpieza en membranas de ultrafiltración", Ingeniería Química, Vol. 423, pp. 182-187

Vincent, M.C.; Álvarez, S.; Lora, J y Bergantiños, E. (2005f): "Crossflow ultrafiltration of cake forming solutes: a non-steady state model", D esalination, Vol. 184, pp. 347-356

Vincent, M.C.; Álvarez, S.; Lora, J.y Bergantiños, E. (2006a): A pplication of a dynamic model that combines pore blocking and cake formation in crossflow ultrafiltration [comunicación presentada en el congreso Euromembrane]. Taormina, Italia.

Vincent, M.C.; Bergantiños, E.; Álvarez, S. y Lora, J. (2006b): $V$ alidation of dynamic models to predict flux decline in the ultrafiltration of macromolecules [comunicación presentada en el congreso Desalination Strategies in the South Mediterranean Countries]. Montpellier, Francia.

Vincent, M.C.; Álvarez, S; Lora, J.y Bergantiños, E. (2006c): M odelling of flux decline in crossflow ultrafiltration of macromolecules: comparison between experimental and predicted results [comunicación presentada en el congreso Desalination Strategies in the South Mediterranean Countries]. Montpellier, Francia. 
Vincent, M.C.; Álvarez, S; Lora, J.y Bergantiños, E. (2006d): U Itilization of a shear induced diffusion model to predict permeate flux in the crossflow ultrafiltration of macromolecules [comunicación presentada en el congreso Desalination Strategies in the South Mediterranean Countries]. Montpellier, Francia.

Vincent, M.C.; Álvarez, S.; Lora, J y Bergantiños, E. (2006e): "Prediction of flux decline in the ultrafiltration of macromolecules", Desalination, Vol. 192, pp. 323-329.

Vincent, M.C.; Álvarez, S.; Lora, J y Bergantiños, E. (2006f): "Application of a dynamic model for prediction of flux decline in the ultrafiltration of macromolecules", D esalination, En prensa.

Vincent, M.C.; Bergantiños, E.; Álvarez, S.; Lora, J. y Gozálvez, J.M. (2006g): "Validation of dynamic models to predict flux decline in the ultrafiltration of macromolecules", D esalination, En prensa.

Vincent, M.C.; Álvarez, S; Lora, J.; Gozálvez, J.M. y Bergantiños, E. (2006h): "Modelling of flux decline in crossflow ultrafiltration of macromolecules: comparison between experimental and predicted results", D esalination, En prensa.

Vincent, M.C.; Álvarez, S; Lora, J. Gozálvez, J.M. y Bergantiños, E. (2006i): "Ultilization of a shear induced diffusion model to predict permeate flux in the crossflow ultrafiltration of macromolecules", D esalination, En prensa.

Vincent, M.C.; Álvarez, S.; Lora, J.y Bergantiños, E. (2006j): "A pplication of a dynamic model that combines pore blocking and cake formation in crossflow ultrafiltration", D esalination, En prensa. 
Wang, L. y Song, L. (1999): “Flux decline in crossflow microfiltration and ultrafiltration: experimental verification of fouling dynamics", Journal of membrane science, Vol. 160, pp. 41-45

Yuan, W.; Kocic, A. y Zydney, A.L. (2002): “A nalysis of humic acid fouling during microfiltration using a pore blockage filtration model", Journal of M embrane Science, Vol. 198 pp. 51-62.

Zhang, M. y Song, L. (2000a): “Mechanisms and parameters affecting flux decline in cross-flow microfiltration and ultrafiltration of colloids", Environmental Science and Technology, Vol. 34, pp. 37673773

Zhang, M. y Song, L. (2000b): “Pressuredependent permeate flux in ultra- and microfiltration", Journal of Environmental Engineering, Vol. 126, pp. 667-674

Zhang, Y.W.; Tang, M.; Jin, X.; Liao, C. S. y Yan, C.H (2003): "Polymeric adsorption behaviour of nanoparticulate yttria stabilized zirconia and the deposition of as-formed suspensions on dense $\alpha$ $\mathrm{Al}_{2} \mathrm{O}_{3}$ substrates", Solid State Sciences, Vol. 5, pp. 435-440

Zydney, A.L. y Ho, C-C. (2002): "Scale-up of microfiltration systems: fouling phenomena and $V_{\text {max }}$ analysis", D esalination, $V o l .146, p p .75-$ 81 


\section{RESÚMENES}

\section{RESÚMENES}

Título: “Modelado dinámico de procesos de ultrafiltración tangencial aplicados a la separación de macromoléculas"

\section{Resumen}

En la presente Tesis Doctoral se analizó la aplicación de modelos dinámicos tanto teóricos como semi-empíricos para predecir el descenso de la densidad de flujo de permeado con el tiempo debido al ensuciamiento en procesos de ultrafiltración tangencial de macromoléculas. Los fenómenos de ensuciamiento están presentes en todas las aplicaciones de los procesos de ultrafiltración y son el principal factor limitante en la aplicación de la tecnología de membranas.

Se realizaron ensayos en planta piloto con dos membranas cerámicas de ultrafiltración y con una alimentación consistente en una disolución acuosa de polietilenglicol. En los ensayos experimentales se varió la velocidad tangencial, la presión transmembranal, la concentración de polietilenglicol y la temperatura. Los datos experimentales obtenidos se compararon con los resultados predichos por los modelos. 
Los resultados demostraron la imposibilidad de predecir de manera totalmente teórica la variación de la densidad de flujo de permeado con el tiempo bajo diferentes condiciones experimentales. Uno de los motivos es la dificultad para estimar de forma teórica todos los parámetros de los modelos. Sin embargo, por medio de los M odelos de Hermia modificados para filtración tangencial, se logró predecir con buen grado de ajuste a los resultados experimentales la variación de la densidad de flujo de permeado con el tiempo para todas las condiciones experimentales ensayadas utilizando únicamente como datos experimentales la densidad de flujo de permeado inicial y estacionaria. El resto de los parámetros se calcularon a partir de correlaciones teóricas. 


\section{Title: "Dynamic modelling of crossflow ultrafiltration processes for the separation of macromolecules"}

\section{A bstract}

In this Doctoral Thesis, the application of theoretical and semiempirical dynamic models was analyzed to predict permeate flux decline with time due to fouling in crossflow ultrafiltration of macromolecules. Fouling is present in every ultrafiltration process and it is the main limiting factor in the application of membrane technology.

Pilot plant tests were performed with two different ceramic ultrafiltration membranes using a polyethylene glycol aqueous solution as feed. Crossflow velocity, transmembrane pressure, feed concentration and temperature were varied. Experimental data and model predictions were compared.

The results demonstrated that it was impossible to theoretically predict permeate flux decline with time under different experimental conditions. One of the reasons is the difficulty to theoretically estimate all the model parameters. However, for the experimental conditions tested, and using $\mathrm{H}$ ermia $\mathrm{M}$ odels adapted to crossflow filtration, it was possible to predict reasonably well permeate flux decline with time from steady state and initial permeate flux data, while the rest of model parameters were theoretically calculated. 


\section{Títol: “Modelat dinàmic de processos d' ultrafiltració tangencial aplicats a la separació de macromolècules"}

\section{Resum}

En aquesta Tesi Doctoral es va analitzar la aplicació de models dinàmics tant teòrics com semi-empírics per predir el descens de la densitat de flux de permeat amb el temps degut al embrutiment en processos de ultrafiltració tangencial de macromolècules. Els fenòmens de embrutiment estan presents en totes les aplicacions dels processos de ultrafiltració i són el principal factor limitant en la aplicació de la tecnologia de membranes.

Es van realitzar assaigs en planta pilot amb dues membranes ceràmiques de ultrafiltració i amb una alimentació consistent en una dissolució aquosa de polietilenglicol. En els assaigs experimentals es van variar la velocitat tangencial, la pressió transmembranal, la concentració de polietilenglicol i la temperatura. Les dades experimentals obtingudes es van comparar amb els resultats predits pels models.

Els resultats demostraren la impossibilitat de predir de manera total ment teòrica la variació de la densitat de flux de permeat amb el temps per a diferents condicions experimentals. Un dels motius és la dificultat per a estimar de manera teòrica tots els paràmetres dels models. N o obstant, mitjançant els M odels de H ermia modificats per a la filtració tangencial es va aconseguir predir amb un bon grau de concordança amb els resultats experimentals la variació de la densitat de flux de permeat amb el temps per a totes les condicions experimentals assajades utilitzant únicament dades experimentals de la densitat de flux de permeat inicial i estacionaria. 
